\title{
RISK COMMUNICATIONS AND \\ THE CHEMICAL STOCKPILE EMERGENCY-PLANNING PROGRAM
}

\author{
Barbara Muller Vogt \\ John H. Sorensen
}

Oak Ridge National Laboratory

Post Office Box 2008

Oak Ridge, TN 37831

Prepared for the

\section{FEDERAL EMERGENCY MANAGEMENT AGENCY \\ Preparedness, Exercises, and Training Directorate \\ Washington, D.C.}

September 1994

\author{
Prepared by the \\ Oak Ridge National Laboratory \\ Oak Ridge, Tennessee 37831 \\ managed by \\ Martin Marietta Energy Systems, Inc. \\ for the \\ U.S. DEPARTMENT OF ENERGY \\ under Contract No. DE-AC05-84OR21400
}




\section{DISCLAIMER}

This report was prepared as an account of work sponsored by an agency of the United States Government. Neither the United States Government nor any agency thereof, nor any of their employees, make any warranty, express or implied, or assumes any legal liability or responsibility for the accuracy, completeness, or usefulness of any information, apparatus, product, or process disclosed, or represents that its use would not infringe privately owned rights. Reference herein to any specific commercial product, process, or service by trade name, trademark, manufacturer, or otherwise does not necessarily constitute or imply its endorsement, recommendation, or favoring by the United States Government or any agency thereof. The views and opinions of authors expressed herein do not necessarily state or reflect those of the United States Government or any agency thereof. 


\section{DISCLAIMER}

Portions of this document may be illegible in electronic image products. Images are produced from the best available original document. 
ACRONYMS AND ABBREVIATIONS ................................................................................................. ix

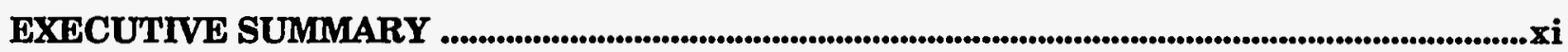

1. RISK COMMUNICATION FOR THE CHEMICAL STOCKPILE EMERGENCY

PREPAREDNESS PROGRAM

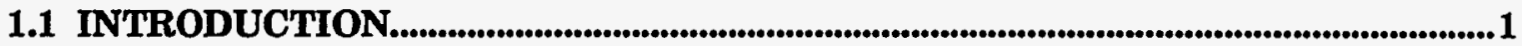

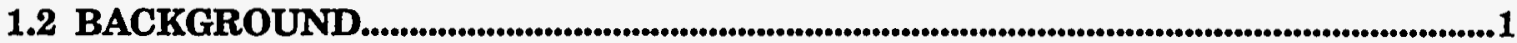

1.3 RISK COMMUNICATION IN CSEPP AND THE CSDP........................................ 3

1.4 EXAMPLES OF RISK COMMUNICATION PROBLEMS IN THE CSEPP................ 6

1.5 EXAMPLES OF GOOD RISK COMMUNICATION PRACTICES IN THE

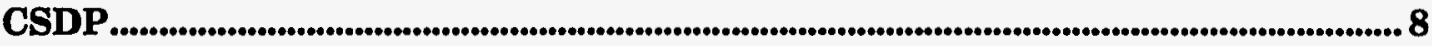

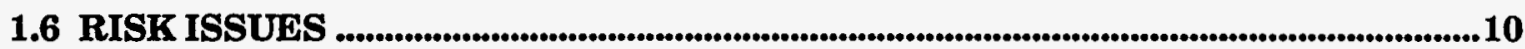

1.7 QUESTIONS RELATED TO THE CSEPP ............................................................. 11

1.7.1 Question 1 (Hazard Identification)............................................................. 12

1.7.2 Question 2 (Public Speculation About Technical Expertise).................... 13

1.7.3 Question 3 (Credibility Of Source/Message) .....................................................13

1.7.4 Question 4 (Media As Sources And Channels).................................................... 14

1.7.5 Question 5 (Institutional Credibility)...............................................................14

1.7.6 Question 6 (Accuracy/Bias Of Message Transmission).................................15

1.7.7 Question 7 (Fear Of Citizen Overreaction)................................................ 15

1.7.8 Question 8 (Warning Message Dissemination) ................................................ 16

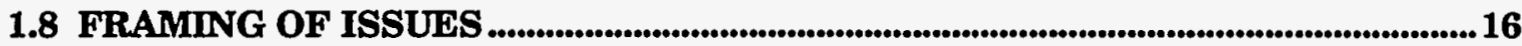

1.9 ORGANIZATION OF DOCUMENT......................................................................... 17

2. RISK AND RISK COMMUNICATION ........................................................................................ 19

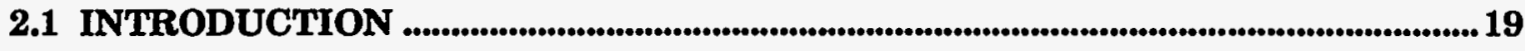

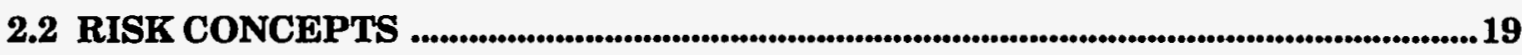

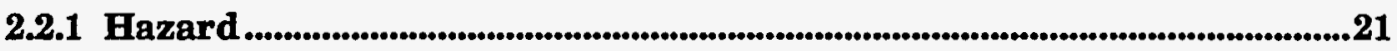

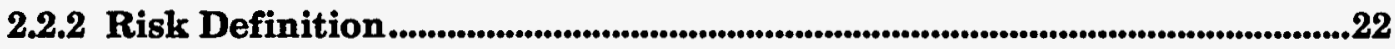

2.2.3 Risk Identification ......................................................................................................25

2.2.4 Symbolism Versus Realism ..................................................................................27

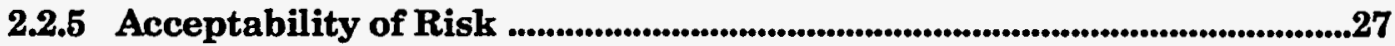

2.2.6 Risk Assessment Versus Risk Management .........................................................29

2.3 RISK ASSESSMENT ........................................................................................................................31

2.3.1 Macro Versus the Micro Perspective ........................................................................32

2.3.2 Hazard Versus Outrage............................................................................32 


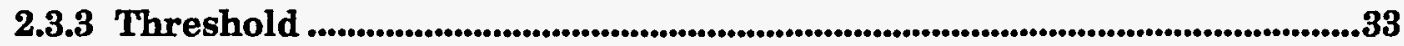

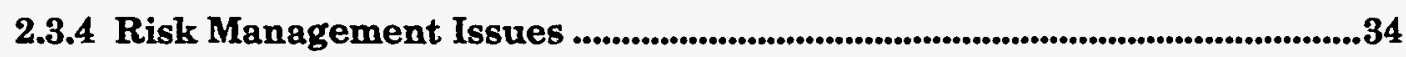

2.3.5 Risk Communication Versus Risk Management .........................................36

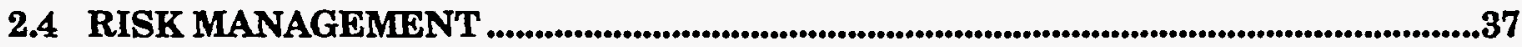

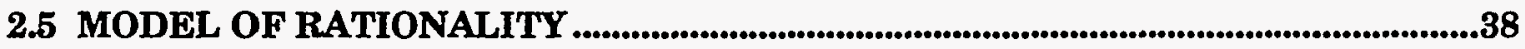

3. ALTERNATIVE PERSPECTIVES ON RISK COMMUNICATION ........................................... 41

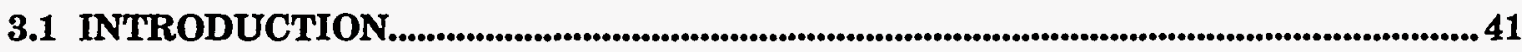

3.2 REVIEW OF RISK COMMUNICATION APPROACHES .........................................43

3.2.1 Classification of Risk Perspectives................................................................43

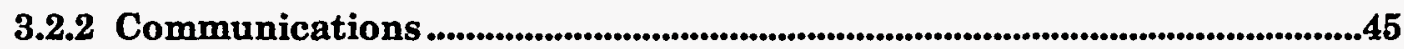

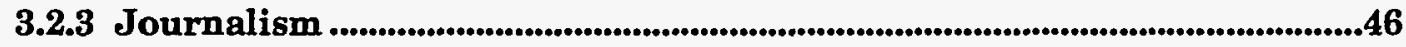

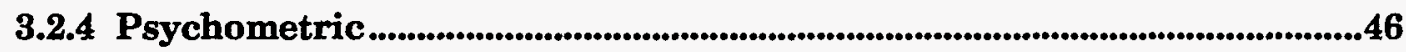

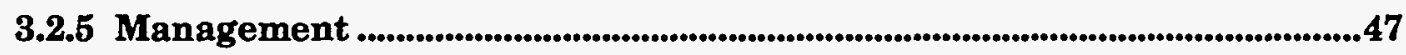

3.2.6 Behavior Modification/Change ...................................................................................47

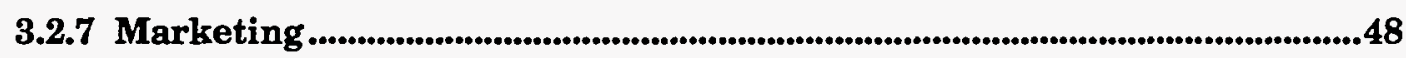

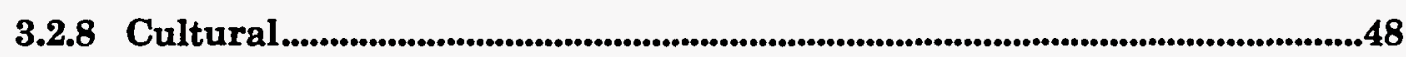

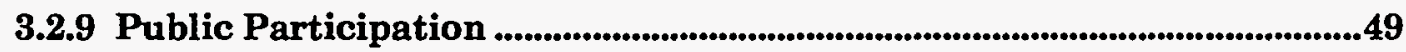

3.2.10 Social Amplification............................................................................................49

3.2.11 Emergency Warning/Disaster...............................................................................50

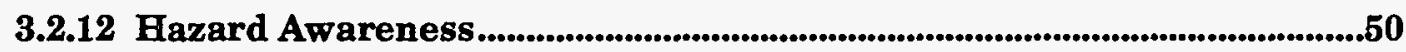

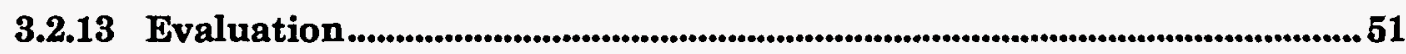

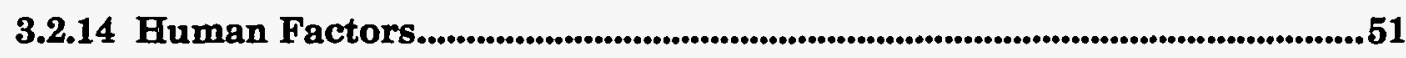

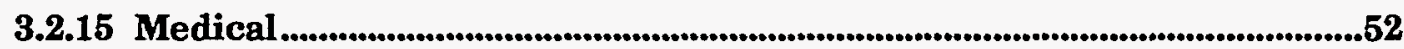

3.2.16 Social Teamwork ..............................................................................................52

3.2.17 Other Perspectives.....................................................................................................53

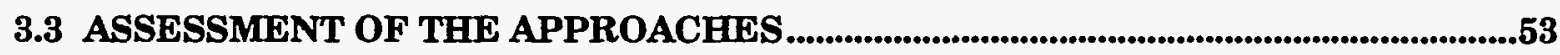

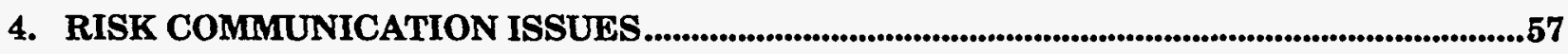

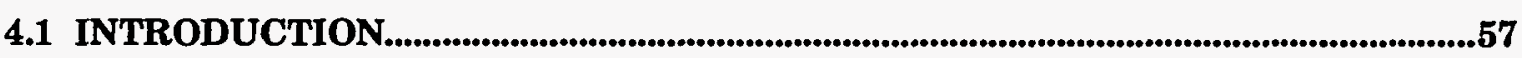

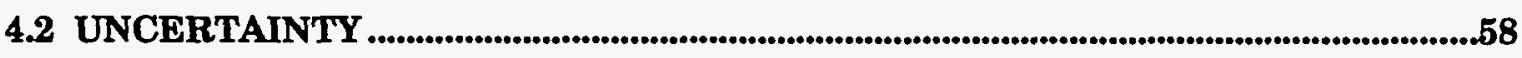

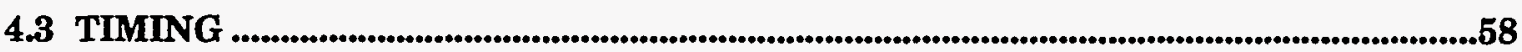

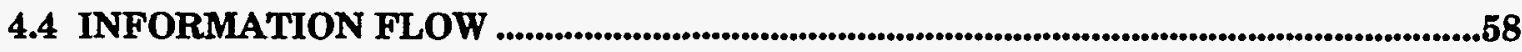

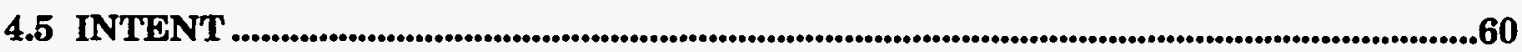

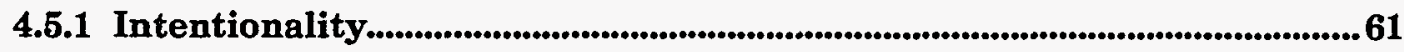

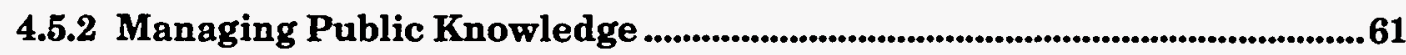

4.5.3 Control of Information..................................................................................62

4.5.4 Release of Information ..................................................................................62 


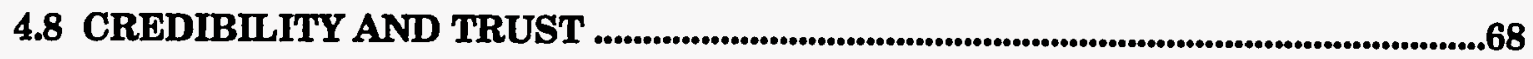

4.8.1 Credibility/Erosion of Public Trust..................................................................68

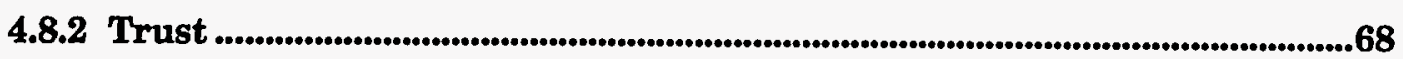

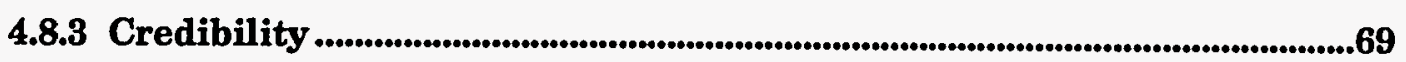

4.9 COMPETING CHARACTERISTICS OF RISK ASSESSMENTS...................................70

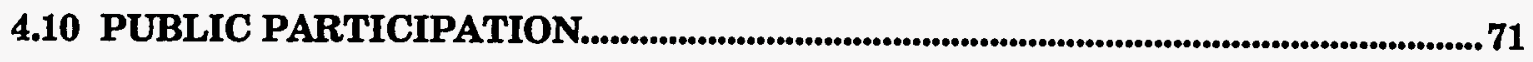

4.11 DEALING WITH DISAGREEMENTS.....................................................................72

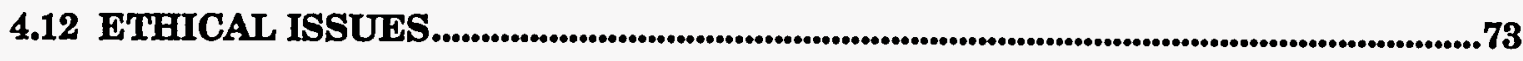

4.12.1 Ethical Issues for the Media........................................................................73

4.12.2 Ethics of Communicators ....................................................................................73

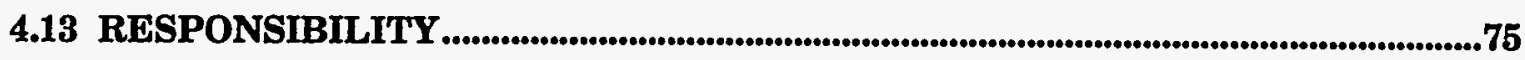

4.13.1 Public Responsibility..................................................................................75

4.13.2 Responsibility in Media......................................................................................76

4.13.3 Responsibilities of Experts and Scientists ....................................................77

4.13.4 Responsibilities of Industry.................................................................................78

4.13.5 Responsibility of Public Agencies .....................................................................78

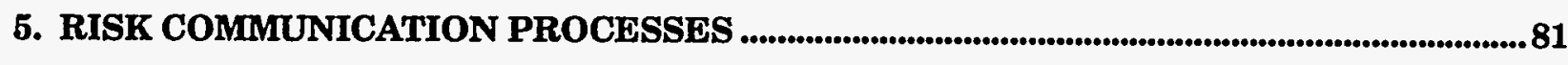

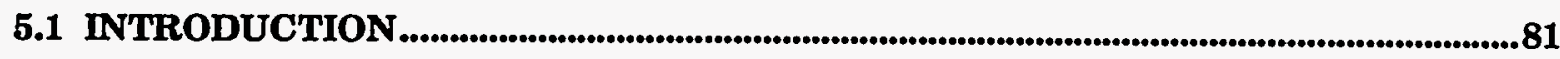

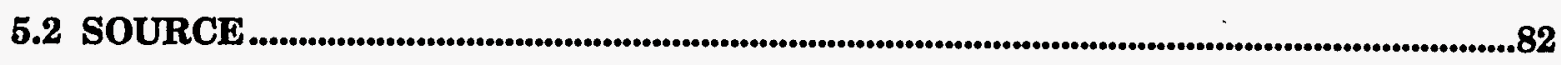

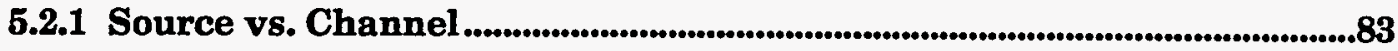

5.2.2 Source Credibility .....................................................................................................84

5.2 .3 Multiple Sources of Information.....................................................................85

5.3 CHANNEL

5.3.1 The Role of the Media as a Channel..............................................................86

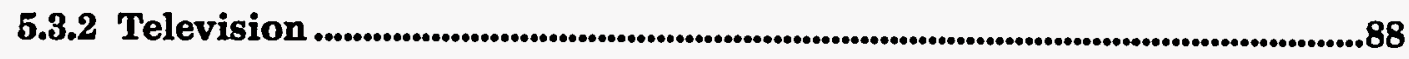

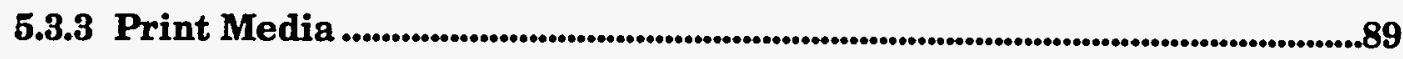

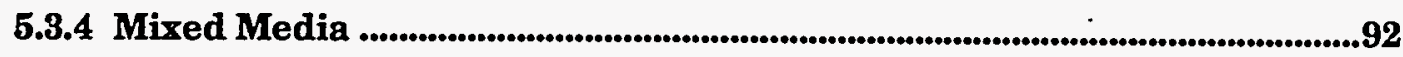

5.3.5 Use of Multiple Channels to Notify the Public about Risks.......................94

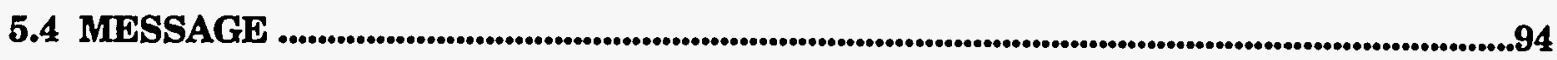

5.4.1 Material to Include in Message ..................................................................94

5.4.2 Promoting Understanding of Risk ...............................................................95

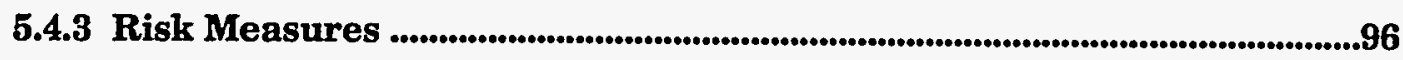

5.4.4 Scientific and Technological Messages........................................................100

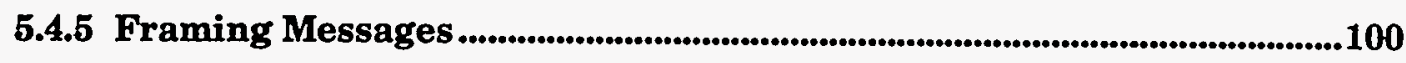




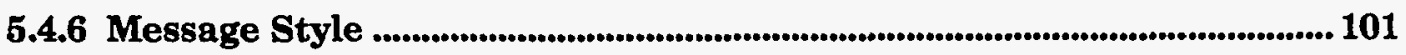

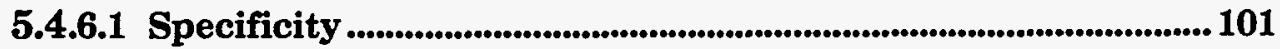

5.4.6.2 Consistency .............................................................................................. 101

5.4.6.3 Certainty .................................................................................... 102

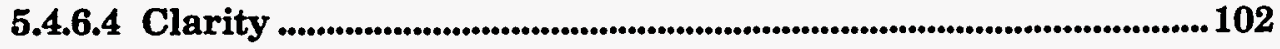

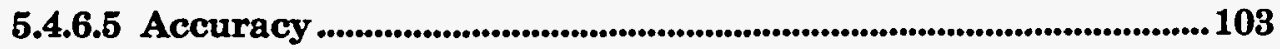

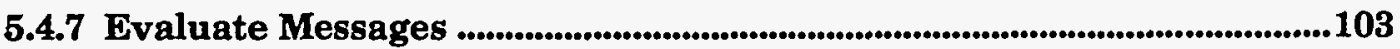

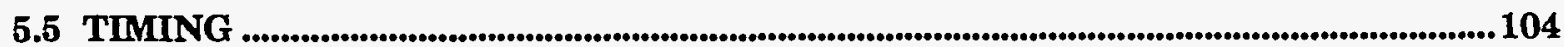

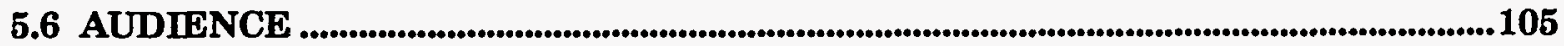

5.6.1 Impacts on Public Perception of Risk................................................................ 106

5.6.2 Differences in Perceptions of Risk.......................................................................108

5.6.3 Public Education and Response ...................................................................... 109

5.6.4 Personification of Risk by Recipients................................................................. 113

5.6.5 Impacts of Public Communication of Risks ................................................ 114

5.6.6 Education of Publics about Risks to Induce Action ................................ 117

6. RISK COMMUNICATION STRATEGIES..................................................................................... 119

6.1 PROGRAM DESIGN................................................................................................................... 119

6.1.1 Design Principles............................................................................................................ 119

6.1.2 Preparation for Risk Communication................................................................ 120

6.1.3 Social Factors in Program Design....................................................................... 121

6.1.4 Role of Public Information Offices in a Program ................................... 121

6.1.5 Establish Rumor Control................................................................................. 122

6.1.6 Institutional Framework and Trust for Risk Communication

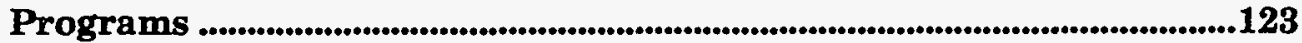

6.1.7 Plan a Program to Fit Audience Needs ................................................................123

6.1.8 Comprehending Public Behavior ................................................................................ 124

6.1.9 Design a Program Based on a Model ................................................................... 124

6.2 PROGRAM COORDINATION................................................................................................. 125

6.2.1 Organizational Needs ..........................................................................................................127

6.2.2 Prior Coordination Needed Between Agencies..........................................127

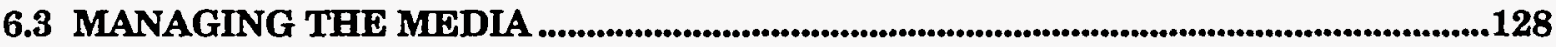

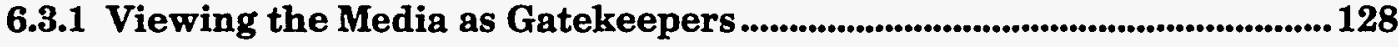

6.3.2 Working with the Media ..........................................................................................130

6.3.3 Involving the Media to Achieve Participation ........................................130

6.3.4 The Media as Channels and Sources ............................................................ 131

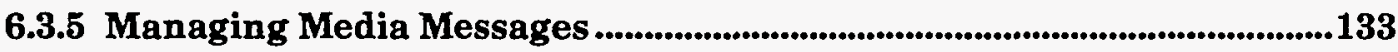


6.4 COMMUNICATION TECHNIQUES......................................................................................133

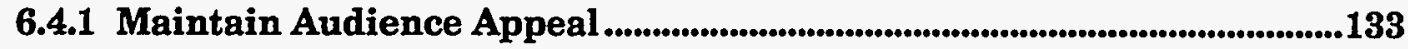

6.4.2 Communicator Skills ..................................................................................................... 134

6.4.3 Managing Audiences ...................................................................................... 135

6.4.4 Communicating Uncertainty ....................................................................................136

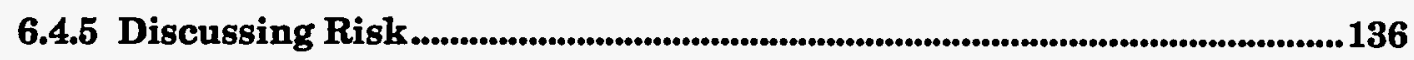

6.4.6 Techniques when Information is Highly Technical..............................137

6.4.7 Dealing with Uncertainty about Audience's Level of Understanding............................................................................................. 138

6.4.8 Communications During Disagreements ..........................................................138

6.4.9 Use of Innovative Channels to Target Information ...................................139

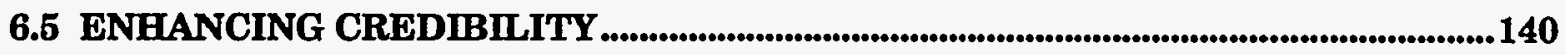

6.5.1 Developing Credibility ......................................................................................... 140

6.5.2 Strategies to Enhance Credibility ........................................................................142

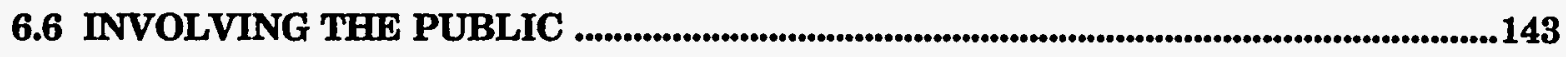

6.6.1 Programs for Enhancing Public Participation ............................................143

6.6.2 Community Involvement ............................................................................... 144

6.6.3 Gaining Feedback from Communities ............................................................. 145

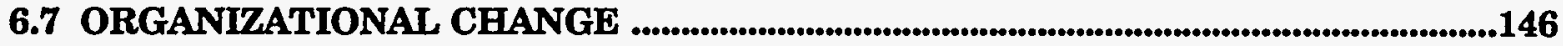

6.7.1 Issuing Warning Messages...................................................................................149

6.7.2 Warning Message Techniques ............................................................................... 151

6.7.3 Program Evaluation and Feedback .............................................................. 151

6.7.4 Evaluating Information Programs .................................................................152

6.7.5 Checklist for Program Evaluation ...........................................................153

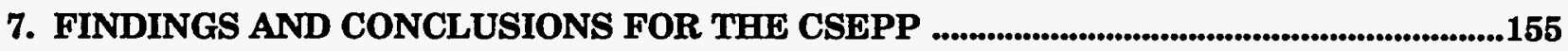

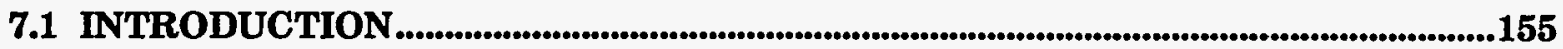

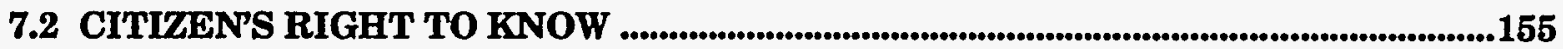

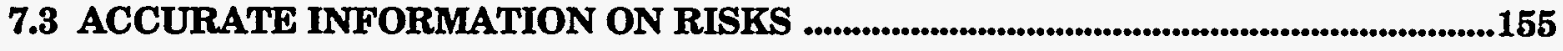

7.4 PRE-EMERGENCY COMMUNICATION PROGRAMS............................................... 156

7.5 IMPLEMENTATION OF FINDINGS INTO STRATEGIES FOR THE CSEPP........159

7.5.1 First Question...................................................................................................160

7.5.2 First Question: Discussion ........................................................................ 160

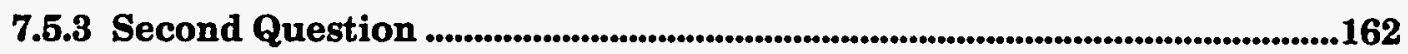

7.5.4 Second Question: Discussion ......................................................................162

7.5.5 Third Question ......................................................................................................163

7.5.6 Third Question: Discussion........................................................................ 164 
7.5.7 Fourth Question ...........................................................................................165

7.5.8 Fourth Question: Discussion ..........................................................................165

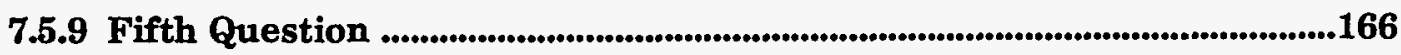

7.5.10 Fifth Question: Discussion........................................................................... 166

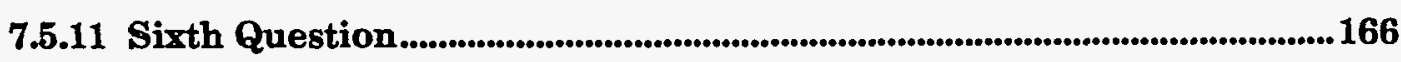

7.5.12 Sixth Question: Discussion........................................................................167

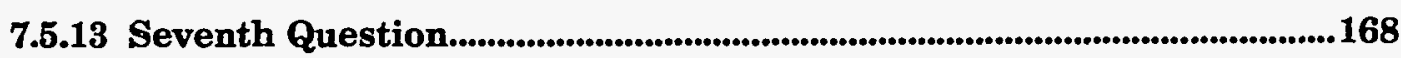

7.5.14 Seventh Question: Discussion ................................................................................. 168

7.5.15 Eighth Question......................................................................................................169

7.5.16 Eighth Question: Discussion ..................................................................................169

7.6 ANALYSIS AND CONCLUSIONS FOR THE CSEPP ..............................................170 


\section{LIST OF TABLES}

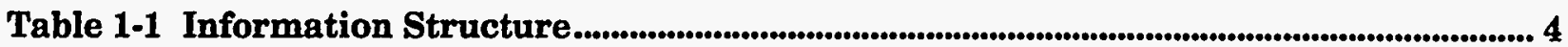

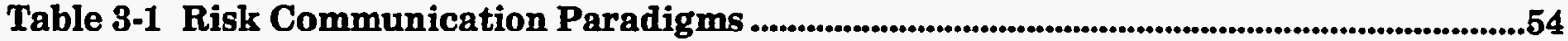

Table 3-2 Structure of Communication in the Paradigms ..................................................................55

Table 5-1 Risk Comparison for CSEPP..........................................................................................................97

Table 5-2 Comparison of Risks from Continued Storage and Onsite Disposal ........................99

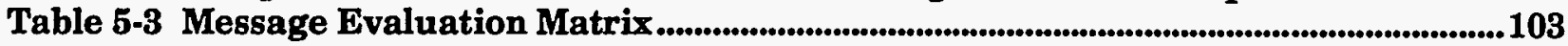

Table 6.1 Alternative Communication Techniques ..............................................................................140

Table 6-2 Checklist for Reviewing a Risk Communication Program .........................................153

\section{LIST OF FIGURES}

Figure 1-1 Information flows in the CSDP/CSEPP.............................................................7

Figure 2-1 Elements of Risk Assessment ........................................................................ 24

Figure 5-1 Communication Process Model..................................................................................... 82

Figure 6-1 Model Framework..................................................................................................... 126

\section{APPENDICES}

Appendix A. Risk Communication References......................................................................................A-1

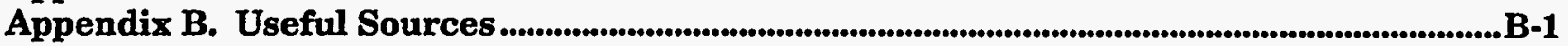

Appendix C. Basic Library of CSEPP Documents ............................................................................. C-1

Appendix D. General and Detailed Facts about Mustard Agents (H, HD, and HT);

Nerve Agents GA and GB; Nerve Agent VX; and Lewisite (L)......................... D-1 


\section{ACRONYMS AND ABBREVIATIONS}

AIDS

ANAD

BGAD

CAC

CAIRA

CDC

CRDEC

CSDP

CSEPP

DA

DATs

$\mathrm{DEH}$

DHHS

DPEIS

EIS

EOC

EPA

EPI

EPZ

ERCP

FEMA

FPEIS

FUDS

HCS

ICCB

IRZ

LBAD

LULU

MOU

MSDS

NASA

NATO

NFIP

NEPA

NIMBY

NOAA

NRC

OPM-CSDP

OSHA

PAO

PAZ

PCBs

PEIS

PIO

ppm

PRA

RCRA

RFP

ROD

SARA

STI

TEAD

TLV

TMI acquired immune deficiency syndrome

Anniston Army Depot

Bluegrass Army Depot

Citizen Advisory Committee

Chemical Accident Incident Response Action

Center for Disease Control

Chemical Research Development and Engineering Center

Chemical Stockpile Disposal Program

Chemical Stockpile Emergency Preparedness Program

Department of the Army

Army's Drain and Transfer Program

Department of Environmental Health

Department of Health and Human Services

Draft Programmatic Environmental Impact Statement

Environmental Impact Statement

emergency operations center

Environmental Protection Agency

emergency public information

emergency planning zone

Emergency Response Concept Plan

Federal Emergency Management Agency

Final Programmatic Environmental Impact Statement

Formerly Used Defense Sites

Hazard Communication Standard

Intergovernmental Consultation Coordination Boards

Immediate Response Zone

Lexington Bluegrass Army Depot

Locally Unwanted Land Use

memorandum of understanding

Material Safety Data Sheet

National Aeronautics and Space Administration

North Atlantic Treaty Organization

National Floodplain Insurance Program

National Environmental Policy Act of 1969

Not In My Back Yard

National Oceanic and Atmospheric Administration

National Research Council

Office of the Program Manager for the Chemical Stockpile Disposal Program

Occupational Safety Health Administration

Public Affairs Officer (for Army)

Protective Action Zone

polychlorinated biphenyls

Programmatic Environmental Impact Statement

public information officer

parts per million

probabilistic risk assessment

Resource Conservation and Recovery Act of 1976

Request for Funded Proposals

record of decision

Superfund Amendments and Reauthorization Act of 1986

scientific and technical information

Tooele Army Depot

Threshold Limit Value

Three Mile Island 
USACMDA

USATHAMA

USANCA

USGS
Threshold Quantity

U.S. Army Chemical Material Destruction Agency

U.S. Army Corps of Engineers Toxic and Hazardous Materials Agency

U.S. Army Nuclear and Chemical Agency

U.S. Geological Survey 


\section{EXECUTIVE SUMMARY CSEPP RISK COMMUNICATION SOURCE BOOK}

The Source Book has been developed for the Chemical Stockpile Emergency Preparedness Program (CSEPP) in support of the training course on risk communications. The purpose of the document is to provide a fairly comprehensive document on risk communication research and recommended practices, especially as they relate to the CSEPP.

The first chapter discusses the background of the program, including why the CSEPP was created and the development of the program to date. Using the communications perspective suggested by Covello and colleagues, the existing practices of communicating risk information about chemical weapons and the associated efforts in emergency planning, storage, and eventual disposal are described.

Risk communication issues specific to the CSEPP are then discussed. Examples selected from the CSEPP and the Chemical Stockpile Disposal Program (CSDP) illustrate some of the major risk communication problems as well as some examples of good risk communication practices. Programmatic decisions characterized as good risk communication practices are also discussed. A series of questions helps the reader understand the broad spectrum of risk communication topics related to the CSEPP.

Basic concepts addressing principles of risk communication are discussed in Chapter Two. The distinctions between risk assessment, risk analysis, risk management, and risk communication are clarified along with the definition of a hazard and risk identification. Both micro and macro perspectives on risk assessment are examined. The differences between and among expert and nonexpert risk definitions and measurements are noted. Variability in how members of the general public and experts view the acceptability of risk is discussed. We also examine factors which determine if effective communication has taken place.

The third chapter presents a comprehensive review of the risk communication literature. By categorizing the perspectives, noting the common theories and methodologies, each perspective is described and then assessed as to its robustness and maturity.

Chapter Four provides an overview of other issues specific to risk communication perspectives. The focus is on the community and collective risk, not on individual behavior or attitude toward risks. In CSEPP there is no debate over 
acceptable risk-all agree with the notion of maximum protection and the eventual elimination of risk. Among the issues examined are problems of uncertainty, timing, and the direction of information flow. Further issues directed toward informing the public about risks include an analysis of the intent of the communications, public information needs, the release of information, and public education. Next discussed are issues related to the social context in which risk communication takes place and the factors related to credibility and trust. How to involve the public and deal with disagreements are examined, and, finally, issues related to ethics and responsibilities of the communicators and the publics involved.

Chapter Five discusses risk communication as a social process. This is organized around the basic model of the communication process that emphasizes the relationships between the source, channel, message, audience, and eventual outcome or impact. Some of theoretical approaches behind the research findings on the risk communications process bias the recommendations as presented. Among the issues discussed are the use of multiple communication channels, the factors associated with the measurement and comparison of risks (including how the risk from a chemical agent accident can be realistically compared), the six stages of human response regarding risk communications (receiving, understanding, believing, personalizing, responding and information seeking), addressing the problems citizens have in processing scientific information, and evaluating message dissemination. Also discussed are the factors related to message style: specificity, consistency, accuracy, certainty and clarity. Timing is another critical aspect of the risk communications process in both emergencies and during pre-emergency communication effort.

Risk communication activities are, by design and intent, a social intervention which have impacts on people exposed to the information. It is also important to identify and understand the different types of audience participants and how risk communications eventually influence individual behavior. Researchers have had difficulty linking public education efforts with actual behavioral changes and in suggesting measures to combat public apathy.

In the sixth section we bring together recommendations from risk communication practices and organize them as risk communication strategies. We do not advocate the application of any single strategy as recommendations for specific actions are largely subjective and situation specific. What is stressed is the importance of developing a well integrated risk communication program as a companion to the CSEPP activities. 
In the final section we attempt to synthesize the findings from the empirical research with recommendations made in the conceptual literature and current guidance manuals available to risk communicators, planners, agencies, and emergency personnel. We also return to address the questions about risk events posed earlier in light of the findings regarding the critical issues.

In a world of increasing risks, appropriate and continual dialogue with affected publics about risks should be one of the foremost concerns of public agencies, especially those involved in risk communications for the CSEPP. How that information is interpreted or modified by existing beliefs remains problematical. To enhance risk communication efforts, we need communications of risks in a language easily understood by the majority of publics. Effective public participation also depends substantially upon the development of indigenous technical and analytic resources and upon the institutional means to act upon and incorporate that increased knowledge.

It is clear that members of the public will continue to differ in scope of involvement even at the group level. Differing thresholds of involvement over time requires alternative communication strategies appropriate to the level of concern and the hazard involved. Although a large array of participation and prescriptive techniques exists, current knowledge does not allow for successful prediction as to which strategies are likely to be most effective under given conditions.

Risk communicators face increasing pressure to present risk issues and respond to risk related questions raised by various parties and constituencies. Whether acting alone or with others, managers of public and private agencies, industry representatives, and governmental bodies must also accept that media communications outlets can and will significantly influence the agenda of most risk communication efforts. Furthermore, newer forms of communication technologies will continue to alter methods used to translate assessments of risks for risk management. Immediate access to data via personal computers places managers in the position of having to make on the spot decisions about conveying information about risks.

Risk communicators for the CSEPP must present risk issues in a fair and unbiased manner as well as answer questions raised by various parties and constituencies at various points in the program. There is every indication that a better understanding of hazards posed by chemical munitions to individuals, groups, and communities can be developed and that preparedness strategies can be enhanced for the CSEPP through better risk communication programs. 


\section{RISK COMIMUNICATION FOR THE CHEMICAL STOCKPILE EMERGENCY PREPAREDNESS PROGRAM}

\subsection{INTRODUCTION}

The purpose of this document is to provide a fairly comprehensive source book on risk, risk management, risk communication research and recommended risk communication practices. It does not merely summarize each publication in the risk communication literature, but attempts to synthesize them along the lines of a set of organizing principles. Furthermore, it is not intended to duplicate other guidance manuals (such as Covello et al.'s manual on risk comparisons). The source book was developed for the Chemical Stockpile Emergency Preparedness Program (CSEPP) in support of the training module on risk communications. Although the examples provided are specific to CSEPP, its use goes beyond that of CSEPP as the findings apply to a broad spectrum of risk communication topics. While the emphasis is on communication in emergency preparedness and response specific to the CSEPP, the materials cover other non-emergency communication settings.

\subsection{BACKGROUND}

The CSEPP was created to improve emergency planning and response capabilities at the eight sites around the country that store chemical weapons. These weapons are scheduled to be destroyed in the near future. In preparation of the Draft Programmatic Environmental Impact Statement (DPEIS) for the Chemical Stockpile Disposal Program (CSDP), it was proposed that the Army mitigate accidents through an enhanced community emergency preparedness program at the eight storage sites. In 1986, the Army initiated the development of an Emergency Response Concept Plan (ERCP) for the CSDP, one of 12 technical support studies conducted during preparation of the Final Programmatic Environmental Impact Statement (FPEIS). The Army adopted emergency planning as mitigation in their Record of Decision (ROD) which was made in January, 1988. In fact, emergency planning was one of the major factors which the Army used to justify the selection of the on-site disposal option over an alternative involving off-site transportation. 
Shortly after the ROD, the then Under-Secretary Ambrose directed the Office of the Program Manager for Chemical Stockpile Demilitarization Program (OPM-CSDP) to begin implementation of that plan due to the risk of accidents from continued storage of the stockpile. To support that effort a series of technical support studies was initiated, the Army provided technical assistance to communities to upgrade their plans and more detailed concept plans were started. Later that year the Army entered a Memorandum of Understanding (MOU) with the Federal Emergency Management Agency (FEMA) to help create the CSEPP program. Army responsibility was transferred to the Deputy for Chemical Demilitarization in the Pentagon.

Although the CSDP and CSEPP are two separate programs, their characters and interrelationship cannot be readily dismissed. The disposal of chemical weapons in the continental United States is a complex undertaking. The technology, in the mind of some of the public, is unproved, risky, is fraught with uncertainty, and not well understood. The managerial arrangements surrounding the program are also complex. Assorted agencies and organizations are involved with the program, often with very different perspectives on managing the program and on policy issues. Furthermore, the program is not independent of other military endeavors. Chemical weapons disposal has been tied in with the binary weapons program, treaty negotiations, base closures, environmental cleanup, disposal of other munitions, and biological weapons. The implication of such characteristics is clear--it has been and will continue to be very difficult to communicate information about the program with the public in general and with various sub-populations with special interests or agendas of their own.

The CSEPP is geared to both the CSDP and ongoing storage activities because the munitions in storage are not totally benign. Periodically the Army find munitions which leak. Crews must be sent in to repackage the leaking munitions. Some allegations have surfaced that the munitions are in a deteriorating state, and may be more likely to spontaneously detonate.

The types of potential communication problems about the risks of the chemical agents are not without precedent. Both the nuclear and chemical industries in the U.S. (as well as other countries) face similar situations. Those industries also present complex technologies, pose a potential threat to public health and safety, have complex organizational structures, and have ties to other issues such as nuclear weapons production and environmental degradation.

One result of recognizing communications problems in these industries was the emergence of the field of "risk communication" research. The chief goal of the research was to improve the dialogue or communications process among risk assessors and 
scientists, risk managers and government officials, and the publics at risk. Covello et al. (1987) suggest that risk communications can address 4 basic communication problems. First, risk communication research addresses problems about the information to be communicated-such as deficiencies in scientific understanding, uncertainties, and the basis for highly technical analyses. Second, the research helps to deal with problems associated with the source of the information-such as lack of trust or credibility in the risk analysis, scientific disagreement among experts, failures of experts to disclose limitations on the analyses, lack in understanding of public concerns and fears, or lack of data to address specific concerns both of experts and the public. Third, risk communication research deals with problems regarding channels of communication-including problems related to selective or biased media reporting, premature disclosures of scientific information, outright inaccuracies, or oversimplifications of a risk problem. Finally, risk communication studies address receiver problems such as differing perceptions about the risk, lack of interest in risk issues, overconfidence in the ability to avoid risks, strong but inaccurate beliefs, misguided expectations, need for greater certainties, and difficulties in understanding complex information.

\subsection{RISK COMMUNICATION IN CSEPP AND THE CSDP}

Using the communications perspective suggested by Covello and his colleagues we can describe the existing practices of communicating risk information about chemical weapons and the associated efforts on emergency planning, storage and eventual disposal. The sources of information, the content, and the channels for communication are listed in Table 1-1. As one can see from the table, many organizations are involved in providing a wide variety of information. A prime source of information has been the OPM-CSDP, now part of the U.S. Army Chemical Material Demilitarization Agency (USACMDA). The FPEIS published by the Army summarizes much of the technical risk information. More detailed information is found in the Resource Conservation and Recovery Act (RCRA) Permit Applications, the M-55 Technical Support Studies, and the National Environmental Policy Act (NEPA) Technical Support Studies, including the detailed and voluminous Risk Analysis and the Emergency Response Concept Plan (ERCP). The OPM-CSDP also published the results of the community study groups which were funded by the Army to do independent assessments of the impacts of the program, and several implementation 


\section{CHANNELS}

\section{INFORMATION CONTENT SOURCE}

1. FEDERAL

\section{CSDP}

DA

Installation

EPA

FEMA

DHHS

National Labs

Contractors

ICCB

\section{STATE}

Governor

Health

Environmental

Emergency Planning

3. LOCAL

Elected officials

Administrators

Emergency planners

ICCB

Community Study Teams

Citizen Groups

Universities

Individuals
1. CSDP

Press Releases/Interviews

NEPA Scoping Meetings

NEPA Hearings

NEPA Public Information Package

NEPA state meetings

NEPA Documents

NEPA Mini-Libraries

Special Meetings

ICCB Meetings

Informal Meetings

2. Installations

Press Releases/Interviews

Open Houses/Tours

ICCB

Videotapes

3. State and Local Government

Press Releases/Interviews

Speeches

ICCB
1. CSDP

PFEIS

RCRA Permit Applications

Community Studies

M-55 Technical Support Studies

NEPA Technical Support Studies Risk Analysis

ERCP

ETYC

Implementation Plan

Site-Specific NEPA Documents

EP Upgrades

Revised Risk Analysis

2a. DA

Programmatic ROD

\section{2b. DA/FEMA}

Site Specific Emergency Response

Concept Plans

EP Management Plan

EP Technical Support Studies

EP Functional Concept Plans

3. USANCA

Atmospheric Dispersion Model

CAIRA Manual Revision

\section{DHHS}

Medical Training Program

5. Other

Army Regulations

CRDEC Technical Reports

Other Army Technical Reports

NATO

Open Literature

FEMA Training Courses 
plans. Currently the USACMDA is supporting the preparation of studies to verify that the programmatic ROD is supported at each site when more detailed data are used. Site-specific NEPA documents include discussions of revisions in emergency plans, design of warning systems, and a revised risk analysis based on findings from the incineration of chemical agents at Johnston Atoll in the Pacific.

Additional risk information has been and is being generated by the CSEPP which is being implemented by the Department of the Army (DA) and the Federal Emergency Management Agency (FEMA). This includes the Site-specific ERCP which identify areas surrounding the current storage sites that are at risk, the Emergency Planning Management Plan, and emergency planning technical support studies which deal with risk reduction from various planning alternatives, accident assessment policies, reentry strategies, and other risk-related topics. In addition National and state level public information programs are being developed. FEMA has also published a very general public affairs brochure on CSEPP.

Other risk information has been generated by the U. S. Army Nuclear and Chemical Agency (USANCA), including a new atmospheric dispersion model and the Chemical Accident Incident Response Action (CAIRA) Manual Revision. The Department of Health and Human Services (DHHS) is also involved through the development of a medical training program. A variety of other sources of risk information exist both within and outside the Army including Army regulations, the Edgewood Research and Development Center [formerly the Chemical Research Development and Engineering Center (CRDEC)], technical reports, other Army technical reports, the North Atlantic Treaty Organization (NATO) and in the open literature. Much of the relevant literature is referenced in the technical reports.

Risk information has been communicated in a variety of ways. The CSDP periodically issues press releases and conducts interviews with media personnel. NEPA Scoping Meetings were held at each storage site. NEPA hearings were conducted following publication of the draft Environmental Impact Statements (EISs). A NEPA Public Information Package was prepared during the programmatic phase. In addition, various meetings were held with state officials during the NEPA programmatic phase and will continue during the NEPA site specific phase and the permitting process. During the programmatic phase, sets of background reports were sent to local libraries at each of the eight sites that store chemical weapons. As part of the NEPA mitigation, Intergovernmental Consultation Boards (ICCBs) were established at each site. The purpose of the boards is to facilitate information exchange between the Army and the community. Periodically ICCBs hold closed meetings although some are open to the 
public. The remainder of communications are fairly standard, although some installations periodically hold open houses or have produced videotapes on their general missions that can be shown to community groups.

The basic structure of communications in the CSDP/CSEPP is depicted in Fig. 1-1 in a very general fashion. Several observations can be made about the organizational structure of communications. First, information flows from both the program office and the installation Public Affairs Officers (PAOs) which are not hierarchically arranged. Thus it is possible that conflicting information can be issued. Second, most information is filtered through the media to the public leaving it open to journalistic license. Third, the ICCBs have few direct links to the public.

\subsection{EXAMPLES OF RISK COMMUNICATION PROBLEMS IN THE CSEPP}

While we have not systematically looked for risk communication issues in the CSEPP and CSDP, we have much anecdotal evidence that suggest such issues exist. The following examples were selected to illustrate some of the major risk communication problems about the existing chemical stockpile.

The first issue concerns conflicting information. Numerous incidents can be documented. For example, the public belief at one of the installations was that a couple hundred M-55 rockets were being stored. This belief stemmed from the miscommunications in the Army's Drain and Transfer Program (DATS) on fixing leaking munitions. A local official asked the installation how many munitions were involved. The response was a couple dozen. Mistakenly the local official thought that the size of the stockpile was very small. Local officials were later shocked when they learned there were actually 70,000 M-55 rockets in storage at the installation. At several sites installation personnel insisted that accidents would be confined within the site. After all this was an Army regulation. The risk analysis studies showed, however, that catastrophic accidents with severe offsite consequences could occur and could affect members of neighboring communities.

The second is the public's perception of information withholding. The public has not forgotten the Dugway, Utah, sheep kill incident in which the Army never admitted responsibility for the event. At Lexington Bluegrass Army Depot (LBAD), now called Bluegrass Army Depot (BGAD), Kentucky, an incident occurred where the Army, for a week on orders from a higher headquarters, denied responsibility for the inadvertent detonation of smoke bombs that caused a nearby interstate to close and people to go to 


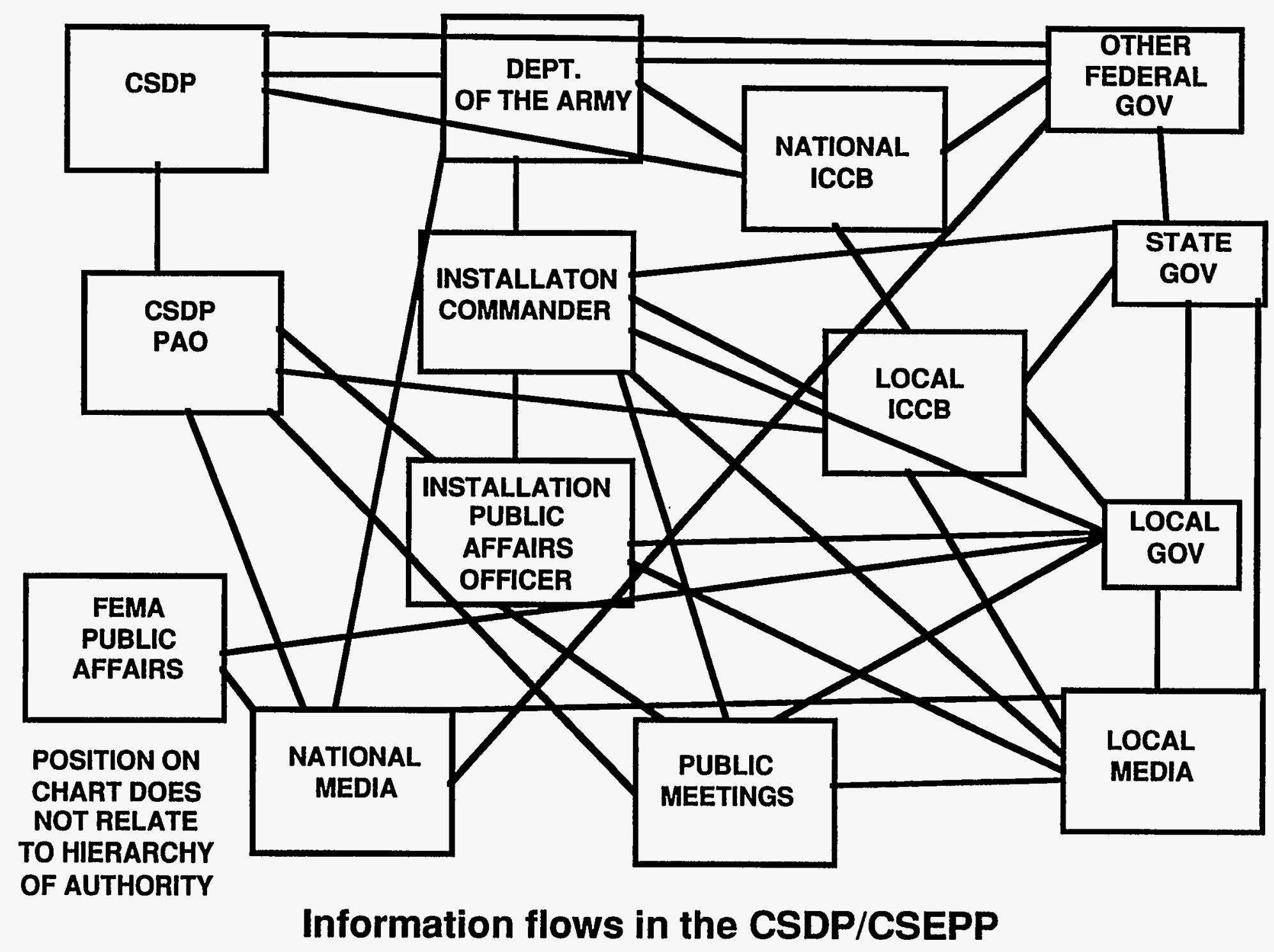


the hospital. The incident is repeatedly raised by the news media and in public meetings.

The third issue involves the credibility of information. Due to incidents such as those cited above, some portion of the public does not believe any information developed by the Army. This lack of trust was reflected in the NEPA public hearings when critics of the Army frequently commented that the analyses were flawed, but those persons criticizing the documents could not say why or how the analysis should be altered.

The fourth issue has to do with the erosion of trust and credibility. For example, the Army decided to give, through FEMA, $\$ 100,000$ to state and local governments for use in improving their emergency planning around the eight storage sites. When conflicts over how the money was to be divided arose at some sites, the money was withheld until agreement was reached on a unified distribution plan. At Anniston Army Depot (ANAD) the failure to receive funds led the county emergency planning organization to withdraw from any emergency planning for the CSDP for a short period of time.

A fifth issue is the provision of timely information. When a small amount of chemical agent was released at a pilot plant at Tooele Army Depot (TEAD), the Army delayed reporting the release to the state for about one week, resulting in severe criticism of the Army by state officials. At BGAD it took a local official 6 hours to find out that the igloo on post that had exploded (caused by dynamite) did not contain any chemical weapons.

All of these issues suggest the need for risk communication skills in the CSEPP. These skills are needed by anyone who can come in contact with the public or media either directly or indirectly.

\subsection{EXAMPLES OF GOOD RISK COMMUNICATION PRACTICES IN THE CSDP}

The CSDP program is not characterized by total pessimism. At some of the sites the Army has developed good communication and rapport with local communities. Furthermore some programmatic decisions can be characterized as good risk communication practices. These include:

- informal meetings with interested citizens and citizen groups,

- community studies, 
- extended comment period on Draft EISs, and

- implementation of the ICCBs.

Informal meetings with interested citizens and citizen groups occur regularly at some installations or on an occasional basis at other sites. The chief value of the meetings is that they allow officials and critics of the program to receive personalized information and to get to know the people running the program. In July, 1993, the Army hosted a hearing at Pueblo Depot Activity to share information about the merits of incineration. Visitors handled gas masks and chemical weapons suits, examined mustard gas shells, and were allowed to inspect every report written about the CSDP since 1988.

At a congressional hearing the Undersecretary of the Army was asked if the Army would give the communities money to conduct independent assessments of the program impacts. The question led to the Army developing a Request for Funded Proposals (RFP) to fund any of the eight communities who wanted to conduct independent assessments. In total, five communities responded. The community studies reflected a legitimate attempt to allow some independent verification of the Army's studies and to involve communities in the scientific discourse. After the studies were funded, the Army also allowed community scientists access to all meetings and information that were being generated by the technical support studies and NEPA analyses.

The draft EIS on the CSDP generated considerable public comment, particularly on the risk assessment. Normally NEPA requires a 30 day comment period. The Army formally extended the period beyond that requirement and responded to all comments received after the formal comment period.

In the FPEIS and programmatic ROD the Army recognized that the program, because of its complexity and level of technical information, impacted communities surrounding the storage sites. To mitigate this impact the Army committed to implementing the ICCB concept. The ICCBs are designed to facilitate information exchange between the Army and state and local officials. Thus, by design, communities will become involved in the risk communication process. 


\subsection{RISK ISSUES}

More basic than the above cited examples of communication problems are issues that fundamentally challenge the technical basis of risk information that currently exists. These include:

- perceived accuracy of risk analysis

- accident impacts

- ability to protect population

- chronic emissions

- long-term health effects

- decommissioning

The basic source of technical risk information is found in the programmatic Probabilistic Risk Assessment (PRA). Parts of this study were classified by the Army because some sections provide information that could reveal the exact size of the chemical stockpile, which is classified information. In part because of the lack of public access and in part due to the credibility problem, the PRA has been heavily criticized. Among the issues raised by critics is that the analysis is not comprehensive nor does it include all possible accidents. Another criticism is that the risk analysis fails to fully reflect human errors that could occur. Other critics maintain that the PRA is biased in that the assessment underestimated the risk of some of the program alternatives. Although the Army spent considerable time to insure that these criticisms have been reasonably addressed, given the state of the art in PRA, the problems still remain in the mind of the public.

Another point of contention concerns accident impacts. A great deal of uncertainty exists over the amount of agent that would be released in many accident scenarios. Further uncertainty exists over whether liquid agent could get beyond the installation boundaries or if only a vapor cloud could travel that far. Large uncertainties also exist in the ability of dispersion models to predict accurately the course of the plume. Controversy has risen over the lethal dose of various chemical agents for infants, children, the elderly and for other vulnerable subpopulations.

A third area of great uncertainty and public questioning concerns the ability to protect people in an accident. Some communities have serious concerns about the Army's ability to make a timely decision about the consequences of a release or whether the public would be notified in a timely fashion (if at all). Some critics have questioned 
the ability to evacuate people in time to prevent fatalities. Other concerns have been expressed over the use of protective equipment or the availability of agent antidotes.

Other publics, while not concerned about accident risks, raise issues about the effects from chronic emissions of agents or polychlorinated biphenyls (PCBs) from the incineration process. A secondary concern is the technical ability to monitor and detect such emissions. A related issue is the long-term health effects of acute and chronic exposure from such exposures and whether sufficient data exists to adequately assess the long-term risk.

A final overriding issue of concern to risk communicators is the decommissioning and future use of the facilities. Many fear that by accepting the risk of agent disposal facilities, the Congress will permit the Army to change their plans for decommissioning the disposal plants and ship in other hazardous wastes for incineration at these sites. The need to dispose of the chemical stockpile in Europe exacerbated this fear but those munitions were taken to Johnston Atoll in the Pacific and are being successfully disposed. The greater concern now is for munitions at formerly used defense sites (FUDS) and other likely or suspect sites where weapons were tested and/or buried.

\subsection{QUESTIONS RELATED TO THE CSEPP}

One problem in developing a risk communication program is determining the range of questions about risk for chemical agents that could be asked over the life cycle of the CSEPP. Manuals depicting methods for effective communication once the problem is identified are readily available, but conceptualizing the needs for an individual agency can overwhelm administrators and managers concerned with limited budgets and of publics highly sensitive to government actions. Although each question must be addressed individually for its appropriate context, certain elements of planning for risk communication can be incorporated into an overall risk communication program. In this section, we present a series of questions which illustrate the types of problems affecting an agency's efforts to communicate risk in the most effective manner. Although the questions are not meant to be comprehensive, we think the hypothetical questions about the CSEPP are ones most likely to be addressed in agency risk communication programs. Some of the more general questions are as follows:

- What is the CSEPP about?

- What does risk communication have to do with the CSEPP? 
- What are the differences in risks from chemical munitions storage versus incineration? On-site transportation? Handling?

- Who are trusted sources of information about chemical weapons? Who can I believe?

-Why can't people understand the technology that accompanies the risk for chemical agent munitions?

- Why can't the risk be made clearer to the publics involved?

- What accidents can happen? How likely are those accidents?

- How were the accidents identified? Can we be sure all possible accidents were identified?

- How will we know the Army is telling the truth?

- How will I know what to do if there is a release that goes off-post?

\subsubsection{Question Set 1 (Hazard Identification)}

A storage tank of agent (HD-mustard) is found leaking into the soil by agency personnel conducting a routine inspection. The damage appears related to the initial deterioration of a valve on the canister containing the agent and, thus, unlikely to have leaked for a long period of time. After discovery, the release was reported to the Environmental Protection Agency (EPA).

\section{QUESTION SET 1}

- What is in the tank/canister?

- Can the chemical explode?

- Is the groundwater affected?

- Can the chemical be safely cleaned-up?

- How long will the cleanup take?

- How can we tell if people living near the site have been exposed to any chemicals?

- Are there any long-term health effects possible from the leak?

- Why are people being evacuated so long after the spill was discovered?

- Why can't I return to my home?

- How can I tell if it's safe to let my animals out after I get home? 


\subsubsection{Question Set 2 (Public Speculation about Technical Expertise)}

A local farmer has a local newspaper reporter out to his farm because he perceives there is a problem with water from a well located near a military depot where chemical agents are being stored. The farmer thinks that agents are leaking from the storage tanks into a nearby stream during heavy periods of rainfall, causing health problems for his cattle. The local health department has investigated and found no likely problems with the tanks, but the possible health effects to both humans and animals remain unconfirmed but highly unlikely.

\section{QUESTION SET 2}

- Why is there uncertainty about the health effects?

- How can it be proven that no agent has leaked out?

- What other problems have occurred that we have not been told about?

-Why haven't the state and local government monitored the situation more closely?

- How much agent does it take to produce lethal effects?

- Are certain people more vulnerable to agent effects?

- What impacts will it have on livestock?

\subsubsection{Question Set 3 (Credibility of Source/Message)}

A small amount of agent released during on-site incineration of some chemical weapons is within exposure limits and the installation commander decides not to notify either the local health agency or inform the public about the release. Two days later, the press learns of the release and cries "cover-up." The questions to the agencies involve more than seeking of facts as the agencies immediately lose credibility for not reporting the release to the public.

\section{QUESTION SET 3}

- Why wasn't the release reported right away?

- Is it true that other releases have not been reported?

- What are the criteria for reporting a release and who makes the decision to report?

- What will be emitted during routine operations?

- How hazardous are those emissions? 
-Will there be long-term effects from exposure to low levels of emissions from the incineration process?

\subsubsection{Question Set 4 (Media as Sources and Channels)}

When a terrorist group threatens to cause a release of chemical agent at one of the storage sites, reporters immediately become involved in negotiations. The questions asked of agency officials and local emergency response officials make the officials feel threatened and left out, fearful that the worst-case accident could occur.

\section{QUESTION SET 4}

- Is there a way in which a terrorist could cause an accident?

- How dangerous are the chemicals in the munitions?

- What is the worst accident that could occur?

- How will it affect my children?

-Will it be better to get away from here while we can?

- How did this happen? Why wasn't security tighter?

- Does CSEPP include plans for such emergencies?

- Does sealing a room protect people in an accident?

\subsubsection{Question Set 5 (Institutional Credibility)}

During a forum, citizens request information that is classified about the quantities of chemicals stored at a military base and about the probability of accidents and/or releases from stored chemicals.

\section{QUESTION SET 5}

-Why won't you tell us about the amounts of chemicals stored on post?

- What is the most likely accident that can occur?

- What accidents are being planned for?

- If you can't tell us, how can we find out the information? 


\subsubsection{Question Set 6 (Accuracy/Bias of Message Transmission)}

During an emergency training exercise, local officials must provide the media with reliable and accurate information about why the exercise is being conducted and what the potential risks are from the chemical agents. Media representatives promise to supply information to the public but officials are skeptical that local distrust will alter the interpretation of the material provided.

\section{QUESTION SET 6}

- Why was this accident scenario chosen for the exercise?

- In reality what is the likelihood that such an accident could occur?

- How can you tell if the exercise was successful?

- How long are the munitions going to remain on site?

- Exactly what are the characteristics of the chemicals and munitions involved?

\subsubsection{Question Set 7 (Fear of Citizen Overreaction)}

Local officials are concerned about the types of questions they will receive when they disseminate tone alert radios to residences and institutions in the Emergency Planning Zones (EPZ), especially since there has been a general apathy about participation in the CSEPP from local residents. Officials must design a program that instructs residents on how the radio is used as well as answer questions about the risks residents face.

\section{QUESTION SET 7}

- How will officials decide where and when to warn people?

- How will I receive a warning?

- Why is a dual indoor/ outdoor warning system needed?

- Do people need protective clothing or masks if they are in the immediate response zone (IRZ)?

- How will my children in school in the IRZ be protected?

- Will this lower property values in the area?

- How will I know that a warning is not a false alarm? 


\subsubsection{Question Set 8 (Warning Message Dissemination)}

When an actual release of chemical agent vapor occurs during incineration, local emergency officials have very little time to notify the public that will be affected by the release. Local officials must move rapidly to alert the public to provide maximum protection and answer questions to dispel the fears about the threat, including when residents can return to their residences.

\section{QUESTION SET 8}

- Why is there so much uncertainty about how much agent was released?

- How can I tell if I am in the plume?

- Is there anyway to recognize that a person has been exposed?

- If I am exposed what should I do?

- Will the agent wash off?

- Is there enough time to evacuate?

- What is the best way to protect myself?

- What can be done to protect school children?

- How will my pets be affected?

- What are the long term effects of exposure?

- When will it be safe to enter an area after an accident?

- Why can't we be told of a release sooner?

- Why can't the release be better predicted?

\subsection{FRAMING OF ISSUES}

When the questions are examined, one can note the way the issues are framed. What are the different types of events that trigger questions about risks? What types of information are required to give out risk communication messages? What types of sources or input is needed to ensure accuracy? One can also ask whether the questions involve a "need-to-know," a "right-to-know," or a "want-to-know," and whether it makes a difference in the risk communication effort.

In the first question set, assessment of risk was defined as an agency problem, whereas the second and third incidents were defined by public or media sources as 
public problems. A general theme throughout the situations is that all questions assume risk assessment and management as part of the problem in the risk communication process. The assumption of management of part of the communication process compounds the uncertainty about how to define the risk involved. All questions discuss the problem as a process, but define issues as agency problems in which the risk must be communicated to the public-that is, one-way communication or monologue, not an interactive dialogue. Dialogue occurs when the discussion involves active participation on both sides. Demanding closure on problems appears to be one of the key elements affecting the unwanted but very real environmental risk communication problems. Yet every day humans adjust to changes in the environment without demanding risks go away or be reduced to zero. Still the assumption persists that the public demands zero-risk solutions as ultimate resolutions of risk management strategies.

\subsection{ORGANIZATION OF DOCUMENT}

This document is organized as follows. The first chapter describes the CSDP and the CSEPP, and reports some of the problems that have surfaced regarding communication of risks of the chemical weapons to the public. Typical sets of questions are presented that focus on the various complexities regarding risk communications for the CSEPP.

The second chapter describes risk definitions and concepts behind risk and risk communications. Cross cutting themes across the literature are discussed. Chapter three looks at different approaches to the study of risk communications.

The fourth chapter discusses basic issues raised. Chapter five then reviews various components of the risk communication process identified by experts and others in the field of risk communication. Chapter six reviews strategies for developing risk communication programs and some recommended practices. Since each CSEPP location will have problems specific to their communities in dealing with the risks involved, no specific strategy is advocated.

The final chapter reviews the conclusions and how the findings can help in the search for better risk communication methods for the CSEPP. The questions are again discussed as to the findings and their relevance to the risk communication process within the CSEPP as well as to other non-emergency risk communication settings. 


\section{RISK AND RISK COMMUNICATTION}

\subsection{INTRODUCTION}

The most effective risk communication involves interaction. A comprehensive view of risk communication states:

"Risk communication is the interactive exchange of information and evaluative principles pertaining to the assessment and management of environmental and health risk among researchers and technical experts, industry, government regulators and agencies, interest groups, and individual members and groups of the general public."

(Adapted from Leiss 1987; National Research Council 1989)

Providing information about risks from hazardous chemical agents in the continental United State's aging weapon stockpile to individuals and groups may seem simple in theory but is difficult in practice. Risk communication techniques for the CSEPP may differ from those strategies used successfully by emergency managers for other hazards or emergencies because of the public's dread and unfamiliarity with chemical agents and their effects. Furthermore, most of the literature in risk communications deals with public acceptance of hazardous facilities and not with preparedness issues from an existing but poorly defined hazard. Improved assessment and communication strategies are needed in the CSEPP because the ground rules associated with assessing the impacts are uncertain and the various public's trust in Army procedures is shaky. For nontechnically oriented risk communicators it is difficult, but not impossible, to learn to separate the expert or technical analysis inherent in the final risk assessment while remaining unbiased in distributing that information to the publics affected.

\subsection{RISK CONCEPTS}

In 1989, the National Research Council (NRC) initiated a study designed to offer knowledge-based advice about the process of risk communication to agencies, industry, and individuals. The committee concluded that many of the participants involved in the process lacked understanding of the terms and concepts used in risk communication, especially between hazards and risk and between risk 
communication and the risk message. In an attempt to facilitate understanding of risk elements, the NRC categorized the terms as follows:

- Hazard: An act or phenomenon posing potential harm to some person, group or thing; the magnitude of the hazard depending on the amount of resulting harm, including the seriousness and the number of people affected.

- Risk: Adds to the hazard and its magnitude the probability that the potential harm or undesirable consequence will be realized.

- Risk assessment: The characterization of potential adverse effects of exposures to hazards; includes estimates of risk and of uncertainties in measurements, analytical techniques, and interpretive models; quantitative risk assessment characterizes the risk in numerical representations.

- Risk control assessment: Characterization of alternative interventions to reduce or eliminate the hazard and/or unwanted consequences; methods to control risks consider technological feasibility, costs and benefits, legal requirements and/or restrictions.

- Risk management: The evaluation of alternative risk control actions, selection among trem and their implementation; the responsible person or agency sometimes oversees the preparation of risk assessments, risk control assessments, and risk messages. Risk management may or may not be open to outside individuals or organizations.

- Risk communication: An interactive process of exchange of information and opinion among individuals, groups, and institutions; often communications involve multiple messages about the nature of the risk(s) or expresses concerns, opinions, or reactions to risk messages or to legal and institutional entities or organizations for risk management.

- Risk message: A written, verbal, or visual statement containing information about risk; the message may or may not include advice about risk reduction; a formal risk message is a structured written, audio, or visual package developed with the express purpose of presenting information about a risk.

- Risk communication/message source: The individual or office sending a risk message or interacting with other individuals, groups, or organizations in risk communication process; the source may also be the risk manager, the risk message preparer, the risk analyst, or some other expert. 
- Audience/recipients: The recipient(s) of a risk message; almost never a homogenous group; an audience may include recipients intended by the preparer of the message as well as others who receive it even though the message was directed elsewhere.

(Adapted from NRC 1989)

\subsubsection{Hazard}

Because risk communications cross disciplinary boundaries, definitions of a hazard and the risks are associated with the hazard vary among groups as well as between experts depending on their orientation and past experience. A broader definition of hazard than that proposed by the NRC is offered by Kates (1978) who states:

"A hazard is the threat potential posed to humans or nature by events originating in or transmitted by the natural or built environment."

The definition implies that a hazard affects not only people, but the physical environment.

Most risk assessment methods focus on the effects from a single hazard with specialists trained in that area performing the risk analysis. Regardless of the method chosen, the intensity and location of the hazard'must first be defined. Most methods used to characterize the degree of hazard use a probability statement to describe the likelihood or frequency of an occurrence of the hazard. The probability distributions for relatively frequent events are usually based on historical data. When data do not exist for very rare events or when plans are being prepared for the possibility of a future event occurring, probabilities can be estimated using models which simulate (i.e., approximate) the physical mechanism of the hazard. When conducted for a relatively large area, the level of hazard will vary with location and that variation can also be calculated. Models have been used to approximate accident scenarios in the CSEPP because the expected probability of a chemical agent release is extremely rare and only limited historical data exists.

The type and intensity of hazards will vary depending on the scale of analysis. For example, on a regional basis earthquakes and landslides are major problems in California but hurricanes and floods present more risks overall to residents in Florida. The likely intensity of a hazard can also vary depending on scale. The intensity of a storm (and the consequent damages) in Florida often 
depends on how close a structure is to the ocean. For the CSEPP, however, a regional spatial analysis was not deemed necessary because the intensity and scope of the hazard of a chemical agent release would be confined to a relatively small area near the storage site.

The degree of risk is related both to the hazard's probability and the magnitude of consequences (Whyte and Burton 1980). Because an event with the potential for disastrous results occurs does not mean that it is necessarily hazardous. Natural hazards are viewed as products of the interaction of the natural environment and society, with individuals and governments able to increase or decrease the degree of risk associated with a hazard (Burby et al. 1991). For example, keeping residences out of floodways reduces the risk from flooding. This does not imply that the mitigation efforts directed toward hazards is equally distributed among risk bearers or that governments will be efficient in dealing with hazards. The daily monitoring for chemical leaks in the munitions stockpiles permits the Army to effectively contain minor leaks and lessen the hazard.

\subsubsection{Risk Definition}

The term "risk" has been used in the literature to mean either the probability of danger or the hazard itself (Whyte and Burton 1980). The concept of risk implies the possibility of suffering from a loss but the size and occurrence of that loss is uncertain. It is that uncertainty which is central to the notion of risk (Burby et al. 1991). Dealing with that uncertainty is one of the primary technical issues in assessing risks in the CSEPP. No loss estimation prepared, however, can ever be completely accurate (or predictive) because of the underlying uncertainty.

Generalizations drawn from results of early psychological studies concluded that perceived risk was quantifiable and predictable but that "risk" meant different things to various people. While we are not directly concerned with analyzing how individuals perceive risks, it is necessary to understand that factual information provided by experts and agencies contains undefined assumptions and values that experts as individuals hold. How they assess risks will differ because those frameworks influence the discussions about risks. By making those assumptions clear, one can better understand why differences exist.

Critical differences between experts and the public raise the issue of who should make or evaluate risk estimates, especially when new risks emerge or benefits from a new technology are not immediately known. For some the issue 
bears on who are the actual "risk-bearers." Another issue arises when risk assessors and risk managers try to communicate that they and members of the public share a common heritage. The "commonality assumption"-that experts share common and cultural heritage in the domain of risk with lay persons-has proven false (Slovic 1986, 1991). Risk is brewed from an equal dose of two ingredients-probabilities and consequences-but most of the attention from experts centers on probabilities (Slovic 1986) or the probability of loss or injury (Rodgers 1989). Conversely, lay persons concentrate on consequences. Although they are not mutually exclusive, problems can arise over the inferences given the underlying assumptions.

Although experts judge risks close to technical (generally the probability) estimates of annual fatalities, lay people assessments are usually more sensitive to other characteristics, "especially for hazards whose adverse effects are uncontrollable, dreaded, catastrophic, fatal rather than injurious, not offset by compensating benefits, and delayed in time so the risks are borne by future generations" (Slovic 1986, 1991). Slovic's studies indicate that those characteristics are amenable to being condensed into a small set of factors for quantifying risk estimates. Factor 1, dread risk, is defined as perceived lack of control, dread, catastrophic potential, fatal consequences, and the unequitable distribution of risks and benefits from a hazard. Factor 2, unknown risk, is defined as those hazards judged unobservable, unknown, new, and delayed in manifesting harm. Another consistent result of studies on risk indicates that non-voluntary risks (and risks that are imposed) are usually regarded as more undesirable than voluntary risks (Hansson 1989).

An individual's qualitative assessments of the probability of risks can also be affected by the level of uncertainty as expressed by experts' opinions of potential effects. Thus descriptions by scientists that a substance is "known" to have possible cancer threats is judged more threatening than a substance labeled as having "possible" causes (Graham 1989).

The qualitative and quantitative dimensions of risks also account for the differences in methods used for risk analysis. Thus definitions of risk differ not only between experts and members of the public, but also can exist between experts themselves. The traditional scientific (quantitative) basis for risk is based on the probability of an event times the consequence of an adverse or hazardous event, given a population exposed to a hazard, occurring over certain time period. (See Figure 2-1) However, most members of the public perceive risks in more comprehensive manner that injects both social and normative characteristics 


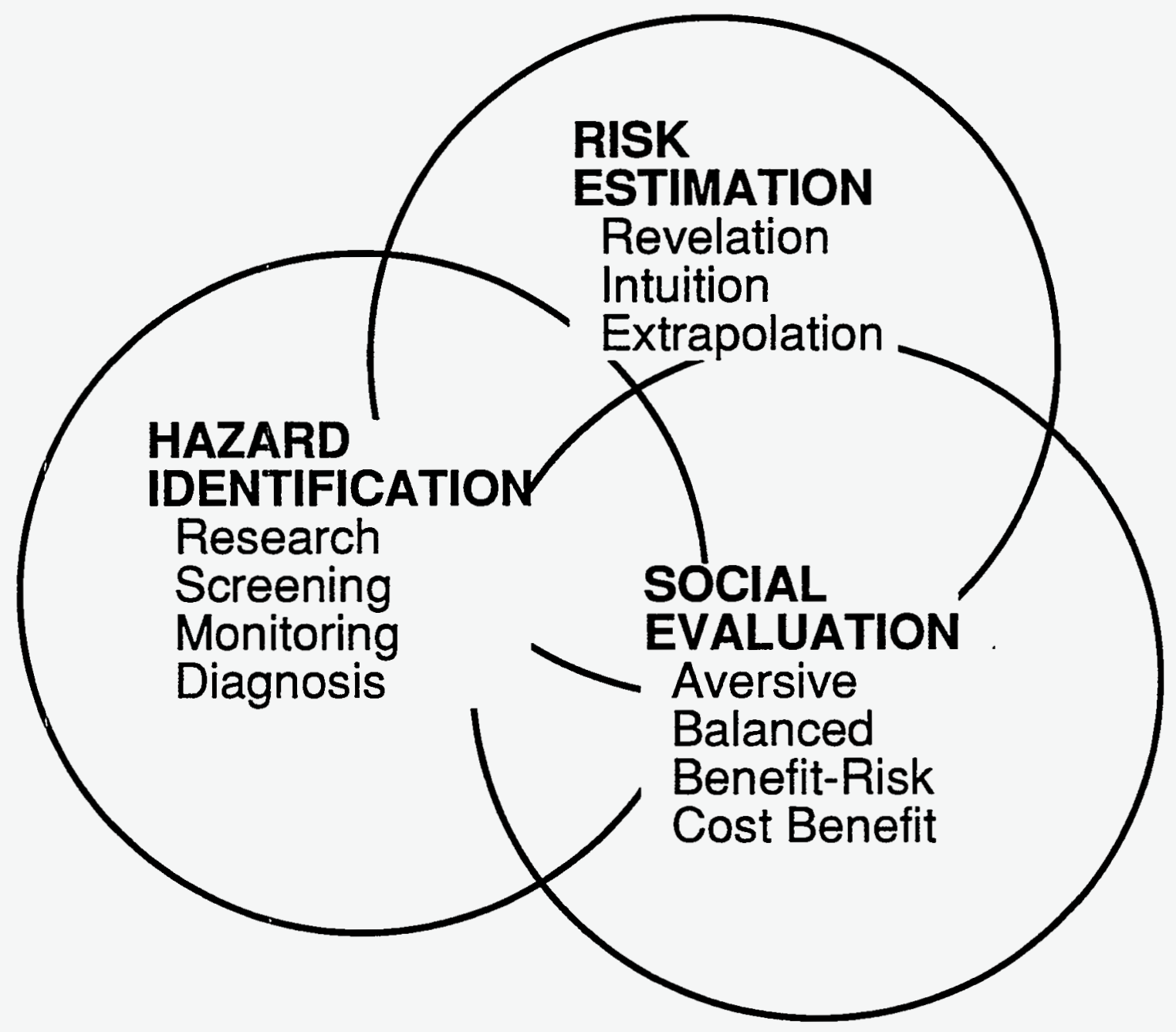

Figure 2-1 Elements of Risk Assessment. (Adapted from Kates 1978)

(the qualitative value dimensions) into a risk assessment. On occasion, the differences have led to the public's distrust of scientific evidence for not taking into consideration "all the facts." In the CSEPP this distrust is evident in the disagreement over what constitutes a credible worst-case accident.

Some researchers have suggested the distrust of scientific risk assessments may be from the use of the de minimis principle by regulatory agencies. In the late 1970 's, regulators adopted policies for designating certain risk levels as too low to merit regulation by their agencies. The de minimis concept stems from the common law practice of relegating certain actions as not worthy of the court's oversight-"the law does not concern itself with trifles" (Jasanoff 1991). Regulatory agencies 
welcomed the opportunity to use the de minimis concept for risks that fell below a certain threshold level because it provided a scientific (and legal) basis for decision making. Since then the trend toward increased reliance on quantitative measures derived from improved analytical techniques has moved analyses of risks further away from qualitative judgments while reinforcing the development of de minimis risk assessment. Critics assert that a policy that permits certain cases to be dismissed immediately fails to allow for incremental or cumulative risk assessment or for hazards that interact synergistically and which need to be analyzed systematically with other hazards. Although efficient, the policy may not be equitable because it does not permit the distributive aspects on risk bearers to be addressed (Jasanoff 1991). Thus groups that may be more sensitive to some hazards (e.g., the young, those with prior physical impairments, or those living in already disadvantaged areas with substandard housing) are not accounted for in de minimis policies. Thus critics claim a de minimis policy provides a "license to harm" at low levels. Emergency plans for the CSEPP try to overcome some inequities by determining what types of structures or susceptible populations are in the area when decisions are made to shelter in place or evacuate.

The insurance industry draws an important distinction between two types of risks: particular risks and fundamental risks (Burby et. al. 1991). Particular risks are those wholly independent events that affect individuals or small groups (e.g., a death, a residential fire, or a property theft). Although large numbers of people are affected by these risks, the consequences are limited and independent from other events. An event that affects a large number of people and has large catastrophic potential is called a fundamental risk (e.g., hurricanes, earthquakes). Insuring fundamental risks is usually deferred to the public sector because writing coverage for catastrophic events could bankrupt a private company.

\subsubsection{Risk Identification}

Originally humans identified risks through their direct experience with the hazards and their consequences and conveyed that information to their groups and colleagues; mitigation efforts may have been real or imagined. Over the last 100 years, the task of identifying risks and their consequences became relegated to experts and institutions that used technically sophisticated methods (such as screening, monitoring, and diagnosis) to identify risks to different population groups. Overall there appears to be little conscious effort to integrate scientific techniques 
between disciplines, and the selection of methods to identify risks remains a matter of disciplinary style of analysis.

Risks are identified by experts, industry, or agencies and the information given to the public, or the risks can be discerned from a public complaint and result in discovery and/or validation of the risk by expert sources. The resulting knowledge is diffused among experts and peers, discussed, and evaluated. Discussions then take place on the management of the risk and include various parties and individuals directly or indirectly involved - often with differing agendas, assumptions, opinions, options, and time frames. Generally, the risk issue, including the assessment and management analysis, then moves into the political sphere to be managed by regulatory agencies or institutions designated to alleviate the risk(s) identified. However, the erosion of public trust in institutions and agencies whose mission is to handle risks has forced more openness among some agencies to interact with the public prior to any regulatory action. In the CSEPP, some information that the Army has about the amount of chemical munitions stored has remained unavailable to the public because it was classified internally as pertaining to national security -a policy which undermined the public's perception of an Army's credibility.

Another issue associated with identification is that some naturally occurring hazards and their related risks may not be detected until consequences are too great to permit management. Risks are not always easy to recognize, especially if the technology is new and untested. Outcries from the public over the hazard potential of biotechnology or genetic engineering are related to the fear about the unknown consequences of such technologies. Sometimes identification of risks occurs long after severe adverse consequences have occurred. Prolonged drought or long-term deforestation resulting in heavy erosion leading to increased risks from flooding are examples of such cumulative hazardous consequences.

Some people have difficulty understanding how risks are estimated. The collective versus the individual interpretation of risk can differ between and among groups as well as between societies. To individuals of the general public, risk implies that not everyone is involved. But statistical probability is typically based on each member of the collectivity (e.g., groups or subgroups within society), having an equal opportunity of being at risk if engaged in a similar behavior or event. Thus risks to male drivers between the ages of 15 and 25 are calculated on all male drivers between those ages. 
Other issues involving hazards are never brought to the forefront of public agenda to be identified as risks. Kasperson and Kasperson (1991) have referred to "hidden hazards" as needing to be identified as part of the public agenda. The increased health risks to infants due to poor prenatal care is often attributed to the pregnant woman's lack of concern (an individual problem), when in reality poverty (a societal problem) prevents many marginal groups from participating in risk prevention measures (e.g., adequate nutrition during pregnancy). Thus associated with risk identification is the problem of equity or distribution of risks among groups, and identifying (and supporting) the overall costs and benefits associated with certain risk prevention strategies.

\subsubsection{Symbolism Versus Realism}

The concept of risk has both symbolic and realistic implications. To an individual, risk can suggest danger, warning of a hazard, or a precursorto potential future threat or harm. Knowing that one can "take a risk" also symbolizes a chance or hope, even though a gamble, depending on the probability of the outcome. Playing a lottery means taking the risk of losing a small amount of cash for the chance of winning a great deal of money.

Moreover, risk perception varies with an individual's own level of understanding and education about the hazard, one's belief in the credibility of the source of the risk information, and the awareness and relevancy of the hazard potential to the person. Also involved are the existing situational factors and the context in which the risks are perceived as well as the individual physiological factors associated with the expected trauma from the risks. Deciding what level of risk is acceptable is not just a technical question but a value laden choice for an individual (Covello et al. 1988).

\subsubsection{Acceptability of Risk}

Critics argue that "acceptable risk" is different from the "acceptability of risk." The distinction hinges on the technical definition of acceptable risk that defines certain levels of substances as not hazardous to human health or welfare. A major difficulty in judging the acceptability of risks is that the evidence is based on probabilistic reasoning about the effects caused by various substances and practices (Mayo and Hollander 1991). For example, EPA's Clean Air Act (1970, 1977, 1990) regulations require emissions of certain substances to be less than so many parts per 
billion regardless of the specific population affected. Because science is so important in determining the acceptability of risks, it's not surprising that disagreements exist about the validity of the assessments of risks.

What factors should be considered or given priority in the assessment of the risks is a major issue in risk communications. Some argue that as a concept risk must accept normative judgments. The level of risk is only one variable among several that determines acceptability-deciding what level of risk ought to be acceptable is not a technical question but a value question (Covello et al. 1988b).

The controversy exists not only between individual members or segments of the public and expert groups but between expert groups themselves. The assessment issue has grown in response to the mandates of the environmental pressures generated during the 1970s and mandated by Title III of SARA, (Superfund Amendments and Reauthorization Act) and the more recent OSHA standards. No longer can government agencies dictate levels of acceptability in the decisions about environmental risks.

The basic issue in defining acceptable risk is over control-who can or should define the level of acceptable risk or tolerable risk. For agency managers charged with protecting the public and familiar with the regulations, public concerns over acceptable risks are often the most thorny issues in discussions of risks with the public. Some agency managers claim the public unjustifiably assumes a "zero-risk" mentality when approaching risk decisions. The assumption projects the public is incapable of making rational decisions because of the host of external factors that cloud the technically derived risk estimates.

While a high level of risk may be tolerated as acceptable by an individual risk-taker, other risks that involve a number of persons may be considered unacceptable; strict safety guidelines have been introduced to ensure the minimization of those risks. Safety experts are constantly issuing reminders that seat belts have been shown to save lives of those in automobile accidents. Individuals, however, voluntarily engage in risk provoking activities (not wearing seat belts when driving) knowing that harm may occur (or occur again if the activity is repeated).

As pointed out previously, risk is generally more acceptable to people if it is voluntary, exhibits some social control, is beneficial, occurs in the short-term, and is distributed fairly (e.g., presumed equitable among all risk-bearers). Conversely, risk is viewed as unacceptable if it is involuntary, uncontrollable, and unfair. People often get very upset about preparing for the risks of a chemical munitions accident 
because they have had little, if any, input on how the weapons were stored in the first place and now, how the munitions will be destroyed. Acknowledging the risks from a hazard without offering any form of negotiation except in the political arena is a problem often faced by CSEPP personnel in dealing with the public.

Another underlying issue involves how much information on risks should be given to the public and when it should be presented in the public decision-making process. The democratic view suggests giving the public all information as soon as available. Others cite the public's usual indifference and apathy to risks for and argue for providing only limited, factual and pertinent information as needed for decision making.

Further contradictions abound between industrial estimates and those of the public, including risk-bearers, about acceptable risks. The issue results in frustrations for both parties. Baram (1986: 568) notes:

"What chemical firms are finding is that risk assessment is fraught with difficulty since it is an art form not reduced to generic practice or confident results; that technical uncertainty prevails; that public values and attitudes about risk are shaped without apparent regard for probabilistic risk estimates by industry or experts; and that there is no "stopping point" at which a firm can determine with confidence that enough assessment and control measures have been undertaken."

When firms try cooperating with local officials in communicating risks at their facilities, they encounter the further difficulty with local government officials who often lack the necessary skills, authority, or resources (including time, money and staff), to develop, test, and manage emergency response systems. And members of the public may be somewhat apathetic, keeping resources limited until a problem actually surfaces.

\subsubsection{Risk Assessment Versus Risk Management}

Confusion also occurs between risk assessment and risk management strategies. Risk assessment involves three basic elements:

- hazard identification,

- risk estimation or analysis, and 
- social evaluation

(adapted from Kates 1978).

Some critics have argued that the separation between assessment and management should be challenged because it presupposes a view that risk assessment is a matter of objective, impartial, empirically oriented fact finding while viewing risk management as vested with social values, subjective, and emotional feelings (Mayo 1991).

Hazard identification methods-the methods used to screen, monitor, and diagnose-are used to determine what constitutes the threat. While the distinctions among methods may appear hazy, conventional usage indicates that screening is the process of hazard identification wherein a standard procedure is applied to categorize products, processes, phenomena, or persons for their hazard potential. Monitoring is the recurrent process of observing, recording, and analyzing those observations for potential hazardous consequences. While screening may involve simply a searching mechanism, monitoring almost always indicates that something is suspect. Diagnosis is the assessment of the symptoms or consequences in relation to possible causes and usually requires some knowledge of the consequences, but where and how the risks from the threat occurs exactly may be in doubt (Kates 1978).

Risk estimation is the measurement of the threat in terms of timing and consequences, sometimes referred to as the magnitude or the dimensions of the threat. While both identification and estimation of risks are fairy straight forward analyses, social evaluation is more problematic. Social evaluation is the meaning attributed to the measurement of the threat potential and involves answers to questions that use methods of comparison such as benefit-cost analysis and aversion factors. Elements of risk assessment are shown in Figure 2-1.

Risk analyses often model the impacts of an unfortunate event (e.g., an accident, a discovery of pollution, product tampering) in terms of direct harm (mortality), injuries (morbidity), and damages (Slovic 1991). While early analyses of risks often equated the magnitude of the hazard's impact with the number of deaths or injuries, we now recognize that characteristics of an event can extend far beyond the initial analysis. Such secondary impacts may implicate other groups and include significant indirect costs that occur later in time or with unexpected frequency. For example, the Three Mile Island (TMI) accident did not result in any injuries or deaths but had significant impact overall on the public's trust in the nuclear power 
industry, resulting in a general societal distrust of the nuclear industry at large. In a similar manner distrust of the Army's information system is usually brought to fore in discussions with reference to the Dugway sheep kill incident. Such incidents are not easily forgotten either by the media or the public.

\subsection{RISK ASSESSMENT}

Accurate risk assessments are difficult at even the simplest level. A risk assessment must contain two distinct parts-measurement and evaluation. Risk assessment recognizes the hazard, appraises the measurement of the associated threat, and displays understanding of the social implications of such measurements (Kates 1978). Although complex, risk assessment is part of everyday life. For example, deciding how fast to drive or even what foods to eat or drink-healthy versus fatty-involves a choice (conscious or unconscious) about the risks we want to take regarding our health.

On a different level are those risk assessments based only on statistical comparisons. Actuarial tables used as a basis for calculating rates by insurers are based on historical data collected for certain groups. Some common classifications are age, gender, and race. Risks associated with various groups are compared and then fee schedules are developed that reflect the risk level of that group. The results may not seem equitable. Women may pay lower rates for some health insurance coverage and male drivers under 25 may be subject to higher automobile premiums. Although it is probably important for us to try to control factors that statistically decrease the probability of an accident or early death, risk can never be eliminated from daily living.

The mere presence of a known hazardous substance in the environment, however, does not automatically lead to an increased health risk. For example, chlorine in certain amounts is considered a hazardous substance but chlorine in public water supplies is a benign, even beneficial chemical. Based on statistical analysis, it is many times more "risky" to refuse to wear a seat belt when driving than to live near the Diablo Canyon Nuclear Power Plant while the statistical risks of a high-fat diet lie somewhere in between (Wilkins 1987). Making such comparisons, however, is not always a good communication strategy (Covello et al. 1988). 


\subsubsection{Macro Versus the Micro Perspective}

It is ironic that the macro perspective toward risk assessment taken by most experts and regulatory agencies in determining risk thresholds may fail to encompass the broadest view by reflecting only statistical measures. Statistics are used to extrapolate results to larger populations, regardless of the characteristics of individuals. Critics point out that the public often takes a more comprehensive framing approach toward risks than agencies by incorporating the qualitative aspects of social values and of one's cultural heritage (Cvetkovich and Keren No date). It is important to know if perceptions of risk among groups differ because of lack of knowledge about the risks or for some other reason, such as variations in cultural backgrounds. Plough and Krimsky (1987) point out that cultural rationality does not deny the role of technical reasoning, but extends the technical analysis perspective by refusing to separate risk assessment from its social setting or context. The dominant model of traditional (scientific) risk assessment methods thus may overlook the complexity of cultural factors inherent in a comprehensive risk analysis.

Other critics have argued that social scientists have abetted the concern among public officials of an 'irrational' public by foisting simplistic names on complex social processes (Kasperson and Kasperson 1991). For example, referring to a LULU (Locally Unwanted Land Use) or to a NIMBY (Not In My Back Yard) syndrome serves only to discredit the reaction of a public expressing rational concerns about risks. Using such acronyms to criticize local activism toward a project may only enhance the image that institutions, such as the military or the federal government, are uncaring monolithic structures.

\subsubsection{Hazard Versus Outrage}

The traditional method for measuring risks to a population relies on mortality statistics to set standards. Statistics are generated by determining by the number of deaths per cohort ( a group of people in a certain age range or other category) over time. Sandman (1988: 163) argues the 'concept of risk' means a lot more than mortality statistics. Essentially there are two independent variables involved in the concept of risk assessment, the social and the statistical, neither of which are positively or negatively correlated. Sandman (1988) advocates using one of the classic definitions of risk-how many people are likely to incur how much 
damage if $\mathrm{X}$ event occurs-and calling that the hazard. Hazards are what risk assessments are designed to estimate quantitatively. Everything else that goes into a lay person's risk perceptions Sandman calls the "outrage" factors. "Outrage is everything about risk that's relevant except how likely it is to hurt you," notes Sandman (1988). Sandman's concept, however, does not fully articulate the probabilistic nature of risk events.

\subsubsection{Threshold}

What constitutes a threshold in assessing risks often confuses people. Technically, a threshold involves both timing and quantity of a substance. A threshold is the point at which a physiological or psychological effect begins to be produced. As Paracelus, the 15th century physician who developed the concept of toxicology, said:

"Everything is poison. There is no substance which is not a poison.

The right dose differentiates a poison from a remedy."

For precision, regulators have added specific values to the concept of threshold. Threshold Limit Value (TLV), Threshold Planning Quantity (TPQ), and Threshold Quantity (TQ) are common terms in agency parlance. The concept of threshold dose is critical because it is often the basis for setting safe exposure limits for certain chemicals. For example, under SARA Title III, whether an industry has to report having certain extremely hazardous substances on site is based on whether the amount stored is in excess of the TPQ.

In the U.S., the EPA is the primary agency involved in risk assessment, but the agency has been criticized for its no threshold, linear multistage assessment model used for regulating substances. Basically, EPA assumes that if any dose of a substance can cause cancer then every higher dose can cause cancer in equal proportion. For example, if 100 parts per million (ppm) of a substance can cause 100 cancers, in theory $1 \mathrm{ppm}$ will cause one cancer (e.g. 100/100 =1). The model assumes that no safe exposure levels exist for carcinogens.

A carcinogen is technically a substance or agent that produces or incites cancer. The risk of developing cancer from exposure to chemicals in the environment is calculated on statistical data, but the evidence of ever-increasing new information and better technologies for analysis increases the complexity of the 
task. One earlier assumption for relying on statistical procedures was that scientists could distinguish carcinogens from non-carcinogens and that only a few chemicals or substances could cause cancer. While as many as 2000 substances are classified as "suspect," "probable," or "definite" human carcinogens, only 23 substances have been proven through human epidemiological studies to increase cancer rates. The remaining carcinogenic classifications rest on animal studies that have been extrapolated (projected with inferences) to human populations.

As important as animal tests are for determining carcinogens, critics often attack the studies as providing distorted data for human populations. For example, in one study on decaffeinating agents for coffee, rats were fed the equivalent dose of 12 million cups of coffee a day. Among critics are those from the Harvard Center for Risk Analysis (1993) who argue for testing all chemicals using Bayesian statistical methods to produce a probability distribution on carcinogenic potency that accounts for the amount and quality of scientific information. That way, when new evidence surfaces, the potency distribution can be revised. Critics further argue that regulated industries would also have an incentive to devote more resources explicitly for testing for carcinogens if it would increase the evidence available for the use of certain substances that are presently questioned. There are about 80,000 commercially produced compounds that have possible negative consequences on human health or the environment, but only a fraction have been subjected to actual quantitative and systematic analysis.

Eliminating the large areas of uncertainty due to limited data on doseresponse relationships would be helpful to the CSEPP. The limited amount of data on human effects from exposure to mustard and VX has hindered the publishing of certain standards for worker protection in the CSEPP. What data was available had to be tracked down through time-consuming methods that involved going through old classified military documents. The Army is currently working to develop improved toxicity values.

\subsubsection{Risk Measurement Issues}

Risks associated with new technologies led to the development of techniques that were quantitatively based in order to arrive at "objective" facts on which to base policies (van de Pligt and de Boer 1991). However, how measurements are made is clearly influenced by underlying assumptions, intuitive judgments, or methodologies 
traditionally utilized as recognized techniques. The large discrepancies involved, however, may push those objective facts into the realm of opinions.

Although measurement is fundamental to scientific activity, each area of science develops its own set of procedures. Such techniques and specialized methods help make sense of the observations about the world around us-people, objects, events, and processes. While statistical measures may be adequate for observable phenomena, the measuring of intangible social phenomena (such as stress) is not as easily calculated because the relationships between concepts and that which is measured may not be easily recognized. When an observation is difficult to validate, direct inquiries on a quantitative or empirical basis can help sort things out initially. For example, counting the number of automobile deaths in accidents with people not wearing seat belts versus those where seat belts were worn may give clues as to whether seat belt use (a behavior) leads to decreased mortality rates from car accidents (a statistic). Likewise, if only a poor measurement is available, the costs of using that measurement may be greater than the benefits gained, because certain factors may be overlooked that bear directly on the level of risk involved. By using a variety of expert opinions, the uncertainty of measurement about the risks can be made more explicit. For example, when officials say that storage of weapons is safe because an accident has never occurred, some members of the public do not accept the premise that sole reliance on historical data (no accidents) is an adequate method on which to base risk assessment.

The tension between views on risks challenges traditional political responsibility, including regulatory actions, for risk management. Some studies attribute this tension to the rise of environmental advocacy in the early 1970 s (Plough and Krimsky 1987) when concern arose about governmental indifference to environmental degradation. Thus the divergence between experts and the public over risk is not caused by ignorance but by differing values of persons involved in judging risks (Renn 1989).

Covello et al. (1989) argue that the roots of most risk communication problems lie in the complexities and uncertainties of the risk problem itself. Communication problems can often be viewed beneficially as decision problems. Whereas federal or state regulatory agencies view risks from a societal or macro perspective, citizens follow a micro perspective and more personal approach that often employs a longer time frame. Thus the micro perspective encompasses more than probability estimates and places the risk in the social context (Plough and Krimsky 1987). 
Developing a consensus on how risk assessment can be achieved between risk perpetrators and those persons at risk in an equitable fashion has been a continuing issue. Some suggest decisions should be based on economic models of rationalityasking whether the hazard from an identifiable source(s) to a small number of people is justification enough to give the problem high priority and a generous share of resources (Allen 1987). If the risk debate is framed in these terms and the value judgment is yes, then that judgment should carry great weight in the decisionmaking process. If the judgment is no, then other changes may be in order. If dimension of risk is high, and experts say the probability is low, then one should develop full understanding of the outrage factors and the hazard probabilities, and frame the issue in terms of competing resources (Sandman 1978).

Hattis (1989) suggests choices on allocating efforts to risk assessment be judged on whether analytic efforts can in fact reduce uncertainty (the technical aspect) and on the relative importance of reducing specific uncertainty. The general criteria the analyst should apply would be analysis of those aspects relevant for foreseeable decisions the intended audience might wish to make based on risk information.

\subsubsection{Risk Communication Versus Risk Management}

Risk communications often do not clarify the distinctions between risk communications, risk assessments, and risk management strategies. Complaints about faulty risk communication efforts frequently confuse the lack of communication about risks with the inability to assess risks or the frustrations involved in managing hazards. Although risk assessment strategies often address the ability (or inability) of experts to control risks, most risk communicators view their communication roles as advisers or moderators in the decision-making process.

In the extended process of identifying and assessing a hazard, some risks are not communicated to the public until after the hazard has occurred or people are already at risk. Sometimes risk generators are also risk communicators, which can provoke distrust and even anger at communication efforts. Moreover, many risk communication efforts in the past were in conjunction with the siting of hazardous waste or nuclear power plant facilities. The co-opting strategies that industries used to facilitate the process were often held in contempt by the publics involved. In the Army's case with the chemical weapons, the present officials are dealing with a hazard generated long ago. Because of the shroud of secrecy, very little technical 
work or openness in the scientific community occurred on the impacts from chemical agents prior to Congress's disposal mandate. Thus the program has had to wait until the technical analyses (and identification) was in place to accurately convey the risks from the chemical agents, even while stored. Another emerging issue is the gap between each installation's assessment of the potential accidents and those found in the Army's formal risk analysis. The accident data base from the formal analysis is very different from the types of events that the installations have historically considered credible events. This difference occurs because the formal risk analysis was conducted to define all possible accidents for making a programmatic decision while the credible events are those the installations consider likely based on experience and regulatory requirements.

\subsection{RISK MANAGEMENT}

William Ruckelshaus (1985) broadly defined risk management as:

"the distribution of current resources to shape some desirable future state; risk management in its broadest sense means adjusting our environmental policies to obtain an array of social goods-

environmental, health-related, social, economic, psychological-that forms our vision of how we want the world to be."

One aspect that Ruckelshaus did not address is that the amount of resources expended affects the time and effort directed toward establishing the level of risks as well as toward the reduction or mitigation of risks. Another problem is that there is little or no public consensus or trust that government can conduct the social management of risk in a fair and equitable manner.

After decision makers have identified paths of exposure to risk, the risk management process proceeds to analyzing the range of tasks and management control actions available (Burby 1991). Major areas of management control involving environmental hazards are research and monitoring and the drafting of legislation and regulations; standard setting; inspection and enforcement; and review of risk levels (Whyte and Burton 1980). The evaluation and selection of alternative risk control measures, and their implementation, may or may not be open to outside individuals or organizations. Resources (money, skills, and time) are required to manage risks and are often directly associated with the costs, delays, and inaction in decisions on managing risks (Whyte and Burton 1980). 
Events themselves may not allow for orderly procedures of risk management. It is important that when an emergency of rapid onset occurs that risk managers can suspend formal decision-making operations and protocols and function in a response mode that communicates to the public the agency's concern, ability, and accountability in a crisis involving risks. Successful risk management depends on an agency's accountability and ability to hold up under scrutiny, and the more officials can be trusted to perform their roles, the better able they will be able to continue to manage future risks effectively-in or out of a crisis. Although the past 25 years have seen remarkable progress in our understanding of hazards and in mitigating their threats, it has only been within the past decade that we have begun to understand the difficulty in communicating information about the risks from a hazard to the public.

\subsection{MODEL OF RATIONALITY}

The rational model assumes that members of the public will accept the directive of technical experts and scientists when given the facts. In concept, an informed public will follow a rational course (advice) as outlined by experts. The flow of information is unidimensional (one direction) from experts to the lay publics.

Needleman (1987) notes that the successive emergence of three risk concepts-assessment, management and communication-acknowledges that the field of risk analysis is inherently political. The models used in risk assessment and risk management tend to make simplifying assumptions about risk related behavior for the purposes of analysis. The models assume rational actions by autonomous, competent individuals with full access to information and data that results in clear, permanent choices. Individuals at risk, however, live in a world where these assumptions may not be valid and who are thus blocked from constructive decision making unless support services, counseling and advocacy are provided along with factual data about risk itself. Needleman (1987) states:

"The sponsors of programs for transferring risk information to the public must go beyond assembling and disseminating the same kind of data used for risk analysis and risk management. They must incorporate a series of a serious affirmative value commitments to assessing and serving the target population's need for practical, personally applicable information." 
The model of rationality assumes that the public needs to be taught to accept the uncertainties of science and to understand the concept of relative risk and the methods used to predict risk. The public must receive, understand, believe, agree, and act accordingly in order for persuasion to work. Regardless of the purpose, messages must be developed with consideration of the desired outcome (Arkin 1989). Says Thomas (1987):

"The ultimate goal is to increase public cognizance of the fact that priorities must be set if any real progress is to be made in dealing with environmental risks, and to gain public acceptance of an ordered and rational program to control the most significant risk. Citizens must share directly in the decisions that affect them, and we must ensure that they do so with a fuller understanding of the inevitable trade-offs involved in the management of risks."

The risk communication decision is itself a decision problem separate from the risk problem and its analysis. The public should know and appreciate that there are no zero-risk solutions, that tradeoffs are necessary, and that uncertainty about risk outcomes cannot be avoided, note Keeney and vonWinterfeldt (1986). To assume that social context is all, and there is no objective knowledge that should be communicated, is as inaccurate as assuming that only technical data is salient (Jasanoff 1988).

Communicators must develop mechanisms to deal not only with scientific data but also with competing needs and values and should not expect to resolve controversial issues with technical expertise alone (Chess and Hance 1989). The similarities should be stressed between risk assessments and other issues that the social decision-making process must handle (Hansson 1989). The summary of results of analysis should allow the diverse members of audience to apply their own value standards to make as informed choice as possible. This involves communicating uncertainties of information and/or reasonable likely worst case scenario (Hattis 1989). Despite its intellectual and practical challenges, the middle way which respects the roles of both technical and contextual information in risk communication seems the most fruitful (Jasanoff 1988). States Slovic:

"To be effective, risk communicators must recognize and overcome the limitation of scientific risk assessment and idiosyncrasies of the human mind. That is, just as they must understand the strengths and limitations of risk assessment, communicators must appreciate the wisdom and folly of public attitudes and perceptions." (1986) 


\section{ALTERNATIVE PERSPECTIVES ON RISK COMMUNICATION}

\subsection{INTRODUCTION}

Risk communication will and should mean a variety of things to different groups and people with alternative frames of reference. In part this is due to the vastly different subject areas that fall under the umbrella of risk communications. Some subject areas have similarities while others are somewhat disparate. For example, in health related areas one can see that there may be some implications or lessons to be learned from EPA's experience with toxic substances for the CSEPP. On the other hand, the link between experience with genetic counseling regarding birth defects and the CSEPP is more tenuous.

Risk communication provides disclosure, but how or what is disclosed about a risk raises disagreements between experts, publics, risk bearers, risk generators, and other interested or associated parties or individuals. Risk disclosure presumes both ethical and legal implications for the individual's or community's right to know. Baram (1986) points out that right-to-know policies are based on three assumptions:

- those who possess information which can enable another to avoid harmful consequence have a duty to disclose the knowledge in a timely fashion;

- that risk management is a joint enterprise between risk generators and persons at risk;

- that risk communication informs the public, thereby promoting agency accountability.

Experts often disagree about how much disclosure about risk is needed for either assessment or management of a risk. Hilgartner and Nelkin suggest the disparity between expert opinions is unavoidable:

"When broad statements, such as risk communication should avoid undue harm or should never withhold necessary information, are applied to actual situations, conflict is inevitable because groups approach risk communication with different economic and professional interests and competing political and ideological concerns." (1987). 
This observation suggests that risk communication faces an obstacle from the onset of a program - the content of risk communication is almost always destined to cause problems for some affected party.

Examining various definitions helps define the broad spectrum of approaches to the risk communication process. Kasperson and Palmlund (1987) argue that risk communication enters our lives in a multiple of forms with any information gleaned (or omitted) from any source a possible form of risk communication. Intentionality is often assumed in risk communication efforts. Thus risk communication can refer to any public or private communication informing individuals about the existence, nature, form, severity, or acceptability of risks (Plough and Krimsky, 1987). Covello et al. (1989) argue for limiting risk communication to "any purposeful exchange of scientific information between interested parties regarding health or environmental risks."

Plough and Krimsky (1987) list five major components of risk communication: intentionality, content, audience directed, source, and flow. The aspect of transferring information about risk to a presumed "reactive" (or passive) public influences methods of communication. Chess and Hance (1989) hold that risk communication should be part of a problem-solving methodology and not a way to avoid solving problems.

Effective communication results from commitment of communicator and of audience participants. Effective risk communication demands (1) a guarantee of agency's resources and actions of personnel; (2) an involved public who have personified the risk, threat, or hazard; (3) an informed public who is collaborative, fair-minded, reasonable, thoughtful, solution-oriented; and (4) trust between all affected parties (Hadden 1989).

The traditional goals or elements of risk communication include: (1) informing the publics about the existence of a risk (with no mention of management of risk); (2) eliciting response from the public about management of risk; and (3) final negotiation with affected publics about management of risk. The outcome of communication depends on intentionality. The monologue, or one-way communication, attempts to persuade others to adhere to one's view, whereas through dialogue, or two-way interaction, the goal is negotiation.

Concern for adhering to prescriptive methods during the communication process to determine various definitions, goals, or outcomes, creates tension between bureaucratic and democratic processes in arriving at a consensus. Deciding who is responsible (or capable) for dissecting scientific evidence into lay person's terms 
remains problematic. Thus discussions center on access to information generated by experts and industry, and who can understand and translate that evidence in risk communications especially when risk is uncertain or imposes burdens on unwilling risk bearers.

Some have criticized prescriptive approaches to effective communication practices because they cannot be implemented in practice (Earle and Cvetkovich No date). Prescriptive approaches do not account for the social dynamics of citizen involvement, the technocratic orientation of risk managers, and the way decisions are made in a democratic society. For example, situational factors may prevent a risk communicator from being completely open about the risks involved. In other cases, institutional limitations may prevent the involvement of all relevant stake-holders. In many cases communication problems are manifested before public involvement can take place. In the case of the CSEPP, the chemical munitions have existed since the 1940 's, but the possible risks associated with continued storage were not recognized by the public at large until Congress ordered disposal of the weapons.

\subsection{REVIEW OF RISK COMMUNICATION APPROACHES}

Comprehensive reviews of the field of risk communications have been limited. Covello et al. (1987) identify four broad types of risk communication according to objective. They label these types as information and education, behavior change and protective action, disaster warning and emergency information, and problem solving and conflict resolution. Kasperson and Palmlund (1987) identify five different, but more specific paradigms or perspectives according to approach: the information system, marketing, psychometric, the cultural, and the public participation approaches. Weinstein (1987) defines five theoretical perspectives on protective behavior in respect to risk communication: behavioral decision theory, social learning theory, psychological emotion and defense perspective, diffusion of innovation perspective, and cultural theory.

\subsubsection{Classification of Risk Perspectives}

Few attempts have been made to develop a transdisciplinary classification of risk perspectives. Renn (1992) presents his classification of risk perspectives by 
matrix. Renn notes that the conception and assessment of risk fall roughly into seven categories under social amplification theory:

- the actuarial approach that relies on statistical projections and predictions,

- the toxicological and epidemiological approach,

- the engineering approach that relies on probabilistic risk assessment,

- the economic approach that includes risk-benefit comparisons,

- the psychological approach (including psychometric analysis),

- social theories of risk, and

- cultural theories of risk.

The approaches vary by the selection of the operational definition, the choice of methodologies (including the underlying assumptions for choice of techniques for assessing the risk), the complexity of the risk measures, and the social function (intent) of the risk perspective (Renn 1992). Renn emphasizes that analyzing risk is an American cultural attribute and must be recognized as an underlying assumption because unlike some cultures, most Americans do not follow a fatalistic credo nor believe the future is predetermined. In a fatalistic oriented culture, attempts to assess risks make no sense as the cultural view holds that the future is predetermined and thus negative circumstances, such as trying to evade a hazard because of its risk, cannot be avoided. Risk is thus both a descriptive as well as a normative concept, dependent on the cultural dictum. What is interesting about Renn's analysis is that all the approaches that rely entirely on quantitative measures (the actuarial, epidemiology, probabilistic risk assessment, and those using expected utility) are considered one-dimensional while those involving public perceptions are viewed as multi-dimensional. While Renn has not examined the cultural validity of the approaches, he does suggest examining the "social function" of each approach, which ranges from mere assessment (characterized as one-dimensional) to political legitimation (characterized as multi-dimensional).

If one takes a broader view, a number of other perspectives on risk communication exist. Some of these overlap as well as share common theories and methodologies. A few are just emerging as new theoretical perspectives.

We categorize the varying perspectives as:

- Communications (Lee 1986, Renn and Levine 1988)

- Journalism (Sandman et al. 1987, Peltu 1988) 
- Psychometric (Slovic 1986, Keeney and vonWinterfeldt 1986)

- Management (Shrivastava 1987, Grunig 1987)

- Behavior modification/change (Covello et al. 1987; Smith et al. 1988)

- Marketing (Kasperson and Palmlund 1987)

- Cultural (Thompson 1980; Johnson 1987, Krimsky and Plough 1988; Raynor 1992)

- Public participation (Kasperson 1986, O'Riordan 1988)

- Social amplification (Kasperson et al. 1988; Kasperson 1992)

- Emergency warning/disaster (Sorensen and Mileti 1989, Covello 1988)

- Hazard awareness (Saarinen 1982, Sorensen 1983, Bolton 1987)

- Human Factors (Letho and Miller 1986)

- Evaluation (Greenberg 1987)

- Medical (Wertz and Fletcher 1987)

- Social teamwork (Earle and Cvetkovitch 1988)

In assessing these perspectives we will look at two factors. The first is the maturity of the theory and amount of empirical research that supports the theory. The second is the nature of the sender and receiver involved in the communication process.

\subsubsection{Communications}

The communications perspective on risk communication grew out of social psychological research on the human communication process (Lasswell 1948; Hoveland 1948; Aronson et al. 1963) and became the central paradigm of mass communications and diffusion of innovation research (Rodgers 1983). The basic model postulates an analogy with a communications system consisting of an information source, channel, message and receiver. The research efforts sought to understand topics like source credibility, the effectiveness of different messages and channels in changing attitudes, the results of fear arousal on attitude change, or characteristics of receivers that effected communication effectiveness. Later research differentiated between a factual information flow process and a cognitive information flow which colors the factual one (Whyte 1977).

The communication approach is quite mature both theoretically and empirically. While it has received criticism on the grounds that it ignores social dynamics, much useful information has been produced by this line of inquiry. 


\subsubsection{Journalism}

The major thrust of the journalism approach to risk communication is to understand how the media covers risk and, in turn, how to improve the use of scientific risk information by journalists. The major approach used by researchers is content analysis of newspapers (Sandberg et al. 1987) and television (Greenberg et al. 1989) and informal interviews (Sandman et al. 1987). Among the issues regarding media coverage that this perspective addresses are the accuracy of news reporting, the level of coverage given to different risks, the sources of the information reported, and the characteristic styles of the reporting. Some of the concerns about the media are the journalists attitudes towards risk information, the sources used by journalists to gather risk information, the levels of detail media reports need, and the difficulties involved in obtaining relevant information.

The journalism perspective is largely theoretical. No overriding theories have been used to conceptualize or design research. The research has a fairly small empirical foundation but is growing.

\subsubsection{Psychometric}

The psychometric approach to risk communication grew out of laboratory studies conducted primarily by cognitive psychologists on how people structure and perceive risks (Slovic 1987, 1992). Much of the research is oriented towards people's use of risk information in decision making, how individual evaluative techniques and biases affect the individual's decision process, and how people attach attributes to the risk. A distinguishing feature is the use of psychometric scaling methods to produce quantitative measures of perceived risk, perceived benefit, and other aspects of individual perceptions.

The psychometric approach is firmly rooted in theories in cognitive psychology. A fairly robust set of empirical studies have been conducted, albeit only a few are directly concerned with the risk communication process. Much of the work has focused on how people perceive risks and segment risk into various qualitative attributes such as fear, dread, or likelihood of the event occurring. Most of the research has involved psychological testing or experimentation with small nonrandom samples. 


\subsubsection{Management}

The management approach to risk communication grew out of industrial crises experienced by large corporations-the Tylenol tampering, the Bhopal accident, and the Gerber baby food incident (Shrivastava 1987). The goal of the research was to seek methods that corporations could use to handle such crises as product tampering or large-scale industrial accidents. From the corporate perspective, the major goal of the research is to develop strategies that preserve the industry's public image and retain customers. Communications, mainly in the context of a public relations perspective, is considered the major vehicle for managing a crisis. Research based on this approach is largely theoretical and utilizes unsystematic case studies of crisis events.

\subsubsection{Behavior Modification/Change}

The behavior modification approach to risk communications developed from the applied behavioral research work in psychology and public health. The major question is what types of interventions prompt people to change their behavior. For example, what would induce people to quit smoking, wear seat belts, stop littering, adopt conservation, or use less energy. The two central theories of this approach are the health belief model (Cleary 1987) and the Fishbein and Ajzen (1972) model of attitude change. A wide variety of empirical investigations have been conducted in laboratory and field settings. The field studies have used a variety of quasiexperimental designs to capture the effects of interventions.

A good example of this approach applied to risk communication is described by Smith et al. (1988). In this study, different brochures with information on radon risk were sent to four groups of homeowners in a radon monitoring program discussing risks from radon. Measurements were made before and after the brochure was distributed in order to capture the differential impacts of the communications on risk from radon. Risk communication strategies used by the Health Protection Branch of Canada are intended to elicit public support on health risks. How people receive official information about health risks was examined in a public opinion survey involving 200 respondents (Liston 1989). 


\subsubsection{Marketing}

The marketing approach adopts the premise that communicating about risks can be accomplished using the knowledge derived from research on how to market various consumer products (Kasperson and Palmlund 1987). A great level of effort is expended each year to research how people make decisions as consumers of various products. A basic thesis is that the public must have a demand for a product before they will consume it. Thus a goal of the risk communicator is to identify what types of information the public is willing to consume. It follows that people will ignore any information for which they do not have a demand.

Significant to this approach is the practice of identifying and segmenting target audiences. This is based on the concept that the same information package will not be suitable to everyone at risk. The basic method of the marketing approach is the attitude survey, although we know of no empirical applications to risk communication per-se.

\subsubsection{Cultural}

The cultural perspective on risk communication primarily came from work by social anthropologists and sociologists on risk acceptance. In part, this research was a reaction to fundamental ideological differences between the cultural and the psychometric perspectives on human behavior. The cultural approach stresses that risks are not a technical phenomena but are socially constructed. Cultural theory argues that risks are defined, perceived, and managed according to principles that are inherent in particular forms of social organization (Raynor 1992). Moreover, the perceiver is not an individual but an institution or organization that is driven by organizational imperatives to select risks for management attention or to suppress them from view (Douglas 1985).

Risk communication in the cultural perspective is not a specific target action but a broad set of practices and flows of information. According to Krimsky and Plough:

"A cultural approach that seriously considers popular behavior and symbolic dimensions distinguished two forms of rationality applied to risk: technical and experiential. Both make contributions to the problems of constructing and analyzing a risk event, but neither is sufficient.... The cultural model is based on the notion that expert and popular approaches to a risk event can each be logical and coherent on its own terms, but may exhibit differences in how the problem is 
articulated, in the factors relevant to the analysis, and in who the experts are." (1988)

Research from a cultural perspective has primarily employed a case study approach involving qualitative data. The development of theory is proceeding, but on a fairly general or global level.

\subsubsection{Public Participation}

The public acceptance approach to risk communication grew out of research on public participation in political decision making (Kasperson and Palmlund 1987), including a number of studies on community or public acceptance of hazardous technology or large-scale engineering projects. Kasperson (1986) argues that the need for risk communication is a part of a longer term trend of increased public participation in decision-making. It is therefore necessary to look to research on public participation to help design risk communication programs.

From this perspective, the public consideration of risk occurs in social groups or community, but little is known about response of public as members of a social group, only as individuals. Since 'tolerable' risk levels are inextricably linked to the process by which risks are allocated or imposed, risk communication often becomes a vehicle of conflict by which community groups seek to create resources, including power, with which to bargain in risk management decisions. The timing of risk communication entails a difficult trade-off between the social imperative to inform without delay and the need for full scientific disclosure and analysis. Different communication strategies and packages are needed to reach the attention of different social groups whose members differ in their participation and arenas of interest. The long-term erosion of public trust suggests the need for innovative programs to achieve short-run informing of the public in given situations, coupled with long-run strategy to recover social trust (Kasperson 1986).

\subsubsection{Social Amplification}

The social amplification perspective is a modern version of the communication perspective using an electronics analogy to replace the communications engineering analogy (Kasperson et al. 1988; Kasperson and Kasperson 1991). The central thesis states that hazards interact with psychological, social, institutional, and cultural processes in ways that amplify or attenuate public responses to risks. Amplification 
occurs both in the transfer of information about the risk and in the response mechanisms of society. Signals about risk are processed by individuals and social amplification stations such as in scientific risk assessments, the news media, cultural groups, interpersonal networks, and so forth. The amplified risk may result in secondary impacts. Models are used to portray elements and linkages of proposed frameworks (Kasperson et al. 1988).

The amplification model has received excellent response among risk communication researchers. Recent additions to the model have incorporated other paradigms and the model appears more robust than when first introduced. One recent addition to the model accounts for 'hidden hazards' whose risks may go unnoticed by the mainstream press or political system (Kasperson and Kasperson 1991).

\subsubsection{Emergency Warning/Disaster}

The emergency warning perspective grew out of sociological studies of human behavior in disaster (Mileti 1975; Mileti and Sorensen 1988). The central research question was why some people respond to emergency warnings, while others do not. The model developed from this approach suggests that people engage in a process in which the warning is heard, understood, believed, and personalized before people make the decision to respond. This process is influenced by characteristics of the warning sender and the receiver. Research has primarily involved cross-sectional studies of people in an area where a disaster warning occurred. A fairly robust set of empirical findings exist.

\subsubsection{Hazard Awareness}

The hazard awareness perspective developed from research conducted primarily by geographers on adoption of mitigative measures for natural hazards (Burton et al. 1977). The basic research question was how to increase public awareness about natural risks so people could make more informed decisions, such as building in a flood plain or buying earthquake insurance. The work has an empirical orientation, but is less developed theoretically than some of the other approaches and is still lacking in empirical findings. Research on how the National Floodplain Insurance Program (NFIP) has affected the ability of people to recognize 
and plan for hazardous situations in flood prone areas may result in a better understanding of risk behavior related to natural hazards.

\subsubsection{Evaluation}

The evaluation research perspective developed from assessments of large scale federal and other programs in domestic policy areas. The evaluations centered on the effectiveness of social programs including crime reduction efforts (such as neighborhood watch programs or home burglar-proofing programs), medical and health care programs (such as smoking cessation or drug abuse programs), educational enhancement programs and the like. It is similar to the behavior modification perspective, although the research questions have been framed differently.

According to this perspective, the primary considerations for successful risk communication programs includes clear definitions of objectives as envisioned by both experts and those at risk, identification of targeted risk groups, achieves identified outcomes, successfully provides a context for risk, is adaptive to new information as needed for management, and involves various stakeholders and interested parties in design and implementation of the program's evaluation. An evaluation is necessary to force clear thinking on goal outcomes, provide new options on risk management, to determine strategies that work or don't work, to meet responsibility that the most effective means are being used to reduce or avoid harm, to allow for monitoring and to ensure greater accountability of risk managers to policymakers and affected publics. Only an understanding of the whole risk communication process will enable valid inferences to be made about the impact of particular interventions.

The findings from evaluation studies are usually quantified and provide a basis for risk comparisons. However, the general public still finds it difficult to understand some of the units used to measure and assess risks or why the units were chosen in the first place.

\subsubsection{Human Factors}

The human factors perspective developed from applied studies of accident prevention in the workplace, assessments of worker right-to-know requirements, and consumer product labeling. Emphasis has been given to investigating the effects of programs such as training, safety campaigns, or workplace placards, such as 
Material Safety Data Sheets (MSDS), on worker performance and accidents. A second emphasis has been on the effectiveness of warning labels on consumer products and instructions inserted in pharmaceutical packages.

Much of the research is quasi-experimental involving pre- and post-treatment measures with control groups. For example, a typical research project would establish a baseline assessment on a group of workers who would be treated with four different safety programs. A post-treatment survey would measure changes in knowledge or attitudes. Additional work to monitor accident rates among the four groups might be performed. Thus findings are usually limited to specific case studies.

\subsubsection{Medical}

The medical perspective developed from research on doctor-patient relationships regarding diagnosis of illness, decisions on medical treatment options, and survival odds. The approach has also focused on genetic counseling and methods of informing workers of possible elevated health risks from chronic or long-term exposure to hazardous substances. Much of the work has studied the communicator, in this case the doctor, rather than the patient. An emphasis is on the ethical and institutional role of the professional rather than on the effects of the communication process on the recipients.

\subsubsection{Social Teamwork}

The social teamwork perspective was proposed out of a desire to get away from the technocentric approach of the psychometric paradigm (Earle and Cvetkovich 1988). The major objections against some of the recommendations emanating from the psychometric paradigm are that the suggestions are not implementable in a sociopolitical sense nor do they provide enough specific guidance on how they might work to solve risk communication problems. In addition, critics argue that the recommendations are anchored to the position that the risk managers have the correct view and communication serves to convince the public the managers have the correct view.

The social teamwork perspective advances the notion that there are multiple legitimate perspectives on a risk issue. The approach holds that solutions to differences in outlooks need to be negotiated rather than persuaded in order to be effective. The concept is still in a preliminary stage of development, largely lacking in 
theoretical development, with no empirical testing, but holds great promise of integrating a number of perspective discussed above.

\subsubsection{Other Perspectives}

Several other perspectives can be identified which are conceptually different from the others discussed above, but are not reviewed in detail. These include what might be labeled as the philosophical and the legal perspectives. The philosophical perspective developed out of research on topics such as the moral or ethical aspects of the communication process as intertwined with risk management practices (McLean 1986). The legal perspective is represented in literature that discusses and analyzes legislation concerning risk communication programs and the underlying legal and social doctrines, such as the right-to-know and need-to-know controversy.

\subsection{ASSESSMENT OF THE APPROACHES}

Tables 3-1 and 3-2 summarize relevant information on the various risk communication perspectives. In Table 3-1 each perspective is described in terms of the stage of theory development, the amount of supporting research, and research methods commonly used. In Table 3-2 the dominant sender and receivers in each perspective are summarized, as well as the perspective's bias, either implicit or explicit, towards treatment of the communication process as one of dissemination (one way) or as a dynamic process with feedback and exchange (two way).

In this source book we do not attempt to use nor advocate any single perspective. Some provide, in our viewpoint, more useful information for the CSEPP participant. Others may advocate positions that seem to be at odds with basic thinking about communications processes from a social perspective. For example, some of the literature that we would categorize as fitting into the management perspective advocate practices that some members of the public would view as dishonest or deceitful. Of course those advocating such practices place the results far ahead of the process. The danger therein is that often the process is a key determinant of effective results. Not all of the literature in the management category should be summarily dismissed on the basis of this one example. We have attempted, however, to focus the reporting to those findings and lessons to relevant aspects of the CSEPP and that are not at odds with the basic tenants of risk management, assessment, and 
Table 3-1 Risk Communication Paradigms

\begin{tabular}{lccc}
\hline \multicolumn{1}{c}{ Perspective } & State of Theory & Amount of Research ${ }^{2}$ & Empirical Research Method $^{3}$ \\
\hline Diffusion/Social Communication & mature & extensive & a b c d \\
Journalism & little & moderate & a \\
Psychometric & maturing & extensive & a b d \\
Management & little & little & a \\
Marketing & maturing & extensive & c c \\
Behavior Modification/Change & mature & extensive & a b d \\
Cultural & developing & little & a \\
Public Participation & developing & moderate & a b \\
Social Amplification & developing & little & extensive \\
Emergency Warning/Disaster & maturing & extele & little \\
Hazard Awareness & developing & extensive & a b c \\
Evaluation & mature & moderate & a b c \\
Human Factors & little & extensive & a b c d \\
Medical & maturing & little & b c \\
Social Teamwork & developing & & a \\
\hline
\end{tabular}

1. State of theory progresses from little to developing to maturing to mature.

2. Amount of research is measured by the relative number of publications in area.

3. The major methods utilized by researchers include:
a. case studies
b. cross sectional
c. quasi-experimental
d. experimental 
Table 3-2 Structure of Communication in the Paradigms

\begin{tabular}{llll}
\hline \multicolumn{1}{c}{ Perspective } & \multicolumn{1}{c}{ Sender ${ }^{1}$} & Receiver & Direction $^{2}$ \\
\hline Diffusion/Social Communication & non-specific & non-specific & two-way \\
Jourmalism & scientist/expert & media & two-way \\
Psychometric & risk manager & public & one-way \\
Management & corporation & customers & one-way \\
Marketing & seller & customers & one-way \\
Behavior Modification/Change & risk manager & target groups & one-way \\
Cultural & non-specific & non-specific & two-way \\
Public Participation & risk managers & public & two-way \\
Social Amplification & non-specific & non-specific & two-way \\
Emergency Warning/Disaster & emergency manager & public at risk & two-way \\
Hazard Awareness & emergency manager & public at risk & two-way \\
Human Factors & producer/employer & customer/worker & one-way \\
Evaluation & program & audience & two-way \\
Medical & medical professional & patient & one-way \\
Social Teamwork & risk manager & public & two-way \\
\hline
\end{tabular}

1. Major communicators and audiences studied.

2. Treatment of the directionality of the communication process. 
communications discussed in the previous chapter. In the next three chapters we summarize some of the commonalties and describe the diversities of the risk communications literature. We do not report these by perspective or discipline, but have attempted to integrate research findings with recommendations along common themes. 


\section{RISK COMMUNICATION ISSUES}

\subsection{INTRODUCTION}

Risk communications contain both factual information as well as undefined assumptions about risk analysis that inherently frame the risk issues under discussion. Some communications are unclear as to what information they are intended to convey as well and what audience the information is intended to reach. While a number of formal models have been developed to describe the process of risk assessment and risk management both in the United States (NRC 1983) and in other countries (such as the Working Group on Risk Assessment and Risk Management in Canada 1988), no one model functions for all situations.

Exchanging information, evaluating measures used in assessments, and determining how to manage risks vary among researchers and technical experts, industry, government agencies, interest groups, and sub-groups and individuals within the general public. Risk communication has both conventional and symbolic meanings depending on the cultural values in which it is embedded and on the specific conditions of the hazard itself.

Risk communications for the CSEPP are somewhat different from other risk communication efforts. Risk communication that have involved community input have traditionally focused on the siting of hazardous waste disposal facilities, nuclear power facilities or some other hazardous facility, or, on emerging public health issues, such as the risks from smoking, drug abuse, recently discovered wastes, or from radon in the home. In the case of the former negotiations over acceptable risk is the dominant issue. In the latter case the issues center around individual behavior and health risks. While these communications involve the public and can include experience with the effects from the hazards, the values and underlying assumptions about the risks associated with the hazards are somewhat different than CSEPP. In CSEPP there is no debate over acceptable risk-all agree with the notion of maximum protection and the elimination of risk. CSEPP also focuses on the community and collective risk, not on individual behavior. 


\subsection{UNCERTAINTY}

Risk communications for the CSEPP involve a great deal of uncertainty about the hazard itself. No government agency nor private industry has had sufficient experience with chemical agents in recent years on which to base an empirical risk assessment. Thus there is uncertainty about the effects from a release of chemical agent either by accident during storage or during the incineration process. The risk analysis originally performed for the chemical munitions determined the major risk to be from low probability, high consequence events. With the storage of the munitions benign to date, critics of the CSDP have raised a number of issues in the political arena about the proposed disposal plans. The uncertainties affect the risk analysis, the risk assessment, and the risk management strategies, all of which affect risk communications for the CSEPP.

\subsection{TLMING}

Risk communications are also time oriented. Information to the public may focus on risks requiring immediate response during crisis events or may relate to long-term personal or institutional changes needed to improve or benefit overall public health or environment. For example, giving information about a hazardous materials spill that requires people to immediately evacuate the area is different from communicating the health risks associated with highly fat saturated diets to a general audience.

In CSEPP there is a great deal of skepticism that timely communications will occur. During a crisis, risk communications require special management that insures coordination among various authorities, and (to the extent feasible) a single place where the public and media can obtain authoritative and current information (NRC 1989).

\subsection{INFORMATION FLOW}

Flow refers to the physical processes behind the communications process. At a simple level, flow can be differentiated into one-way versus two-way communications, depending, for example, on whether it is a party issuing 
information versus two parties entering into a dialogue. The direction of information flow should be examined when focusing on communication efforts. Whether the purpose is exchange, dialogue, and/or participation depends on the identification of the communication flow as one-way or two-way oriented.

One-way also includes warning messages. For example, issuing emergency notification for a CSEPP related accident would not leave time for a dialogue. Providing information via a brochure or calendar is also considered one-way communication. Information generally flows in two directions (dialogue) during public meetings or when the installations hold open houses for the public and people can ask questions about installation activities. The impetus for the CSEPP came out of public scoping meetings the Army held at sites when preparing the draft programmatic EIS.

To date, most of the information flow in CSEPP has been one-way, with little dialogue or negotiation about the risk in the communities where the munitions are stockpiled. The general lessons learned in risk communications would suggest that this may be setting the program up for public controversy and conflict as people will feel they have not been brought into the dialogue early in the process.

Recommendations on discussing risks suggest that a tension exists in goals and methods used to attain the ends. Some advocate a continuing dialogue to enhance communication attempts. States Covello et. al:
"The goal of risk communication should not be to avoid responsible action nor simply to pacify local citizens but to produce an involved, informed, interested, and fair-minded public whose opinions and concerns will be (or remain) reasonable, thoughtful, calm, solution- oriented, and collaborative." (1988a)

Only through genuine dialogue can the multiple characterizations of risk (all of which hold some claim to legitimacy) be accommodated and proponents and opponents attempt to understand each other's data and how each frames the issues (Jasanoff 1987; Davies et al. 1986). Because risk is a complex problem that transcends industrial concerns, risk management should be viewed as a joint enterprise providing for informed participation between persons at risk, risk generators, risk control agencies and their various experts (Baram 1986).

Dialogue often assumes negotiation. In the CSEPP little room exists for negotiating the impacts of an chemical agent accident. Communities will continue to live with the risk of the stored munitions. Moving the munitions from one locale to another (as advocated by some critics) was ruled out by expert risk assessments. 
Relocation of communities away from the storage sites would likely be socially unacceptable.

However, some negotiation has been possible. For example, how to use resources provided by the Army for CSEPP has been left to local jurisdictions. Local officials have been able to negotiate conditions for warning publics as long as the standards for timing of warnings and notification have been met. The Army has also investigated using other methods of disposal besides incineration and brought it to the attention of national experts.

Another issue is dealing with public apathy. Johnson and Fisher (1989) contend that the usual method of attempting to reduce anxiety about risks is not consistent with public educational programs about risk facts. Some CSEPP communities have had to deal with a generally apathetic and passive community. Thus some risk communications may have to prod the public toward taking protective actions.

\subsection{INTENT}

A second major dimension of risk communications is intent. This refers to the psychological process, or goals as outlined by the communicator. The objective can be either exchange of information or persuasion. In the former, the emphasis is on compromise or negotiation, and in the later on cooperation, or indoctrination of the audience to the views of the communicator. Examples of intent in the CSEPP involve:

- Persuasion - the Army has tried to convince the public that the agency is capable of maintaining a safe disposal process.

- Exchange - finding out concerns of public about safety, i.e. how will an accident affect home values?

- Acknowledgment - understanding between CSEPP and CSDP is not always clear and acknowledging that some issues are beyond the scope of the CSEPP is the only feasible communication message.

- Empathy - understand that people might still be apprehensive no matter how factual the information is and how clearly it is presented.

- Information dissemination is on-going - providing public information in the CSEPP will not be finished until the final munitions is destroyed. 


\subsubsection{Intentionality}

The conventional definition of risk communication centers on the intentionality of the source of the information and the quality of the information. The orientation of risk communications as the flow of messages to audiences has encouraged a "product delivery" perspective among some risk communicators. Within this mindset, the message or information is separated from the existing context and from the risk generation process, the assessment activities, and the broader range of social actions composing the risk management process as a whole (Kasperson and Stallen 1991). Risk managers usually focus on the intentional transfer of information designed to respond to public concerns to real or perceived hazards. The conventional definition of risk communication thus incorporates defined or implicit goals for targeted groups about specific events or processes and how the information will be channeled from experts to a general audience.

As most people recognize, risk messages intentionally delivered to audiences are only one part of the interactive risk communication process. Risk messages include verbal statements, advertisements, pictures or videos, publications, legal briefs, warning signs, or other declaratory activities that describe, characterize or advocate positions or actions regarding risks, hazardous situations or technologies, or risk control options (NRC 1989). Sources who actually present or deliver (intentionally or unintentionally) risk messages are just as diverse - physicians, regulatory agencies, journalists, environmental or watchdog groups, health officials, or agency spokespersons can all act as sources of messages (NRC 1989).

\subsubsection{Managing Public Knowledge}

A strong theme in the literature on risk communications concerns implementing actions to influence public knowledge about a risk. One issue relates to the mechanisms to provide the communicator with insight into public thinking, such as daily polls to track people's awareness, perceptions and knowledge (Covello et al. 1988). Are such techniques merely the acquisition of knowledge about people's information needs or merely manipulative or public relation oriented?

A traditional mechanism for listening to public concerns is a public hearing. However, there are other alternatives to public hearings. For example, holding smaller, more informal meetings with clear-cut goals outlined or using one-to-one communication techniques for some situations may increase understanding (Hance 
et al. 1988). It is also suggested that communicators provide qualified experts, sometimes from outside the agency, who can consistently be relied on to present information throughout the life of the project (Hance et al. 1988). If an agency wants to control information reaching the public, public statements and contact with reporters and citizen groups by all employees also must be carefully controlled . (Ozonoff and Bowden 1987). Sometimes it is in the best long-term interest of an agency to be tentative in identifying risks and at the same time create a frame to add future information (Sandman 1987).

\subsubsection{Control of Information}

How the flow of scientific information to the public is controlled has also been an issue, especially among experts who do not feel that the information they give is accurately reported. Dunwoody and Ryan's (1983) study found that most scientists perceive public relations (PR) offices at their institutions to play non-existent or peripheral roles in scientists' interaction with the journalists. Most journalists initiated their own contacts with individual scientists for information when it was needed. This contradicts the idea that PR offices control news about their organizations. The study also found information generated by PR offices was biased in reporting in that the offices relied on a few individuals within the organization who were older, prominent, and more organizationally powerful.

Recommendations about the amount of information to release to the public vary. Some experts advise giving only what is needed (i.e., need-to-know), with others advocate complete disclosure as soon as possible to all publics (i.e., right-toknow). Even what type of information is legally required will vary among jurisdictions as well as agencies.

\subsubsection{Release of Information}

Advocates suggest providing information tailored to specific audiences. Successful communications depend on providing people with the information they want (Cvetkovich and Earle No date). In this respect public comprehension of information need not be perfect, only good enough so that further precision would not materially improve decision making (Fischoff 1987).

Others advocate communication programs that provide honest, complete, and accurate information responsive to the needs and demands of the prospective 
audience (Renn and Levine 1988: 70). Evidence of competence, fairness towards other viewpoints, and references to commonly shared values and beliefs will make the message more attractive and help address the concerns of the centrally and peripherally interested audiences at the same time (Renn and Levine 1988). Some recommendations advise using a central source or spokesperson as a means of controlling the flow of information to the public. Centralize the flow of emergency information through a single, credible, senior spokesperson with good presentation and interaction skills (Covello et al. 1988a).

Risk communication should be looked at not only in terms of how accurate, detailed, or intelligible the information is but also in terms of how the information will be interpreted by the receivers (Fessenden-Raden et al. 1987). Communication activities should be tailored to meet the expectations of specific needs of each community and coordinate with a specific response schedule (Pavlova and Luftig No date). The communicator working with a large audience must make distinctions related to individual and group differences in information needs (Cvetkovich and Earle No date). When determining what information is necessary, decide on major points to provide the media and add what people must know in order to understand and feel they understand (Sandman 1987).

Information must be conveyed in perspective and in the proper context (Upton 1989). Accurate dissemination to and among disparate groups requires appropriately specialized communication programs (Upton 1989). When information is released to the public, the potential regulatory and scientific uses of the information, as well as the policy implications it may have, should be indicated to the audience (Upton 1989).

Since accident risks require both preventative measures as well as "post-loss" measures (to control losses after an accident), industry officials must cooperate with local authorities. However, firms often encounter difficulty with local government officials because public authorities often lack the necessary skills, authority, and resources to develop, test, and manage emergency response systems (Baram 1986). Information on accidental releases of hazardous substances should be shared with the public, regardless of whether or not there is an impact on the community. To prepare for these events, hazardous facilities should routinely perform accident simulations with the community (Black 1989). This concept has been particularly important in the CSEPP exercise and training schedules.

Length of communication efforts is also an issue. This is a thorny issue when a hazard evolves over a lengthy time period. Gori and Hays (1987) observe that 
communication over natural hazards may have to be an on-going process, not a single act, and may involve continuing federal, state, and local interaction. How the U.S. Geological Survey (USGS) communicates information about geologic hazards may be even more important in averting future disaster than in the actual assessment and monitoring of geologic hazards leading to the disaster.

How technically oriented risks (often using specific technical terms) are translated to the public is a recurring issue. Jargon and acronyms are not helpful in communicating scientific risk information except among peer networks. Workers need information at a level of language that they can understand. Except for trade secrets, information supplied to the employee should be freely available not only to those entitled but to anyone else who needs information (Brower 1986).

Friedman's (1989) analysis of the TMI accident coverage suggest scientists would benefit from training in handling public relations. Without that training, scientists and the media act "like oil and water" (Friedman 1989).

\subsection{PUBLIC EDUCATION}

Another flow-related issue is educating the public about risk assessment. The basic argument is that an informed public, given necessary information, can make basically good decisions on its own-and in most cases will follow the advice of authorities or other "experts." Some advocates argue the public needs to be educated in how the information is derived in case inappropriate information is given initially and must be corrected at a later date (Perry and Lindell 1989). Since trust and credibility are assumed essential to those heeding warning messages at a latter date, the public should be advised that information is uncertain at the time of transmission if that is really the case.

The ability of the public to comprehend risk or to make "informed" (rational) decisions about risk management is a questionable issue among some risk communicators and managers. This apprehension about the public's ability reflects other deep concerns about public education overall and about individual citizen's general interests and abilities to comprehend risks. The issue also points out the underlying conflict between expectations of government agencies and the public in both communication and management of risks. In an era of rapid technological changes, critics have challenged the rationale of citizen's rights-to-know versus needs-to-know. The argument is that a proliferation of information about different 
risks, especially concerns for those risks which affect very small numbers, will mask the most important risks that individuals can control. A related issue is whether information or education about risks provides an adequate basis for "good" decision making or if publics will continue to base evaluations of risk on the more personal and qualitative or what Sandman (1988) refers to as the "outrage" aspects of risk.

The issue of public education of risks continues in the debate over when to start informational programs. Some see the need for comprehensive education of the public about risks and risk assessment as starting in the primary grades. Better judgments are supposedly based on facts underlying the process of risk assessment which can be learned at an early age. Some view on-going education as necessary to ensure public compliance to warnings in regions exposed to natural hazards such as those with extended volcanic threats. Perry and Lindell (1989) suggest in disseminating information about risks, emergency managers should seek to educate the public not only about environmental threats but about the process (i.e., the bases) for evaluating such threats. Thus risk communication involves educating not only for the present but for future criteria for assessing risks.

The structural issue of revamping the public educational system has been raised. Keeling (1987) contends that higher educational institutions may be forced to take risks in educating their students about health risks such as acquired immune deficiency syndrome (AIDS). The results may structure consensus in the community to eventually provide good, solid risk reduction programs. Arkin (1989) argues the public needs to be taught to accept the uncertainties of science and to understand the concept of relative risk and the methods used to predict risk. The general public does not understand the concept of relative risk, and so personal decisions may be based on faulty assumptions. In Arkin's view, an informed public is more likely to be able to identify the strengths and weaknesses of risk measures and new risk information, relate that information to their personal situations, and thus avoid comparisons of dissimilar risks. But this knowledge is gained only through comprehensive changes in the educational system.

The issue that educational efforts have concentrated on hazards affecting individuals rather than risks that affect the collectivity or society at large has also surfaced. Plough and Krimsky (1987) argue that risk factor research and risk intervention programs have increasingly focused on the risky individual and less on the social and cultural context of risk, especially in the field of public health. These personal health risk assessments share with environmental risk assessments the notion of the "irrational individual," an individual who does not make rational 
choices about personal behavior to alleviate risks (such as wearing a seatbelt) and who exaggerates fears of hazards that experts consider relatively safe.

The issue of the irrational individual concerns underlying theoretical assumptions. Many assumptions about human reaction to risks or the probability of risks have been derived from the psychological literature. Cvetovich and Keren (No date) argue that, as a consequence of existing mental models, many people make incorrect conclusions that lead to undesirable actions or failures to adopt appropriate actions regarding risks. By examining the differences in audience's mental models, one can identify whether the differences are in knowledge bases or basically structural in nature, thus making risk communication strategies appropriate to different segments of the public.

Methodological strategies to reach the public through risk communication raise other issues. Studies have shown when multiple cues to characterize the same risk concept were used, people generally used the representation they found most comfortable and ignored the others (Desvouges and Smith 1988). While technicians and other experts place primary weight on the importance of the magnitude of the probability estimates, lay publics used multiple cues in arriving at decisions. To overcome these differences, Desvouges and Smith (1988) advocate using focus groups to explore risk perceptions and how those perceptions are linked to personal attitudes and characteristics. Such focus groups are thought to improve the quality of information ultimately required in surveys and suggest further hypotheses for testing data while providing insights that illustrate the findings from quantitative results. Although focus groups are generally helpful in assessing risk communication efforts, focus groups alone are insufficient for evaluating the effectiveness of risk communication because the findings are qualitative and cannot be generalized to a larger population.

\subsection{SOCIAL CONTEXT}

It is important to identify whether the differences in perceptions are based in the group's lack of knowledge or if the differences are more structural in nature (Cvetkovich and Keren No date). A structural difference means that an institution or society may have attributes that make it difficult to understand about risks. For example, a fatalistic orientation toward accidents (I can't prevent accidents-they 
are part of my karma) may prevent mitigative measures to reduce risks from being made.

At a more complex level, efforts can be made to determine the validity of assumptions about audience mental models. When more than one group is involved in the communication process, the different mental models of these groups can be compared by experts and lists of common and distinctive aspects prepared and evaluated in terms of common and distinguishing aspects. The concept of developing audience appeal is widely used as a marketing strategy to target different audiences. However, it should not be concluded automatically that the purpose of risk communication is to convert audiences into accepting official models (Cvetkovich and Keren No date).

Communication tasks within the social context perspective suggest that the risk communicator can start to deal with the message recipient's social context by clearly defining the change in recipients' behavior which is the desired outcome of the risk communication (1988). Cultural rationality can only be understood when people's cognitive behavior is observed as they are threatened by an actual risk event. Some argue that to understand cultural rationality, one must address anthropological and phenomenological issues as well as behavioral ones (Krimsky and Plough 1988). Adds Mason (1989):

"As we seek to create an enlightened awareness of relative risk, we need to take into account risk perceptions that already are in the public eye."

Other suggestions include changing the term "acceptable risk" to "tolerable risk" because the residual risk is tolerated, but not always accepted. "Tolerable risk assessment is therefore a scientific art form" (O'Riordan 1988). One of the most promising developments of community acceptance to tolerable risk includes using respected local people as risk translators (O'Riordan 1988). Communications programs that involve risk studies should also include a plan for informing the wider community of the progress of the study on a regular basis, for communicating results as soon as they become available, and at the same time for educating the public about the difficulties and uncertainties of performing and interpreting risk studies (Ozonoff and Bowden 1987). 


\subsection{CREDIBHITY AND TRUST}

Establishing trust about the Army's commitment to the CSEPP has been difficult given the history of Army activities in past. Opponents to the CDSP cite the Dugway 1960's incident and, more recently, two minor releases at Tooele and Johnson Atoll. In the case of one bunker explosion, a local mayor spent 6 hours to find out from the installation what happened from the installation headquarters. Such incidents, while related to the chemical weapons operational programs have strong implications for credibility and trust in CSEPP.

\subsubsection{Credibility/Erosion of Public Trust}

One major issue involves the credibility of experts, especially when consensus among experts is missing. Since both sides of controversial issues are now able to gain the help of experts, who the public should or chooses to believe about the consequences of a hazard is a real problem to achieving consensus about how to manage risks. Communicating the risk about a hazard includes estimating the range of problems associated with the hazard, and many experts disagree among themselves about probabilities or how to arrange a scale that is accurate yet reflects concerns of all involved, which may require more than numbers or statistics.

The issue reflects the contextual aspect of risk assessment, i.e., how to define to the publics, the risk to them at that time, at a later time, and so forth. What may be called for is a different type of scaling that reflects other issues (such as age, proximity to hazard) that could be integrated into the existing representations to amplify their usefulness. Management strategies for long term risks may call for other types of scales or criteria that reflect other factors related to expanded timeframes.

\subsubsection{Trust}

Understanding the distinction between risk and risk acceptability is critical to overcoming mistrust and communicating effectively (Covello et al. 1988b). Trust in communication efforts refers to the generalized expectancy that a message received is true and reliable and that the communicator demonstrates competence and honesty by conveying accurate, objective, and complete information (Renn and Levine 1991). Trust consists of five components: perceived competence (the degree of technical expertise assigned to a message or source); objectivity (lack of biases in 
information as perceived by others); fairness (acknowledgment and adequate representation of all points of view); consistency (predictability of arguments and behavior based on past experiences and previous communication efforts); and faith (the perception of 'good will' in composing information) (Renn and Levine 1991).

Although trust and confidence are used interchangeably, confidence in a source can be distinguished from trust as a more enduring experience of trustworthiness over time. Confidence denotes the subjective expectation of receiving trustworthy information from a person or an institution. Dissenting groups are more likely to express concerns in a constructive manner when the decisions are not perceived as prejudiced (Pollak 1985).

\subsubsection{Credibility}

Credibility has been defined as "the degree of shared and generalized confidence in a person or institution based on their perceived performance of trustworthiness" (Renn and Levine 1991). The source must be viewed as competent, fair, flexible to new demands, and consistent in task performance and communication efforts to have credibility (Renn and Levine 1991). Since credibility plays a major role in the selection and evaluation of messages, the messages should contain enough cues to establish validity. Reference to neutral experts, explicit disclosure of motives, and justification for vested interests are among the factors that influence public perceptions of credibility.

It is important to assess and nurture credibility. One of the most effective ways to earn and nurture credibility is to follow up words with concrete actions (American Chemical). Emergency managers must attend carefully to credibility issues to insure effectiveness in providing information and should be aware of factors influencing public perceptions of the credibility of their agency (Perry and Lindell 1987). At times recommendations confuse credibility with self-image and reward. For example, in an situation involving an industrial accident, it was recommended that the company use high level management to notify victims' families in person and assist in providing food, paying travel money, and arranging funerals--"Spending a few dollars on the families will pay for itself in the good will received" (Mitchell 1986). However it will not necessarily buy credibility which must be earned, not purchased. One challenge facing CSEPP is to avoid being labeled as a program to buy good will for the CSDP. 
To improve credibility of an institution the vital factor is performance, not public relations. Confidence and credibility as linked by evidence of costeffectiveness and openness to public demands have to be treated as complimentary, and not as substitution goals (Renn and Levine 1988). Governmental institutions will receive more credibility if they do not leave the impression of permanent crisis management, but of competence and preparedness for long-term threats and challenges (Renn and Levine 1988). The decision-making process and the past record of the institution should be included in the message so that people can assign competence to the actors and understand the trade-offs that have to be made in meeting the specific risk management tasks (Renn and Levine 1988). For example, the NRC should have played a greater role in providing neutral and objective information, but by fudging its position it lost credibility not only as an affective regulatory agency with anti-nuclear public but with the public at large (Mitchell 1986).

\subsection{COMPETING CHARACTERISTICS OF RISK ASSESSMENTS}

A complexity revealed in the daminozide (Alar) case is that for many technological hazards, multiple competent characterizations of risk can exist in the public domain with many different institutions invested with the responsibility for conducting scientific research and making credible pronouncements on risk (Jasanoff 1987). The important consideration for the public was not so much the substance of each statement but the more basic question as to who should be believed in the ensuing controversy.

Neutra (1989) examined problems with chemicals leaking from landfill for factors relating to credibility and community trust in government officials ability to handle the problems. The case illustrates that society's outrage increases with the visibility and concentration of the people at risk. By giving the community a substantial role in suggesting what needed to be accomplished, the agency established an on-going and valuable relationship with the community resulting in increased trust and credibility in official actions.

Morgan and Vlek (1988) reviewed laws and examined four case studies on right-to-know policies. The case studies indicated that good neighbor relationships and sincerity coupled to appropriate constructive mechanisms significantly alleviated public concern about risks and established communal trust. The EPA policy included forming a community leaders network at the onset of a risk 
communication project, incorporating evaluation strategies employing focus groups and other appropriate methodology, maintaining flexibility that adjusted to community dynamics during the program, and planning presentations around community timetables.

Wynne's (1988) study on communicating risk information to sheepherders after Chernobyl found credibility affected communication efforts. The credibility of scientists and governments greatly influenced the effectiveness of communicating complex hazard information to lay people. The findings indicate that a communication program which ignores the social and historical context is likely to be self-contradictory, unrelated to rooted experiences and concerns and thus ineffective. Scientists misconstrue the lay populations fear of hazards-assuming that lay people expect a risk-free environment is false. The Cumbrians' reaction to Sellafield, a nuclear plant in England, and Chernobyl release substantiate the finding that lay people define and judge a risk according to their experience of those institutions supposedly 'in control' of hazardous processes, not just according to the physical parameters alone.

In CSEPP we have seen the beginnings of controversies over what constitutes an adequate assessment of risk and what are legitimate accidents to plan for. Often the views toward these topic are shaped and mixed by other issues such as the prevention of agent incineration or the procurement of new communication systems. Disagreements exists over the methods of risk assessment. Furthermore, difference have emerged over what constitutes a credible accident scenario. Often the accidents in the formal PRA that was conducted are viewed by local planners as nonsensical.

\subsection{PUBLIC PARTICIPATION}

The amount of public participation-how much the public should be told or involved-is an issue in any risk communication effort. Some support institutional changes in basic agency strategies and management to include more public input. As only monologues can be pre-packaged, dialogue with a community is the key to successful risk communications, requiring commitment from both agency management and implementation by staff (Chess 1987).

The extent of public participation depends on the participants. Brown (1987) asserts that corporate legal defense may not be in collusion with professional dominance, but corporate attorneys challenge that citizen activists are untrained 
individuals who are incapable of making valid judgments regarding hazards such as pollution. This affinity is due to the fact that popular participation threatens not only the professional-lay division of knowledge and power but also the social structures and relations that give rise to environmental hazards. Traditionally, health hazards have been identified by two sources-scientific research and governmental regulation-but the efforts of environmental activists of the past decade have made community groups a third force in bringing environmental risks to the political agenda. "Popular epidemiology" is risk communication by lay persons to professional and official audiences, and as such it demonstrates that risk communication is an exercise of political power.

\subsection{DEALING WITH DISAGREEMENTS}

Risk communication is often stymied by differences between the lay public and public officials views of experts and expert systems in decision and communicating processes (Zimmerman 1987). The failure to deal with disagreements about the appropriate scope of concerns that the risk estimation process should cover arises continually and is a major factor in stopping projects. This can be partially alleviated with a comprehensive strategy which addresses people's fears that the facility will be abandoned or mismanaged or that the objectives approved today will differ from future purposes (Zimmerman 1987). In order to be successful in resolving conflicts, stakeholder groups should be involved early on, their values and concerns taken seriously, and the effort should be directed toward joint problem solving (Keeney and vonWinterfeldt 1986). Dissenting groups are more likely to express concerns in a constructive manner when there is appropriate involvement of all directly affected parties (Pollak 1985).

Some solutions to disagreements are counterproductive. The public emphatically does not need to be deluged with data on health risks from chemical exposures, general or specific, and told to make up its mind. The public instead needs clear signals; for example, when a chemical exposure crosses the boundary from trivial to significant (Roe 1989). It should be recognized that minimal standards are questions of expert judgment and are not necessarily a good mechanism for resolving disputes (Fischoff 1987). 


\subsection{ETHICAL ISSUES}

\subsubsection{Ethical Issues for the Media}

A number of ethical issues have been raised about mass media behavior. The most critical researcher is Scanlon (1989), whose work in Canada on hostage taking and terrorist actions have led him to conclude that the media does not follow normal practices of checking out information when covering a terrorist-related crisis.

Scanlon suggests that the media is often manipulated into assisting the criminal in seeking the maximum publicity in covering an event. Because the problem is so extraordinary (e.g., Scanlon uses the example of hostages being killed because of the media interference), Scanlon calls for a review of media practices and ethics in such events-before the government is forced to regulate media actions.

Shain (1989) raised the theoretical issue of how the media, primary the entertainment and news outlets, have influenced the American cultural antagonism toward all things nuclear. Although the accuracy of reporting is a major concern to risk communicators, the nature and roots of values, beliefs and fears that draw people together in opposition to nuclear power suggests the media has a more significant role than previously accorded in molding public perceptions. How risk communicators can counter the biased images promoted by popular mediaespecially inaccurate myths-is also an issue.

Another issue is the media's attitudes towards assessing risks in news reports. Singer and Endreny (1987) argue that media outlets tend to report on harms, not risks. Their studies on information supplied by media outlets suggest that the media can provoke serious distortions by not placing risks in a proper perspective. They found that the media rarely discuss benefits associated with risks. Virtually no news stories analyzed by Singer and Endreny provided readers with methods of assessing risks or risk impacts.

\subsubsection{Ethics of Communicators}

That effective communication is an interactive "two-way street" or "dialogue" is often forgotten in the melee of introducing information from experts or government agencies to the publics involved or affected. Moreover, that information must reach a number of audiences, not a single entity called the public, with different needs, wants, and levels of understanding. Unlike classic marketing 
strategies, risk communicators often direct their messages toward a more global public, ignoring factors such as age, gender, and ethnicity of their targeted audiences.

Agreement generally exists on how messages are transmitted to the public. Two mass media outlets-television and newspapers-are used most prominently. A related issue of information transmission involves not only the accuracy of the message but the credibility of the source behind the information provided. A related question is how far the media should go in attempting to provide balanced viewpoints in risk communications. A final issue concerns how those in the mediajournalists, editors, newscasters, science writers-refine, interpret, frame, synthesize, and rephrase the material in the original transmission in presenting the message to the public. It is this issue which may be the most critical. No matter how credible the source, how accurate the original message, how much information is given, it makes no difference if the message does not reach the intended audience. In this respect, the concept of the media as gatekeepers in determining what topics the public thinks about (but not how to think or how much thought to give about an issue) becomes important from a behavioral standpoint. Some experts providing information on risk thus prefer to handle the message themselves without the intervening reporter. Neil Frank, former head of the National Hurricane Center in Miami, was a prime example of an expert source transmitting his own message. There will still be interpretation of the message by media representatives 'to help the public understand' the terms and concepts, as well as the 'technical details,' in lay person's language. At that point the dissemination of information on risk becomes murky as to what message is finally transmitted.

Most risk communicators advocate that information dissemination on risks be an on-going, educational process. Journalists, however, look at events from the traditional 'news pegs' viewpoint-yesterday's news is old news-making continuing dialogue difficult. Some risk analysts have suggested continuing education programs for reporters and editors on communication of risk and have been fairly successful in promoting the use of media packets and forums (Sachsman et al. 1988). Sachsman et al. (1988) found that presenting information describing environmental risk issues at organized sessions, such as national or professional meetings, provided the greatest benefit and gained the most amount of feedback from journalists themselves. They also found that no matter what the risk issue, journalists still emphasized traditional methods of promoting events, no matter whether the risk was significant or not- perhaps reflecting the lack of responsibility to other than 
their professional interests. Their suggestion to make friends of the media and not view them as adversaries (i.e., remember their constraints and deadlines) appears one method of co-opting the media to consider the problem of transmission of risk. For those with high standards of integrity or who have been burned by misapplication of their information when printed or quoted previously, the advice may appear irrelevant. Clearly it becomes an adversarial position from which no one benefits-least of all the public who wants and needs access to accurate, unbiased information to make the best decision about the risk. But reporters, as well as all other risk communicators, reflect their own biases as involved members of the public sector with their own definitions, values and belief structure about risks, and how to communicate such information.

\subsection{RESPONSIBILITY}

\subsubsection{Public Responsibility}

When the information provided to the public by the decision maker is honest, clear and as complete as possible, the public should be more responsive to the real issues; the public must then take responsibility for the decision that is finally made (Ruckelshaus 1987).

To determine allocation of risk management efforts, one should ask whether the hazard to a relative few from an identifiable source justifies giving the problem high priority and a generous share of resources. If the risk debate is framed in these terms and the value judgment is yes, then that judgment should carry great weight in the decision-making process. If the judgment is no, then changes may be in order. If the public "outrage" is high, and experts say it is low, then officials should get full understanding of outrage in the context of the hazard, and frame the issue in terms of competing resources (Allen 1987). "Not only must we raise, by direct action, the level of sophistication of the public's thinking about risk issues, but we must also do what we can to increase the number of people who can communicate effectively about risk." (Thomas 1987). 


\subsubsection{Responsibility in Media}

The news media has been criticized for not acting responsibly in communicating risks to the public. News media should make every attempt to provide accurate, complete, balanced, and relevant information (Elliot 1989). Journalists must provide accurate information, particularly during a crisis. The most accurate media message might be the assessment that no one is really sure of the situation at the moment. Journalists are obligated by their promise of accuracy (Elliot 1989). Journalists should try as hard as possible to present accurate reflections of reality (Greenberg et al. 1989). Journalists should carefully evaluate and cross-check validity and reliability of all disaster-related information (Covello et al. 1988a).

The first requirement for responsible journalists is to provide a truthful, comprehensive, and intelligent account of the day's events in a context which gives the misunderstanding (Krieghbaum 1979). Critics charge that current media coverage provides lopsided forms of environmental surveillance that points to an event as a random, unavoidable problem rather than as a problem for the social and technical system that produced it (Wilkins 1989).

It has been suggested that information be given that enables citizens to act responsibility. The new media is obligated to give readers and viewers information that tells them what they need to know to function effectively in society (Elliot 1989). Public panic is more likely to be caused by giving too little information too late than by "crying wolf" (Elliot 1989). Journalists should become well versed in the context in which disasters occur and should be critical of information provided by official sources. Prior to disasters, journalists should become aware of potential problems and should know the relevant context before a problem occurs (Elliot 1989). News organizations ought to help the public prepare for dealing with disasters. They should be willing to be active informants rather than reactive documentarians. This information should be given without causing harm (Elliot 1989).

One problem is how the media defines an event. Media should focus on the contextual meaning of the event rather than on victims or drama during coverage of a disaster. The audience needs a way to put the disaster into a context so people can cope and deal with the disaster; as part of public policy victims do not need further victimization by media (Elliot 1989). Media knowingly and responsibly ought to participate in setting the agenda for public and governmental discussions of issues 
involved with the disaster. There can never be enough public attention on the question of preventing and mitigating harm (Elliot 1989). For example, it has been suggested that TMI coverage should continue to keep the issues of safety and risk of nuclear power in the public's mind (Friedman 1989). Others argue that the public can and should be provided with a greater variety of kinds of news stories, and a better understanding of the risks involved in chronic environmental problems (Greenberg et al. 1989).

Although it is legitimate for journalists in their risk reporting to focus on risk aspects other than the statistical risk figures, they should not completely ignore quantitative assessments (Sandman and Peters 1988). Journalists should seek and use a wider rang of sources of risk information (Sandman and Peters 1988).

\subsubsection{Responsibilities of Experts and Scientists}

Scientists need to keep local communities involved. There is no truth to the notion that panic is generated by risk announcements by scientists (Gori and Hays 1987). The task of the risk analyst should be to shed light on different factors of risk and not to hide them through reduction to a unidimensional concept that ignores them (Hansson 1989). By focusing primarily on the obligations of the expert risk analyst, advocates of improved risk communication often define problems too narrowly (Jasanoff 1987).

The traditional concerns of democratic societies-the effectiveness of participation and the procedural correlates of fairness-cannot be forgotten in the search for improved communication of technical uncertainty (Fischoff 1987). Experts themselves need to be educated about their own biases and about the existence of competing cognitive systems for evaluating risk (Jasanoff 1987). Future policy making, in the light of Bhopal, should focus at least as much on communicating what is known as seeking to fill in what is "completely unknown" (Jasanoff 1988).

In the minds of some, the major role of science is clear-cut: it must provide information on the analyses of risk (Press 1987). High quality science has to be partnered with a language to express risks clearly and accurately (Press 1987). Public pronouncements on risk are often put in policy terms that tend to be macro and not in a language that sensibly informs the individual (Press 1987). The responsibility to inform the media, and through them the public, about 
environmental risk belongs to the technical, scientific, corporate, regulatory and community news sources involved with environmental issues (Sandman et al. 1987).

\subsubsection{Responsibilities of Industry}

Right-to-know regulations are based on the premise that those who posses information that can enable another to avoid harmful consequences has a duty to disclose such information in a timely fashion (Baram 1986). One consequence of recent regulations is that managers must list hazardous chemicals known to be present in the workplace, indicating methods to inform workers of hazards associated with non-routine tasks and of the hazards associated with chemicals in unlabeled pipes (McDaniel 1986).

The risk creator should be a good neighbor to the community (O'Riordan 1988). Industry crisis management programs should provide proper treatment of victims and families; minimize the length of crisis; and hasten remobilization (Mitchell 1987). It is important for industry to have, and to present to the public and press, pre-established methods for dealing with a crisis (Otway et al. 1988). What firms disclose, however, may not influence the community. People do not receive information in a vacuum. For example, some experts feel that nuclear energy is such a highly charged and symbolic issue that thinking in terms of risk is not the right way to view the conflict (Mitchell 1987).

\subsubsection{Responsibility of Public Agencies}

Little consensus exists over the extent and nature of responsibilities that are held by government in the risk communication process. A minimal requirements is that a communication have positive expected value and that it's anticipated net effect should be for the good, considering the magnitude and likelihood of possible consequences (Fischoff 1987). It is the responsibility of a government agency to communicate both what is known and what is unknown (Mason 1989). It is up to government agencies, or those agencies with more congruent time references and values, to take action to protect resident ( $\mathrm{Palm}$ 1987). It is important that agency staff should amplify, not muffle, community concerns with the agency (Chess and Hance 1989). Risk communicators should increase their efforts to encourage the public to take personal risk reduction measures (Keeney and vonWinterfeldt 1986). Risk regulators must examine and analyze the whole spectrum of possible actions 
that can be taken to address a risk (Keeney and vonWinterfeldt 1986). In disseminating information emergency managers must strive to provide data as technically accurate as possible. When information turns out to be unreliable, the manger should make follow-up information that corrects the inappropriate information and provides a brief explanation of how the information got disseminated in the first place as this demonstrates control of the situation (Perry and Lindell 1987).

The extent of a program is also of concern. Administering any treatment should require a deliberate decision to the effect that its expected benefits outweigh its risks. The duty to inform should be more burdensome the greater the magnitude of risk (Fischoff 1987). New information on risk exposure should yield predictable change in observed behavior to reduce the probability of unfavorable outcomes (Johnson and Luken 1987). The consequence of ultimate interest is a potentially observable surrogate for actual improvements in well-being (Fischoff 1987). To establish the rights of professionals, it is recommended that risk communicators create an analogous institutional setting, with appropriate standards and responsibilities imposed on practitioners (Fischoff 1987).

Finally, agency responsibility for the consequences of a program is an important issue. Risk communicators must anticipate the consequences of their communications to increased risk group (Schulte 1989). Subtle changes in the way that risks are expressed can have a major impact on perceptions and decisions; this raises ethical problems that must be addressed by any responsible risk information program (Slovic 1986). Whatever the state of knowledge, those administering any treatment should be ready to ameliorate any side effects and perhaps provide compensation for them (Fischoff 1987). Public health policy should ensure safety, not harass industry or needlessly terrify the public (Whelan 1989). The consequences of risk notification should not be used as an excuse to avoid communicating pertinent risk information but rather be viewed as an inspiration for initiating the risk communication process correctly (Schulte 1989).

This chapter raised more questions than it provides answers. It illustrates both the breadth as well as the complexity of risk communication issues and sheds light on how controversy occurs among and between communicators. In the next chapter a more proactive approach to practical communication processes is addressed. 


\section{RISK COMMUNICATION PROCESSES}

\subsection{INTRODUCTION}

The various perspectives used to analyze the risk communication process are basically related; some crucial divisions in theoretical approaches bias the arguments as presented in the literature. Those writing from a communication viewpoint focus on the source, the channel, the message and the receiveressentially a one-way linear flow model that assumes a receptive, although not necessarily passive, receiver. Recipients, moreover, seek out more than one transmission of the message. Whether such action, referred to as personalizing, is intended to verify, to confirm the information, or to assess other options before taking action is unclear-and probably all three behaviors occur at some time during the early response process.

The six stages of human response regarding risk communications include receiving, understanding, believing, personalizing, responding and information seeking (Sorensen and Mileti 1989). Receiving can involve using sensory abilities including hearing, seeing, smelling, or feeling as an information recognition process (I hear a siren; I smell something strange). Understanding involves attaching a meaning to the sensory observation (it might be a chemical accident). Believing involves the cognitive acceptance that the understanding is correct (the threat is real). Personalization is the acceptance that the belief affects one self (I could be hurt). Response is the decision to take an action because of the new information (I will stay inside the house). One of the actions can be to seek new information or confirm existing beliefs (I will call 911 to ask if something is wrong).

In this model cognitions and behavior are affected by a number of factors regarding the communication process-essentially the who, what, when, where, and why of communications. These include:

- Source: Who is the information from?

- Message: What is said and why?

- Channel: How is it disseminated?

- Audience: To whom does the message go? and,

- Timing: When and how often is it received?

- Impact: Where are response made? 
In this section we explore some of the research finding on the risk communications process. This is organized around the basic model of the communication process (see Fig. 5-1).

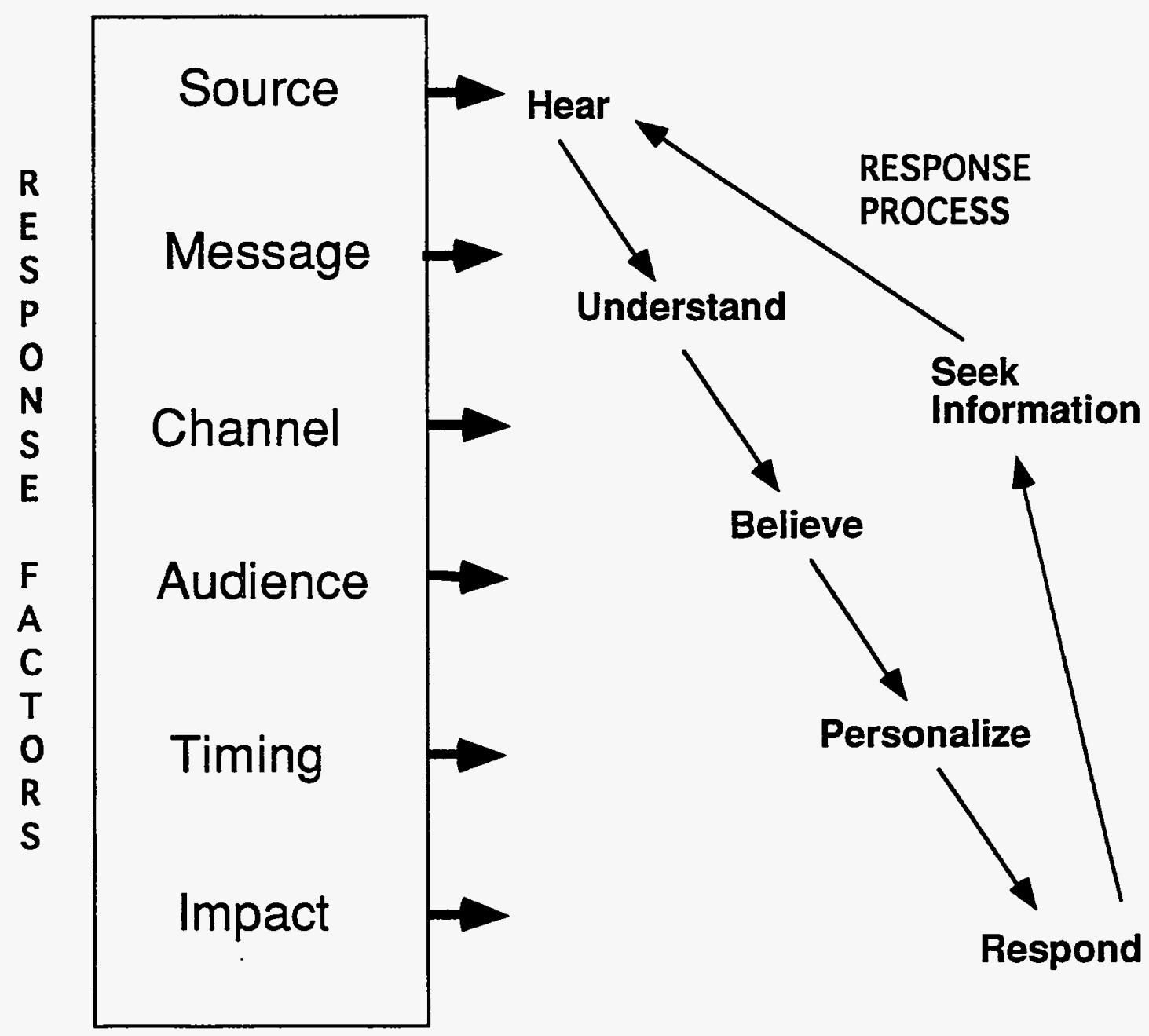

Figure 5-1 Communication Process Model

\subsection{SOURCE}

In communications literature, a source is the basis for information contained in the message. Generally, a source is considered an expert or authority on some aspect. In other instances, information may come from official government sources. As mentioned previously, the media can also act as a source when journalists use investigative reporting techniques. In Chapter 1 we listed some examples of information sources for the CSEPP. Consideration of source in a risk communication program is critical as no single source is credible to all people. In 
CSEPP we know that the Army is not credible for some but highly credible for others. The same can be said about others involved in the program.

\subsubsection{Source vs. Channel}

Certain channels are more frequently used by specific sources. Whereas information from friends, relatives, and neighbors is derived through personal conversation, authorities generally use a variety of other channels, both visual and audio, to reach audiences. The mass media can be conceived both as a channel and a source-a channel through which information is passed and a source when information is gathered by reporters and disseminated to the public. The latter occurs particularly when journalists report on a chronic environmental problem or on multiple or extended disasters.

Perry and Lindell's (1989) sensitive treatment distinguishing source and channel illustrates the difficulties in methodological discussions of message transmissions. The distinction between source and channel is clear analytically but in reality rigorous attention to differentiation is seldom made in the literature. Perry and Lindell point out that risk communications take place over time among a variety of social actors to ensure or preserve public safety or as a precautionary measure to alleviate future threat or harm.

Perry and Lindell (1989) discuss the difficulty in separating the information source from the communication channel. Conceptually the information source concentrates on the person or agency that constructs the information forming the message. A communication channel is a mechanism through which the message is transmitted. Emergency management authorities, police, firefighters, friends and neighbors are clearly sources. Messages developed by these sources may be delivered through a variety of channels-personal conversation, public meetings, brochures or mass media.

Sachman et al (1988) argue that the concept of the mass media as a source may be a semantic rather than a theoretical proposition. Messages are frequently changed as they move in a multi-step process through various opinion leaders or experts to audiences. In mass communication the source is the medium (journalists and editors), not the government, industry or experts who attempt to provide their own messages through the mass media. The source of mass communications is, in reality, the mass media themselves and their means of operation. The mass media through their own values and constraints are not only a critical source of risk 
information but an active transmission channel that can change and frame the messages chosen to be delivered. In setting the context and language of messages, the media can shape audience perceptions (Sachman et al, 1988). To improve news coverage of environmental risks, it is critical that experts improve access to and availability of environmental risk information to the media (Sandman et al. 1987).

Wilkins (1987) suggests using critical events theory to understand the media's messages on technological hazards. According to this theory, coverage is event oriented and assumes media messages have greater impact than just the factual information disseminated. According to Wilkins, while the dramatic retelling of an event by media provides a qualitative understanding of an hazardous event, such reporting is distorted because it does not include the deeper issues related to the "whys" of a situation or to the associated preparedness and warning factors. To permit more political and social debate about hazards, such as the trade-offs between costs and benefits of technologies and the associated risks, media should educate their members about hazards and shift the tone of news reports by placing the hazard in context, discussing how uncertainties in science occur, and broaden sources. By more comprehensive reporting, the media can provide information about technological hazards that encourages dialogue that is both appropriate and capable of leading to change.

\subsubsection{Source Credibility}

Most everyone involved in risk communications agree that a credible source of information is needed. Some believe that credibility of information sources is the key issue in risk communications (Renn and Levine 1991). Credibility is influenced by a variety of factors which are reflected in the following recommendations. When using a single spokesperson choose one that is knowledgeable and never change spokespersons in the middle of a crisis (Withers 1988). Try to use intermediaries (especially the news media-conscientious scientists, health professionals, and journalists) who share common perceptions that the public has a right to know about risks that affect them (Mason 1989). In general, lawyers do not make good public relations people (Grunig 1987).

It is important that communicators place news into the media rather than to wait for the media to discover news on their own (Mazur 1987). New sources for disseminating risk information in a community, in addition to existing sources, should be developed and supported (McCallum and Covello 1989). For example, 
physicians could also be trained in chemical risk issues (McCallum and Covello 1989). Press coverage of environmental risks can be improved both through the use of continuing education techniques and the actions of environmental news source (Sandman et al. 1987).

In CSEPP, little attention has been given toward figuring out how the information source affects the use of information. Very little attention has been paid on setting the agenda for the media rather than allowing the media to set the agenda.

\subsubsection{Multiple Sources of Information}

Differences exist over whether a single or multiple source of information is advantageous. For example, some have recommended that evacuation and shelter instructions should be provided through a single, authoritative, and credible source (Covello et al. 1988a). Others suggest that enhanced response to warnings occurs when specific, consistent, and clear warning messages are given; messages should be frequent in number and come from multiple sources (Sorensen and Mileti 1987). Some argue that three strong arguments presented by three separate experts is more persuasive than using a single presenter (Lee 1986). Repeat the message using a variety of media, organizational vehicles and authorities (Needleman 1987). The primary lesson is that a single notification, even in written letter form, is not enough (Schulte 1989).

Whether or not a single spokesperson is advantageous in CSEPP is a matter of situation. In an emergency it is desirable to have multiple sources. Given a controversy over an uncertain issue, multiple perspectives are desirable. In an event like a terrorist incident, a single spokesperson may be advantageous. Our interpretation of the literature is that in most every situation, multiple sources are desirable as long as there is some consistency in the message.

\subsection{CHANNEL}

A channel is the means or conduit by which a message reaches the intended audience. In communications literature, the channel is differentiated from the source as being the vehicle that transmits information from a source to a receiver, or multiples thereof. 


\subsubsection{The Role of the Media as a Channel}

One of the major findings from the empirical studies concerns the role of the news media when other normal channels of communications fail during a crisis. For example, following the Miamisburg, Ohio, train derailment in which phosphorus was released from a tanker, communications among responders were hampered initially by lack of knowledge about what was happening, what agency was in charge, and in emergency responders lacking basic equipment, such as walkie-talkies, for communications (Franks 1989). The news media were the most used channels for communications with the public (Franks 1989). The pre-planned policy of having a single spokesperson respond to media requests and of discussing items before they were released to the media resulted in only a few instances of conflict and helped to maintain credibility (Franks 1989). During the event, helicopters operated by the news media allowed emergency responders to maintain visual reconnaissance of the site obscured at ground level by billowing smoke. Likewise $86 \%$ of respondents in one study reported they received most of their information about Hurricane Hugo from television (Faupel and Kelley 1992).

Just as audiences should not be viewed as a single entity, the mass media should not be viewed as a single entity-multiple media with multiple impacts (Peltu 1988). The "news media" is not a monolith but a term that stands for a large variety of organizations which differ greatly in practices (Litchtenberg and MacLean 1991). It helps for the communicator to develop contacts and show respect for the media as viable channels for transmitting emergency information (Stockdale and Sood 1989). Emergency managers need to reevaluate the nature of communication channels used to provide hazard information (Perry and Lindell 1987). To maximize communication efficiency, a mix of channels should be used with thought given to systematically incorporating the news media into the mix (Perry and Lindell 1989). When there is minimal time for advance warning of certain natural hazards, the media are effective warning devices (Wilkins 1989), although others recommend that the media provide effective warnings when given lead times of three hours or more (Sorensen and Mileti 1988).

Friedman's analyses $(1981,1989)$ of the content of media coverage of the 1979 accidental release at the TMI nuclear power plant suggest that most journalists are influenced by direct involvement in community events. While local media outlets increased the scope of TMI coverage since the event, coverage has been spotty for national media outlets where journalists continue to make mistakes or show 
extensive bias in their reports on nuclear power (Friedman 1989). The continuing lack of journalistic training in radiological issues suggests that in another accident members of the pubic will again lack the in-depth coverage and people will be forced to judge their own long-term risk and overall safety of nuclear power without explanatory help from an informed media (Friedman 1989).

Interpreting radiological information provided by experts for public consumption is not just an issue within the United States. A similar lack of understanding was clearly evident after the Chernobyl accident where journalists from the European communities had trouble interpreting the radiological measurements and the effects of the assessments issued by various experts. A 1987 study that systematically analyzed British and Dutch newspapers reporting on the Chernobyl accident found more than 400 quotes illustrating ideas on radiation incongruent with the accepted scientific theory about radiation and its effects (Eijkelhof, Klaassen, Scholte, and Lijense 1987; Keren and Eijkelhop 1991). Confusion existed between irradiation (being exposed externally to radiation) and contamination (having inhaled or ingested radioactive substances).

Wilkins (1987) concludes from her analysis of the media's role in the Bhopal chemical disaster that the mass media plays a central role in societal discussions about hazard mitigation from harmful but useful technologies. By portraying science-related stories both visually and from the individual victim's viewpoint, rather than from a broad analysis that includes the benefits and costs at the societal level, the media may be contributing to a mythology about science and technology that may have far-reaching implications for decision-making. Lichenberg and MacLean (1991) conclude that over the last twenty years the media has become increasingly negative in the portrayal of technological issues, while the objective indicators for those issues have shown a decline in risk. Moreover, as an integral part of the social and political processes covered, and not simply detached transmitters of messages, the media can easily become tools of politically interested parties. Lichenberg and MacLean (1991) also suggest that when risk issues are embroiled in social and political controversies, media reports of such issues are more likely to fuel rather than resolve disputes over the issues.

The media's influence on risk communications is undebatable (Plough and Krimsky 1987; Covello et al. 1988; Byer 1989). What is questioned is the extent and in what areas the media exerts the most influence (Peltu 1988; Lichtenberg and MacLean 1991). The issue is further complicated by evidence that media outlets can serve as both sources and channels for information about risks, thus raising the 
media's ability to influence, and hence bias, public debate by disseminating risk information to the various audiences and decision-makers. The media also exerts influence over the topics reported and the methods of presentation designed to attract audiences. Which segments of the public are most likely to respond to specific messages and if the messages are ignored or eventually translated into appropriate actions, given the level of risk involved, are additional issues. A particular concern is the disproportionate amount of network news time focused on acute and dramatic events rather than on the chronic environmental risks which directly affect more people (Sandman et al. 1987).

Wilkins (1987) notes in analyzing the media's coverage of the Bhopal disaster that the media's role in hazard awareness points in two directions. While the media can be very effective in educating the public on hazards, the actual information in messages may be distorted or never disseminated because reporters lack the scientific basis for understanding hazards.

\subsubsection{Television}

Greenberg et al. (1989) reviewed television coverage of risks over a 26 month period between January, 1984, and February, 1986. The study found that television media are more attuned to visual impact and drama rather than to risk issues, with newness required for newsworthiness. In terms of sources used, journalists try to balance competing viewpoints, except where the source is the "official word" of the federal government. In addition, risk as calculated by scientists had little to do with the amount of coverage provided by the three networks' evening new broadcasts. Only 13.8 hours (1.7\%) of network evening news time in 26 months concerned human-induced environmental risk issues. The disproportionate emphasis on the spectacular events rather than chronic risk issues reinforces the public's overestimation of health impacts of acute risks and underestimation of most chronic risk issues. Greenberg et al. (1989) concluded that the public's conception of risk is almost certainly distorted by television's focus on catastrophes and its dependence on film images.

Results of Hurricanes Alicia and Danny studies support other research that media (especially television and radio) were the pervasive first sources of disaster warnings and served a distinct surveillance function (Ledingham and Walters 1989). The media had reasonable credibility in forecasting and reporting news in general and was used as the major source of information on how to prepare for storms. 
Although the media served to alert the population and to provide information on response options, discussions with friends and family were found equally important in determining the options respondents ultimately choose (Ledingham and Walters 1989).

Some evidence exists that media reporting of crises in newscasts shape public values and perceptions. Nimmo and Comb's (1985) review of the nightly evening coverage of six events-Jonestown, TMI, American Airlines flight $191 \mathrm{crash}$, Mt. St. Helens eruption, the Tylenol deaths and the American hostages in Iran-confirms the role of value assessment of events by the three major networks, ABC, NBC and CBS. The authors argue that by offering a view of what things are about and a value-oriented interpretation of the situation, the networks make assumptions about situations and about their audiences that significantly influence their audience's perceptions of the event. The coverage shows that the three networks define crisis for viewers in distinctly different ways. CBS relies on interpretative sources whose overall purpose is to make the awesome more manageable-to make the system work. $\mathrm{ABC}$ features famous actors as ordinary people in which the crisis becomes an ever-intensifying alarm, a type of subversive rhetoric that seeks to undermine the credibility of some person, idea or institution. Resignation with the affirmation-life will continue-is the byword with NBC.

Other researchers of the media are more critical of the role of visual images portrayed by the television media in bringing the incident "home" to viewers. It is television's ability to "show" rather than "tell" that makes its reportage so potent. Wilkins (1987), after examining media coverage of the Bhopal disaster, suggests a four-point program to remedy the current portrayal of technological accidents. The remedies include placing the event in larger context, providing a discussion of the science of the event that necessitates journalists becoming better informed about science and not just discussing opposing views, broadening existing sourcing patterns to include more balanced interpretation of events, and a discussion of the long-term issues. Such changes will allow hazards, particularly technological hazards, to be placed in the political and social arena where democratic decisionmaking can take place.

\subsubsection{Print Media}

A content analysis of AIDS editorials conducted over a five year period by Burd (1989) found that originally most editorials were directed to physical mortality 
rather than to the issue of social morality. Overall, editorials emphasized a "fix-it" mentality, assigning to "education," "science," and "research" a public (often government) responsibility rather than focusing on a personal liability for ADS. As the epidemic worsened in 1986-87, editorials were less tolerant of gay civil rights but still lacked specific information about safe and unsafe sex practices.

Freimuth and VanNevel's (1981) studies on the asbestos public service information campaign revealed a lack of incentive for media outlets to publicize the asbestos risk. The asbestos campaign had difficulty in influencing the newspaper coverage of asbestos awareness. The asbestos awareness campaign was a model campaign because it incorporated objectives commonly advocated for public service campaigns: clear campaign goals, adequate campaign length, targeting messages to specific audiences, high quality production, use of localized tags, personal contact with gatekeepers, and evaluation of the campaign with the use of controls.

McKay's (1984) studies included pre- and post-surveys on flood information given to the public. The results indicated that media coverage of the flood hazard information reduced public criticism of the flood reduction works attributable in part to media emphasizing positive aspect of projects. The survey demonstrated that personal delivery of the information raised perception of the risk, improved comprehension of the risk and discouraged respondents from seeking information in the future but had no impact on acceptability of the risk. Explanatory factors include the map sheet and low salience of flood hazard. To reduce negative impact, hazard information should be launched after a local occurrence of a hazard because the event will increase the salience of the hazard and the hazard information may have more positive impact on the population (McKay 1984). Results suggested the most desirable format for news releases was obtained by manipulating the scale or size of the map to depict the hazard prone zones as small in relation to the hazard free zones (McKay 1984).

McKay and Finlayson's (1982) studies on media reporting and requests for flood information maps indicated saliency played a major role in getting media response in publicizing a potential risk. A content analysis of various news media's coverage showed the media generally ignored the floodplain maps. Requests for maps were minuscule compared to sales of flood inundation maps prepared for Brisbane, Queensland, after a disastrous flood in 1974. The effect of experience of a flood is evident on both population and the media in Brisbane when compared to the Adelaide data. In addition to low prior awareness of flood risk, the low prominence of the story in the mass media, the content of the media reports and the positions of 
the paid advertisements in the press all contributed to poor community response to the maps and inhibited the impact of the information given to the public on awareness of flood risk (McKay and Finlayson 1982).

Mazur's (1987) review of the national news media coverage of homeowners' risk from radon revealed the media waited four months after discovery of the radon problem to promote public awareness. The lack of interest shows that it is important for sources to place news into the media rather than waiting for the media to bring the risk to public attention. "The mass media are the primary vehicle that conveys information about hazards to the public attention," notes Mazur (1987: 86). However, it is uncertain if the worries and remediation costs now being expended on lower levels of radon are warranted. Since no one profits from defending natural radon, there is little challenge to dire risk estimates-estimates most experts regard as exaggerated (Mazur 1987).

Sandman et al.'s (1987) study criticized journalists for failing to report the contextual aspects of risk when the New Jersey Department of Environmental Policy promoted efforts to increase radon awareness. The results of surveys indicated the most common response to the radon issue was apathy, and that most individuals in the at-risk area needed to be prodded in the direction of rational concern. The results support the contention that homeowners are not using the same type of information as experts (i.e., radon levels) in forming their response to radon. Factors such as fairness, naturalness, familiarity, and controllability are seen as essential components of risk. If these factors are taken into account, the public's response to risk becomes both rational and predictable.

Nelkin (1987) reviewed media coverage of health risks from dioxin to explore characteristics of risk reporting. Based on secondary information and case studies of news media coverage of risk events, Nelkin (1987) advocates using public relations techniques to package information about health risks of dioxin for dissemination to media outlets.

Krieghbaum's (1979) short pictorial article on the TMI coverage revealed the New York Times provided best and most accurate information on TMI. The New York Times provided readers with a crash course on background needed for making intelligent decisions following the nuclear power accident at TMI. 


\subsubsection{Mixed Media}

Lichtenberg and MacLean's (1988) research focused on the media's role in risk communication by reviewing previous research and case studies. Because people process positive and negative information differently, it is unreasonable to expect that an adequately and accurately delivered communication will suffice for achieving consensus on risk issues. Risk communication cannot be expected to resolve the conflicts which inevitably arise in society over the choice and implementation of technologies (Cannel and Otway as found in Lichtenberg and MacLean, 1988).

Evidence suggest a gap exists between the content of news coverage and public perceptions and understanding of risk issues with the media constituting the source of much if not most of the public's information about risks and technologies. They suggest that risk is not an either/or concept but a matter of degree. Where risk issues are embroiled in social and political controversies, those controversies themselves form an essential part of the "reality" that news media must cover. Moreover, it is never possible to be certain, and rarely possible to be confident, that an effect was caused by media coverage rather than something else (Lichtenberg and MacLean 1988). These authors note the media do not convey an accurate picture of reality and that this new portrayal of reality by the media leads to a fundamental change in the public's views. They further note that the increase in press coverage of an event or technology contributes to intensifying the sense of danger, even if the coverage is not particularly negative. They found that most people rely on a few heuristics and rules of thumb in estimating risks or probabilities and are concerned not only about the magnitude of risks but also about other qualities of the risk, adopting a reference point from which outcomes or choices are seen as positive or negative. This reference point is influenced by how the choice is presented or described by people. They suggest that the most important reason behind the inadequacy of risk communication is the fact that they are judged against criteria which are inappropriate (Lichtenberg and MacLean 1988).

Otway et al. (1988) analyzed the Chernobyl media coverage in seven countries following the radioactive release. Although all media types reflected confusion, print media was found more accurate than television. Otways findings on media accuracy agreed with the United Kingdom study by Herbert (1987) that the more "responsible" print media did a good job of covering Chernobyl accident, especially in conveying information provided by the authorities. The Otway (1988) 
study found media reasonably good at reporting information provided by official sources but problematic in highly technical topics, especially with units of radiation, contamination and exposure. Crisis management procedures were generally perceived by the public as inadequate and confused. Confusion as to differences in cross national attitudes in handling problems affected communication credibility. In this case, the media coverage reflected confusion but did not create it.

Sachsman et al. (1988) describe the continuing education programs designed by the Environmental Risk Reporting Project to educate media representatives about covering environmental risk. The key audience for the continuing educational programs is the local-beat and general assignment reporters and their editors, not the specialized science and environmental writers from the larger news networks. In conducting the programs it was evident that journalists think in terms of traditional journalistic determinants of news- "news pegs"-rather than in the scientific degree of risk. Thus journalists make assumptions based on their own definitions and expectations. To influence the media and provide better information, news sources should adjust their messages according to the needs of journalists.

Sandman et al. (1987a) reported on the archival analysis of 26 newspapers in New Jersey. They found that: (1) reporters do not perceive a need for background risk information in stories about hazardous environmental situations; (2) when reporters do include risk information in breaking stories, it is the most basic risk information; (3) in some cases reporters have trouble finding risk information, but in general, the little they want in breaking stories they have little trouble finding; and (4) when reporters want risk information, they want it chiefly from officials, preferably government-sources.

Scanlon (1989) studied media reaction to terrorist events. Arguing that the media reacts differently when criminal or terrorist events occur, the study details a number of events in which the media responded to hostage taking by intervening in the event. The interference of the media in publicizing and reporting the events was occasionally disastrous, resulting in the deaths of hostages. Scanlon argues that the manipulation of the media publicity by the hostage takers cannot be avoided through voluntary media practices and may have to be regulated. In dramatic criminal acts, normal media procedures such as checking information is ignored. 


\subsubsection{Use of Multiple Channels to Notify the Public about Risks}

A consistent recommendation is that multiple channels should be used for communications. Normal communication channels often break down in emergencies (Covello et al. 1988). Emergency managers need to reevaluate how they can use media outlets to expand the available sources of hazard information (Perry and Lindell 1989). The media and interpersonal channels of communication serve complimentary roles, with each acting, at different times, as a prelude or as a support for the other while fulfilling their unique roles (Ledingham and Walters 1989). In some emergencies, especially when the public must be informed rapidly of developments and advised on how to behave, governments can communicate effectively with citizens only through the mass media channels (Otway et al. 1988).

Individual notification of risk also must be accommodated through multiple channels. It is not sufficient to consider the notification process as merely a dispatch about individual risk status (Schulte 1989). The initiation of individual notification activities should be approached as a process with component stages (Schulte 1989). Opportunities should be provided for confirmation through multiple channels (Covello et al. 1988a; Covello et al. 1989b), including the popular media, health professionals, and peers (McCallum 1986). Risk communicators can reach workers through union and company publications, meetings, and training efforts that employ videos, print materials and classroom instruction (Callaghan 1989) or use networks to act as channels of two-way communication about risks (O'Riordan 1988).

\subsection{MESSAGE}

The content of the risk communication message is thought to be important because it is the major element of a risk communication program that a communicator can manipulate. Of course, this assumes that message content has an effect on recipient behavior and attitudes toward risk.

\subsubsection{Material to Include in Message}

There's no consensus about what material to include in a message on risk. Depending on the context, radically different recommendations can be found in the literature. Some suggest presenting both sides of an argument in a message, others 
only one side. Some argue to generalize the risk, protecting against arguments not specifically mentioned by opposition (Lee 1986). In other contexts it has been recommended to provide very specific and detailed information (Mileti and Sorensen 1988).

Risks do exist, they are being managed and we must learn to talk about them (Black 1989). One of the problems in CSEPP is that people want to avoid acknowledging that accident can occur. People want information that is certain and without ambiguity (Hamilton 1986). Often this is difficult in a program like CSEPP where there are great uncertainties. Communications on risks should include a discussion of what control measures and precautionary actions are being taken as well as what cannot be done (Covello et al. 1988). The message should help people understand uncertainties in warning systems and provide the reasons for false alarms (Covello et al. 1988a). Include in the message specific information on arrangements for evacuating or sheltering children, disabled people and other vulnerable populations and provide information on how to obtain updated disaster information (Covello et al. 1988a). Present recommendations in the context of a balanced argument that accurately describes the strengths and weaknesses of both sides (Covello et al. 1989). The language of warnings should be standardized to the extent possible (Gori and Hays 1987). Whenever possible, solutions and recommended actions should be provided with hazards and risk information as part of a warning message (Gori and Hays 1987). Also, be sensitive to the possibility of overloading people with too much information (Covello et al. 1989).

\subsubsection{Promoting Understanding of Risk}

Myriad warnings that surround everyone and often call attention to trivial or well-known risks tend to reduce the attention that is paid to warnings in general, thereby reducing their overall effectiveness (Green 1989). Dissenting groups are more likely to express concerns in a constructive manner when consideration is given to the social and political factors when developing a 'formula' for assessing risk (Pollak 1985).

One source of communication problems on health risks may be that the conceptual knowledge of the average reader might not be sufficient to integrate the risk information. For example, when information provided in pharmaceutical package inserts is written by medical experts, the material is often inappropriate for the lay person's understanding of the effects of a drug (Jungermann et al. 1988). 
Another source of miscommunication is when audience behaviors are at fundamental odds with those of health experts. For example, acknowledgment as well as acceptance of the fact that adolescents and young adults experiment with behaviors that carry a high risk of transmitting AIDS constitutes a key feature of planning programs on health risk reduction (Keeling 1987).

In a similar vein is the public's lack of understanding of probabilistic risk information. To assist people in understanding probabilities, compare a particular probability to events in the public's experience with other risks (1 per million compares to an individual's risk of being killed by lightening in a year) and/or use graphical representations (Kasperson and Kasperson No date). However risk comparisons should always be done between similar risks. In CSEPP comparing risks of storage to demil is a legitimate comparison. Comparing demil to smoking or driving an automobile are not good risk comparisons (see Table 5-1).

It is also important to note the impacts of the risk on vulnerable as well as 'average' people. Risks are not necessarily evenly distributed among different subgroups of the population. The differences in vulnerability occurs for both scientific and social reasons. Elderly persons may be more susceptible because of impaired mobility, hearing, or sight. Social vulnerability may be hidden because certain groups or individuals are marginal to society or are politically powerless (Kasperson and Kasperson No date).

Communicators should be sensitive to the qualitative aspects of the risk. Experts and publics often evaluate risks very differently. Characteristics of a risk, such as newness, catastrophic potential, and familiarity with risk, are important qualities of risk assessment for the public. One of the more important criteria is whether a risk is voluntary or imposed (Kasperson and Kasperson No date). A condition in which risk comparisons may be useful is when the situation is not emotionally charged (Sandman 1987). Risk communications can be most effective when they reflect an understanding of what the public wants to know (Upton 1989).

\subsubsection{Risk Measures}

In many situations communicators cannot avoid using quantitative measures of risk. Identify and explain the strengths and limitations of different risk measures, and present (whenever possible) alternative measures and indices of risk (Covello et al., 1989). Risk comparisons, although only part of the answer, should be fundamental component of any risk communication program (Covello et al. 1988: 
Table 5-1 Risk Comparison for CSEPP

Comparing existing situation to a proposed action:

Expected Fatalities (EF) per year

- Onsite risk per year (3 year ave) $\quad .00033 \mathrm{EF}$

- Storage risk per year $\quad .015 \mathrm{EF}$

Storage is $45 \mathrm{x}$ more risky

Probability Of Fatal Accident Per Year

- Onsite risk per year (3 year ave) .00011

- Storage risk per year

.000052

Disposal accidents are twice as likely per year as storage accidents but storage accidents cause $90 \times$ more fatalities

Comparing alternative ways of implementing the same action:

\section{Effects of Mitigation}

- Storage:

Yearly risk of a fatal accident without mitigation $\quad .0026$

Yearly risk of a fatal accident with mitigation $\quad .000052$

or roughly 50 times less likely or safer with mitigation

- Disposal:

Yearly risk of a fatal accident without mitigation $\quad .0024$

Yearly risk of a fatal accident with mitigation $\quad .00011$

or roughly 22 times safer with mitigation

Comparing sources of total risk:

\section{What Munitions Create the Risk?}

- Storage:

99\% of the storage risk is from accident involving bulk storage containers caused by an external event and $1 \%$ is from all other munitions and causes (using EF measure) 
- Disposal:

$50 \%$ of the risk from disposal activities is from accidents involving M55 Rockets and

$50 \%$ is from all other munitions (using EF measure)

There are few valid risk comparisons identified as yet in the CSEPP

Program. The above examples are based on the risk analysis performed by Mitre and Oak Ridge National Laboratory for the Army's CSDP prior to the programmatic environmental impact statement on the CSDP. Remember that data can change when risk analyses are updated or actual operations data becomes available. These data are for program activities at all eight storage/demil sites. These examples are given to illustrate some of the ways risk comparisons can be done based on general guidelines developed by risk communication experts.

Source: adapted from Fraize, Cutler, and Flanagan (1989)

5b). It is important to avoid comparisons of risks that may appear to the audience to be non-comparable because of the different qualitative characteristics. For example, the risk of smoking compared to that of living near a nuclear power plant is not an appropriate risk comparison because they are not at all similar (Covello et al. 1989a).

It is recommended that risks be placed in perspective (Keeney and vonWinterfeldt 1986) by giving the best case as much attention as the worst. Presenting only the worst case does not serve the public; instead present the best case, the most likely case, and the worst case (Kasperson and Kasperson No date). Try to include all consequences that concern people. A hazard has both multiple causes and multiple effects. Thus, communication of risk needs to address a set of consequences rather than a single consequence measure of risk (Kasperson and Kasperson No date).

For example, consider the following table (Table 5-2) in which we compare disposal of chemical weapons with continued storage for 25 years using three different risk measures. The three measures are expected fatalities, probability of an accident that cause one or more fatalities, and maximum fatalities. Expected 
fatalities is the probability of an accident multiplied times the estimated fatalities from that accidents and summed for all accidents. Probability of a fatal accident is the sum of the probabilities of all accidents which are estimated to cause fatalities. Maximum fatalities is the estimated fatalities from the largest accident under the meteorological conditions that will cause the largest exposure. If we use only one risk measure we get a different picture depending on the measure. For example if we look at maximum fatalities for the program overall, we see no significant differences in risk. If we use expected fatalities we see that continued storage is more risky.

Table 5-2 Comparison of Risks from Continued Storage and Onsite Disposal

\begin{tabular}{|l|c|c|c|l|}
\hline \multicolumn{1}{|c|}{ Site } & \multicolumn{2}{|c|}{$\begin{array}{c}\text { Riskier } \\
\text { Alternative } \\
\text { Based on 3 Risk } \\
\text { Measures* }\end{array}$} & \\
\hline & EF & PAF & MF & \\
\hline APG & CS & CS & NSD & $\begin{array}{l}\text { Continued Storage for 25 years clearly more } \\
\text { risky than On Site Disposal }\end{array}$ \\
\hline ANAD & CS & NSD & CS & $\begin{array}{l}\text { Continued Storage for 25 years clearly more } \\
\text { risky than On Site Disposal }\end{array}$ \\
\hline LBAD & ND & ND & NSD & $\begin{array}{l}\text { Continued Storage and On site Disposal have } \\
\text { equivalent risks }\end{array}$ \\
\hline NAAP & CS & NSD & CS & $\begin{array}{l}\text { Continued Storage for 25 years clearly more } \\
\text { risky than On Site Disposal }\end{array}$ \\
\hline PBA & ND & NSD & NSD & $\begin{array}{l}\text { Continued Storage is not significantly more } \\
\text { risky than On Site Disposal }\end{array}$ \\
\hline PUDA & ND & NSD & CS & $\begin{array}{l}\text { Continued Storage for 25 years more risky than } \\
\text { On Site Disposal }\end{array}$ \\
\hline TEAD & CS & NSD & CS & $\begin{array}{l}\text { Continued Storage for 25 years clearly more } \\
\text { risky than On Site Disposal }\end{array}$ \\
\hline UMDA & CS & NSD & CS & $\begin{array}{l}\text { Continued Storage for 25 years clearly more } \\
\text { risky than On Site Disposal }\end{array}$ \\
\hline PROGRAM & CS & NSD & NSD & $\begin{array}{l}\text { Continued Storage for 25 years more risky than } \\
\text { On Site Disposal }\end{array}$ \\
\hline
\end{tabular}

*Codes:

EF: Expected Fatalities,

PAF: Probability of an accident causing 1 or more fatalities

MF: Maximum number of fatalities

CS: Continued Storage

NSD No Significant Difference (CS is higher but not significantly)

ND: No Difference (CS and OS are equal)

OS: On Site Disposal

Source: CSDP Final Programmatic Environmental Impact Statement 


\subsubsection{Scientific and Technological Messages}

Messages on risks must address the problems citizens have in processing scientific information. The information presented must simultaneously acknowledge scientific uncertainties, perhaps through such means as presenting data in different numerical or pictorial ways (Jasanoff 1988). Conveying technical risk information from experts to lay public is unlikely to be successful unless social context (i.e., social networks, economic resources, political right and responsibilities, histories and ideologies) of such messages is addressed (Johnson 1987).

Technical information often does not play a dominant role in a risk communication controversy (Krimsky and Plough 1988). In explaining risk to nonexperts, risk information may have to be simplified (Sandman 1987). The dilemma is that simplification can also undermine the credibility and accuracy of the information. It is recommended that technical studies be accompanied with nontechnical executive summaries so that assumptions and methods are clear to all readers (Konheim 1988). When there is an action message or something that people can do to protect themselves, communicators should be especially clear and persuasive about that component (Mason 1989). Sometimes this dilemma undermines agency effectiveness. Until an agency like the EPA learns to manage both the regulatory (macro-risk) role and the public information (micro-risk) role the agency will continue to confront crisis after crisis (Sharlin 1986).

\subsubsection{Framing Messages}

People adopt a reference point from which outcomes or choices are seen as positive or negative, but this reference point is influenced by how the choice is presented or described (Lichtenberg and MacLean 1988: 38). The principal task for regulatory agencies and academia is presenting risk information to public to overcome the "no risk" mentality (Long 1988). The more a communicator manages to avoid the mask of an institutional spokesperson and the more he or she can express compassion and empathy for the audience, the more likely the audience will identify with the speaker and feel compelled to agree with the argument (Renn and Levine 1988).

The quality of message depends on good science with information clearly and accurately presented (Mason 1989). Factors which should be incorporated in risk communication efforts should encourage individual health protection by 
personalizing the message enough to provide a framework for individual action (Needleman 1987). This helps to avoid ritualism and to minimize overreaction.

In CSEPP it is a major challenge to frame the risks. Clearly the public wants a no risk situation, but that is technologically infeasible. Media coverage of demil activities has painted a very negative image of a complex technology. This has had a detrimental affect on achieving the CSEPP goal of public protection.

\subsubsection{Message Style}

The style of the communicator as well as the communications process will likely affect how the risk is determined by the audience. Although this concept is relatively simple, it is much more difficult to adjust than most communicators are willing to admit. Five elements of style seem to be important in an emergency message: specificity, consistency, accuracy, certainty and clarity (Mileti and Sorensen 1990; Vogt and Sorensen 1992).

\subsubsection{Specificity}

Hazard notification messages should be very specific. Specifically recommending hazard mitigation measures, stating the precise character of the hazard, and indicating how much time the respondents have to engage in protective actions, results in prompt reaction by the community and the execution of the appropriate protective measures. The content of the hazard notification message must be very specific in this regard. On those occasions in which specificity on all content items cannot be detailed (because details are unknown or only known approximately), the warning message itself and the style with which it is written must still remain as specific as possible. For example, the message could state: "We do not know nor can it be known which buildings in the city are the safest for sheltering, but we do know that most everyone will be protected if they shelter inside buildings and do not attempt to evacuate to outside areas."

\subsubsection{Consistency}

Hazard notification messages must also be consistent, both within a single message and across different messages. Messages should also be consistent in describing the actions being taken. For example, a message telling respondents to remain indoors and await further information is of little help if the respondents 
observe that families of community emergency personnel are leaving their residences. It is important to avoid any inconsistencies across different messages. As the crisis progresses and more is learned about the potential hazard(s), hazard notification updates should be issued. These updated notification messages in turn must be consistent with the previous notification messages. Consistency can be rendered across notification messages by referencing and/or repeating the information in the previous message(s), by clearly stating the additional information on the hazard(s), and by pointing out the changes from the previous messages along with a brief explanation for the basis in such changes.

\subsubsection{Certainty}

Hazard notification messages should be written with as much certainty as possible, even in circumstances in which there is ambiguity associated with the chemical accident's impact on the community. Where there are low probabilities or ambiguities associated with a hazard's impact, the message should be stated with certainty, even when discussing the ambiguity. For example, the message could say: "There is no way for us to know if there really is going to be an explosion in the plant, but we have decided to recommend that everyone in the Immediate Response Zone (IRZ) be evacuated now; everyone should act as if the explosion is a real threat."

Certainty in warning messages, however, extends beyond the actual message content. Certainty also includes the style with which the message is delivered to a public. The warning messages should be read by spokespersons in a tone of firm belief that convey the impression that he/she believes they are certain about what is being said in the message.

\subsubsection{Clarity}

Hazard notification messages must be worded in a language that can be understood by all respondents. Avoid the use of complex scientific or engineering terminology. For example, describing an accident as "a release of sarin due to a unplanned detonation of munitions in the primary combustion chamber of the dunnage furnace which subsequently caused a loss of pressure and a breach of containment" should be phrased in more understandable terms. Greater 
understanding would be conveyed by stating: "An exploding shell in an incinerator caused a vapor cloud of nerve agent to be released at the incineration plant."

\subsubsection{Accuracy}

Every hazard notification message should contain timely and accurate information. If the respondents in a community suspect that they are not receiving the "whole truth" about the chemical accident, people who are at risk may not believe the advice contained in the messages and refrain from taking the appropriate emergency protective actions.

\subsubsection{Evaluate Messages}

It is important to understand how messages are being interpreted by the public. Confirm that people understand the precise nature of different warning signals and their meanings (Covello et al. 1988a). At various points in a communication program assess community wants and needs as well as information already in the community, pretest informational materials, determine public response to public meetings, track media coverage, and identify public reaction to overall programs (Pavlova and Luftig No date). Focus group discussions are especially useful to gather information about public perceptions. Researchers also need to examine the complex intermix of mass media communications and interpersonal communications in the receipt and use of warning messages (Quarantelli 1989). Better ways are needed to convey quantitative risk information, in researching how framing of messages affects risk communications, and in testing messages (Slovic 1986).

Table 5-3 provides a tool to evaluate the text of risk communication with respect to style and content:

Table 5-3 Message Evaluation Matrix

\begin{tabular}{|l|l|l|l|l|l|}
\hline Style & & & Content & & \\
\hline Specificity & Hazard & Location & Guidance & Time & Source \\
\hline Consistency & & & & & \\
\hline Accuracy & & & & & \\
\hline Certainty & & & & & \\
\hline Clarity & & & & & \\
\hline
\end{tabular}




\subsection{TIMING}

Timing is a critical aspect of the risk communications process in both emergencies and during pre-emergency communication effort. In CSEPP timing is certainly important in an accident as very little time exists to provide a warning. In other situations timing is also important. Several historical events in CSEPP underscore this issue. When a week elapses before disclosure of a leak, it may be difficult for the responsible party to retain credibility.

One of the continuing controversies throughout the literature is when to release data to the public, especially if data are suspect or uncertain. CSEPP abounds with uncertain information, including the size of potential accidents, their probability, and areas they could affect. Some advocate immediately releasing all data to the public (Marshall 1989). Thus the public can be involved from the very beginning, even when hazard is only suspected, and the agency can focus on control, not reaction (Hance et al. 1988). Open, accurate, and timely communication of environmental risk information is essential to the mission of public health and safety agencies (Ozonoff and Bowden 1987).

Others suggest a more circumspect criterion for release of information. For example, if people are at risk, communicate immediately; if there is potential risk, communicate to unaware people and release information before media outlets do (Hance et al. 1988). If the data appear untrustworthy, discuss procedures of how the data were obtained, not the data; if the data show a problem, release and discuss the tentativeness of the data (Hance et al. 1988). In addition, release information when risk management options are tentative; release information at once but tell the public why; and use quality assurance rationale only if needed--above all, say something, don't remain silent (Hance et al. 1988). Except for trade secrets, information supplied to the employee should be freely available not only to those entitled but to anyone else who needs information (Brower 1986).

The main recommendation is that messages be disseminated as early as possible through channels that will reach the public (Mason 1989). If information is put out through an agency's own initiative and its terms, the results are usually good; bad stories result from leaks or from sources with special axes to grind (Mason 1989). To reduce negative impact, hazard information should be launched immediately after a local occurrence of a hazard. After such an occurrence, the report of the event will increase the salience of the hazard and the hazard 
information may have more positive impacts on public adoption of safety measures (McKay 1984).

\subsection{AUDIENCE}

It is important to identify and understand the different types of audience participants. Identifying audiences is no more than thinking through very specifically who might want to be talking to you (Hance et al. 1990). Although boundaries may well overlap, five categories are basic: emergency responders, commentators from both private and public sectors, those with special needs to know, the news media, and the general public (local, regional, national, international) (Bell 1989).

Decide on how to best target the information to different audiences. FEMA (1985) recommends that officials target information to the educational level of the majority of those in the area at risk or if the level is unknown, to a 7-9 grade reading level. It is recommended to translate information into a foreign language if the foreign language speaking population of age 21 or older equals $5 \%$ of population. Handicapped or disabled persons must have information in a format that meets their specific needs. Thus an oral briefing to visually impaired may be necessary to communicate risk information. One way to assess who in the planning area requires special communication efforts is to provide a self-identification card in general public information material that can be returned to emergency officials.

The material on risk must be carefully tailored to different sectors of society (Long 1988) and take into account the previous knowledge and experience of the audience about risk issues (Cannel and Otway 1988). To determine the suitability of the material, try to determine the attitudes held by public at large before designing appropriate communications (Lee 1986). Information to be communicated must fit into the frameworks of the receivers because they will interpret the information according to those frameworks (Mitchell 1986).

Receiver problems sometimes consist not of finding out why the public is appearing to behave irrationally, but in finding out what political positions have been staked out and how those positions relate to public attitudes (Mitchell 1986). A prime example is the siting of nuclear power plants. The degree to which the nuclear hazard issue is embedded in value systems and political debates makes it an extreme case for risk communicators and any attempts to communicate technical 
information regarding nuclear power must take into account the existing individual frameworks for interpreting information (Mitchell 1986). In Tauton, Massachusetts, officials' experience in siting a hazardous waste processing plant also made it clear that no matter how good or how long the communication process was, the local community must have adequate information to participate effectively in the negotiation process (Kauffman 1986). Good practices include fully informing the public from the outset (Lagadec 1987) so that what people care about is making good decisions (Fischoff 1987).

Risk communication activities are, by design and intent, a social intervention which have impacts on people exposed to the information. The communication can change people's perceptions and behaviors. In some cases the impacts are intended, in other instances, unintentional. For example, in the CSEPP one is always hearing someone say "we can't tell (or show) the public that--they will be frightened." What the research shows is that the public should be given as much information as possible without communicators' prejudging the public's reaction. Indeed, negative effects can result from a poorly designed as well as a good risk communication program, but negative results are less likely if thought and skill have been integrated into the risk communication program.

\subsubsection{Impacts on Public Perception of Risk}

Public perceptions of risk do not always correspond to expert rankings. Allen (1987) found the EPA task force rankings of high risk problems did not correspond well with EPA's current risk mitigation program priorities but did correspond closely to public opinion. The researcher divided up the universe of environmental problems into 31 categories and compared the ranking to data from Roper polls collected between 1984 and 1986 on 20 categories. The high/low combinations of outrage and hazard issues presented the most complex problems indicating the public takes a more personal view of risk than EPA's macro perspective in determining resource allocation in risk assessments.

Cvetkovich and Earle (no date) conducted a three panel telephone survey on multiple expectations of risk. A confirmatory factor analysis showed that multiple indicators of hazard, risk, benefit, cost, and environmental impacts, did not converge into a single concept. Measures of risk, including mortality, morbidity and loss were not related to information seeking or acquisition of mitigation knowledge. On the other hand, factors such as education, length or residence, and attitude toward 
technology/science were significantly related to information seeking or to acquisition of mitigation knowledge. Attitudes toward governmental desire to control hazard, and desire to communicate with the public were significantly related to information seeking or acquisition of mitigation knowledge.

Earle and Cvetkovich's (no date) study involved three surveys comparing risk perceptions from earthquake with that of water pollution. They found respondents felt that scientists and technical experts serve the public well in regard to general hazard management. Respondents also felt that government officials have not done a good job of hazard management. The earthquake hazard was most frequently experienced and feared, but the least frequently discussed.

In a comparison of the risk perceptions from earthquakes with those from water pollution, Earle and Cvetkovich (no date) found that respondents considered earthquakes more understood by scientists than water pollution. Individuals, however, understand more about water pollution than earthquakes. Earthquakes were associated more with economic benefits than non-economic benefits. Information on earthquakes was received more through the media than through personal conversations. Water pollution was judged to be a more serious risk than earthquakes in terms of likelihood of injury/illness, level of concern, and to require personal activities to reduce risk. Earthquake hazards were not found to be personally salient.

Fessenden-Raden et al. (1987) examined factors influencing public understanding of risk information involving chemical contamination of water supply. Two sets of factors appear to underlie intercommunity variability: components involved in the discovery of the problem and in the initial response of officials and the contextual aspects of the local community. This study's main finding is that people's perceptions of risk were affected by their perceptions of the way in which the risk was handled over time. The receiver-oriented focus on risk communication suggested that reception of information about risk will vary between communities, among various publics within a community, and over time. Secondly, receivers bring cultural assumptions and inputs of individual knowledge and experience to the communication interaction. Moreover, while many messages, both official and unofficial, are involved in presenting information to the public about a given risk, lack of training among participants may compound the problems of translating, conveying and understanding the risk. Thus risk communication involves the dissemination of many risk messages. 
Grunig (1987) examined the role of public reactions in dealing with an industrial crisis at a wood processing plant. The study found using a press agent and the public information approach (the one-way communication approach) was unsuccessful for dealing with the citizen groups concerned with waste disposal practices. Instead a two-way symmetrical approach that gathers and disseminates information encourages cooperation.

Perry and Lindell (1989) studied credibility based on past experience and access to information about the volcanic hazard from Mt. St. Helens on two communities. They found that during the emergency response phase of impending threat citizens are more likely to comply promptly with warning messages from sources perceived to be credible. Secondly, during non-emergency times when environmental dangers are present but not imminent, citizens attend more carefully to information and preparation suggestions disseminated by credible sources. Two dimensions that enhance credibility are past experience and access to skills and information. The results emphasize the diversity of citizen channel preference thus underscoring the importance of using multiple channels in disseminating threat information. Data show citizens do rely on, and some cases prefer, media for all types of hazard information.

Research on five natural disasters by Sood et al. (1987) illustrates how media personnel and local officials often cooperate but sometimes conflict in accomplishing their respective goals and how this process affects the public's understanding of the disaster event. Examples of the process defining an event as a disaster demonstrates the importance of considering the interaction of many key actors in news coverage. Technological disasters present different types of questions about the media's power to define an event. For example, although public reactions to most technological disaster is negative, Miller (1987) found that the "immediate impact of the Challenger accident was to stimulate a wave of positive attitudes (on the part of the public) toward the space program and toward funding it. This finding suggest that a typology of effect from disaster should take into account the perceived extent of personal risk.

\subsubsection{Differences in Perceptions of Risk}

Dutton (1987) examined how the perception of information on prescription drugs differs between experts and the public. The study found that people are more likely to exaggerate the perceived likelihood of events they consider particularly 
undesirable and to minimize the likelihood of events of little concern. Perceptions of risk differ between experts in a given field and from nonexperts. Experts are more likely to define issues in the narrow and technical terms of their own specialty and to ignore related nontechnical problems. Other studies have shown that the poorer the data and less rigorous the evaluation, the more exaggerated the claimed benefits tend to be. Experts tend to more optimistic about benefits and less worried about unknown risks, particularly human errors, than nonexperts.

Wertz and Fletcher's (1987) two studies on genetic risks found that disclosures were differently interpreted by experts and families. Almost $97 \%$ of geneticists responding worldwide would fully disclose all information about scientific uncertainty, with the exception of a colleague's disagreements. Geneticists in the U.S. and Canada were more willing to disclose colleague disagreements than they were in Great Britain. Almost 96\% of geneticists indicated that they would not tell the husband if the wife requested that he not be told if he was not the father of the child. Clients were most likely to learn medical information in sessions where both counselor and client had become aware of what the other most wanted to discuss. While counselors were satisfied with $95 \%$ of the sessions, patients understood their risk in fewer than half of the sessions.

Gender differences in hypothetical directed situations were also studied in discussion of genetic risks. Women geneticists were more likely to disclose when unasked, and also more likely to disclose to relatives at risk. Male geneticists were more likely than female geneticists to tell patients what they would do in the patient's situation or to tell them what they ought to do. Given the gender differences, patients might be well advised to seek information from counselors of both sexes. Patients were more likely to interpret a particular numeric risk as higher if they had a living affected child living at home, if the disorder in question caused intellectual impairment, and if they thought that their risk was high before

counseling. They were more likely to interpret their risk as higher if they discussed, in counseling, the effects of an affected child on the parent's relationships with their normal children and whether or not they should have another child.

\subsubsection{Public Education and Response}

Several studies have investigated the impacts of hazard awareness programs on people's knowledge about a hazard, their perception of risk, and on the adoption of mitigation measures. The first attempt to do so was a study by Roder (1961) who 
distributed flood plain maps to resident of Topeka, Kansas. The study found that the maps had no effect on people's awareness of the flood hazard or knowledge of flood problems.

Bolton's (1987) findings from the final report on the dissemination of earthquake information in three trial programs suggested that messages on hazards disseminated through many different channels at once are effective in gaining attention and interest. The study found that initial enthusiasm was a necessary but not sufficient condition for having a successful school program. A combination of teaching earthquake science and safety protection program reduced anxiety among school children.

The results of surveys conduced by Johnson and Fisher (1989) during the summer of 1986 on information learned from brochures on radon risk indicated that the way in which information on health risks was presented had a measurable impact depending on the measure of effectiveness used. Quantitative information treatments were statistically significant in reducing discrepancies between objective and perceived risk. While results confirm that conventional wisdom that personal characteristics influence risk perception, the results do not suggest that such characteristics can identify target "publics" for particular risk information program. No information treatment was superior for all tasks. Neither was there a single set of personal characteristics that identified a groups with a clearly defined set of perceptual problems. Different personal characteristics were important for different perceptual tasks.

Johnson and Luken's (1987) study on radon risk examined the perceived risks and mitigating behavior of Maine householders who received new information on their exposures to significant health risks from indoor levels of radon. Despite the involvement of well-motivated homeowners and well-intentioned researchers and government officials, the authors conclude that the risk information approach failed to induce appropriate, cost-effective voluntary protection. The results indicate that the information of risk perceptions and subsequent behavioral adjustments involve complex interactions among information, contextual, socioeconomic, and psychological variables. Thus governments that seek to educate rather than regulate must do so carefully.

Smith et al.'s (1988) survey of brochure use for radon information shows success varied with the format presented to the 2300 homeowners involved. The different designs of four brochures employed provided experimental control of materials presented to householders in the radon measurement study. The findings 
indicate that learning was systematically related to what and how information was presented. As expected, education was a significant determinant of learning while age again exhibited a negative influence on the prospects of learning. It seems clear that the success of an information program depends, in part, on the format of the material presented. Framing effects related to the presentation of risk information were similar to those observed in contingent valuation studies. Most important, the findings indicate that learning about risk is a systematic process.

Roesner and Russell's (1987) report on the analysis of emergency plans for nuclear power plants in California questioned the assumptions about who should be included in learning about nuclear risks. Specifically, the study was concerned with the program goals and who should be educated and who should be responsible for developing and evaluating the program (suggests the government, not just the utilities and FEMA). The study also suggested adding both citizens and social scientists to the emergency planning committee.

Palm (1981) evaluated the effects of the 1977 Alquist-Priolo Act disclosure requirement which specifies disclosure of earthquake hazard information by realtors. The research sought to determine whether the presence of special zones delineating areas of high earthquake risk and the mandatory disclosure of this information to home buyers affected people's adoption of earthquake mitigation measures or had an effect on house prices. Three surveys were conducted with recent home buyers, real estate agents were interviewed, and an analysis of hedonic price indexes were conducted. The homeowners in the evaluation included a group within the special zone, a group near the zones, and a subgroup of the first group who were particularly knowledgeable about the zones.

The results indicated that the disclosure had little impact on buyers or on housing prices. Few purchasers indicated that earthquake risk disclosure played a role in the decision to purchase. Many were not aware of the high risk zones even if they resided within them. No differences between groups was found regarding adoption of protective actions. Furthermore, prices had not been negatively affected by disclosures.

Several problems exist, however, with the study. First, any people who were affected by the disclosure and chose to locate away from earthquake risk were not identified and included in the study. This makes it impossible to infer the program has no impact. Second, the study is vulnerable to possible response bias. People may have downplayed the role of the hazard disclosure process in order to avoid admitting a "poor" decision. Furthermore, since the disclosure is made at the time of 
closing, and motivation to ignore new information when a decision has been made may be particularly strong, but the same information may have a much greater impact if provided earlier. Despite such issues, the research does suggest that some changes in the program are probably needed.

Ruch and Christensen (1980) attempted to assess the effectiveness of a hurricane awareness program. Findings were based on interviews with a randomly selected group for 381 households in Galveston, Texas. Three methods of information dissemination were involved: a checklist/map brochure, five-minute radio spots, and television ads and feature programs. Subjects were divided into four groups: one with no recall and three others, each composed of individuals remembering only one of the above program elements.

The results suggest that the brochure increased knowledge but decreased perceptions of risk. Television had no significant effects. Radio slightly decreased risk perceptions. The results suggest that written information is more effective than electronic media in education, but that all may have counterproductive impacts. Nevertheless, the questionable equating of program recall with programs exposure seriously undermines our confidences in these conclusions.

Waterstone (1978) conducted a study of the hazard mitigation behavior of flood plain residents in Denver, Colorado. A major goal was to assess the effectiveness of an informational brochure. The evaluation used three groups of subjects from two areas similar in risk. Group 1 had received the brochure twice prior to the interview. Group 2 had not yet received the brochure. Group 3, from the same area as Group 2, had recently received the brochure.

Telephone surveys were conducted with 249 residents to ascertain the effectiveness of the brochure as well as to measure a number of other relevant variables postulated to affect protective behavior. Results indicated that people who remembered receiving the brochure were more knowledgeable about floods and were more concerned about flooding than those who had not. Furthermore, the brochure seemed to have increased awareness and interest in flood problems and encouraged adoption of family contingency plans. Since people who remembered the brochure are more likely to have been concerned initially, conclusions about brochure effects based on brochure recall are questionable.

Haas and Trainer (1974) attempted to evaluate the effectiveness of a tsunami hazard public education efforts in four Alaskan communities. Three education programs were implemented and one community was utilized as a control. The programs used mass-media, a mail-out brochure or personal contact. Pre- and post- 
measurements were employed to measure various perceptions and knowledge about tsunamis and emergency response. The post-test, conducted 4.5 months after the completion of education efforts, showed minimal effects. No significant changes were observed in what people knew about tsunamis, how reliable they felt the warning system was, or in intended behavior in response to a warning. The mass media and personal contact approaches did elevate perception of the severity of local tsunami threat.

Baumann (1983) describes a project designed to identify cost-effective programs. As part of the research, three programs were designed to provide information to the public, differing as to the amount of information involved. The evaluation included four groups of people selected from flood-prone areas in the three program communities, plus a control group. The communities were matched according to demographic characteristics and flood risks and subjects were randomly chosen.

The results indicated that the information programs elevated awareness of flood problems. Furthermore, in comparison to the control group, program groups reported more activities to reduce flood losses. Of major significance, however, was the finding that each program had about the same impact. Amount of information had no detectable effects. No attempt was made to examine the duration of effects, which might have been sensitive to the differences among the information programs.

Some anecdotal evidence of the effects of educational programs exists. Foster (1980) reported a case where a school bus driver was confronted by a tornado and did not know what to do. An education program on tornadoes in the school enabled a student to remember the correct action. The driver followed the advice of the recently informed student to pull over and let everyone on the bus get into a ditch. The bus was subsequently destroyed but all passengers were saved because they acted in a manner that maximized their chance of survival.

\subsubsection{Personification of Risk by Recipients}

Probably one of the major recommendations in the literature is that audiences should not be viewed as static entities. Research on emergency warnings suggests that communicators should be attuned to the dynamic social presses involved in communications. For example, once a warning is heard, understood and believed, the warnings must be personalized by those at risk (Sorensen and Mileti 1987). A number of factors influence interpretations of warning messages. Receiver 
determinants include environmental cues, proximity, social networks, level of resources, role membership, socio-economic status, age, sex, cultural aspects (such as membership in a minority group), psychological attributes (such as knowledge, cognitions and hazard experience) or may be constrained by physiological problems. All process determinants (hearing, understanding, believing and personalizing ) also influence response. Communicators should plan that the most likely initial warning response is to seek to confirm the original warning message received (Sorensen and Mileti 1987).

\subsubsection{Impacts of Public Communication of Risks}

Gori and Hayes (1987) presented results of a USGS workshop concerning dissemination for public information on uncertain geologic risks, and concluded that communicating information on risks was an on-going activity. Communication is a process, not a single act, involving federal, state and local interaction. How the USGS communicates information about geologic hazards may be considered as important or even more important in averting disaster than the direct assessment and monitoring of geologic hazards.

Blair (1987) analyzed the response to the volcanic risk issued by the USGS for the Mammoth Lake area in California. Four negative effects were identified from the notice: town officials and business people in Mammoth Lakes believe the economy was adversely impacted by the notice; that the method of release put public officials on defensive (local officials learned of the notice from an article in the Los Angeles Times); that the press coverage exaggerated the hazard; and that the risk was inadequately defined for decisive public action. Positive aspects included public recognition of the volcanic notice, instituting a USGS workshop that effectively communicated to the community what was known about the risk, construction of an evacuation route from Mammoth Lakes, preparation of a state emergency plan for response to the threat, and improvement of some land use plans. Although the USGS notice had been cautiously worded to convey a high degree of uncertainty about all aspects of the situation, the notice was greeted with anxiety and sometimes exaggerated public reaction. Local officials and business people saw the notice as a direct threat to the local economy, rather than as a warning about the possibility of a volcanic eruption.

Browning (1988), reporting on the Challenger explosion, found that members of NASA before the accident and the Presidential Commission following the accident 
acted in different ways to protect the survival of NASA as a viable agency. The strategies of protection centered on blaming individuals at lower levels of NASA and to fix blame on communications failure (a technical problem) rather than blaming leadership of NASA (an institutional problem). They concluded the type of accident determines the risk for decision makers, but only in retrospect.

Hance et al. (1988) conducted 50 interviews about successful risk communications with experts and agency personnel from both the public and private sectors. Enhancing trust and credibility were critical for agency practitioners in dealing with the public. They found program effectiveness to increase when the following practices were used: involving the public from the beginning, being aware of the "outrage factor" of public concerns, being consistent, having articulate personnel sensitive to public's needs as communicators, communicating risks through personalization and comparisons to similar situations and substances, not confusing acceptability of risk with understanding of risk, admitting uncertainty, and educating the public through involvement in the process.

Hilgartner and Nelkin's (1988) study included reviews of four case studies on dietary risks. The debates in these cases centered on questions of the strength of technical evidence, the reliability of public statements, the dangers promoting "undue" alarm or anxiety, and on the public's right-to-know. The findings suggested that technical issues often served as surrogates for skirting the more contentious issues of political and social control of risk communication.

Johnson and Fisher (1989) conducted surveys during the summer of 1986 to measure information learned from brochures on radon risk distributed to the public. The methods used to inform about the health risks had a measurable impact on recipient's resulting risk perception, depending on the measure of effectiveness used. Quantitative information treatments were statistically significant in reducing discrepancies between objective and perceived risks. While results confirm conventional wisdom that personnel characteristics influence risk perception, the results do not suggest that such characteristics can identify target "publics" for particular risk information programs. No information treatment was superior for all tasks. Neither was there a single set of personal characteristics that identified a group with a clearly defined set of perceptual problems. Different personal characteristics were important for different perceptual tasks.

McCallum (1986) concluded that the cardiovascular disease was reduced in the United States through a program that utilized coalitions and networks that sent complementary messages, promoting a synergistic effect on recipients. The effect 
was fostered through local and national involvement, using multiple communication channels that provided daily messages for continuing reinforcement of the message.

Kauffman (1986) studied the Tauton, Massachusetts, proposal for a hazardous waste site. The findings suggest the inability of the government to overcome public fears and uncertainties about certain complex technologies stemmed from the public's distrust that perceives government to have a hidden agenda. A second problem was asking the local community to serve regional, and even national needs. Third, compensation was a thorny area of communication with compensation regarded as a bribe. Findings from the Tauton experience suggest that no matter how good or long the communication process is, the local community must have all the necessary information to participate effectively in the negotiation process.

Five case studies researched by Krimsky and Plough's (1988) suggest the importance of visible and independent scientific validation of technical decisions supporting official risk communications. The study found that one of the common mistakes in attempting to understand public attitudes about risk was to measure people's responses to hypothetical questions.

Ruckelshaus (1987), reviewing past EPA actions in the Seattle ASARCO closure, concluded that the public must have access to the decision maker early on and be given honest and complete information to make an informed decision. At that point the public must take responsibility for the decision. The "task is to elicit from people a response that is both sensible and consistent with their own interests" (Ruckelshaus 1987).

Schulte's (1989) studies found that individual notification of workers to a past chemical exposure did not have satisfactory outcomes in light of the health agency's goals of stimulating additional medical screening. The primary lesson was that a single notification letter was not enough to stimulate worker action. Three barriers to individual notification are: (1) epidemiological risk information was not made group specific, so that the experience of one group could not be compared to another; (2) in many of the mortality studies estimates were based on deceased who may have had greater exposure than the notified workers; and (3) workers questioned the truth of the study findings. Individual notification procedures for risk factors should be based on a firm scientific foundation and reflect the relative importance of the risk to the individual. 


\subsubsection{Education of Publics about Risks to Induce Action}

The issue of how risk communications eventually influence individual behavior has been raised. Researchers have had difficulty linking public education efforts with actual behavioral changes. Despite the involvement of well-motivated homeowners, well-intentioned researchers, and government officials in one study in Maine, the risk information/education approach failed to induce appropriate, costeffective voluntary protection regarding individual homeowner risk from radon (Johnson and Luken 1987). Instead the results indicate that the formation of risk perceptions and subsequent behavioral adjustments involve complex interactions among informational, contextual, socioeconomic, and psychological variables. "Governments that seek to educate rather than regulate public on risks must do so carefully," note Johnson and Luken.

Other research on the benefits of education has had more favorable results. The final report evaluating FEMA-sponsored programs to raise community awareness of earthquake hazard initiated in three earthquake prone areas (Seattle, Memphis, and Charleston) included a number of methods to enhance public awareness (Bolton 1987). The report compared the various strategies used in the school earthquake education and safety and the community outreach programs, described activities and approaches tested in the three projects, and the accomplishments of the projects in disseminating earthquake hazard and preparedness information. "By being sensitive to the constraints and concerns that teachers and principals face, the earthquake project can foster the enthusiasm that can eventually lead to widespread involvement and significant risk reduction" (Bolton 1987). The combination of earthquake science and protective actions in one educational program reduced anxiety about the earthquake hazard among primary school children.

This chapter has presented risk communication as a social process. It has gleaned information from actual studies in risk communication research that have enabled the design of other risk communication programs. The studies did not address strategies and practices to use when confronted with a particular issue or problem. That is the topic of the next chapter. 


\section{RISK COMMUNICATION STRATEGIES}

\subsection{PROGRAM DESIGN}

In this section we attempt to bring together recommendations for risk communication practices and organize them as communication strategies. We are not advocating every practice that is recommended as many are largely subjective and situation-specific. These are meant to stimulate your thinking about how to deal with a particular problem. As Jasanoff (1988) notes:

"In a world which can produce such risk 'communications,' a simple emphasis on how to transfer technical information to lay people should not be lightly dismissed. What is at stake is what institutions and society should do, and messages ignoring this are unlikely to convey conviction."

\subsubsection{Design Principles}

It is important to design an integrated risk communication program. Before a program is initiated, establish a working team with authority for resolving problems; identify who will be responsible for addressing the public's questions and who has responsibility for each of the program's components (Pavlova and Luftig No date). Repetition and frequency are two very important components of timing that deserve careful consideration. A graphic representation of the long-term process (e.g., a timeline) should be published repeatedly throughout the program. Communications should be frequent so as to give the perception that government is an effective structure for responding to the community's concerns (Pavlova and Luftig No date). Conclusions should be made explicit and vested interests should not only be admitted, but justified in terms of public mandate or economic function (Renn and Levin 1988). In the CSEPP it is important to remind people that the incentive for disposal came from congressional mandate and not the agencies involved in the CSEPP.

In establishing a risk communication program, careful attention should be given to start-up tasks before dissemination activities start to consume staffs time. New projects should be careful about obtaining too much publicity before agencies are really prepared to begin providing information or offering well-developed presentations (Bolton 1987). 


\subsubsection{Preparation for Risk Communication}

One reason that risk communication efforts often fail is lack of preparation. For example, even simple mechanical factors, such as having to prepare material quickly for short deadlines can constrain risk reporting (Peltu 1988). It is recommended that communicators inform all agencies potentially affected by another agency's actions and communicate routinely as a means of avoiding misunderstandings (Chess 1987).

Plan carefully before communicating by developing clear and explicit objectives which address multiple audiences. Determine the objectives of the plan prior to its development. Alternative objectives are to educate, to build credibility, or to reduce conflict (Bell 1989). Once the types of risks to an organization are analyzed, they should be prioritized to provide a list of potential concerns (Bell 1989). When establishing a risk communication program, it is important to plan for what type of information needs to be collected to document program implementation. For example, maintaining a daily log of documents may be needed for obtaining further funding or to defend credibility. In the CSEPP, documenting when and where monies were used to improve communication coverage (i.e., sirens or tone alert radios) is helpful in promoting agency credibility.

Preparation takes many forms. For example, in SARA Title III programs, communities must first identify the chemicals most likely to cause concern and contact plant managers in their area. Officials then need to obtain toxicity and exposure information on reported chemicals and associated risks, especially about personal health. To identify perceptions and concerns of the community, it is helpful to initiate a baseline study of the community's "chemical risk" awareness (American Chemical 1988).

It's helpful to determine in advance what specific questions will be asked by the public about risks in the community, such as "Is it safe to drink the water?" or "Can I let my livestock graze near the depot?" Plans should also include a policy statement for emergency public information (PI) plans and a selected staff to serve as a PI team prior to an event (Bell 1989). It is important to specify program goals, rationale, physical features, and desired actions (Diggs 1988). Agencies should discuss plans openly instead of waiting to release results of an investigation (Chess and Hance 1989). Furthermore, it is important to maintain flexibility and to adjust to community dynamics during program implementation (Morgan and Vlek 1988). Communicators will be better prepared when, prior to final production, messages 
are pretested with target audiences (and in some cases with channel "gatekeepers") to ensure public understanding and to achieve intended responses (Arkin 1989).

\subsubsection{Social Factors in Program Design}

Effective programs are based on understanding and incorporating local social factors into the program design. The social dimensions of routine decision making and communication should allow negotiation between experts and the public to determine the appropriate levels of uncertainty in each particular case and to allow for intercultural understanding about expectations for knowledge or information (Wynne 1988). For example, in developing a dialogue between scientists and farmers after the Chernobyl accident, researchers found that a less centralized organization of scientific expertise would have aided the two-way information exchange as well as negotiation of what was expected from the scientific community (Wynne 1988).

Social factors are important in developing individual perceptions of risk. For example, if communication of information on genetic health risks is intended to form an effective basis for reproductive decisions, it must not only reach both spouses but must be interpreted in similar fashion by both (Wertz 1989). Patients must be encouraged to think independently and critically and transcend the passivity implied by the term "consent" by becoming full-fledged partners in the therapeutic process (Dutton 1987).

\subsubsection{Role of Public Information Offices in a Program}

Dunwoody and Ryan's (1983) research on the utilization of information offices by scientists within organizations found support for two propositions: (1) the PI component had something of a marginal status within the organization and (2) PI personnel within an organization did not utilize all scientists within an organization equally. Rather, PI personnel tend to interact with few individual scientists, most likely those who are older, prominent and more organizationally powerful than others. The study found that over half (52\%) of the scientists that responded agreed that scientists are responsible for making research findings available to colleagues. Ninety-seven percent agreed that it is important for researchers to learn to communicate with nonscientists, and $72 \%$ agreed strongly that researchers should be free to deal with the popular media. Although $66 \%$ of respondents agreed that PI personnel sometimes hindered scientists who want to be completely open with their 
research efforts, $72 \%$ indicated that PI staffs generally make it easier for scientists to deal with journalists. Only $15 \%$ agreed that it would be a good idea to dismantle PI staffs and allow scientists to deal directly with journalists. Almost all (93\%) of the sample agreed that most scientific training does not teach those in scientific endeavors to deal with the media. While $72 \%$ of sample said no media contacts were initiated through their PI offices, $87 \%$ noted that $25 \%$ to $100 \%$ of their journalistic contacts were initiated through journalists. These findings agree with other studies that scientists apparently want PI persons around but don't view them as integral to their activities with the media.

Goldman's (1986) review of nuclear utility responses to emergency events found most events were classified by the companies as "unusual events" or "alerts" with one classified as a "site area emergency." Although none of the events posed a public hazard, each posed a threat to the credibility of the utility when the event was reported. The public response demonstrated that (1) media response to a nuclear power plant accident is not necessarily related to the technical severity of the accident, and (2) utilities must have in place effective and coordinated emergency PI program, particularly for "lower level" emergency classifications. These findings indicate that risk communication programs for the CSEPP should include prepared statements for events which are not critical but which may cause citizens to have some concern about their safety.

\subsubsection{Establish Rumor Control}

Rumors can undermine the credibility of any risk communication program. The best strategy to control rumors is to refute rumors with facts, using outside opinion to support the information. Don't refute one rumor with another rumor or with incomplete facts, overstatements, and above all, don't joke about the rumor (Bell 1989). One established mechanism for rumor control is to install hot lines to answer questions from residents (Covello et al. 1988b). After a crisis, one should avoid a silence heavy with embarrassment because this promotes rumors. Do not pretend nothing has happened, issue denials, or refuse to release information or details (Lagadec 1987). 


\subsubsection{Institutional Framework and Trust for Risk Communication Programs}

A prerequisite for effective communication is a procedural and institutional framework for decision making that encourages public participation and inspires public trust (Jasanoff 1987). Government should incorporate the public into its decision-making processes early in the project development with incentives for citizen involvement (Zimmerman 1987). Joint problem solving means discussing as many alternatives as early as possible and leaving some aspects of the policy or project adjustable for a wide range of values. In addition, any party should have the resources needed to participate and be able to propose new alternatives (Jasanoff 1988). Although citizens did not determine the location of the chemical munitions, the Army has provided resources to communities to determine the validity of their decisions.

Public interest groups with demonstrated capabilities for risk management should be drawn as much as possible into the network of information sharing, thus reinforcing the lines of communication between industry, government, and the general public (Jasanoff 1988). Almost all research indicates involving the public is an inevitable condition for success. If the public does not perceive the problem as "its" problem, actions will be difficult to implement or even to justify (Jungermann et al. 1988).

\subsubsection{Plan a Program to Fit Audience Needs}

The major recommendation from the analysis is to assess the concerns of the targeted audience--but audiences and publics frequently have differing information needs. Communicators should allow for an individual's need to confirm disaster and emergency information. Compare risks within a carefully defined context that is relevant to the target audience and at the same time provides opportunities for people to learn how to interpret risk information (Covello et al. 1989). Find out what types of risk information people want (Hance et al. 1988).

Identify and respond to the needs of different audiences through

responsiveness and equitable treatment of different groups (Hance et al. 1988). Recognize that individual value systems are legitimate and may convey a valuable information source. Provide a forum for expression of feelings and values and be open about agency values or constraints as well as conflicting personal values (Hance et al. 1988). Understand and respect individual interests, emotions, values, 
priorities, preferences, and concerns (Covello et al. 1989). Risk communicators should be sensitive to the characteristics of mental models because of framing differences between the public and that of experts (Cvetkovich and Keren No date). Consider these audience factors for successful risk communication: the level of involvement (as indicated by measures of issue importance, such as the personal consequences for the individuals), the motivation to process specific information about the issue, and the ability to process the given information (Earle and Cvetkovich 1988).

\subsubsection{Comprehending Public Behavior}

Risk communications can be improved by a greater sensitivity toward the audience's needs. It also helps to understand how people behave in an emergency (Bell 1989). Try to understand and recognize the qualitative concerns some members of the public have about hazards. Such concerns often focus on the catastrophic potential, dread, equity, and controllability of risks (Covello et al. 1988b). People are concerned not only about the magnitude of risks (i.e., their probability-weighted outcomes), but also about their other qualities; the clearest example is whether the risk appears voluntarily or involuntarily imposed (Lichtenberg and MacLean 1991). Use community relations staff to interpret public concerns (Hance et al. 1988).

\subsubsection{Design a Program Based on a Model}

Using the two dichotomies of flow and intent, we can identify four different models of risk communication. It is recognized that these models simplify the underlying structure of the processes which are actually continuums and not categories.

Nevertheless, the typology allows us to examine critical assumptions underlying the communication process and to impose order on relatively complex phenomena. The models are labeled as follows:

\footnotetext{
- one-way exchange

- one-way persuasion

- two-way exchange

- two-way persuasion
} 
Figure 6-1 summarizes various assumptions which further describe these four models.

The framework does not imply that any one of the four model types is incorrect or superior. That is situation-specific. For example, in the event of a sudden release of chemicals that present a hazard to nearby populations, the communicator needs to persuade the public to take protective actions, and with such limited time frame, does not have the time to establish a dialogue. Thus a one way persuasion model would be desirable. In a situation such as in the case of an agency with a mission to reduce high risk behavior for contracting the AIDS virus, the twoway persuasion model may be more appropriate. It is persuasive since a desired outcome is the goal, but two way as interaction and dialogue is needed to achieve the goal. In the case of negotiating a common position, such as when the Army should directly activate the alert/notification system, a two way exchange model would be desirable. In this case both parties need consensus on how to plan for the event. In the case of CSEPP public information, a one-way exchange might be an appropriate model. Most of the information is flowing from the agency to the public but feedback and evaluation is also important.

\subsection{PROGRAM COORDINATION}

Coordination enhances the likelihood of a successful risk communication program. Carefully and closely coordinate all communications within and between organizations, including all initiatives and actions (Covello et al. 1988a). For example, in developing emergency information programs, carefully coordinate evacuation/shelter plans and programs with all agencies involved, public, private or semi-public (Covello et al. 1988a). Develop communication plans for different scenarios by expecting the unexpected (Covello et al. 1988a). Key elements to a successful emergency public information program include:

- a detailed emergency public information plan;

- an established chain of information flow outlining responsibilities;

- coordinated information sources and spokespersons;

- exercises and drills practiced regularly;

- management support, including both time and resources, for the public information efforts (Goldman 1986). 


\section{One Way $\leftarrow$ Flow $\rightarrow$ Two Way}

\section{Exchange}<smiles>CC1CC1</smiles>

Intent

$\downarrow$

Persuasion
ONE-WAY EXCHANGE

Public will act on given information

Assumes "economic model of rationality"

Often bureaucratic in nature

Technical focus

Limited and/or selected information

ONE-WAY PERSUASION

Experts are correct

Public is uninformed or misinformed

Style determines success

Economic model of rationality

Limited time frame

Selected information
TWO-WAY EXCHANGE

Assume no absolute truths

Assumes social process

will determine success

Assumes non-rationality

Extended time frame (discussions may continue indefinitely)

Broad-encompassing

Assumes multiple perspectivespluralistic

TWO-WAY PERSUASION

Assumes non-rationality

Dialogue is top-down

Style will determine success

Expert is correct

Public is uninformed

Limited time frame

Selective information

Figure 6-1 Model Framework. 


\subsubsection{Organizational Needs}

As in all preparedness plans, it is important to define organizational relationships in advance to avoid overlapping responsibilities and conflicts of interest in the heat of developing crisis (Otway et al. 1988). Examine the weaknesses of your organization to determine an appropriate structure for an emergency public information plan (Bell 1989). Agencies should examine their relationship with various interest groups and explore how such relationship could be improved (Chess and Hance 1989). Government programs that seek to reduce health and safety risks with information programs, instead of more conventional enforced standards, must be carefully crafted to accommodate the complex process (Johnson and Luken 1987). It is critical that crisis management programs have mechanisms for prompt notification of emergency personnel and for correct and judicious dealings with the media (Mitchell 1987).

From a different perspective, a much tighter control of the organizational environment is recommended for corporations. For example, corporate personal relations personnel should seek all information; be careful about letting the media take pictures; emphasize previous safety records and heroic acts; avoid speculation about the emergency; give facts to media but say no more than to confirm what is known; never release names of victims; and always accentuate the positive (Mitchell 1987). Chemical companies must continue to communicate, not only concerning the criteria for determining what is deemed to be acceptable levels of exposure, but the plans for reducing releases (Black 1989). Companies should not try to sugar coat sour news (Grunig 1987). In establishing an understanding with and gaining cooperation from government agencies, develop information packages for agency heads, provide personal presentations, and concentrate efforts on key officials (Collagen 1989).

\subsubsection{Prior Coordination Needed Between Agencies}

Coordination between agencies communicating risk should be established before any information program is initiated. Information sharing and exchange between scientists, policymakers, administrators, and spokespersons from federal, state, and local governments must be assured. This avoids the appearance of conflict or lack of cooperation that could be used by critics as examples of bureaucratic inefficiency (Pavlova and Lufing No date). For example, the USGS recommends initiating communications with local communities by providing officials 
with key information which will eventually be distributed to the general public (Gori and Hays 1987). Where feasible, local communities should be involved at the research stage (Gori and Hays 1987).

\subsection{MANAGING THE MEDIA}

Managing the media is probably one of the more difficult aspects in designing a risk communication program for the CSEPP. Although most CSEPP programs now have trained PI staff, in the midst of a crisis others may have to communicate with the pubic and with the media.

\subsubsection{Viewing the Media as Gatekeepers}

A basic assumption in much of the literature is that the media is a pervasive first source of information throughout American society, setting public agendas for determining what people think about, and acting as "gatekeepers" for the types and sources of information given to the public about risks. Other studies suggest a more benign view of the media's influence by emphasizing the contextual and social factors that continually interact with public perceptions of risks. Studies also indicate a biased viewpoint presented in the media coverage of both technological risks and natural hazards that are characterized by subjective rather than objective reporting formats and which rely on visual aids to enhance the dramatic rather than the factual information.

This issue of the media control of information involves two factors: the media's ability to publicize and promote public readiness for future protective actions and the individual or receiver's actual behavior in response to media warnings. The consensus in the research on natural hazards is that people use media sources selectively, relying on the media as a surveillance tool and for some information but still using family and friends for advice and suggestions on options for action (Ledinghan and Walters 1989). A further issue is how those personal contacts are themselves influenced by the media and how the advice from family and friends correlates with that of experts as given initially through media sources. If the media does have an agenda-setting capacity, that ability may translate to alerting specific populations and keeping channels open about what options are 
available when discussing risks-perhaps the most important capability of media communications.

Some confirmatory information to previous research exists on how mass media influences communication of risks. In survey findings after two hurricanes, one after Hurricane Alicia (1983) and the other after Hurricane Danny (1985), the media served to alert the population and to provide information on response options, but discussions with friends and family were found equally important in the options respondents ultimately choose (Ledinghan and Walters 1989).

An on-going issue in risk communications is the way in which different risks are projected through media accounts as being important. Greenberg et al. (1989) found that risks as calculated by scientists as critical had little to do with the amount of coverage provided by the three networks' evening news broadcasts. The 13.8 hours (1.7\%) of actual network evening news time for man-made environmental risk issues in 26 months with emphasis on the spectacular or acute rather than the chronic effects appeared disproportionate given the overall concerns for chronic risks as expressed by experts. In their opinion the unequal coverage reinforced the public's overestimation of health impacts of acute risks and created underestimation of most chronic risk issues. "The public's conception of risk is almost certainly distorted by television's focus on catastrophes and its dependence on films," report Greenberg et al. (1989).

Issues arise over the media's actual and perceived public roles in communicating risk information. Nimmo and Combs (1985) point out that television networks are large scale corporate organizations whose interests go well beyond the altruistic motives of informing the public. Coping with the internal needs of the organization as well as coping with external pressures are significant factors in shaping the news content as the "objective" realities of reported events. In addition to performing their daily work, television correspondents develop forms of shared definitions of news, conventions of objective reporting, an aesthetic and visual presentation, and an accepted grammar of news writing, and a logic of television news, as distinct from other modes of reporting. These factors play prominent roles in crisis reporting, regardless of the crisis itself (Nimmo and Combs 1985). Bias is also a problem. Some health risks, such as AIDS, are given moral overtures that bias the amount of factual information presented to the public by the media (Burd 1989). 


\subsubsection{Working with the Media}

Methods to promote better working relationships between public officials with the media have been suggested. Ranking high on recommendations is to respect and work closely with news media, but not to depend on them to fulfill your communication needs. In a crisis, add staff to specifically answer media queries and hold regular and frequent press conferences and briefings, even if no new information is available. Respect media deadlines and provide information to the media of emergency communication plans and procedures (Covello et al. 1988a). If at all possible, improve interaction with information transmitters (science writers, community leaders, media) prior to a event and educate them over time (Keeney and vonWinterfeldt 1986). Corporate public relations persons should actively maintain contact with media, check with upper management before responding to questions, and keep a log of all information disseminated through their office (Mitchell 1987).

\subsubsection{Involving the Media to Achieve Participation}

Despite the difficulties of media communication about issues and the cost of public scrutiny, there remain sound political, ethical, and pragmatic reasons for improving media access to risk communication (Nelkin 1989). It is necessary to involve media and other information sources because the public's main source of information about risk issues is often the media (Pavlova and Lufing No date).

To minimize problems with the media outlets, develop an ongoing relationship marked by careful coordination between emergency managers and the media representatives. Such coordination has been an important avenue to increased public safety in areas with volcano threats (Perry and Lindell 1987). The responsibility to inform the media and, through them, the public about environmental risks belongs to everyone associated with environmental issues. These include the technical, scientific, corporate, regulatory, and community news sources (Sachsman et al. 1988).

To remove barriers, communicators need to better understand and respect journalistic norms, values and needs. Developing a certain degree of sympathy for the needs of working journalists should improve press coverage of risk (Sandman et al. 1987). Communicators must understand that the media have a legitimate "alarming function" and seek to overcome professional or organizational norms that prohibit communication with the public (Sandman and Peters 1988). 
A continuing educational program for journalists should include a training session on the use of informational materials. Better understanding of the role of media is important because the media is important in improving risk regulation (Peltu 1985). The media has helped broaden the base of participation in regulatory decision-making by giving prominence to views of intervener groups, dissenting experts, and local communities. The media have also supported the status quo by too readily accepting public relations techniques of government agencies, industry and politicians (Peltu 1985). Risk communication informs the public and thereby promotes agency accountability (Baram 1986). For the risk communication process to be effective, people must be aware of the risk, have knowledge and skills for appropriate action, and receive positive reinforcement for appropriate behavior (McCallum 1986).

\subsubsection{The Media as Channels and Sources}

A theme running throughout the risk communication literature is that the media is not a passive channel to the public. The growth of the disaster culture, and the intrusion of the mass media into that culture, has become a new element for the hazards community to both understand and harness for certain goals (Wilkins 1989). It is recommended that communicators take a proactive approach to establish relationships with media and to demonstrate the ability to serve as a source of objective, balanced information for news media because the media have the potential to either seriously undermine or enhance communication efforts to provide objective and accurate information (Pavlova and Luftig No date).

The ability of the media to help set regulatory agendas can mean that risks which meet certain criteria of journalistic "news worthiness" are given greater priority than chronic hazards which may be of wider importance (Peltu 1985). Many organizational factors and professional practices influence decision on what finally appears in the media (Peltu 1988). Press coverage of environmental risks can be improved both through the use of continuing educational techniques, and the actions of environmental news sources to educate journalists (Sachsman et al. 1988).

Attempts should be made to meet the needs of news media by being open and accessible to reporters while respecting their time and space constraints; provide information tailored to the media's needs. Try to establish long-standing relationships with reporters and editors in your community prior to an event. Don't 
be discouraged that journalists often seem more interested in politics than risk, in simplicity than complexity, and in danger than safety (Covello et al. 1988).

As part of a formal emergency plan, establish rapport with media outlets before a crisis occurs (Bell 1989). Although the media are usually considered a channel through which to reach an audience, in risk situations that involve complex and highly technological issues, journalists must often be educated before they can be accurate channels (Collagen 1989). Getting the media, as an audience, to understand how risk is determined is like "force-feeding"; bring experts to the media for in-depth interviews and have a comprehensive background paper to present basic science and studies involved in particular issues (Collagen 1989). Provide information tailored to needs of different media such as visual material for television and short spoken quotes by senior official for radio (Covello et al. 1988).

Take steps to ensure the quality of media reporting by establishing a news monitoring system within your agency (Covello et al. 1988). Other suggestions include having background information prepared for the media (Sandman 1987) and using public relations techniques for packaging press releases to the media to increase risk coverage (Nelkin 1987). Risk assessment experts can overcome the limitations of televisions news criteria, which emphasize the visual and the acute, by making chronic risk information more visual; this will help break the barriers of television news and help provide the press with a more accurate perspective on risk (Greenberg et al. 1989). To maximize news media opportunities, the public information office needs a support staff and sufficient time in which to design public service communication (Stockdale and Sood 1989). Another recommendation is to provide a hard copy of announcements and dissemination of repetitive information for increased efficiency in public information operations (Stockdale and Sood 1989). Solutions to the information lag problem include changing topical agendas and having updated status boards (Stockdale and Sood 1989).

Journalists need to learn more about technical aspects of hazards and emergency response (Stockdale and Sood 1989). News managers should withhold reports until confirmation of sensational stories can be made and avoid being driven by the "scoop" mentality (Stockdale and Sood 1989). To improve media performance and help journalists get reliable information about risk topics, reporters need to be educated in the importance and subtleties of risk stories with access to knowledgeable and cooperative scientists (Slovic 1986). 


\subsubsection{Managing Media Messages}

One problem for communicators is providing information to media outlets that will be used in the intended communication. Factual information provided to the media should be given in an orderly controlled fashion (Mitchell 1987). One of the chief roles of the media after a disastrous event is to reconstruct the event, instructing the viewer or reader as to why the recent event happened, and how to interpret future occurrences with the mediated reconstruction geared to prediction and prevention of future disasters (Wilkins 1989). The accuracy of reporting is a major concern in risk communications. How the nature and roots of values, beliefs, and fears develop that draw people together in opposition or in support to things nuclear illustrates the impact of media influence. This includes the influence of messages sent through the entertainment media (Shain 1989).

\subsection{COMMUNICATION TECHNIQUES}

\subsubsection{Maintain Audience Appeal}

A difficult task is to attract and maintain an audience's attention. In some cases, it is desirable to use innovative ways to attract the attention of the audience (Covello et al. 1988b). Desvouges and Smith (1988) make the following recommendations when working with focus groups. When working with civic groups, church groups, and social organizations, it is preferable to offer a modest fee to create a sense of responsibility for attendance. Keep groups relatively small (8-10 people). Send people confirmation notices and brochures to reduce anxiety about intentions. Make sure the moderator is represented as a nonexpert. Don't try to hold focus groups with respondents who might have difficulty with the topic because they are not informed. Arrange for multiple record-keeping for each session, videotaping if possible. Have clear objectives and a written agenda. Select a relaxed setting and keep an informal format (perhaps including refreshments). Keep sessions under two hours. Remain at the location for some time after session to attend to informal opportunities for discussion that help alter impacts and ease anxieties. 


\subsubsection{Communicator Skills}

Select the most appropriate communicator for the situation, if there is any room for choice (Jasanoff 1988). The American Chemical guidance manual (1988) advises:

"Be honest, frank and open. When communicating with the public and the media, state your credentials but do not expect to be trusted. Admit your ignorance and mistakes, and if in doubt share more information."

It is important to speak clearly and with compassion, using simple language (Hamilton 1986). Technical language and jargon pose substantial barriers to successful communication with the public (Covello et al. 1988b). It helps to acknowledge and respond both verbally and through actions to the emotions people may express. Try to avoid distant, abstract, unfeeling language about deaths, injuries, and illness. Respond to dimensions of risk (e.g., equity and catastrophic potential) and avoid comparing unfamiliar risks to familiar ones unless they are in all the dimensions people consider important (American Chemical 1988).

To be effective, spokespersons should have both good presentation skills and good interactive skills (Covello et al. 1988b). Spokespersons at public meetings should identify with the audience and avoid violations of community norms regarding dress, language, and demeanor (Covello et al. 1989). The expert should show his human side (similarly between source and receiver) and establish agreement on some issues even when irrelevant (Lee 1986).

Portray results in terms lay people understand (Keeney and vonWinterfeldt 1986). Risk communicators should avoid technical and bureaucratic language and, try to address people's concerns directly. Communicators should provide the public with information that can be related to personal experiences and which fosters individual learning (Keeney and vonWinterfeldt 1986). Recognize the power of subtle changes in the way information is presented and the use the knowledge responsibly (Covello et al. 1989). Relate on a personal level without minimizing risks and uncertainties (Covello et al. 1989) and respond to people's concern by personalizing responses (Hance et al. 1988).

The factors that improve public acceptance of messages are:

- clarity of information,

- consistency, 
- clarification of main points,

- appropriate tone and appeal,

- credible spokesperson, and

- information based on what the public perceives as the most important to know (Arkin 1989).

\subsubsection{Managing Audiences}

Several methods of managing audience response have been suggested. If resources are not an issue consider this directive: prior to message development, divide the public into manageable groups according to risk, media exposure, attitudes, knowledge, and behaviors, or other characteristics to help define an appropriate message (Arkin 1989). What is important is to recognize that the public is not a single, undifferentiated mass. To create a good risk communication program, segment the audience when possible (Covello et al. 1988). To aid in honing a message, use market research techniques to identify an audience's awareness of risk and related issues (Collagen 1989). To encourage behavior change and protective action communicators should attempt to identify a target audience and tailor communication to that audience (Covello et al. 1989).

Successful risk communication rests on the generation of knowledge about the target audience and on the ability of the communicator to create messages to fit the identified needs of the targeted audience (Earle and Cvetkovich 1988). Successful targeting requires research into the perceptions, needs, and social characteristics of all involved (Diggs 1988). Shotgun (scattered) risk communications to the general public are ineffective especially when targeting organized groups such as environmentalist or neighborhood groups. Pavlova and Luftig (No date) suggest thinking of the public as segmented into three types of audiences that include:

- those individuals who are open-minded, interested, and want to know more about the issues

- those most immediately affected by the risk situation such as the citizens living closest to the area of risk, such as a Superfund site; and.

- those intermediaries or others who serve as gatekeepers in reaching audiences. 
Another important issue for risk communicators is how to use focus groups effectively. Focus groups can be especially effective in exploring people's perceptions of risk, how those perceptions are linked to personal attitudes and characteristics, the influence of visual aids on perceptions, as well as highlighting the differences between technical risk assessment results and people's risk perceptions (Desvouges and Smith 1988).

\subsubsection{Communicating Uncertainty}

One of the most difficult tasks for a risk communicator is to discuss uncertainty with audiences. It is important to identify, acknowledge, and explain uncertainties in risk estimates (Covello et al. 1988b). Oftentimes acknowledging the uncertainty relieves some of the tension between parties. Even when certain about risk measurements, communicators need to be cautious with point estimates of risk. It is a fallacy to assume that precise estimates of risk are true representations. Begin by stating that risk is uncertain; next, state the extent of uncertainty; bracket the range of credible risk estimation to indicate the major sources of uncertainty; and (if possible) state the sensitivity of the estimate to each of the different types of uncertainty (Kasperson and Kasperson No date).

Attention to the conveying technical information must go hand-in-hand with attention to the contextual factors affecting its reception and in raising issues not addressed by the technical information (Jasanoff 1988). It is important to realize that no single approach will be adequate. In communicating with the public on risks to health, the uncertainty in the information that is conveyed must be specified, along with the reasons for uncertainty (Upton 1989). Oversimplification is dangerous; the idea that each issue can be divided neatly into two and only two sides (pro and anti) does not indicate that news coverage of a issue should be balanced (Lichtenberg and MacLean 1991).

\subsubsection{Discussing Risk}

Discussing the quantitative aspects of risks is often a challenge. A point to remember is that just as good comparisons help, poor comparisons can mislead and confuse. Avoid lumping comparisons that will be seen as misleading, such as comparing voluntary and involuntary risks, risks affecting different generations, or risk from small repeated events with those from catastrophes (Kasperson and Kasperson No date). 
If comparing risks, avoid comparisons that mask "outrage factors" or that minimize or trivialize the risk; instead develop comparisons of similar substances or situation (Hance et al. 1988). The effect of comparing an environmental risk to some other for which the public has a "better feel" trivializes the environmental risk (Ozonoff and Bowden 1987). Conditions in which risk comparisons may be useful occur when the comparison clarifies but does not minimize or dismiss the issue, and when the information is personalized for the individual (Sandman 1987). Add enough qualifiers and guidelines to prepare people for what you are not telling them. For example, likening the level of PCB emissions from a proposed incinerator to that emitted from a home fireplace. In addition avoid abstraction, use concrete examples, and avoid oversimplification (Sandman 1987).

Risk communicators should try to understand lay people's individually oriented structures of risk problems and the result of risk analyses both within the individual's perceptions and within the society they are working with (Keeney and vonWinterfeldt 1986). Another common mistake-not recommended-is to attempt to identify public attitudes about risk by measuring peoples' responses to hypothetical questions (Krimsky and Plough 1988).

\subsubsection{Techniques when Information is Highly Technical}

When confronted by an unusually complex scientific issue, it is important to use simple and non-technical language to communicate scientific information about health and environmental risk. Communicators should attempt to use simple, graphic, and concrete material, and avoid technical or specialized language whenever possible (Covello et al. 1989). When discussing risks, various social and psychological perception factors should also be taken into consideration, remembering that people's perceptions are neither right nor wrong. As identified by researchers factors of risk include voluntariness, controllability, benefits, alternatives, familiarity and fairness (American Chemical 1988).

It helps to provide a perspective for risk numbers by explaining risk assessment techniques before presenting the actual numbers. Try using graphics and avoid dichotomizing risk; express risks in several ways and explain the agency's approach to risk assessment (Hance et al. 1988). Acknowledge uncertainty about risk assessment (Hance et al. 1988). Personalize responses to personal questions about risk. Take the most care in presenting technical information in ways and in language that informs the recipients. If possible, limit a message to only three or 
four main ideas with sufficient background to avoid oversimplification (Hance et al. 1988).

Agencies should develop mechanisms to make the agency "user-friendly" to those outside the government (Chess 1987). When selecting an agency spokesperson, choose a person who is able to speak to the media, to the public, and to interested groups (Withers 1988). Agencies should establish internal policies requiring early release of information (Chess and Hance 1989). Agencies should also establish free, easily accessible telephone hotlines to control rumors and updates of the latest information (Covello et al. 1988a).

\subsubsection{Dealing with Uncertainty about Audience's Level of Understanding}

The best way to deal with uncertainty concerning the audiences' level of problem representation might be a top-down approach. Start with the highest level of the audience, establish shared understanding, and work your way down to the lower levels. Starting at the bottom and moving to the top may obstruct further communication efforts (Cvetkovich and Wiedermann 1988).

\subsubsection{Communications During Disagreements}

An important aspect of risk communication is to distinguish the level of debate: investigate the level of debate beforehand and design different communication program for each level (Renn and Levine 1988). Communicators should be aware that their and their audience's concept of "risk" differs from that of experts and that both concepts are legitimate and useful (Sandman and Peters 1988). Dissenting groups are more likely to express concerns in a constructive manner when there is a fair distribution of expertise among affected parties (Peltu 1988). Communicators need to adopt different communication strategies by carefully analyzing the nature of conflicts and distinguishing between different types of conflict (Covello et al. 1989). For example, distinguish factual disagreements from deeply rooted ideological conflicts (Covello et al. 1989).

Above all know your risk communication problems (Covello et al. 1989). Try to generate involvement by creating vivid, concrete images that the audience can relate to on a personal level (Covello et al. 1989). If possible, include information for the public in the planning process that focuses on resolving conflicts between expert and public risk judgments (Earle and Cvetkovich 1988). 
One of the main purposes of advertising and public relations is to frame the attributes of the subject matter in the most favorable light by emphasizing the positive aspects and minimizing negative ones. The use of these techniques can be of major significance to avoiding disagreements during risk communication activities (Peltu 1988).

\subsubsection{Use of Innovative Channels to Target Information}

To reach other segments of the public, use alternative, even unconventional, channels (see Table 6-1). For example, volunteers from teacher workshops, PTA meetings, and groups such as the Girl Scouts can help expand community awareness (Bolton 1987). The Utah CSEPP used Boy Scout Troops to disseminate public information brochures. To reach the scientific and medical communities, publish in medical or scientific journals, use the semi-technical press, and send speakers to scientific and regional conferences. When an issue is cloudy or controversial, have a media tour, have experts on radio and talk shows, and use editorials, newspaper articles, and bylined magazine articles (Callaghan 1989). Other related suggestions include developing a scientific newsletter when a risk issue is embroiled in controversy, organizing traveling seminars when the audience is dispersed, and using qualified professional writers for all communication efforts (Callaghan 1989). Flexible methods (slides, videos) are necessary for reaching different audiences. Include local touches to enhance relevance of material for the intended audience (Bolton 1987). Clearly such techniques would lend themselves to improving communications within the CSEPP.

Modern communication technologies also offer an unprecedented means for transmitting facts, knowledge, discussion, and ideas that help decision-makers become better informed, more participative, and responsive to issues than previously feasible. Presently, there is a need to examine how news media-from video text to personal computer networks, from communication satellites to fiber optics-are adding an interactive and feedback element that was absent from the one-way media communication channels of the past (Quarantelli 1989). 
Electronic Media

Radio Spots

Public Service Announcements

News Programs

TV Specials

Films/Videos

Slide Show

Records

Written Media

Ads

Feature Stories

Editorials

Special Publications

Pamphlets

Comic Books

Instructional Books

Flyers

Phonebook Inserts

Newsletter

Specialized Prompts

Signs

Stickers

Magnets

Calendars

Phonebook Cover

Community Outreach

Community Meetings

Focus Groups

Lectures at Civic Meeting

Door to Door Canvassing

Information Center

Kiosk

Displays in Public Buildings

Hotlines

\subsection{ENHANCING CREDIBHITY}

\subsubsection{Developing Credibility}

Credibility is a scarce resource for which different groups compete in communication process. Both trust and confidence are necessary conditions for the assignment of credibility to a source (Renn and Levine 1991). Credibility is also 
related to the perception the public holds of past performances both of the communicator and the institution.

To facilitate media relations procedures, assign a specific person as well as a back-up as spokespersons so that a quick reaction is guaranteed (Mitchell 1987). Institutional as well as individual sources of risk information could learn to be more effective communicators by avoiding jargon and being accessible to and cooperative with journalists. All efforts should be made to identify and eliminate barriers for effective communication (Sandman and Peters 1988). New as well as traditional means of communication (computers, videotapes) should be used to help people "find out how to find out" (Upton 1989). Lack of information creates credibility problems. Journalists need to understand that information becomes available at different points in time and should avoid demanding information that does not yet exist (Stockdale and Sood 1989).

To earn trust and credibility, be aware of factors that inspire trust, pay attention to process, explain agency procedures, be forthcoming with information and involve the public from the onset, focus on building trust as well as generating good scientific data, provide follow-up, make only promises that can be kept, provide information that meets everyones' needs, get facts straight, coordinate with other agencies and within the agency, avoid mixed messages, listen to citizens' groups, avoid closed meetings (Hance et al., 1988). Situations involving low levels of social trust require an explicit recognition that an agency faces both short- and long-run objectives that may be inconsistent and even in conflict (Kasperson 1986). We must restore public confidence in government's ability to anticipate and prevent accidents (Zimmerman 1987).

Agencies seeking credibility should develop internal policies requiring public participation. Management can also routinely raise questions about the adequacy of public participation during internal discussions of plans and policies; consider withholding approval of agency actions, programs, regulations, and policies that have developed without input from those affected; and take care to consult with the public before promoting their own policies (Chess 1987). Another suggestion is to encourage open communication within the agency (Chess 1987). Institutionalize early release of information (Chess 1987). For example, the Centers for Disease Control's (CDC) experience in carrying out the government's role in risk communication has been to tell the truth, the whole truth and nothing but the truth (Mason 1989). 
To overcome credibility problems, industry has to develop honest communication rather than propaganda (Long 1988). Case studies show that good neighbor relationships and sincerity coupled to appropriate constructive mechanisms work wonders for alleviating public concern and establishing communal trust (Morgan and Vlek 1988). Credibility problems have been associated with the "cry-wolf" syndrome. Thus it is important to design warning systems that can remain credible even if the threat does not materialize (Covello et al. 1989).

\subsubsection{Strategies to Enhance Credibility}

Several tactics have been suggested to enhance credibility efforts. Among the methods recommended is to coordinate and collaborate with other credible sources, such as third-party experts, have internal coordination with government agencies, and coordinate with other organizations that have similar interests. For example, cooperation between federal, state and university researchers should be maintained in order to develop wider expertise and to expand credibility (Gori and Hays 1987).

Another method to increase credibility is to establish relationships with community leaders (including media representatives) early in the communication program. However, agency personnel will need training before they can be expected to be spokespersons and reach out into the community. Enhancement of credibility requires continuous coordination and the perpetuation of network activities; a singular attempt will not suffice (Pavlova and Luftig No date).

Credibility is also a function of the individual within the organization. A spokesperson must be credible (Withers 1988). It is recommended that agencies use two credible senior spokesperson who understand the situation and can explain it to the lay public, provide details, and use correct, consistent, and current information (Lagadec 1987). Build on expertise, trust, and credibility. States Covello et al. (1989):

"People are more willing to accept a communication if the communicator is believed to be knowledgeable, respected, unbiased, and truthful."

To improve trust in a personal communicator, the major goal is to develop a communication climate that enables the audience to identify with the communicator and share his or her experiences and beliefs (Renn and Levine 1988). Confidence in experts is a key part of the risk communication process and this should be established early in the process (Zimmerman 1987). 
Risk assessors must be sophisticated in the risk and policy decision arenas in order to achieve reasonable fairness in communicating (Hattis 1989). Improve communications of the results of standard risk assessment by building trust in individuals who are undertaking analyses, preferably through Citizen Advisory Committees (CAC) (Konheim 1988). Public perception of fair treatment is critical to effective risk management (Long 1988). Journalistic and public relations skills can be of great value to all communicators and can be as influential as the distribution of other forms or expertise among actors (Peltu 1985). Reports Slovic (1986):

"To be credible and trustworthy, a communicator must know enough to acknowledge valid criticisms and to discern whether the available risk estimates are valid enough to have value for helping the public gain perspective on the dangers they face and the decisions that must be made."

Conditions in which risk comparisons may be useful is when the source is credible and neutral (Sandman 1987). Risk communication suggests that communication by experts is the key to trust but experts themselves need to be educated about their own biases and adopt the existence of competing cognitive systems for evaluating risk (Jasanoff 1987).

\subsection{INVOLVING THE PUBLIC}

\subsubsection{Programs for Enhancing Public Participation}

A variety of model programs have been designed to improve risk communication efforts. Alternative model programs to improve risk communication efforts include establishment of a local liaison committee, an independent advisory committee, an office of technology assessment, a local environmental risk ombudsman office or a community risk communication office; each help to increase citizen participation albeit through different methods (O'Riordan 1988). Public and intervener group pressures have also been a significant factor in focusing regulatory attention on industrial risk, making public opinion, as expressed through various participatory approaches, an important ingredient in determining regulatory outcomes (Otway and Petu 1985). 


\subsubsection{Community Involvement}

In general communicators should involve the community as soon as possible in implementing a program. It is important to recognize the importance of community input and involve the community in decision-making process by clarifying the public's role from onset, acknowledging situations where an agency can give a community only limited power, and finding out what levels of involvement communities actually want (Hance et al. 1988). By involving the concerned publics from the earliest possible stage, the public knows what the agency plans. Often in the process the agency goals become their goals with the outcomes more likely to be comprehended and accepted (Mason 1989). Activities aimed at informing the public should occur early on, and continue throughout the consideration and decision process (Kasperson 1986). It is important to involve local citizens in environmental studies from design stage onward to improve program design and performance (Ozonoff and Bowden 1987). Involve local citizens in the design of programs aimed at providing disaster warnings and emergency information (Covello et al. 1989). Involve community groups in drafting evacuation and sheltering plans (Covello et al. 1988a). Information from simulation exercises should be shared with the public (Black 1989). Finally, it is important to leave room for alternatives proposed by those directly involved with or affected by the decision (Covello et al. 1989).

Using a two-way symmetrical approach in which the communicators and the public are considered equals facilitates communication efforts (Grunig 1987). One should acknowledge the community's outrage in understanding their perceptions of risk (Neutra 1989). For example, by giving communities a substantial role in suggesting what tasks need to be accomplished, a California state agency established an on-going and valuable relationship with community members (Neutra 1989). It is also important to educate emergency managers on the various requirements of different groups, such as local populations, news media, and the distant mass media (Stockdale and Sood 1989).

To build a successful risk communication program, communicators should accept and involve the public as a legitimate partner with the goal to produce an informed public that is collaborative (Covello et al. 1988b). By listening to an audience, a risk communicator can distinguish what concerns people in the community. Communities are often more concerned about such issues as trust, credibility, control, competence, voluntariness, fairness, caring, and compassion than about mortality statistics and the details of quantitative risk assessment (Covello et 
al. 1988a). To avoid conflict, communicators should attempt to involve the public early in the decision-making process before critical assumptions have been made, alternatives narrowed, key decisions made, and before decision makers have become committed to a particular course of action (Covello et al. 1987). The usual strategy of simply reducing anxiety may not be consistent with educating the public about risks, helping then to identify their personal risks, or helping them to improve their perceptions about relative risk exposures (Johnson and Fisher 1989).

\subsubsection{Gaining Feedback from Communities}

Risk communication should be looked at not only in terms of how accurate, detailed, or intelligible the information is but also in terms of how the information will be interpreted by the receivers (Fessenden-Raden et al. 1987). One way to gain instant feedback from the public and to set the stage for continuing dialogue is to use open public meetings (Collagen 1989). Alternative models for public input (other than public hearings) include setting up informal meetings, hotlines, communitybased task forces, and "out-of-office hour" (Chess 1987). Holding routine informal meetings with representatives of community and environmental groups outside of crisis situations aids in gaining feedback from the community (Chess 1987).

To improve communication with the public, agencies should develop mechanisms that make an agency approachable. Agencies should discourage "bouncing of callers" by agency staff (Chess and Hance 1989) and have communication experts assist technical and policy staff to interact effectively with communities. Most people prefer to talk directly with people making technical and policy decisions (Chess 1987).

Within the agency, senior officials should clearly mandate public involvement in decision-making (Chess and Hance 1989). Risk communication should be regarded as a reciprocal process of interaction between information disseminators, decision makers, and local people (Diggs 1988). In a controversial dioxin case, effective communication techniques included early high-level involvement with the governor and an EPA official, recognition that priority for monitoring of health hazards should be given to people at risk, referred to outside experts, the immediate release of data when it became available, involvement of local officials and agencies, frequent briefing of the press, and regular one-on-one contact with residents. Other tactics included providing advance information about monitoring and clean-up activities, avoidance of large public meetings in favor of a small, individual, or group 
sessions, and making available to the public a sufficient number of press and community relations specialists (Marshall 1989).

Feedback is particularly important when the communication structure is designed to be one-way. A better understanding of cognitive structures and processes is another important condition for successful risk communication, especially when communication is one-way (Jungermann et al. 1988). It is important to provide information to audiences in ways that will be meaningful to them (Mason 1989). Tell people what they ought to know, answer their questions, and provide instructions for what they need to know (Sandman 1987). For example, when issuing disaster warnings and emergency information, communicators should provide concrete information about specific actions individuals can take.

To be effective, information about risk reduction must be direct and explicit enough to make clear what is necessary. Communication must teach by word and mouth and not by euphemism and implication (Keeling 1987). Telling the public not to worry about a public health concern does not help if agency staff are seen moving their families out of the area. Strategies for improving risk communication should be aimed at increasing the learning potential both for both regulator and the public and improving public long-term education about risks (Keeney and vonWinterfeldt 1986). In this context, communicators must be clear in their own minds that the process is one of negotiation rather than manipulation (Kauffman, 1986).

\subsection{ORGANIZATIONAL CHANGE}

Internal policy changes within organizations may improve risk communication processes. Assign communication staff to amplify community concerns within the agency and to bring community needs and concerns to the agency "before communities feel the need to shout" (Chess 1987). Create communication positions at all levels of the agency to promote interaction with communities (Chess 1987). What is important is that organizations devote resources and top-management attention to crises communications (Shrivastava 1987). Chess (1987) offers these suggestions to enhance communication efforts within organizations: 
- Consider communication abilities and experience when developing job descriptions and in hiring decisions so fewer staff members are "communication averse";

- Coordinate communication functions within the agency using a mechanism such as a communication office that serves as a resource to the agency, facilitates consistency, reduces duplication and handles a limited number of programs outside program boundaries;

- Disseminate information about risk communication successes through an internal "good news letter" and working group;

- Involve communication staff in developing (not just transmitting) policy;

- Provide information about risk communication in orientations for new staff or in the hiring process;

- Provide training through in-depth workshops for agency staff on handling public meetings, dealing with the media, developing communication plans, and reward staff communication efforts;

- Make organizational objectives for involving the public clear from the beginning;

- Require funding for communication efforts in project budgets;

- Use innovative means to resolve disputes so citizens have alternatives to taking to the courts or to the street. Suggestions include developing internal ombudsman positions or offering negotiation or mediation that involve neutral outsiders.

Changes in internal policies can improve communication crisis. For example coordinate disaster warning systems of different organizations; establish a centralized communication center at onset to collect, analyze, and interpret all disaster-related information and manage all disaster communications (Covello et al. 1988a). Devote resources to resolving uncertainties and expert disagreements about what constitutes an effective and efficient response to emergencies; organize a crisis management team or task force at onset to coordinate all disaster-related activities and communications (Covello et al. 1988a).

An emergency public information staff should be top quality; they should be able to transfer from normal operations to emergency operations smoothly and efficiently. To respond to emergency activities and to service the company's own interests, a company must develop a comprehensive corporate emergency 
communication program that involves the entire company, not the public relations personnel (Goldman 1986).

An example is provided by recommended shifts in policy within the USGS hazard program. One suggestion was to provide a coordinating mechanism within the Office of Earthquakes, Volcanoes and Engineering to continue exploring social science applications of USGS hazard and risk information. Hazard warnings and notifications issued between 1976-1986 were to be reviewed with social science participation and a feedback process established to develop recommendations for improvement. It was also recommended that a few key projects to assist USGS scientists in improving communication with key users and decision makers should be undertaken (Gori and Hays 1987). Federal, state and local networks should be established in areas where hazard detection research is taking place and where hazard warnings are a possible outcome of research (Gori and Hays 1987). It was also suggested that the USGS needs to recognize and reward individuals who are responsible for interacting with the public and state and local government (Gori and Hays 1987).

Policy makers should determine at the onset whether their response to a hazard, such as radon, should be consistent with the implicit objective of the conventional standard-setting approach or whether the facts and context of the radon problem justify a more radical policy change (Johnson and Luken 1987). Agencies must frequently address multiple conflicting policy objectives. In such cases interdisciplinary teams may be needed to address risk problems as no single person can be expected to be an expert in all disciplines (Keeney and vonWinterfeldt 1986).

Government can alter its institutional processes or the process by which risk is communicated by broadening the risk communication processes to include generic forums that precede project development. Forums are needed to assess the need for a facility independent of any proposal. Risk communication should address an agency's or sponsors' overall expertise and standing in the area of risk analysis and environmental decision making prior to any site-specific proposal (Zimmerman 1987). A prerequisite for effective communication is a procedural and institutional framework for decision making that encourages participation and inspires trust (Jasanoff 1987). 


\subsubsection{Issuing Warning Messages}

To improve on short- and long-term information the issuance of warnings and the communication of hazards should be seen as a process, not as a single act (Mileti and Sorensen 1988; Gori and Hays 1987). Warnings must be well thought out with messages drafted and tested in advance of needs (Gori and Hays 1987).

Ten factors have been documented as being important to issuance of a good warning (Mileti and Sorensen 1987; Sorensen, Mileti, and Vogt 1987). First is the source of information. People have different views about who is credible and who is not and any one source will not be perceived as credible by an entire population. A warning message which contains endorsements by a mix of scientists, organizations, and officials is more likely to be considered credible. Emergency public information or warnings that are credible and reliable to the people receiving them are more likely to stimulate response.

Second, a warning message is more effective if it is consistent in the information given and the tone used to convey the message. Inconsistency in the tone or information is a message creates confusion and uncertainty among recipients (Segaloff 1961). Consistency in the way the message conveys information about the level of risk is also important. For example, a message that states that something is happening but there is no cause for concern is less effective than one that states how concerned people should be in light of the situation.

Consistency among multiple warnings is also a determinant of understanding and belief. In a study of the Rio Grande Flood, Clifford (1956) found that inconsistent information caused confusion and people were less likely to understand or believe that a flood was going to occur. Fritz (1957) reached the same finding in a study of warning responses in a wide range of disasters.

Third, accuracy of the information also affects understanding and belief. For example, Mileti et al. (1975) state that past errors in disaster warnings can cause people to be less likely to believe subsequent warnings.

Fourth, the clarity of the emergency information is important. A warning message that is worded clearly in simple language is more effective because people are more likely to understand what is happening and what they should do about the situation. A lack of clarity in a message can lead to people misunderstanding the message or ignoring it.

Fifth, a message that conveys a high level of certainty about the events taking place and what people should do is more effective than a tentative one. Even 
if there is a low probability or the situation is ambiguous, messages can vary in their level of certainty (even about the ambiguity). Certainty determines the level of belief in a warning and affects decision making. In a study of response to earthquake prediction, it was found that warnings become more believable as the probabilities attached to them become greater (Mileti et al. 1981). If warnings are certain, people are more likely to evacuate.

Sixth, the level of detail of the information in a message influences evacuation decision. Not knowing or feeling that one has insufficient information on which to act creates confusion, uncertainty, and anxiety. If messages contain insufficient information, the public's response is to fill the information void. This can promote rumors or uniformed misperceptions or fears. The amount of information provided affects understanding, personalization, and decision-making. A study of family response to hurricane and flood warnings conducted at the University of Minnesota found that general and vague warnings caused people not to take protection actions (Leik et al. 1981). In a study of response to the Mount St. Helen's eruption, it was found that a more detailed information led to higher levels of perceived risk, and therefore to protective action being taken (Perry et al. 1982b).

Seventh, messages containing a clear statement of guidance about what people should do about the event being described and how much time they have in which to act are more effective than ones that don't provide specific instructions. Guidance is often necessary to encourage people to take the proper action. A study of the Big Thompson Canyon Flood (Gruntfest 1977) found that people who received warnings during the flood were not necessarily advised on what to do. As a consequence, many who were warned attempted to drive out of the canyon and were killed.

Eighth, the frequency of public messages influence evacuation behavior. People frequently do not evacuate after hearing one warning. Frequent information is thought to reduce anxiety created by not knowing when one can confirm what is happening or learn more details. In addition, frequent messages reduce the effect of misinformation and misperceptions. Frequency affects hearing, understanding, believing, and deciding, and is thus important at most stages of response. Numerous studies underscore the importance of repeated hearing of a warning as a condition for response.

Ninth is the specification of location in the message. Emergency warning information should clearly state the areas affected or potentially affected by the event. Identifying a location is important in determining belief and personalizing a 
warning. For example, Diggory (1956) found that the greater the proximity to a threatened areas, the more likely a message will be believed. Other studies show that more location-specific messages lead to greater levels of personalized risk (Perry and Greene 1983).

Tenth, the channel of information plays an important role in warning response. Effective warnings use a range of possible channels instead of a single channel. This helps in reaching as many people as possible in a short amount of time. Personal communications are generally more effective at getting people to rapidly evacuate than media or sirens (Mileti 1975; Gruntfest 1977).

\subsubsection{Warning Message Techniques}

It is important to provide precise, unambiguous information on actions people can take to protect themselves and their property in an emergency (Covello et al., 1988a). Messages should be presented with clarity, certainty, accuracy, specificity and frequency (Mileti and Sorensen 1988). Disclose disaster or emergency information fully and promptly presenting disaster and emergency information in context of concrete events (Covello et al. 1988a). Stagger the provision of evacuation information and provide frequent updates and briefings about disaster situation (e.g., the geographic area affected, the population at risk, alternative escape routes) (Covello et al. 1988a). Develop disaster awareness campaigns that educate, not frighten, the public (Covello et al. 1988a). Provide specific information and actions that people can use in preparing for a disaster or during an emergency (Covello et al. 1988a).

Be honest, frank and open in communicating risk information. Trust and credibility are most precious assets-difficult to obtain and once lost, almost impossible to regain (Covello et al. 1988b). The need for clearer and more effective communication should be prime consideration (Brower 1986). Formulating a message on risk requires maximum accuracy and minimum gimmickry; communications will not occur in a vacuum; make sure the same information is being conveyed to all audiences (Collagen 1989).

\subsubsection{Program Evaluation and Feedback}

No matter how well a communicator or agency believes the communication program is progressing, some outside feedback is necessary for an unbiased 
evaluation. A good risk communication program encourages evaluation of communication efforts (Chess 1987). A number of ways exist to do so. A simple method is to obtain feedback from audiences (Bolton 1987); evaluate performance and learn from past mistakes (American Chemical 1988; Covello et al. 1988a). Agencies need to pay greater attention to understanding how the public interprets the scientific bases of their proposals. Just as the public may need to improve its comprehension of the science behind proposals, officials need to improve their understanding of what concerns the public (Chess and Hance 1989). It has been suggested that communicators should evaluate performances in terms of different goals because audiences and media require different risk communication strategies (Covello et al. 1988b). Agencies should develop case studies of effective risk communication and publicize success stories (Chess and Hance 1989).

Different types of evaluation have varying levels of reliability. For example, findings from focus groups are qualitative (which cannot be generalized to a population) and need to be buttressed with quantitative measures of effectiveness (Desvouges and Smith 1988). However, such findings can also provide immediate feedback.

Provisions should be made to ensure evaluation results are explained and disseminated to improve risk communications (Kasperson and Rohrmann 1988). Decide on criteria for evaluation and implement the plan with appropriate follow-up measures (Bell 1989). Ten criteria for evaluating risk communication programs include: performing a needs appraisal; capturing how the program deals with risk complexity and social pluralism; examining the context of the risk; assessing the comprehensiveness of the program's efforts; assessing the timeliness of the communication; assessing the interactiveness of the communication process; assessing the transfer of power; assessing ethical issues such as unintended adverse consequences; and assessing whether the program attempted to anticipate failure (Kasperson and Palmlund 1987).

\subsubsection{Evaluating Information Programs}

In the previous section it was pointed out that evaluation is a necessary component of program planning. In designing a communication program, communicators need to incorporate citizen input in the development and evaluation of public information programs (Roesner and Russell 1987). A broad range of interests should be consulted and involved in the design and implementation of an 
evaluation program (Kasperson and Rohrman 1988). For example, EPA policy includes forming a community leaders network at the onset of a risk communication project and incorporating evaluation strategies at that time- (Morgan and Vlek 1988).

To gain the greatest level of citizen participation in evaluation, pretest all education materials and provide a time frame for releasing information. If the date is missed, give the public an explanation. It is important to differentiate between former and current risk problems and provide information about the possible range of issues that concern citizens (Pavlova and Luftig no date).

\subsubsection{Checklist for Program Evaluation}

The following checklist (Table 6-2) provides a simple means of reviewing a risk communication program to evaluate its adequacy. Bear in mind there is no "ideal" method to judge adequacy or effectiveness.

Table 6-2 Checklist for Reviewing a Risk Communication Program Assessment of Content: For each activity assess the following.

1. Nature of the hazard.

2. Range of accidents.

3. Consequences of accidents.

4. Risk of accidents (probability).

5. Geographical distribution of threat.

6. High vulnerability groups.

7. Protective actions options.

8. Criteria to use protective actions.

9. How to implement actions.

10. Source of a warning.

11. How a warning will be made.

12. Pre-warning actions to enhance response.

13. Where to get more information.

14. Benefits associated with risks.

Assessment of Style: For each activity assess the following.

1 . Is the information clear?

2. Is the information specific?

3. Is the information accurate?

4. Is the information consistent?

5. Is the information conveyed with certainty?

6. What is the general conceptual approach used?

7. Who is the target audience? 
Table 6-2 continued

Assessment of Overall Program:

1. Is there a mix of information activities to inform different subgroups of the population?

- transients?

- foreign language speaking?

- institutional or otherwise impaired?

2. Does the program use different "sources" to enhance credibility?

3. Is the information consistent across activities? 


\section{FINDINGS AND CONCLUSIONS FOR THE CSEPP}

\subsection{INTRODUCTION}

In this final section we examine the recommendations in the research literature and current guidance manuals available to risk communicators, planners, agencies, and emergency personnel. We also return to address the questions about risk events posed earlier and to examine some issues pertinent to the CSEPP.

Although there are a number of recommendations made without empirical validation in the how-to literature, some methods appear significantly related to the solving of basic risk communication and to problems related to the CSEPP.

\subsection{CITIZEN'S RIGHT TO KNOW}

Democratic participation in the United States includes the inherent right of citizens to obtain relevant information about risks when they want that information. Right-to-know is embodied in both legal and ethical principles. This does not imply that citizens must use that right or that non-use implies consent or acceptance of the risk. Individuals differ in scope and public commitment that results in different interests and involvement in issues over time. The variations require different communication strategies in the CSEPP to maximize the effectiveness of emergency protection for affected populations. Communicating risks on a potential accident from the stockpiled chemical weapons needs to be done on an on-going basis until the munitions are destroyed. This is not a public relations incentive, but a public information program designed to provide the public with accurate, up-to-date information on risk issues.

\subsection{ACCURATE INFORMATION ON RISKS}

The second doctrine proceeds from the same democratic principle for right-toknow-that those who know or who suspect that they generate risks to a population have a fundamental duty to inform the affected parties about those risks. These two basic positions lead to a third conclusion. Those who communicate the risks to affected parties 
are obligated to make that information as accurate and as relevant as possible to facilitate understanding of the risk and the consequences.

It is a false assumption to conclude that generating and disseminating factual information is enough to satisfy right-to-know principles, or even that facts satisfy the basic requirements for risk communication in general. In the truest sense, risk communication is an exchange of information or a dialogue between those that generate the risk and those that bear the risk through direct or indirect consequences. As noted in the following discussion of the questions presented in Chapter One, current implementation of this concept is not an exact science nor is it solely an art. There is no panacea to replace misguided efforts with a instant solutions. If trust has been lost in the past, the acknowledgment that both discussions and people can change may be difficult to admit for all affected parties, including communicators.

\subsection{PRE-EMERGENCY COMMUNICATION PROGRAMS}

As previously noted, risk communication covers a broad range of activities and timescales. One such activity is providing information and education to the public about potential accidents, including the nature of the hazard, ways of mitigating losses, and protective actions to take in an emergency. A second activity is providing emergency warnings to the public when an event is about to occur or is taking place. Other activities may also involve explaining an event to the public, even when no actual risk occurred to populations off site. Another way of describing these two functions is pre-emergency risk communication and emergency risk communication.

A risk communication program should provide as much relevant information as is possible to get the message across. This includes:

- providing information on the hazard, including how it was identified and assessed,

- information on responding to the hazard, and,

- information on the management of the hazard.

Relevant information to include on the hazard per-se covers the general nature of the hazard, when the hazard can occur, the range of events, the consequences of events, the probability or frequency of events, and the geographical distribution of hazard.

Information on response includes defining protective action options, how to implement 
the actions, pre-warning actions that can be taken at home to enhance response, and alerting groups particularly vulnerable to the hazard, such as pre-schools. Hazard management topics include identifying credible sources of a warning, how a warning will be made and carried out, coordinating protective action decision processes, and finding sources to further information about the risks (enhancing media relations, giving talk to civic groups, etc.). The style of the information presentation is best when communications are clear, specific, accurate, consistent, certain, and provide sufficient detail.

It is well documented that an overall risk communication system must have a mix of information activities and channels to inform different subgroups of the population about the risks. Among the subgroups that are often overlooked are mobile groups (travelers, recreationists, daily employees), individuals who only speak a foreign language, ethnic groups with different cultural norms from the residents, and institutional populations or groups with specific constraints, such as the physically or mentally impaired. It's also important to identify those persons diffused throughout the general population that may have difficulty responding on their own (the mobility or physically impaired).

Different sources of information serve to enhance credibility about the potential risk because any single source is not universally credible to all people. While official sources, such as the sheriff, may be considered highly reliable in one location, other sources, such as a respected priest, may have more influence in other locations. In addition, the information in a multi-faceted program must be consistent across various activities.

While the style and content of programs designed to provide general information as opposed to emergency information overlap, the mechanisms for diffusing information are more varied than similar. Emergency communications require a very rapid dissemination time designed for maximum short-term impact. On the other hand, preemergency mechanisms require a more restrained effort that must be maintained over time to stimulate understanding of the risk, not response. As a result, the format for emergency information will vary. It is important, however, that the content of emergency communication be built on and be consistent with the pre-emergency programs.

Six general questions about the interrelationship between pre-emergency and emergency communications that risk managers should be concerned with are addressed. 
- Does pre-emergency information reduce losses in a disaster by affecting the adoption of precautionary measures and taking of adaptive behaviors?

In reviewing the empirical evidence we do not have a conclusive answer regarding whether or not a program actually makes a significant difference in reducing losses. Our most reasonable interpretation of the evidence, when considering the empirical and anecdotal events and practical wisdom, is that a good pre-emergency information program will reduce loss, although the specific amount cannot be estimated. Conversely a poor program will not likely make a great overall difference. Any program, when we shift to the individual as the focal point of attention, can impact an individual's behavior in an emergency. It is therefore important that a program minimizes the likelihood the program will create greater risks for the individual.

- How much information is enough?

There are no precise guidelines on how much information is needed to produce benefits from the program. It is clear that a program cannot provide either an overly simplistic amount of information nor an inundation of information. Most officials, however, underestimate the amount of information that the interested public will want. This suggests that a program needs to provide various levels of information geared towards differing desires of the public. In both pre-emergency and emergency communications the maxim should be, when in doubt give out more information. The idea of an information overload seems to less problematic than that of an information void.

- What are the most effective combinations of information format and contents?

Again there is no precise formula for designing the ultimate program. The literature suggests that one should not rely on a single mechanism for disseminating information. Rather, a program needs to have multiple formats and styles, but which conveys the same information content.

- How should information be targeted to different sub-groups in society?

Information definitely needs to be targeted toward differing subgroups of the population. People will have varying definitions of what is credible, what is 
understandable, and what will be remembered. The most important factors to consider in targeting information are age, language, and cultural differences. Targeting can be achieved through a mix of information sources, channels and contents.

- Does provision of information have unintended negative results?

Often officials are reluctant to provide information on risks to the public because they believe it will unnecessarily alarm people or produce negative effects. The idea that "crying-wolf" will decrease protective actions in future events which may be more critical has been shown to be false. There is no evidence to suggest that such effects actually occur. Instead such comments are probably excuses for not providing information. Furthermore, no evidence exists that information will have a negative effect on response to a hazard, even though the potential theoretically exists.

- How often does information need to be updated and repeated?

The most effective programs are ones that are repetitive and provide information on an ongoing and updated basis. There is no substantive basis for suggesting how frequent a program must actively reinitiate efforts to communicate with the public. A single or one-shot effort, however, will likely have few benefits or impacts, unless the situation is clearly catastrophic.

\subsection{IMPLEMIENTATION OF FINDINGS INTO STRATEGIES FOR THE CSEPP}

In this section we return to the questions introduced in Chapter One in light of the findings and recommendations from the study. Although not totally inclusive, the questions reflect the various issues that can arise in agency efforts to communicate risk information to affected publics or in activities involving the management of a crisis, presentation of a risk assessment, or negotiation of risk mitigation strategies with concerned communities. It is not our intent to answer the individual questions posed as each answer is unique to the specific situation and site. Instead, our intent is to provide a context in which a strategy to deal with such questions can be developed. 


\subsubsection{First Question}

The first issue related to a storage tank of agent (HD-mustard) found leaking into the soil by agency personnel conducting a routine site investigation in a remote area of an Army depot. Although it was unclear when the leak occurred or how long the agent had been dispersing into the environment, the damage appeared related to the deterioration of a valve on the container holding the agent and probably would have leaked for only a short duration. After discovery, the release is reported to the EPA which is uncertain about possible health effects. The issue for the EPA and Army personnel involves communicating a possible risk to the public most likely affected. A related issue for both agencies is dealing with the media which may escalate the local issue into a national problem.

\subsubsection{First Question: Discussion}

Waiting for positive scientific confirmation of data to notify the public about possible health risks can devastate agency credibility, impair subsequent risk assessment efforts, and obstruct future risk management strategies, especially when the public perceives an agency is "foot-dragging." The public will construe the agency as incompetent, unprepared, faltering, deficient, or hesitant. Yet disclosing information of unconfirmed but potential health risks is problematic at best. Since the leaking agent was discovered by Army personnel, the situation could be interpreted by both the public and the media as the "tip of the iceberg" of a larger, existing problem kept hidden from outsiders for an undisclosed period of time. The uncertainty can lead to rumors and media sensationalism.

There is the additional concern of "crying-wolf" about a problem which in all aspects appears benign within the present confines of the investigation. If the release is within the category determined insignificant by legal standards, that is, when emissions are not required to be legally reported, agency management may assume that it is pointless to alarm (or overload) the public with such insignificant information. The debate then centers on the public's right-to-know versus need-to-know, an often bitter issue in risk communication.

From the empirical research it is clear that managing any potential risk involves both forthrightness and considerable diplomacy of agency personnel. To manage the immediate threat to credibility, both the public and the various media outlets should be kept adequately informed, in fact swamped, with all available related information. 
In addition, credibility can be enhanced through agency actions that include:

- informing local officials as one of the first steps;

- the use of high-level management personnel as spokespersons;

- the rapid deployment of information through media and other sources such as informal or targeted community groups;

- admitting uncertainty and/or refuting rumors when necessary;

- involving the community as early as possible in the decision-making process about possible risks, including the consequences of the immediate or delayed risk management decisions;

- listening to the audience and not making assumptions about what people do or do not already know or want to know.

Although risk statistics carry neither positive nor negative value attachment, risk is most often viewed as having unfavorable consequences for the individual or group involved. Thus risk in the context of communication activities often takes on an adversarial perspective, resulting in misinterpretation and confusion as to the desired outcome of the communication. Recommending that an outside agency or third party assess the problem and the associated risks may enhance the credibility of the agencies involved as perceived by the public. Coordinated messages on the risk disseminated through many different channels at once are also effective in gaining attention and interest.

Positive media reporting has been found to reduce stress. The ability to gain the media's sympathetic attention can thus facilitate communicating the risks to the publics involved. Prior networking with media representatives can also help overcome some of the inaccuracies in media reports that stem from misinformation or lack of environmental education on risks and hazards. Making information packets available that describe the situation and provide names of third-party experts to help explain technical terms increases agency credibility while decreasing negative publicity. Having agency personnel readily available-with no "bouncing" of callers-to answer questions also improves credibility. Thus planning involves active commitment of resources to enhancing efforts to communicate risk issues by agency personnel. 


\subsubsection{Second Question}

The second question relates to a different mode of discovery of a potential health threat. A local farmer perceives a problem exists with water from a well located near the perimeter of a military base where large tanks of chemicals are being stored. In addition, several of the farmer's livestock have died for unexplained reasons. The farmer charges that agents leaking from the storage tanks into a nearby stream during heavy periods of rainfall are the cause of the problems. The local health department has investigated and found that some problems with the tanks do exist but the possible health effects to both humans and animals remain unconfirmed. The issue for the health agency is how to communicate uncertain findings to the public without raising alarm or unjustified concerns about health from the media, but which contain enough information to alert the public to possible health problems. In addition, the uncertainty about health affects may never be resolved because causation may never be determined.

\subsubsection{Second Question: Discussion}

The question reflects a growing concern among segments of the public about institutional integrity as well as competency. To influence public perceptions of an agency's credibility requires the build-up of trust over time with attention directed toward community involvement and the acknowledgment of public fears. When faced with uncertain findings, the best interests of both the agency and the public are served by publicizing the results as quickly as possible, readily admitting the uncertainty, and explaining the basis for the uncertainty.

There are several reasons for explicitly addressing the causality of the livestock deaths when discussing uncertainty. One, agreement on causality (e.g., the 'root cause') is often lacking among experts in making risk assessments. Admission by the agency that uncertainty exists provides not only a method for reducing criticism, but offers the opportunity for public involvement and input. In this case it may be possible to encourage farmers to assist in collecting information that may solve the mystery. Secondly, credibility is threatened through delay and not acknowledging potential guilt. Since time will be needed to determine the risk involved, as well as strategies to manage the threat, agency credibility will be enhanced if the public perceives the agency is actively searching for means to alleviate a possible threatening situation. Thirdly, rumors can be more easily refuted when the problem has been admitted and channels are open for dialogue 
on the risk. Strict denial of any causal link with be seen as an attempted cover-up of the truth and an unwillingness to get to the bottom of the problem by agency personnel.

The decision to require further testing or data collection before arranging to deny, reduce, or eliminate a risk is a valid concept understood by the majority of the publics and media outlets. What is not condoned is refusal of an agency to examine possible hazards whether they appear significant or otherwise. To place the problem in perspective and help reduce negative rumors about risks, hazard information should be launched as soon as possible after a local occurrence of a hazard has been reported. The actual report of the event will generally increase sensitivity to the hazard and subsequent risk communication efforts may have a more positive impact on public perceptions of the threat itself.

It has been found that the multiple dimensions of hazard-risks, benefits, costs, and environmental impacts-do not converge into a single concept in the public's mind (Cvetkovich and Earle, no date). Neither have measures of risk-mortality, morbidity, and loss-been found related to information seeking or to the acquisition of mitigation knowledge by the public. Thus agencies must be sensitive to other aspects of risk communications rather than focusing solely on the objective considerations.

To determine what or how much information will be most useful to the publics involved, audience interest should be surveyed to determine the nature of specific concerns and to ascertain the mental models of causality they are using to describe the problem. These factors as well as attitudes toward governmental desire to control hazard and to communicate with the public were found significantly related to information seeking or acquisition of mitigation knowledge.

The problem of uncertainty is not a question of how much information should be conveyed but how to provide the most useful information without tying up agency resources unnecessarily. The objective of risk communication is to provide data for informed decision-making among all involved parties-risk generators, risk bearers and governmental or other involved entities.

\subsubsection{Third Question}

In the third question there is consensus that the legality of the actions are not in question. In this instance a small release of agent occurs during on-site incineration of a chemical weapons. The release is within normal exposure limits and the installation commander decides not to notify either the local health agency nor to inform the media or the public about the release. Two days later the press learns of the release and accuses 
the installation of 'cover-up.' The agency immediately loses credibility in not reporting the release to the public. How to overcome the loss of credibility then becomes an issue in communicating about the risk for the specific release and for future communication efforts.

\subsubsection{Third Question: Discussion}

The issue of credibility involves timely disclosure in releasing information to the public. Change is not likely to occur in the media's perceived responsibility as gatekeepers or alarmists for agency actions. Plans prepared by an agency prior to an event, no matter how remote the occurrence, can alleviate delay and confusion in responding to such criticism. Having high-level spokespersons available to speak competently about the situation helps dispel the aura of agency ineptitude.

The goal of risk communication should not be to discredit the possibility of a risk or to avoid risk communication. Instead it should be to prepare other government agencies, the media and the public to the possibility of an incident. In this case the media and others should have been brought to the understanding that such an incident may occur despite low consequences or even probability. While this flies in the face of the normal wisdom of an agency which wants to only tell the public that a technology is safe, it is more in line with what the public expects from a credible organization. Accepting and involving the public as a legitimate and concerned partner in risk decision-making means the public should not be manipulated into accepting decisions that were made internally by agency management or through decisions designed to avoid further action.

Discussing forthrightly why initial decisions were taken not to inform the public can educate citizens in the risk management process, creating a more informed public able to distinguish levels of risk and consequent exposure. The aim of risk communication efforts is to provide information that empowers citizens to make knowledgeable decisions. Nor should the opportunity be overlooked following the exposure to inform the public about future risk and management strategies when media follow-up reports provide the chance to insert appropriate material for public education. The key is being able to provide material suitable for media needs with consideration on the agency's part for the constraints imposed on journalists by deadlines and other requirements, such as having access to experts themselves. Having prepared information packets further suggests agency competency in handling such situations. 


\subsubsection{Fourth Question}

The fourth question includes the spectacular event involving a terrorist group's threat to release stored toxic chemicals through detonation if their demands are not met. Reporters anxious to cover this spectacular event immediately focus on negotiations while agency officials fume at the interference. The terrorists' manipulation of media representatives and agency personnel is evident as demands remain unmet. Meanwhile the risk to the public remains uncertain with a magnitude of potentially unparalleled threat both for the institution and to the surrounding community.

\subsubsection{Fourth Question: Discussion}

The most dreaded event for any agency is an unanticipated threat of unknown and potentially enormous magnitude that creates immediate convergence of representatives from various media outlets. From all accounts, we know that the media personnel will converge on any event that smacks of newsworthiness, especially if the event appears to have associated sensational factors. Moreover, the media may well interrupt actual negotiations or other planned agency strategies during the event.

Having a plan prepared for such emergencies with specific persons assigned to a public relations team and qualified and experienced personnel available to act as credible spokespersons is crucial to the eventual outcome. As Scanlon points out, both the agency and media frequently end up as hostages in such events.

Coordination among staff members and agencies associated in the event affects the public perception about correct handling of the situation. Having single spokespersons respond to media requests and discussing items internally before release to the media decreases conflict and helps maintain agency credibility. That single spokesperson, however, must get the message out through a variety of channels and elicit the support of credible sources of information to verify and confirm the official posture.

Providing information about the possible risk also educates the public about other consequences from a similar threat and can establish a framework for future discussions of risk issues should another volatile situation occur. It is also possible that some segments of the public may perceive the event as one demanding unusual outcomes such as entirely removing the risk source out of the community. Thus it is important to inform the public about agency constraints and responsibilities to avoid future confusion or antagonism. Agency spokespersons must be directed and forthright in approaching 
the public which requires preparation prior to such a situation, complemented with adequate resources and direction from higher level management.

\subsubsection{Fifth Question}

In this question no accident has occurred but citizens are demanding to have access to classified information about the quantities of chemicals stored at a military base adjacent to their community. In addition, citizens want information about the probability of accidents and/or releases from stored chemicals. The Army's official response is "We can't tell you-it's classified information." The response enrages the community while the base authorities feel unfairly blamed for the situation.

\subsubsection{Fifth Question: Discussion}

One of the most difficult situations that military base or agency officials must face is having to deal with a citizen group seeking information that cannot be revealed to them because the information has been "classified." Given the fact that the military is a public institution designed to protect citizens, the response is often interpreted with anger and charges of bureaucratic intimidation. Until such information is publicly available, communities will continue to feel like second-class citizens. The best solution is to allow citizens access to the material, an action that will need to be accomplished largely through agency or institutional change. Failing this, an alternative strategy would be to explain to the public the security need for the classification and the associated benefits as well as limitations.

\subsubsection{Sixth Question}

This question involves an actual exercise that is required by FEMA. Local officials must provide the media with reliable and accurate information about why the exercise is being conducted and what the potential risk is from various chemical accidents. Media representatives promise to present the information to the public, but officials are skeptical that local distrust will alter the material provided. 


\subsubsection{Sixth Question: Discussion}

This requires a pro-active, integrated approach by emergency officials. Media packets provide excellent means of ready information. References to the documents in the packets enhances agency credibility and reliability in dealing with the situation. Media packets should include background materials that explain the concept and objectives of the CSEPP program, how the program was instigated and the Army's and FEMA's responsibilities in the program, how the program is administered locally, and what has been done or is proposed for future improvements. A media packet may consist of the following background information fact sheets:

1. Background information on the Chemical Stockpile Disposal Program

2. History of the emergency planning for the CSEPP

3. A description of the plan/equipment upgrade activities

4. An overview of the emergency planning program guidance

5. CAIRA planning objectives and activities

6. An overview of the CSEPP emergency concept plans

7. How CSEPP is structured at the federal levels including the role of the Joint Steering Committee and the six subcommittees

8. Technical support activities for the CSEPP

9. Program implementation at state, local, and installation levels

10. Descriptions of previous exercise scenarios.

Providing media representatives with materials to enhance their portrayal of the event also makes points with the media. Such materials in the packet might include photographs of the storage site, the various munitions at the site, the TEAD demilitarization plant or others that are constructed, the interior of the emergency operations center (EOC), the sensors and monitoring equipment used on post to establish levels of emissions, warning equipment, and examples of the protective equipment used by Army responders or other official emergency responders. Maps of the site might include depiction of the EPZ and the IRZ. Video tape materials might present examples of other storage sites, how data is analyzed, pilot plant operations, how an EOC operates, the Chemical Stockpile Agent Characteristics and Effects video produced for training emergency workers, an exercise recently completed, and the decontamination boundaries. 


\subsubsection{Seventh Question}

In this question, local officials are about to disseminate tone alert radios to residences in the EPZ. Local citizens who have not been following the progress of the program are stunned to find out that they will have to have a radio in their homes.

Officials must design a program that instructs residents on how the radio is used as well as inform them about the risks they should be prepared for. Officials are swamped by numerous requests for information and the multitude of questions that follows the announcement about the radios.

\subsubsection{Seventh Question: Discussion}

Be prepared. There is a need to get information out to the public well in an advance. For some residents, however, this will be their first actual involvement with the program. The key is anticipating the most likely questions that residents will ask. Some questions may be as follows:

Where in the house is the best place to put the radio?

How will we know the radio is working?

What do I do if I think it's not working?

Will the radio interfere with television reception?

What if I refuse to take a special radio?

Will it be an inconvenience?

Will the radio go off accidentally?

Will it be used for emergencies other than chemical accidents?

Can I use the radio for other purposes?

Does it emit any harmful waves?

I already have a NOAA weather radio; why do I need this one?

Will it raise my electricity bill?

What if I want to move it to a different location?

Why do I need it when the sirens are next to my house?

Who else is getting radios?

I have difficulty hearing. Will it wake me up if I'm sleeping?

Who's paying for all these radios anyway? 
In addressing some of the questions, specific references should be made to all groups in the population, such as the hearing impaired or non-English speaking individuals. Although some questions may seem irrelevant, the fact that people have asked questions indicates a degree of personalization about the situation. Anticipating what issues may be raised can be determined by discussions with community groups or addressing specific questions in media releases.

\subsubsection{Eighth Question}

The last question involved an actual release of chemical agent vapor emitted during incineration. The army installation has identified the incident as hazardous for off-post personnel and reported the release to the local emergency officials. However, there is very little time to notify the public that will be effected by the release. Local officials must move rapidly to alert the public to provide maximum protection.

\subsubsection{Eighth Question: Discussion}

Alert/notification messages are very important elements of the warning effort. The ability to have people comply with recommended protective actions in particularly important in a fast moving event when the first warning message must convey all the information to help the public make appropriate decisions. Planning efforts should be undertaken to prepare messages with the desired clarity, precision and authority.

One of the clearest and most consistent conclusions of research is people's response to warnings is that the hazard notification message is one of the most critical factors in determining the effectiveness of a warning system. It is the content and style of the hazard notification message which largely shapes protective action behavior. Five factors are essential to the content of a hazard notification message:
a) a description of hazard or risk,
b) the location of the origin of hazard,
c) telling the respondents to take protective action,
d) the official source of the hazard notification message, and
e) the time available to respond. 
The hazard notification message should be written in a style which clearly conveys to the respondents the potential hazard. Five factors are important to remember regarding the style of the notification message. These are:
a) specificity,
b) consistency;
c) accuracy;
d) certainty; and
e) clarity.

Hazard notification message should be very specific as to the character of the hazard and how much time the respondents have to engage in protective actions. Messages must also provide consistent information within a single message as well as across different messages as to the actions being taken. In later messages, references should be made to the information in the previous message. Clearly stating all new or additional information available and pointing out all changes from the previous messages, preferably with a brief explanation of the basis for such changes, avoids inconsistencies across different messages.

Certainty in warning messages extends beyond actual message content to the actual style of delivery by the communicator. The warning message should be spoken as if the person delivering the warning believes and is certain about what is being said in the message. In additional, notification messages must be clearly worded in a language that can be understood by all respondents and which avoids the use of technical jargon.

Hazard notification message must contain timely and accurate information. If the respondents in a community suspect that they are not receiving the "whole truth," about the chemical accident they may not believe the content of the message and/or choose not to undertake the required emergency response activities. In general, increased frequency of hazard notification messages inform more respondents in a shorter period of time.

\subsection{ANALYSIS AND CONCLUSIONS FOR THE CSEPP}

When the question sets are examined the crucial differences in how the issues are framed by the public, media and the agencies become evident. In the first situation the risk was defined as an agency problem by all parties whereas in the second and third, the 
incidents were defined by public or media sources as agency problems. Agency actions did not reflect that assessment. The fourth question was defined by the media not as a criminal event but as a newsmaking situation with the potential risk secondary to the media's interest in the event as a sensational "newspeg." The agencies involved, however, defined the crisis as much more serious with the media perceived as interfering. The fifth question reflects the issues of community right-to-know versus need-to-know as well as control of information that includes changing institutional structures. The sixth and seventh questions relate to the need for planning for anticipated media needs. The seventh question indicates some of the questions that officials should be prepared to answer even in routine preparations. The last question set indicates what may happen should a release occur during storage or incineration, and addresses the need for timely, accurate notification and how those warnings need to be disseminated to ensure maximum protection for the public at risk.

A general theme throughout the situations is that risk assessment and management are part of the problem in the risk communication process. The assumption that management is part of the communication process compounds the uncertainty about definition of the level of risk, who should be informed, and when that information should be given to the public. The communication problem for the CSEPP is a complicated process involving risk generators, risk bearers and associated interested parties such as the media, and concerned citizen groups. A basic understanding of how the risk assessment for the chemical stockpile was conducted is critical to effective risk communication for the CSEPP.

Risk issues have traditionally been defined as agency problems in which the risk, once assessed, must be communicated to the public, that is, one-way communication, in monologue, not dialogue, form. Through planning and active participation in opportunities that educate the public about the risks related to the CSEPP, the situations with citizen questions could be changed to continuing dialogues and the risk problems receive active participation from both sides. The side effect of such actions, however, is that eventual closure on the problem would be difficult. Demanding closure on problems appears to be one of the key elements affecting the unwanted but very real environmental risk communication problems. The CSEPP will eventually have closure with destruction of the chemical stockpile, but that closure is somewhat uncertain in timing and methodology. It has been shown that publics adjust to changes in the environment without demanding elimination of the risk. However, the assumption that the public demands zero-risk as an ultimate solution persist in risk communication efforts. 
How to maintain credibility of agency actions and personnel in an era of increasing agency scrutiny remains a key issue for managers in the CSEPP. Coordinated networking and planning strategies between agencies with media outlets prior to an event appears critical when focusing on communicating about risks and proposed mitigation tactics. How different perceptions among various publics frame risk communication issues should be identified and debated long before a risk situation becomes critical.

Perhaps the most prominent risk communication issue involves the discrepancy between supporters of a right-to-know policy versus those advocating information of a need-to-know basis. Those claiming need-to-know base their assumptions on the feared consequences of information overload on public perceptions of risk. The fear is that too much information about risks will lull the public into ignoring avoidable risks (such as reducing injury by wearing seatbelts) by focusing on the most sensational but infrequent events that command the greatest media attention.

Who controls information remains a factor in negotiation of risk communications. The "limit/no limit" controversy can be expected to decrease as communication facilities expand the resources of both individuals and agencies to effectively access information sources. However, the techniques for dialogue needed for such communication can be developed now by agencies committed to sharing information immediately rather than selectively with affected publics. Experience repeatedly demonstrates that a lack of early and continuing involvement is a characteristic source of failure for public participation.

The contentious issues of defining or interpreting risks as well as assuming responsibility plague risk communication efforts. Agencies are typically unwilling to accept public challenges to their credibility and skills. It is clear that certain factors of risk trigger intense objections among segments of the public no matter how scientific, unbiased and objective the assessment of the risks. These factors are especially noticeable for hazards whose adverse effects are uncontrollable, dreaded, catastrophic, fatal rather than injurious, not offset by compensating benefits, and delayed in time so the risks are borne by future generations (Slovic, 1986). Public perceptions of risk often include subjective evaluations beyond those factors used in rational or scientific decision making, such as the perceived responsibility, credibility, and trust of institutions, agencies, and journalists. Determining the factors that are the most important in the assessment of the risk will continue to necessitate dialogue between all parties involved. For example, "quick fixes," such as comparisons that contrast chemical agent accidents to that of driving or smoking will not convince the public that either storage or incineration is safe. 
What are perceived as public warning needs may need further examination as public knowledge evolves through education and experience with risks. The concepts of accidents as signals indicates that when informed about a particular hazard, people's concern will generalize beyond the immediate problem to other related hazards. The factors that divide the public's individual orientation toward risks from that of the larger societal perspective will need further elucidation and concern among risk communicators for the CSEPP. Although it is advantageous to the nation as a whole to have the weapons eliminated, that perspective will not be held by all residents located near the stockpile sites.

Media coverage of risks can be expected to continue as spotty and uneven. Moreover, the media's perceived responsibility as the traditional "gatekeeper" is not likely to diminish in the future. Concerns about media bias, ethics, and responsibilities in reporting need to be addressed in context with the traditions and constraints of media reports and much of the technical information that is available in the CSEPP needs to be repackaged before the media will use it. The interface as well as linkages between the media as a channel and the media as a source needs examination to facilitate risk communication.

Public education has been suggested as an important component in understanding risks. When to begin education about risk and hazard, at what level of detail risks should be discussed, what methods to bring about public education and ultimately, who should be responsible for public education are all part of the public education agenda. Concentrating on targeted audiences or focus groups to enhance education of those most affected has had some success for agencies with available resources.

In a world of increasing risks, appropriate and continual dialogue with affected publics about risks should be one of the foremost concerns of the CSEPP. How that information is interpreted or modified by existing beliefs remains problematical. The fear that too may warnings can hamper emergency communications appears illfounded. Results of assessments of risks in language and visuals that are easily understood by the majority of publics is a basic necessity in risk communication for the CSEPP.

Effective public participation depends substantially upon the development of technical and analytic resources in agencies responsible for the public welfare and upon institutional means to act upon increased knowledge. Members of the public will continue to differ in arenas and scope of involvement, suggesting differing "thresholds" of involvement and requiring alternative communication strategies. Although a large 
array of participation technique exists, current knowledge does not allow for successful prediction as to which strategies are likely to be effective under what conditions.

As CSEPP is implemented, risk communicators are likely to face increasing pressure to present risk issues and respond to risk related questions raised by various parties and constituencies. Whether acting alone or with others, managers of public and private agencies, industry representatives and governmental bodies must accept that media communications outlets will significantly influence the agenda of most risk communication efforts. Furthermore, newer forms of communications will continue to alter methods used to translate assessments of risks for risk management. Immediate access to data via personal computers places managers in the position of making immediate decisions about conveying information about risks.

It is likely that some incidents have occurred at the stockpile sites that have led to some erosion in public confidence in those parties and agencies participating in emergency management. To regain and/or enhance credibility and trust will require changes and modifications that can only be instituted through structural or institutional change-a process which appears undeniable, but not impossible in the CSEPP. 


\section{Appendix A}

\section{RISK COMMUNICATION REFERENCES}

Adams, J., 1990. "Evaluating the Effectiveness of Safety Measures," pp. 173-193 in J. Handmer and E. Penning-Rowsell, eds., Hazards of Risk

Communication, Gower Publishing Co., England.

Alberta Public Safety Services, 1992. A Technical Study of Shelter Versus Evacuation When Faced with a Release of Hydrogen Sulfide, Alberta Public Safety Services, Edmonton, Alberta.

Allen, F. W., 1987. "Towards a Holistic Appreciation of Risk: The Challenge for Communicators and Policy Makers," Science, Technology and Human Values 12(3\&4): 138-143.

American Chemical Society, 1988. Chemical Risk Communication, American Chemical Society, Washington, DC.

Anonymous, 1988. "Communicating in a Crisis: Media and Community Relations," The Environmental Manager's Compliance Advisor 228(April): 8-11.

Arkin, E. B., 1989. "Translation of Risk Information for the Public: Message Development," pp. 127-136 in V.T. Covello, D. B. McCallum and M. T. Pavlova, eds., Effective Risk Communication, Plenum Press, New York, NY.

Aronson, E., et al., 1963. "Communication Credibility and Communication Discrepancy as Determinants of Attitude Change," Journal of Abnormal and Social Psychology 67: 31-36.

Baird, B. N., T. C. Earle and G. Cvetkovich, 1985. Public Judgement of an Environmental Health Hazard: Two studies of the ASARCO Smelter, Paper presented at the Society for Risk Analysis Annual Meeting, Alexandria, VA.

Baram, M. S., 1991. "Rights and Duties Concerning the Availability of Environmental Risk Information to the Public," pp. 67-78 in R. E. Kasperson and P. J. Stallen eds., Communicating Risks to the Public, Kluwer Academic Publishers, Dordrecht, Netherlands.

Baram, M. S., 1988. "Rights and Duties Concerning the Availability of Environmental Risk Information to the Public," pp. 105-122 in H. Jungermann, R. E. Kasperson and P. M. Wiedermann, eds., Risk Communications: Proceedings of the International Workshop on Risk Communications, FRG.

Baram M. S., 1986. "Chemical Industry Accidents, Liability and Community Right-to-know," American Journal of Public Health 76(5): 568-572.

Baram, M. S., 1984. "The Right-to-know and the Duty to Disclose Hazard Information," American Journal of Public Health 74(4): 385-390. 
Baumann, D., 1983. "Determination of the Cost Effectiveness of Flood Hazard Information," Papers and Proceedings of the Applied Geography Conference 6: 292.

Bell, D., 1989. "What to Think About Before You Write an Emergency Public Information Plan," Emergency Preparedness Digest 16(1). 10-13.

Black, R. F., 1989. "What Kind of Data Does the Public Need?" EPA Journal, May/June: 12.

Blair, M., 1987. "Response to a Warning of Volcanic Hazards, Long Valley, California," pp 105-120 in P. Gori and W. Hays, eds., A Workshop on the U.S. Geological Survey's Role in Hazards Warnings, Proceedings of Conference XL, US Department of the Interior Geological Survey, Reston, VA.

Bocella, C. M., 1986. "Legal Issues Related to Hazard Communication Standards," pp. 131-149 in J. E. Brower, ed., Hazard Communication, ASTM, Philadelphia.

Bohrer, R. L., 1987. "Hazard Communication Training for Hazardous Waste Sites," pp. 75-85 in Oak Ridge Model Conference, Proceedings, Vol. III, Health and Safety, Oak Ridge National Laboratory, Oak Ridge, TN.

Bolton, P., 1987. Final Report on the Evaluation of Three Earthquake Prediction Projects, Battelle Memorial Institute's Pacific Northwest Laboratory, Seattle, WA.

Brody, J. G., 1988. "Responses to Collective Risk: Appraisal and Coping Among Workers Exposed to Occupational Health Hazards," American Journal of Community Psychology 16(5): 645-663.

Brower, J. E., ed., 1986. Hazard Communication, ASTM, Philadelphia.

Brown, J. 1990. "Evaluating Communications About Nuclear Energy: The Case of Sizewell 'B'," pp. 157-172 in J. Handmer and E. Penning-Rowsell, eds., Hazards of Risk Communication, Gower Publishing Co., England.

Brown, P., 1987. "Popular Epidemiology: Community Response to Toxic-Induced Disease in Woburn Massachusetts," Science, Technology and Human Values 12(3\&4): 78-85.

Browning, L. D., 1988. "Interpreting the Challenger Disaster: Communication Under Conditions of Risk and Liability," Industrial Crisis Quarterly 2: 211-227.

Burby, R. J., et al., 1991. Sharing Environmental Risks, How to Control Government's Losses in Natural Disasters, Westview Press; Boulder, CO.

Burd, G., 1989. "Preventive Journalism and AIDS Editorials: Dilemmas for Private and Public Health," pp. 85-113 in L. M. Walters, L. Wilkins and T. Walters eds., Bad Tidings: Communication and Catastrophe, Lawrence Erlbaum Associates, Hillsdale, NJ. 
Burkhart, F. N., 1991. Media, Emergency Warnings and Citizen Response. Westview Press, Boulder, CO.

Burton, I., 1989. "The Criterion of 'Reasonableness' in the Communication of Risk Information," pp. 211-216 in Leiss, W., ed., Prospects and Problems in Risk Communication, University of Waterloo Press, Waterloo, Ontario.

Burton, I., R. Kàte and G. White, 1977. The Environment as Hazard, Oxford Press, New York, NY.

Callaghan, J. D., 1989. "Reaching Target Audiences with Risk Information," pp. 137-142 in V. T. Covello, D. B. McCallum and M. T. Pavlova, eds., Effective Risk Communication, Plenum Press, New York, NY.

Cannel, W. and H. Otway, 1988. "Audience Perspectives in the Communication of Technological Risks," Futures 20(October): 519-531.

Caza, M. 1989. "Response to Lind," pp. 175-192 in Leiss, W., ed., Prospects and Problems in Risk Communication, University of Waterloo Press, Waterloo, Ontario.

Chalk, R., 1987. "Looking for the Common Good," Science, Technology and Human Values 12(3\&4): 11-12.

Chess, C. and B. J. Hance, 1989. "Opening Doors: Making Risk Communication Agency Reality," Environment, 31(5): 11-15, 38-39.

Chess, C., B. J. Hance and P. M. Sandman, 1988. Improving Dialog with Communities: A Short Guide for Government Risk Communication, NJ Department of Environmental Protection, Trenton, NJ.

Chess, C., 1987. Encouraging Effective Risk Communication in Government: Suggestions for Agency Management, Unpublished Manuscript, Environmental Cook College, Rutgers University, New Brunswick, NJ.

Cleary, P., 1987. "Why People Take Precautions Against Health Risks," pp. 119149 in Weinstein, N. D., ed., Taking Care: Understanding and Encouraging Self-protective Actions, Cambridge University Press, New York, NY.

Clifford, R.A., 1956. The Rio Grande Flood: A Comparative Study of Border Communities, National Research Disaster Study \#17, National Academy of Sciences, Washington, DC.

Colglazier, E. W., 1991. "Evidential, Ethical and Policy Disputes: Admissible Evidence in Radioactive Waste Management," pp. 137-159 in Acceptable Evidence, Science and Values in Risk Managment, D. G. Mayo and R. D. Hollander, eds., Oxford University Press, New York, NY.

Covello, V.T., 1991. "Risk Comparisons and Risk Communication: Issues and Problems in Comparing Health and Environmental Risks," pp. 79-124 in R. E. Kasperson and P. J. Stallen, eds., Communicating Risks to the Public, Kluwer Academic Publishers, Dordrecht, Netherlands. 
Covello, V. T., 1989. "Informing People About Risks from Chemicals, Radiation and Other Toxic Substances: A Review of Obstacles to Public Understanding and Effective Risk Communication," pp. 1-49 in W. Leiss, ed., Prospects and Problems in Risk Communication, University of Waterloo Press, Waterloo, Ontario.

Covello, V.T., P. M. Sandman,and P. Slovic, 1991. "Guidelines for Communicating Information About Chemical Risks Effectively and Responsibly," pp. 66-90 in Acceptable Evidence, Science and Values in Risk Management, D. G. Mayo and R. D. Hollander, eds., Oxford University Press, New York, N.Y.

Covello, V. T., D. vonWinterfeldt, and P. Slovic, 1989. "Communicating Scientific Information About Health and Environmental Risks: Problems and Opportunities from a Social and Behavioral Perspective," pp. 221-239 in V. T. Covello, L. B. Lave, A. Moghissi, and V. R. Uppuluri, eds., Uncertainty in Risk Assessment, Risk Management and Decision Making, Plenum Press, New York, NY.

Covello, V. T., D. B. McCallum and M. T. Pavlova, eds., 1989. Effective Risk Communication, Plenum Press, New York, NY.

Covello, V. T., P. Slovic, and D. vonWinterfeldt, 1988(a). "Disaster and Crisis Communications: Findings and Implications for Research and Policy," pp. 131-154 in H. Jungermann, R. E. Kasperson, and P. M. Wiedermann, eds., Risk Communications: Proceedings of the International Workshop on Risk Communications, Kernforschungsanlange, Julich, FRG.

Covello, V. T., P. M. Sandman and P. Slovic, 1988(b). Risk Communication, Risk Statistics, and Risk Comparisons: A Manual for Plant Managers, Chemical Manufacturers Association, Washington, DC.

Covello, V. T., D. vonWinterfeldt and P. Slovic, 1987. "Communicating Scientific Information on Health and Environmental Risk: Problems and Opportunities from the Social and Behavioral Perspective," pp. 109-134 in J. C. Davies, V. T. Covello and F. W. Allen, eds., Risk Communication, The Conservation Foundation, Washington, DC.

Cvetkovich, G., 1988. Public Images About Chlorine Storage Hazards Following an Accidental Gas Release, Quick Response Project \#22, Natural Hazards Research and Applications Information Center, University of Colorado, Boulder, CO.

Cvetkovich, G. and T. C. Earle, 1991. "Hazard Images, Evaluations and Political Action: The Case of Toxic Waste Incineration," pp. 327-343 in R. E. Kasperson and P. J. Stallen, eds., Communicating Risks to the Public, Kluwer Academic Publishers, Dordrecht, Netherlands.

Cvetkovich, G. and T. C. Earle, No date. "Communicating Environmental Hazard Information: A Hazard Adaptation Decision Making Model," Western Washington University, Bellingham, WA. 
Cvetkovich, G. and P. M. Wiedermann, 1988. "Trust and Credibility in Risk Communication; Results of the Working Group," pp. 83-86 in H. Jungermann, R. E. Kasperson and P. M. Wiedermann, eds., Risk Communications: Proceedings of the International Workshop on Risk Communications, Kernforschungsanlange, Julich, FRG.

Cvetkovich, G., C. Vlek and T. C. Earle, No date. "Designing Public Hazard Communication Programmes About Large-Scale Technologies," Western Washington University, Bellingham, WA.

Cvetkovich, G. and G. Keren, No date. "Mental Models and Communicating Environmental Information," Western Washington University, Bellingham, WA.

Davies, R., 1987. "The Effectiveness of the Sizewell 'B' Inquiry in Facilitating Communication About the Risks of Nuclear Power," Science, Technology and Human Values 12(3\&4): 102-110.

Davies, J. C., V. T. Covello and F. W. Allen, eds., 1987. Risk Communication., The Conservation Foundation, Washington, DC.

Day, I., 1989. "Response to Pochin," pp. 171-173 in Leiss, W., ed., Prospects and Problems in Risk Communication, University of Waterloo Press, Waterloo, Ontario.

Desbarats, P., 1989. "Response to Roberts," pp. 207-209 in Leiss, W., ed., Prospects and Problems in Risk Communication, University of Waterloo Press, Waterloo, Ontario.

Desvousges, W. H. and V. K. Smith, 1988. "Focus Groups and Risk Communication: The 'Science' of Listening to Data," Risk Analysis 8(4): $479-484$.

Diggory, J. C., 1956. "Some Consequences of Proximity to a Disease Threat," Sociometry 19(March): 47-53.

Diggs, D. M., 1988. Risk Communication, Lessons From Natural Hazards: An Annotated Bibliography, Topical Bibliography No. 15, University of Colorado, NHRAIC, Boulder.

Dooley, J. E., 1989. "Response to Somers," pp. 153-158 in Leiss, W., ed., Prospects and Problems in Risk Communication, University of Waterloo Press, Waterloo, Ontario.

Dunwoody, S. and M. Ryan, 1983. "Public Information Persons as Mediators Between Scientists and Journalists," Journalism Quarterly 60(4): 647-656.

Dutton, D. B., 1987. "Medical Risks, Disclosure and Liability: Slouching Toward Informed Consent," Science, Technology and Human Values 12(3\&4): 48-59.

Earle, T. and G. Cvetkovich, 1988. "Risk Judgements, Risk Communications, and Conflict Management," pp. 361-400 in Rohrmann, B. and C. R. B. Joyce, 
eds., Human Judgement, Elsevier, North Holland.

Earle, T. and G. Cvetkovich, No date. "Platitudes and Comparisons: A Critique of Current (Wrong) Directions in Risk Communication," Western

Washington University, Bellingham, WA.

Earle, T. and G. Cvetkovich, No date, "The Role of Information in the Judgment of Risks from Natural Hazards: Technical Description of Project and Results," Western Washington University, Bellingham, WA.

Einsiedel, E. F., 1989. "Response to Grima," pp. 135-138 in Leiss, W., ed., Prospects and Problems in Risk Communication, University of Waterloo Press, Waterloo, Ontario.

Elkins, C. L., 1989. "Right-to-know: What it Means for EPA," EPA Journal, May/June: 17-19.

Elliot, D., 1989. " Tales from the darkside: Ethical implications of disaster coverage," pp. 161-170 in Walters, L. M., L. Wilkins, and T. Walters, eds., Bad Tidings: Communication and Castastrophe. Hillsdale, NJ: Lawrence Erlbaum Associates.

Faupel, C. E. and S. P. Kelley. No date. Individual and Household Response to Hurricane Hugo. College Station, TX: Recovery Center, College of Architecture, Texas A\&M University.

Fessenden-Raden, J., J. M. Fitchen and J. S. Heath, 1987. "Providing Risk Information in Communities: Factors Influencing What Is Heard and Accepted," Science, Technology and Human Values 12(384): 94-101.

Filderman, L., 1990. "Designing Public Education Programmes: A Current Perspective," pp. 219-231 in Handmer, J., and E. Penning-Rowsell, eds., Hazards of Risk Communication, Gower Publishing Co., England.

Fischoff, B., 1987, "Treating the Public With Risk Communications: A Public Health Perspective," Science, Technology and Human Values 12(3\&4): 1319.

Fishbein, M. and I Ajzen, 1972. "Attitudes and Opinions," Annual Review of Social Psychology 6: 487-554.

Fisher, A., L. G. Chestnut and D. M. Violette, 1989. "The Value of Reducing Risks On Death: A Note On New Evidence," Journal of Policy Analysis and Management 8(1): 88-100.

Foster, H., 1980. Disaster Planning. New York, NY: Springer-Verlog.

Fraize, W., et al., 1988. "Risk Assessment of the Army's Chemical Stockpile Disposal Program," pp. 667-686 in Zervos, C., ed., Risk Analysis, Prospects and Opportunities, Plenum Press, New York, NY.

Franks, A. D., 1989. "Phosphorus Release in Miamisburg, Ohio," pp. 101-104 in V. T. Covello, D. B. McCallum and M. T. Pavlova eds., Effective Risk Communication, Plenum Press, New York, NY. 
Freimuth, V. S. and J. P. VanNevel, 1981. "Reaching the Public: The Asbestos Awareness Campaign," Journal of Communication 31(2): 155-167.

Freudenburg, W. R., 1992. "Heuristics, Biases, and the Not-so-general Publics: Expertise and Error in the Assessment of Risks," pp. 229-249 in S. Krimsky, and D. Golding, eds., Social Theories of Risk, Praeger, Westport, CT.

Friedman, S. M., 1981. "Blueprint For Breakdown: Three Mile Island and the Media Before the Accident," Journal of Risk Communication 31(2): 116128.

Friedman, S. M., 1989. "TMI: The Media Story That Will Not Die," pp. 63-83 in L. M. Walters, L.Wilkins, and T. Walters, eds., Bad Tidings: Communication and Castastrophe, Lawrence Erlbaum Associates, Hillsdale, NJ.

Fritz, C., 1957. "Disasters Compared in Six American Communities," Human Organization 16(Summer): 6-9.

Funtowicz, S. O. and J. R. Ravetz, 1992. "Three Types of Risk Assessment and the Emergence of Post-normal Science," pp. 251-273 in S. Krimsky and D. Golding, eds., Social Theories of Risk, Praeger, Westport, CT.

Garie , H. L., C. Chess, and E. Stephenson, 1986. "Overview of the Implementation of a Statewide Worker and Community Right-to-know Act," pp. 118-123 in J. E. Brower, ed., Hazard Communication, ASTM, Philadelphia.

Giere, R. N., 1991. "Knowledge, Values, and Technological Decisions: A Decision Theoretic Approach," pp. 183-203 in Acceptable Evidence, Science and Values in Risk Managment, D. G. Mayo and R. D. Hollander, eds., Oxford University Press, New York, N.Y.

Golding, D., 1992. "A Social and Programmatic History of Risk Research," pp. 2352 in S. Krimsky and D. Golding, eds., Social Theories of Risk, Praeger, Westport, CT.

Goldman, S. B., 1986. "Emergency Planning, Public Information and the Media: Some Recent Experiences."NUTECH Engineers, Bethesda, MD.

Gori, P. and W. Hays, eds., 1987. A Workshop on The U.S. Geological Survey's Role in Hazards Warnings, Proceedings of Conference XL, US Department of the Interior Geological Survey, Reston, VA.

Graham, J. D., 1989. "Communicating About Chemical Hazards," Journal of Policy Analysis and Management 8(2): 307-313.

Green, C., 1990. "Perceived Risk: Past, Present and Future," pp. 31-52 in J. Handmer and E. Penning-Rowsell, eds., Hazards of Risk Communication, Gower Publishing Co., England. 
Green, M. D., 1989. "When Toxic Worlds Collide: Regulatory and Common Law Prescriptions for Risk Communication," Harvard Environmental Law Review 13(1): 209-243.

Greenberg, M. R., et al., 1989(a). "Network Evening News Coverage of Environmental Risk," Risk Analysis 9(1): 119-126.

Greenberg, M. R., et al., 1989(b). "Network Television News Coverage of Environmental Risks," Environment 31(2): 16-20 and 40-44.

Greenberg, M. R., et al., 1989(c). "Risk, Drama and Geography in Coverage of Environmental Risk by Network TV," Journalism Quarterly, Summer: pp. 267-276

Greenberg, S., 1987. "Why People Take Precautions Against Crime: A Review of the Literature on Individual and Collective Responses to Crime," pp. 231253 in N. D. Weinstein, ed., Taking Care: Understanding and Encouraging Self-protective Actions, Cambridge University Press, New York, NY.

Gregory, R., 1989. "Improving Risk Communication: Questions of Content and Intent," pp. 71-79 in Leiss, W., ed., Prospects and Problems in Risk Communication, University of Waterloo Press, Waterloo, Ontario.

Grima, A. P., 1989. "Improving Risk Information Transfer: Instrumental and Integrative Approaches," pp. 135-134 in W. Leiss, ed., Prospects and Problems in Risk Communication, University of Waterloo Press, Waterloo, Ontario.

Grunig, L. S., 1987. "The Role of Public Relations During Industrial Crises," Industrial Crisis Quarterly 1(2): 10-19.

Gruntfest, E., 1990. "Assessing Programme Effectiveness: A 1987 Report on Warning Systems in the USA," pp. 195-215 in J. Handmer and E. Penning-Rowsell, eds., Hazards of Risk Communication, Gower Publishing Co., England.

Gruntfest, E., 1977. "What People Did During the Big Thompson Flood," Working Paper 32, Institute of Behavioral Science, University of Colorado, Boulder, $\mathrm{CO}$.

Haas, E. and P. Trainer, 1974. "Effectiveness of the Tsunami Warning System in Selected Coastal Towns in Alaska," Proceedings of the Fifth World Conference on Earthquake Engineering, Rome.

Hadden, S. G., 1989(a). "Right-to-know: What It Can Mean for Citizens," EPA Journal, May/June: 13-16.

Hadden, S. G., 1989(b). "Institutional Barriers to Risk Communication," Risk Analysis 9(3): 301-308.

Hadden, S. G., 1989. A Citizen's Right to Know, Risk Communication and Public Policy, Westview Press, Boulder, CO. 
Hamilton, M., 1986. "Chernobyl: A Cloud Over the Media," Occupational Safety and Health 16(August): 18-20.

Hance, B. J., Chess, C. and P. M. Sandman, 1990. Industry Risk Communication Manual: Improving Dialogue with Communities, Lewis Publishers, Boca Raton, FL.

Hance, B. J., C. Chess and P. M. Sandman, 1989. "Setting a Context for Explaining Risk," Risk Analysis 9(1): 113-117.

Hance, B. J., C. Chess, and P. M. Sandman, 1988. Improving Dialog with Communities: A Risk Communication Manual for Government, NJ Department of Environmental Protection, Trenton, NJ.

Handmer, J. and E. Penning-Rowsell, eds., 1990. Hazards of Risk Communication, Gower Publishing Co., England.

Hanson, D., 1989. "Public's Misconceptions Act to Bar Effective Risk Communication," C\&EN, Sept. 25: 31-32.

Hansson, S. O., 1989. "Dimensions of Risk," Risk Analysis 9(1): 107-112.

Hattis, D., 1989. "Scientific Uncertainties and How They Affect Risk Communication," pp. 117-126 in V. T. Covello, D. B. McCallum and M. T. Pavlova, eds., Effective Risk Communication, Plenum Press, New York, NY.

Hester, G., et al., 1991. "Small Group Studies of Regulatory Decision Making for Power-frequency Electric and Magnetic Fields," pp. 413-455 in R. E. Kasperson, and P. J. Stallen, eds., Communicating Risks to the Public, Kluwer Academic Publishers, Dordrecht, Netherlands.

Hilgartner, S. and D. Nelkin, 1987. "Communication Controversies Over Dietary Risks," Science, Technology and Human Values 12(3\&4): 41-47.

Hollander, R., 1991. "Expert Claims and Social Decisions: Science, Politics, and Responsibility," pp. 160-173 in Acceptable Evidence, Science and Values in Risk Managment, D. G. Mayo and R. D. Hollander, eds., Oxford University Press, New York, N.Y.

Holt, F. X, 1991. Emergency Communications Management, PennWell Publication, Saddle Brook, NJ.

Hoveland, C. I. and W. Weiss, 1952. The Influence of Source Credibility on Communication Effectiveness, Public Opinion Quarterly 15: 635-650.

Hoveland, C. I., 1948. "Social Communication," Proceedings of the American Philosophical Society 92: 371-375.

Jackson, J., 1989. "Response to Gregory," pp. 81-83 in W. Leiss, ed. Prospects and Problems in Risk Communication, University of Waterloo Press, Waterloo, Ontario. 
Jasanoff, S., 1991. "Acceptable Evidence in a Pluralistic Society," pp. 29-47 in Acceptable Evidence, Science and Values in Risk Managment, D. G. Mayo and R. D. Hollander, eds., Oxford University Press, New York, N.Y.

Jasanoff, S., 1988. "The Bhopal Disaster and the Right-to-know," Social Science Medicine 27(10): 1113-1123.

Jasanoff, S., 1987. "EPA's Regulation of Daminozide: Unscrambling the Messages of Risk," Science, Technology and Human Values 12(3\&4): 116124.

Johnson, B. B., 1987. "Accounting for the Social Context of Risk Communication," Science and Technology Studies 5(3/4): 103-111.

Johnson, F. R. and A. Fisher, 1989. "Conventional Wisdom on Risk Communication and Evidence from a Field Experiment," Risk Analysis 9(2): 209-213.

Johnson, F. R., et al., 1988. "Informed Choice or Regulated Risk?" Environment 30(4): 12-15 and 30-35.

Johnson, F. R. and R. A. Luken, 1987. "Radon Risk Information and Voluntary Protection: Evidence From a Natural Experiment," Risk Analysis 7(1): 97107.

Johnson, R., 1986. "EDB (Ethylene Dibromide)" pp. 83-85 in C. J. Davies, V. T. Covello and F. W. Allen, eds., Risk Communication, The Conservation Foundation, Washington, DC.

Jungermann, H., H. Schutz and M. Thuring, 1991. "How People Might Process Medical Information: A 'Mental Model' Perspective on the Use of Package Inserts," pp. 219-236 in R. E. Kasperson and P. J. Stallen, eds., Communicating Risks to the Public, Kluwer Academic Publishers, Dordrecht, Netherlands.

Jungermann, H., H Schultz, and M. Thuring, 1988. "Mental Models in Risk Assessment: Informing People About Drugs," Risk Analysis 8(1) 147-155.

Jungermann, H. , R. E. Kasperson and P. M. Wiedermann, eds., 1988. Risk Communications: Proceedings of the International Workshop on Risk Communications, Kernforschungsanlange, Julich, FRG.

Kartez, J. D., 19xx. Community Planning for Industrial Risk: A Title lll Research Agenda.

Kasperson, R. E. 1992. "Progress in Developing an Integrative Framework," pp. 153-178 in S. Krimsky and D. Golding, eds., Social Theories of Risk, Praeger, Westport, CT.

Kasperson, R. E. and J. X. Kasperson, 1991. "Hidden Hazards," pp. 9-28 in Acceptable Evidence, Science and Values in Risk Management, D. G. Mayo and R. D. Hollander, eds., Oxford University Press, New York, N.Y. 
Kasperson, R. E. and P. J. Stallen, eds., 1991(b). "Risk Communication: The Evolution of Attempts," pp. 1-12 in Communicating Risks to the Public, Kluwer Academic Publishers, Dordrecht, Netherlands.

Kasperson, R. E. and P. J. Stallen, eds., 1991(a). Communicating Risks to the Public, Kluwer Academic Publishers, Dordrecht, Netherlands.

Kasperson, R. E. and B. Rohrmann, 1988. "Evaluation of Risk Communication Strategies: Results of the Working Group, "pp. 159-162 in

H. Jungermann, R. E. Kasperson and P. M. Wiedermann, eds., Risk Communications: Proceedings of the International Workshop on Risk Communications, Kernforschungsanlange, Julich, FRG.

Kasperson, R. E., et al., 1988. "The Social Amplification of Risk: A Conceptual Framework." Risk Analysis 8(2): 177-187.

Kasperson, R. E., 1986. "Six Propositions on Public Participation and Their Relevance for Risk Communication," Risk Analysis 6(3): 275-281.

Kasperson, R. E. and I. Palmlund, 1987. "Evaluating Risk Communication." CENTED, Clark University, Worcester, MA.

Kasperson, R. E. and J. X. Kasperson, No date, "Guides for the Presentation of Quantitative Risk Information," Unpublished manuscript, Clark University, Worcester, MA.

Kates, R. W., 1978. Risk Assessment of Environmental Hazards, John Wiley \& Sons, Chichester, Great Britain.

Kauffman, J., 1986. "Hazardous Waste Siting: The Massachusetts Experience," pp. 71-85 in C. J. Davies, V. T. Covello and F. W. Frederick, eds., Risk Communication, The Conservation Foundation, Washington, DC.

Keating, M., 1989. "Response to Grima," pp. 139-141 in W. Leiss ed., Prospects and Problems in Risk Communication, University of Waterloo Press, Waterloo, Ontario.

Keeling, R. P., 1987. "Risk Communication About Aids in Higher Education," Science, Technology and Human Values 12(3\&4): 26-36.

Keeney, R. L. and D. vonWinterfeldt, 1986. "Improving Risk Communication," Risk Analysis 6(4): 417-424.

Keren, G. and H. Eijkelhof, 1991. "Prior Knowledge and Risk Communication: The case of Nuclear Radiation and X-rays," pp. 145-155 in R. E. Kasperson and P. J. Stallen, eds., Communicating Risks to the Public, Kluwer Academic Publishers, Dordrecht, Netherlands.

Konheim, C. S., 1988. "Risk Communication in the Real World," Risk Analysis 8(3): $367-373$.

Krieghbaum, H., 1979. "Three Mile Island: A Crash Course for Readers," Mass Communication Review 6(2): 2-10. 
Krimsky, S., 1992. "The Role of Theory in Risk Studies," pp. 3-22 in S. Krimsky and D. Golding, eds., Social Theories of Risk, Praeger, Westport, CT.

Krimsky, S. and D. Golding, eds., 1992. Social Theories of Risk, Praeger, Westport, CT.

Krimsky, S. and D. Golding, 1992. "Reflections," pp. 355-363 in S. Krimsky and D. Golding, eds., Social Theories of Risk, Praeger, Westport, CT.

Krimsky, S. and A. Plough, 1988. Environmental Hazards: Communicating Risks As a Social Process, Auburn House, Dover, MA.

Kunreuther, H., 1992. "A Conceptual Framework for Managing Low-probability Events," pp. 301-320 in S. Krimsky and D. Golding, eds., Social Theories of Risk, Praeger, Westport, CT.

Lagadec, P., 1987. "Communication Strategies in Crises Situations," Industrial Crisis Quarterly 1(2): 19-26.

Lasswell, H. D., 1948. "The Structure and Function of Communications in Society," pp. 32-35 in Bryson, L. ed., The Communication of Ideas, Harper, New York, NY.

Ledingham, J. and L. M. Walters, 1989. "The Sound and the Fury: Mass Media and Hurricanes," in L. M. Walters, L. Wilkins and T. Walters, eds., Bad Tidings: Communication and Castastrophe, Lawrence Erlbaum Associates, Hillsdale, NJ.

Lee, T. R., 1986. "Effective Communication of Information About Chemical Hazards." The Science of the Total Environment, 51: 149-183.

Leik, R. K., et al., 1981. Community Response to Natural Hazard Warnings: Final Report., University of Minnesota, Minneapolis, MN.

Leiss, W., ed., 1989. "Prospects and Problems in Risk Communication," University of Waterloo Press, Waterloo, Ontario.

Leiss, W. and D. Krewski, 1989. "Risk Communication: Theory and Practice," pp. 89-112 in W. Leiss, ed., Prospects and Problems in Risk Communication, University of Waterloo Press, Waterloo, Ontario.

Letho, M. A. and J. M. Miller, 1986. Warnings, Fuller Technical Publications, Ann Arbor, MI.

Lichtenberg, J. and D. Maclean, 1991. "The Role of the Media in Risk Communication," pp. 57-173 in R. E. Kasperson and P. J. Stallen, eds., Communicating Risks to the Public, Kluwer Academic Publishers, Dordrecht, Netherlands. 
Lichtenberg, J. and D. MacLean, 1988. "The Role of the Media in Risk Communications," pp. 33-48 in H. Jungermann, R. E. Kasperson and P. M. Wiedermann, eds., Risk Communications: Proceedings of the International Workshop on Risk Communications, Kernforschungsanlange, Julich, FRG.

Lind, N. C., 1989. "Measures for Risk and Efficiency of Risk Control," pp. 171-187 in Leiss, W., ed., Prospects and Problems in Risk Communication, University of Waterloo Press, Waterloo, Ontario.

Lindell, M. K. and R. W. Perry, 1992. Behavioral Foundations of Community Emergency Planning, Hemisphere Publishing Company, Washington, DC.

Liston, A. J., 1989." Risk Communication and Health Protection," pp. 51-64 in W. Leiss, ed., Prospects and Problems in Risk Communication, University of Waterloo Press, Waterloo, Ontario.

Long, B. L., 1988. "Risk Communication: Where to From Here," pp. 177-182 in H. Jungermann, R. E. Kasperson and P. M. Wiedermann, eds., Risk Communications: Proceedings of the International Workshop on Risk Communications, Kernforschungsanlange, Julich, FRG.

MacLean, D., 1986. "Values at Risk," Rowman and Littlefield, New York, NY.

Marks, D., 1990. "Imagery, Information and Risk," pp. 19-29 in J. Handmer and E. Penning-Rowsell, eds., 1990. Hazards of Risk Communication, Gower Publishing Co., England.

Marshall, J. R., 1989. "The Newark Dioxin Case," pp. 91-94 in V. T. Covello, D. B. McCallum and M. T. Pavlova, eds., Effective Risk Communication, Plenum Press, New York, NY.

Mason, J. O., 1989. "The Federal Role in Risk Communication and Public Education," pp. 19-26 in V. T. Covello, D. B. McCallum and M.T. Pavlova, eds., Effective Risk Communication, Plenum Press, New York, NY.

Mayo, D. G., 1991. "Sociological Versus Metascientific Views of Risk Assessment," pp. 249-279 in Acceptable Evidence, Science and Values in Risk Managment, D. G. Mayo and R. D. Hollander, eds., Oxford University Press, New York, N.Y.

Mayo, D. G. and R. D. Hollander, eds., 1991. Acceptable Evidence, Science and Values in Risk Managment, Oxford University Press, New York, N.Y.

Mazur, A., 1987. "Putting Radon on the Public's Risk Agenda," Science, Technology and Human Values 12(3\&4): 86-93.

McCallum, D. B., 1986. "Risk Factors for Cardiovascular Disease: Cholesterol, Salt, and High Blood Pressure," pp. 67-70 in C. J., Davies, V: T. Covello and F. W. Allen, eds., Risk Communication, The Conservation Foundation, Washington, DC. 
McCallum, D. B. and L. Anderson., 1991. "Communicating About Pesticides in Water," pp. 237-262 in R. E. Kasperson and P. J. Stallen, eds., Communicating Risks to the Public, Kluwer Academic Publishers, Dordrecht, Netherlands.

McCallum, D. B. and V. T. Covello, 1989. "What the Public Thinks About Environmental Data," EPA Journal, May-June: 22-23.

McDaniels, T., 1988. "Chernobyl's Effects on the Perceived Risks of Nuclear Power: A Sample Test," Risk Analysis 8(3): 457-461.

McDaniel, D. W., 1986. "The OSHA Hazard Communication Standard," pp. 13-19 in Brower, J. E., ed., 1986. Hazard Communication., ASTM, Philadelphia.

McKay, J. M., 1984. "Community Response to Hazard Information," Disasters 8(2): 118-123.

McKay, J. M. and B. Finlayson, 1982. "Observations on Mass Media Reporting and Individual Motivation to Obtain Flood Information Map-River Torrens, Adelaide, South Australia," Applied Geography 2: 143-153.

Mike, V., 1991. "Understanding Uncertainties in Medical Evidence: Professional and Public Responsibilities," pp. 115-136 in Acceptable Evidence, Science and Values in Risk Managment, D. G. Mayo and R. D. Hollander, eds., Oxford University Press, New York, N.Y.

Mileti, D., 1975. Natural Hazard Warning Systems in the United States., Institute of Behavioral Science, University of Colorado Boulder, CO.

Mileti, D. and J. Sorensen, 1988. "Planning and Implementing Warning Systems," pp 321345 in M. Lystad, ed., Mental Health Care In Mass Emergencies: Theory and Practice, Brunner/Mazel Psychological Stress Series, New York, NY.

Mileti, D. and J. Sorensen, 1987. "Natural Hazards and Precautionary Behavior," pp. 189-207 in Weinstein, N. D., ed., Taking Care: Understanding and Encouraging Self-protective Behavior, Cambridge University Press, Cambridge.

Mileti, D., T. Drabek and J. Haas, 1975. Human Systems in Extreme Environments, Institute of Behavioral Science, University of Colorado, Boulder, CO.

Mitchell, M., 1987. "Crisis Management: Handling Public Relations in a Disaster," Professional Safety, January: 28-31.

Mitchell, R. C., 1986. "Nuclear and Other Energy Sources," pp. 77-81 in C. J. Davies, V. T. Covello and F. W. Allen, eds., Risk Communication, The Conservation Foundation, Washington, DC.

Morgan, M. G. and C. Vlek, 1988. "The Right-to-know and Community Dynamics: Results of the Working Group," pp. 123-130 in H. Jungermann, R. E. Kasperson, and P. M. Wiedermann, eds., Risk Communications: Proceedings of the International Workshop on Risk Communications, Kernforschungsanlange, Julich, FRG. 
Musselman, V. C., 1989. "Emergency Planning and Community Right-to-know: An Implementer's Guide to SARA Title III." Van Nostrand Reinhold, New York, NY.

National Research Council, 1989. "Improving Risk Communication." National Academy Press, Washington, D.C.

Needleman, C., 1987. "Ritualism in Communicating Risk Information," Science, Technology and Human Values 12(3\&4): 20-25.

Nelkin, D., 1989. "Communicating Technological Risk: The Social Construction of Risk Perception," Annual Review of Public Health 10: 95-113.

Nelkin, D., 1987. "Risk and the Press," Industrial Crisis Quarterly 1(2): 3-9.

Neutra, R. R., 1989. "A Landfill Case in California," pp. 95-100 in V. T. Covello, D. B. McCallum and M.T. Pavlova, eds., Effective Risk Communication, Plenum Press, New York, NY.

Nichols, E. and A. Wildavsky, 1988. "Regulating the Numbers-Probabilistic Risk Assessment and Nuclear Risk," Evaluation Review 12(5), October: 528-546.

Nimmo, D. and J. E. Combs, 1985. Nightly Horrors: Crisis Coverage by Television Network New, The University of Tennessee Press, Knoxville, TN.

Noel, V., 1987. "Communicating in a Crises: Choosing the Right Vehicle," Industrial Crisis Quarterly 1(2): 27-37.

Nudell, M. and N. Antokoi, 1989. The Handbook for Effective Energy and Crisis Management., Lexington Books, D.C. Heath and Co., Lexington, MA.

O'Riordan, T., 1990. "Hazard and Risk in the Modern World: Political Models for Program Design," pp. 293-301 in J. Handmer, and E. Penning-Rowsell, eds., Hazards of Risk Communication, Gower Publishing Co., England.

O'Riordan, T.,1988. " The Right-to-know and Community Dynamics," pp. 87-104 in H. Jungermann, R. E. Kasperson and P. M. Wiedermann, eds., Risk Communications: Proceedings of the International Workshop on Risk Communications, Kernforschungsanlange, Julich, FRG.

Otway, H., 1992. "Public Wisdom, Expert Fallibility: Toward a Contextual Theory of Risk," pp. 215-228 in S. Krimsky and D. Golding, eds., Social Theories of Risk, Praeger, Westport, CT.

Otway, H. and B. Wynne, 1989. "Risk Communication: Paradigm and Paradox," Risk Analysis 9(2): 141-145.

Otway, H., et al., 1988. "Risk Communication in Europe after Chernobyl: A Media Analysis of Seven Countries," Industrial Crisis Quarterly 2: 3-15.

Otway, H. and M. Peltu, 1985. Regulating Industrial Risks, Butterworths, London. 
Ozonoff, D. and L. I. Bowden, 1987. "Truth and Consequences: Health Agencies Response to Environmental Health Problems," Science, Technology and Human Values 12(3\&4): 70-77.

Palm, R., 1987. "Perspectives and Discussion of What Was Learned From the California Experiences," pp. 86-99 in P. Gori, and W. Hays, eds., $A$ Workshop on The US.Geological Survey's Role in Hazards Warnings, Proceedings of Conference XL, US Department of the Interior Geological Survey, Reston, VA.

Palm, R., 1981. Real Estate Agents and Special Study Zone Disclosure., Institute of Behavioral Science, University of Colorado, Boulder CO.

Palmlund, I., 1992. "Social Drama and Risk Evaluation," pp. 197-212 in S. Krimskyand D. Golding eds., Social Theories of Risk, Praeger, Westport, CT.

Parker, D. and J. Neal, 1990. "Evaluating the Performance of Flood Warning Systems," pp. 137-156 in J. Handmer and E. Penning-Rowsell, eds., Hazards of Risk Communication, Gower Publishing Co., England.

Patterson, P., 1989. "Reporting Chernobyl: Cutting the Government Fog to Cover the Nuclear Cloud," pp. 131-147 in L. M. Walters, L. Wilkins and T. Walters, eds., Bad Tidings: Communication and Castastrophe, Lawrence Erlbaum Associates, Hillsdale, NJ.

Pavlova, M. T. and S. D. Luftig, No date. "Risk Communication: Case Studies at the Community Level," Unpublished paper, USEPA Region II, New York, NY.

Peltu, M., 1988. "Media Reporting of Risk Information: Uncertainties and the Future," pp. 11-32 in H. Jungermann, R. E. Kasperson and P. M. Wiedermann, eds., Risk Communications: Proceedings of the International Workshop on Risk Communications, Kernforschungsanlange, Julich, FRG.

Peltu, M., 1985. "The Role of Communications Media," pp. 128-148 in H. Otway and M. Peltu, eds., Regulating Industrial Risks, Butterworths, London.

Penning-Rowsell, E. and J. Handmer, 1990 "The Changing Context of Risk Communication," pp. 3-15 in J. Handmer and E. Penning-Rowsell, eds., Hazards of Risk Communication, Gower Publishing Co., England.

Perry, R. W. and M. K. Lindell, 1989. "Communicating Threat Information for Volcano Hazards," pp. 47-62 in L. M. Walters, L. Wilkins and T. Walters, eds., Bad Tidings: Communication and Castastrophe, Lawrence Erlbaum Associates, Hillsdale, NJ.

Perry, R. W. and M. R. Greene, 1983. Citizen Response to Volcanic Eruptions: The Case of Mount St. Helens., Irvington Publishers, Inc., New York, NY.

Perry, R. W., M. Lindell, and M. R. Greene, 1982. "Threat Perception and Public Response to Volcano Hazard," The Journal of Social Psychology 116: 199204. 
Plough, A. and S. Krimsky, 1987. "The Emergence of Risk Communication Sudies: Social and Political," Science, Technology and Human Values 12(3\&4): 4-10.

Pochin, E. E., 1989. "Using Quantitative Assessments of Risk," pp. 159-169 in W. Leiss, ed., Prospects and Problems in Risk Communication, University of Waterloo Press, Waterloo, Ontario.

Pollak, M., 1985. "Public Participation," pp. 76-93 in H. Otway, M. Peltu, eds., Regulating Industrial Risks, Butterworths, London.

Press, F., 1987. "Science and Risk Communication," pp. 11-18 in J. C. Davies, V. T. Covello and F. W. Allen, eds., Risk Communication, The Conservation Foundation, Washington, DC.

Prothrow-Smith, D., H. Spivak and A. J. Hausman, 1987. "The Violence Prevention Project: A Public Health Approach," Science, Technology and Human Values 12(3\&4): 67-69.

Quarantelli, E. L., 1989. "The Social Science Study of Disasters and Mass Communication," pp. 1-19 in L. M. Walters, L. Wilkins and T. Walters, eds., Bad Tidings: Communication and Castastrophe, Lawrence Erlbaum Associates, Hillsdale, NJ.

Rayner, S. F., 1992. "Cultural Theory and Risk Analysis," pp. 83-115 in S. Krimsky and D. Golding, eds., Social Theories of Risk, Praeger, Westport, CT.

Rayner, S. F., 1988. "Risk Communication in the Search for a Global Climate Strategy," pp. 169-176 in H. Jungermann, R. E. Kasperson and P. M. Wiedermann, eds., Risk Communications: Proceedings of the International Workshop on Risk Communications, Kernforschungsanlange, Julich, FRG.

Renn, O., 1992(a). "Concepts of Risk: A Classification," pp. 53-79 in S. Krimsky, and D. Golding, eds., Social Theories of Risk, Praeger, Westport, CT.

Renn, O. 1992(b). "The Social Arena Concept of Risk Debates," pp. 179-196 in S. Krimsky and D. Golding eds., Social Theories of Risk, Praeger, Westport, CT.

Renn, O., 1991. "Strategies of Risk Communication: Observations From Two Participatory Experiments," pp. 457-481 in R. E. Kasperson and P. J. Stallen Publishers.

Renn, O., 1989. "Risk Analysis: A Need to Communicate," Forum for Applied Research and Public Policy, Summer: 86-92.

Renn, O. and D. Levine, 1991. "Credibility and Trust in Risk Communication," pp. 175-218 in R. E. Kasperson and P. J. Stallen, eds., Communicating Risks to the Public, Kluwer Academic Publishers, Dordrecht, Netherlands. 
Renn, O. and D. Levine, 1988. "Trust and Credibility in Risk Communication," pp. 51-82 in H. Jungermann, R. E. Kasperson and P. M. Wiedermann, eds., Risk Communications: Proceedings of the International Workshop on Risk Communications, Kernforschungsanlange, Julich, FRG.

Rip, A., 1991. "The Danger Culture of Industrial Society," pp. 345-365 in R. E. Kasperson and P. J. Stallen, eds., Communicating Risks to the Public, Kluwer Academic Publishers, Dordrecht, Netherlands.

Rip, A., 1988. "The Danger Culture of Industrial Society," Unpublished paper.

Roberts, J. R., 1989. "The Conundrum of Risk Communication: Error, Precision and Fear," pp. 193-205 in Leiss, W., ed., Prospects and Problems in Risk Communication, University of Waterloo Press, Waterloo, Ontario.

Roder, W., 1961. "Attitude and Knowledge on the Topeka Flood Plain," in G. White ed., Papers on Flood Problems, University of Chicago, Department of Geography, Chicago.

Rodgers, E. M., 1989. Life in Balance, Dow Chemical USA, Midland, MI.

Rodgers, E., 1983. Diffusion of Innovation, 3rd ed., Free Press, New York, NY.

Roe, D., 1989. "What Kind of Data Does the Public Need?" EPA Journal, May/June: 11.

Roesner, J. P. and S. C. Russell, 1987. "Cows, Sirens, Iodine and Public Education About the Risks of Nuclear Power Plants," Science, Technology and Human Values 12(3\&4): 111-115.

Ruch, C. and L. Christensen, 1980. Hurricane Message Enhancement, Report published by the Texas Sea Grant College Program, Texas A and M, College Station, TX.

Ruckelshaus, W. D., 1987. "Communicating About Risk," pp. 3-9 in J. C. Davies, V. T. Covello and F. W. Allen, eds., Risk Communication, The Conservation Foundation, Washington, DC.

Ruckelshaus, W. D., 1985. "Risk, Science and Democracy," Issues in Science and Technology, 1(3): 19-38.

Rutgers University, 1985. "Environmental Emergencies: Are Journalists Prepared?" Scientists Institute for Public Information 13(4), Sept.-Oct.: 1-11.

Rycroft, R. W., J. L. Regens and T. Dietz, 1987. "Acquiring and Using Scientific and Technical Information to Identify Environmental Risks," Science, Technology and Human Values 12(3\&4): 125-130.

Saarinen, T. 1990. "Improving Public Response to Hazards Through Enhanced Perception of Risks and Remedies," pp. 279-292 in J. Handmer and E. Penning-Rowsell, eds., Hazards of Risk Communication, Gower Publishing Co., England. 
Saarrinen, T., 1982. "The Relation of Hazard Awareness to Adoption of Mitigation Measures," pp. 1-38 in T. Saarinen, ed., Perspectives on Hazard Awareness, Institute of Behavioral Science, University of Colorado, Boulder, CO.

Sachsman, D. B., et al., 1988. "Improving Press Coverage of Environmental Risk, "Industrial Crisis Quarterly 2: 283-296.

Sandman, P. M., 1988. "Hazard Versus Outrage: A Conceptual Frame for Describing Public Perceptions of Risk," pp 163-168 in H. Jungermann, $R$. E. Kasperson, and P. M. Wiedermann, eds., Risk Communications: Proceedings of the International Workshop on Risk Communications, Kernforschungsanlange, Julich, FRG.

Sandman, P.M., 1987. "Explaining Risk to Non-experts: A Communications Challenge," Emergency Preparedness Digest 14(4): 25-29.

Sandman, P. M., 1987. "Risk Communication: Facing Public Outrage," EPA Journal, Nov.: No page \#.

Sandman, P. M., et al., 1987. Environmental Risk and the Press, Transaction Books, New Brunswick, NJ

Sandman, P. M., et al., 1987. Environmental Risk and the Press: An Exploratory Assessment, Transaction Books, New Brunswick, NJ.

Sandman, P. M., N. D. Weinstein and M. L. Klotz, 1987. "Public Response to the Risk From Geological Radon," Journal of Communication 37(3): 93-108.

Sandman, P. M. and H. P. Peters, 1988. "Media Reporting of Risk Information: Results of the Working Group," pp. 49-50 in H. Jungermann, R. E. Kasperson and P. M. Wiedermann, eds., Risk Communications: Proceedings of the International Workshop on Risk Communications, Kernforschungsanlange, Julich, FRG.

Scanlon, J., 1990. "People and Warnings: So Hard to Convince," pp. 233-245 in J. Handmer and E. Penning-Rowsell, eds., Hazards of Risk Communication, Gower Publishing Co., England.

Scanlon, J., 1989. "The Hostage Taker, the Terrorist, the Media: Partners in Public Crime," pp. 115-130 in L. M. Walters, L. Wilkins and T. Walters, eds., Bad Tidings: Communication and Castastrophe., Lawrence Erlbaum Associates, Hillsdale, NJ.

Schaffner, K. F., 1991. "Causing Harm: Epidemiological and Physiological Concepts of Causation," pp. 204-217 in Acceptable Evidence, Science and Values in Risk Managment, D. G. Mayo, R. D. Hollander, eds., Oxford University Press, New York, N.Y.

Schrader-Frechette, K., 1991. "Reductionist Approaches to Risk," pp. 218-248 in Acceptable Evidence, Science and Values in Risk Managment, Mayo, D. G., and R. D. Hollander, eds., Oxford University Press, New York, N.Y. 
Schulte, P. A., 1989. "Individual Notification of Workers Exposed to 2-Napthylamine," pp. 105-108 in V. T. Covello, D. B. McCallum and M. T. Pavlova, eds., Effective Risk Communication, Plenum Press, New York, NY.

Segaloff, L., 1961. Task Sirocco: Community Reaction to an Accidental Chlorine Exposure, Institute for Cooperative Research, University of Pennsylvania, Philadelphia, PA.

Shain, R. E., 1989. "It's the Nuclear, Not the Power and It's in the Culture, Not Just the News," pp. 149-160 in L. M. Walters, L. Wilkins and T. Walters eds., Bad Tidings: Communication and Castastrophe, Lawrence Erlbaum Associates, Hillsdale, NJ.

Sharlin, H. I., 1986. "EDB: A Case Study in Risk Communication," Risk Analysis 6(1): $61-68$.

Shoreham Nuclear Power Station, No date. "Public Emergency Procedures-Maps for Zone R.," LILCO, Long Island, NY.

Shortreed, J. H., 1989. "Response to Liston," pp. 65-69 in Leiss, W., ed., Prospects and Problems in Risk Communication, University of Waterloo Press, Waterloo, Ontario.

Shrivastava, P., 1987. "Crisis Communications," Industrial Crisis Quarterly 1(2): 2-3.

Silbergeld, E. K., 1991. "Risk Assessment and Risk Management: An Uneasy Divorce, "pp. 99-114 in Acceptable Evidence, Science and Values in Risk Managment, D. G. Mayo, and R. D. Hollander, eds., Oxford University Press, New York, NY.

Singer, E. and P. Endreny, 1987. "Reporting Hazards: Their Benefits and Costs," Journal of Communications 37(3), Summer: 10-26.

Slovic, P. 1992. "Perception of Risk: Reflections on the Psychometric Paradigm," pp. 117-152 in S. Krimsky and D. Golding, eds., Social Theories of Risk, Praeger, Westport, CT.

Slovic, P., 1991. "Beyond numbers: A Broader Perspective on Risk Perception and Risk Communication," pp. 48-65 in Acceptable Evidence, Science and Values in Risk Managment, D. G. Mayo and R. D. Hollander, eds., Oxford University Press, New York, N.Y.

Slovic, P., 1987. "Perception of Risk," Science 236: 280-90.

Slovic, P., 1986. "Informing and Educating the Public About Risk," Risk Analysis 6(4): $403-415$.

Smith, V. K., et al., 1988. "Learning About Radon's Risk," Journal of Risk and Uncertainty 1: 233-258. 
Somers, E., 1989 "Improving Risk Communication From Governments to the Public," pp. 143-152 in Leiss, W., ed., Prospects and Problems in Risk Communication, University of Waterloo Press, Waterloo, Ontario.

Sood, R., G. Stockdale and E. M. Rodgers, 1987. "How the Media Operate in Natural Disasters," Journal of Communication 37(3), Summer: 27-41.

Sorensen, J. H., 1983. "Knowing How to Behave Under the Threat of Disaster: Can It Be Explained?" Environment and Behavior 15: 438-457.

Sorensen, J. H., and W. R. Dombrowsky, 1988. "Risk Communications for Emergencies and Disasters: Results of the Working Group," pp. 155-158 in H. Jungermann, R. E. Kasperson and P. M. Wiedermann, eds., Risk Communications: Proceedings of the International Workshop on Risk Communications, Kernforschungsanlange, Julich, FRG.

Sorensen, J. H., and D. Mileti, 1991. "Risk Communication in Emergencies," pp. 367-392 in R. E. Kasperson and P. J. Stallen eds., Communicating Risks to the Public, Kluwer Academic Publishers, Dordrecht, Netherlands.

Sorensen, J. H., and D. Mileti, 1989. "Warning Systems for Nuclear Power Plant Emergencies," Nuclear Safety 30: 358-370.

Sorensen, J. H., and D. Mileti, 1987. "Programs That Encourage the Adoption of Precautions Against Natural Hazards: Review and Evaluation," pp. 208230 in N. E., Weinstein, ed., Taking Care: Understanding and

Encouraging Self-protective Behavior, Cambridge University Press, Cambridge.

Sorensen, J. H., and D. Mileti, 1987. "Public Warning Needs," pp. 9-75 in P. Gori and W. Hays eds., A Workshop on The U.S. Geological Survey's Role in Hazards Warnings, Proceedings of Conference XL, US Department of the Interior Geological Survey, Reston, VA.

Sorensen, J. H., D. Mileti and B. Vogt, 1987. Evacuation: An Assessment of Planning and Research, Oak Ridge National Laboratory, Oak Ridge, TN.

Stallen, P. J., 1991. "Developing Communications About Risks of Major Industrial Accidents in the Netherlands," pp. 55-66 in R. E. Kasperson and P. J. Stallen, eds., Communicating Risks to the Public, Kluwer Academic Publishers, Dordrecht, Netherlands.

Stallen, P. J. and R. Coppock, 1987. "About Risk Communication and Risky Communication," Letter to the Editor, Risk Analysis 7(4): 413-414.

Stallen, P. J., No Date, "Planning for Risk Communication in the Netherlands, Art. 8.1 of the 'Seveso'-Directive," Center for Technology and Policy Studies TNO, Apeldoorn, Netherlands.

Stockdale, G. P. and R. Sood, 1989. Emergency Public Information: A Quick Response Study of Coalinga, Natural Hazards Research and Information Center, University of Colorado, Boulder, CO. 
Swenson, O., 1991. "The Time Dimension in Perception and Communication of Risk," pp. 237-285 in R. E. Kasperson and P. J. Stallen, eds., Communicating Risks to the Public, Kluwer Academic Publishers, Dordrecht, Netherlands.

Thomas, L. W., 1987. "Why We Must Talk About Risk, " pp. 19-26 in J. C. Davies, V. T. Covello and F. W. Allen, eds., Risk Communication, The Conservation Foundation, Washington, DC.

US FEMA, 1985. A Guide to Preparing Emergency Public Information Materials, FEMA REP-11, US Federal Emergency Management Agency, Washington, DC.

US GAO, 1987. Nuclear Regulation: Public Knowledge of Radiological Emergency Procedures, GAO/RCED-87-122, US General Accounting Organization, Washington, DC.

Upton, A. C., 1989. "Communicating with the Public on Health Risks," pp. 27-30 in V.T. Covello, D. B. McCallum and M. T. Pavlova, eds., Effective Risk Communication, Plenum Press, New York, NY.

U.S. Army Environmental Hygiene Agency and the CSEPP Sub-Committee on Reentry and Restoration. 1993. General and Detailed Facts about Mustard Agents $(H, H D$, and $H T)$; Nerve Agents GA and GB; Nerve Agent $V X$; and Lewisite (L) Aberdeen, MD: U.S. Army Environmental Hygiene Agency, Aberdeen, MD

USEPA, 1988. Report of a Conference on Risk Communication and Environmental Management, Preparedness and Prevention Technical Assistance Bulletin \#4, USEPA, Washington, DC.

van der Plight, J., and J. de Boer, 1991. "Contaminated Soil: Public Reactions, Policy Decisions and Risk Communication," pp. 127-144 in R. E. Kasperson and P. J. Stallen, eds., Communicating Risks to the Public, Kluwer Academic Publishers, Dordrecht, Netherlands.

van Eijndhoven, J., 1991. "Risk Communication: The Need for a Broader Perspective," pp. 393-412 in R. E. Kasperson and P. J. Stallen, eds., Communicating Risks to the Public, Kluwer Academic Publishers, Dordrecht, Netherlands.

van Eijndhoven, J. and C. Worrell, 1991. "Active and Passive Provision of Risk Information of Major Industrial Accidents in the Netherlands," pp. 35-54 in R. E. Kasperson and P. J. Stallen, eds., Communicating Risks to the Public, Kluwer Academic Publishers, Dordrecht, Netherlands.

Viscusi, W. K. and W. A. Magat, 1987. Learning About Risk, Harvard University Press, Cambridge, MA.

vonWinterfeld, D., 1992. "Expert Knowledge and Public Values in Risk Management: The Role of Decision Analysis," pp. 321-342 in S. Krimsky and D. Golding, eds., Social Theories of Risk, Praeger, Westport, CT. 
Walters, L. M., L. Wilkins and T. Walters, eds., 1989. Bad Tidings:

Communication and Castastrophe, Lawrence Erlbaum Associates, Hillsdale, NJ.

Waterstone, M., 1978. Hazard Mitigation Behavior of Flood Plain Residents, Natural Hazard Working Paper No. 35, Published by the Institute of Behavioral Science, University of Colorado.

Weinstein, N. D., ed., 1987. Taking Care: Understanding and Encouraging Self-protective Actions, Cambridge University Press, New York, NY.

Wertz, D. C. and J. C. Fletcher, 1987. Communicating Genetic Risks," Science, Technology and Human Values 12(3\&4): 60-66.

Whelan, E. M., 1989. "What Kind of Data Does the Public Need?" EPA Journal, May/June: 10.

Whipple, C. 1992. "Inconsistent Values in Risk Management," pp. 343-354 in S. Krimsky and D. Golding, eds., Social Theories of Risk, Praeger, Westport, CT.

Whyte, A., 1977. "The Role of Information Flow in Controlling Industrial Lead Emissions: The Role of the Avonmouth Smelter," Proceedings of the International Conference of Heavy Metals, Institute for Environmental Studies, Toronto.

Wilkins, L., 1989(a), "Conclusion: Accidents Will Happen," pp. 171-177 in L. M. Walters, L. Wilkins and T. Walters, eds., Bad Tidings:

Communication and Castastrophe, Lawrence Erlbaum Associates, Hillsdale, NJ.

Wilkins, L., 1989(b), "Bhopal: The Politics of Mediated Risk," pp. 21-34 in L. M. Walters, L. Wilkins and T. Walters, eds., Bad Tidings: Communication and Castastrophe, Lawrence Erlbaum Associates, Hillsdale, NJ.

Wilkins, L., 1987. Shared Vulnerability, the Media and American Perceptions of the Bhopal Disaster, Greenwood Press, New York, NY.

Wilson, C., 1990. "Education and Risk," pp. 69-75 in J. Handmer and E. Penning-Rowsell, eds., Hazards of Risk Communication, Gower Publishing Co., England

Withers, R., 1988. "Communicator: Decision-Maker: A Dual Role for the Successful Senior Government Manager," Emergency Preparedness Digest 15(1): 18-22.

Wynne, B., 1992. "Risk and Social Learning: Reification to Engagement," pp. 275-297 in S. Krimsky and D. Golding, eds., Social Theories of Risk, Praeger, Westport, CT.

Wynne, B. and J. van Eijndhoven, 1991. "Risk Communication in Europe: Ways of Implementing Art: 8 of the Post-Sevesco Directive," pp. 15-34 in R. E. Kasperson and P. J. Stallen, eds., Communicating Risks to the Public, Kluwer Academic Publishers, Dordrecht, Netherlands. 
Wynne, B., 1988, "Sheepfarming After Chernobyl: A Case Study in Communicating Scientific Information," Environment 31(2): 11-15 and 33-39.

Zervos, C., ed., 1988. Risk Analysis, Prospects and Opportunities, Plenum Press, New York, NY.

Zimmerman, R., 1987. "A Process Framework for Risk Communications," Science, Technology and Human Values, 12(3\&4): 131-137. 


\section{Appendix B}

\section{USEFUL SOURCES}

\section{Risk Communication}

Callaghan, J. D., 1989. "Reaching Target Audiences With Risk Information," pp. 137-142 in V. T. Covello, D. B. McCallum and M. T. Pavlova, eds., Effective Risk Communication, Plenum Press, New York, NY.

Chess, C., B. J. Hance and P. M. Sandman, 1988. Improving Dialog with Communities: A Short Guide for Government Risk Communication, NJ Department of Environmental Protection, Trenton, NJ.

Covello, V. T., 1989. "Informing People About Risks From Chemicals, Radiation and Other Toxic Substances: A Review of Obstacles to Public Understanding and Effective Risk Communication," pp. 1-49 in W. Leiss, ed., Prospects and Problems in Risk Communication, University of Waterloo Press, Waterloo, Ontario.

Covello, V. T., D. B. McCallum and M. T. Pavlova, eds., 1989. Effective Risk Communication, Plenum Press, New York, NY.

Covello, V. T., P. M. Sandman and P. Slovic., 1988. Risk Communication, Risk Statistics and Risk Comparisons: A Manual for Plant Managers, Chemical Manufacturers Association, Washington, D.C.

Davies, J. C., V. T. Covello and F. W. Allen, eds., 1987. Risk Communication, The Conservation Foundation, Washington, DC.

Hance, B. J., C. Chess and P. M. Sandman, 1988. Improving Dialog with Communities: A.Risk Communication Manual for Government, NJ Department of Environmental Protection., Trenton, NJ.

Kasperson, R. E. and P. J. Stallen, eds., 1991. Communicating Risks to the Public, Kluwer Academic Publishers, Dordrecht, Netherlands.

Krimsky, S. and A. Plough, 1988. Environmental Hazards: Communicating Risks As a Social Process, Auburn House, Dover, MA.

Leiss, W., ed., 1989. Prospects and Problems in Risk Communication, University of Waterloo Press, Waterloo, Ontario.

Lindell, M. K. and R. W. Perry, 1992. Behavioral Foundations of Community Emergency Planning, Hemisphere Publishing Company, Washington, DC.

Sandman, P. M., 1987. "Risk Communication: Facing Public Outrage," EPA Journal, Nov.: No page number.

\section{Chemical Agent and Characteristics}

Pechura, M. and D. P. Rall, eds., 1993. Veterans at Risk: The Health Effects of Mustard Gas and Lewisite, National Academy Press, Washington, DC. 
B-2 


\section{Appendix C \\ Basic LIbrary of CSEPP Documents}

The purpose of this bibliography is to provide a fairly comprehensive listing of reports and publications concerning the CSEPP program for chemical agent accidents. It is not intended to be a bibliography on chemical agent disposal, nor an inventory of all literature that may have implications for emergency preparedness. Furthermore, it does not inventory emergency plans at each site. It represents a core library of materials that an emergency manager, planner, or trainer interested in details about CSEPP may wish to consult for basic information. These sources will contain many references should more detailed information be needed about a specific topic. To obtain copies of these documents, contact FEMA Headquarters or the U.S. Department of the Army.

\section{CSEPP LEGISLATION AND REGULATIONS}

Federal Emergency Management Agency and U.S. Department of the Army Memorandum of Understanding (MOU), August 1988. This MOU between FEMA and the U.S. Department of the Army created the CSEPP and identified the Agencies' respective areas of responsibility.

Public Law 99-145 (50 USC 1521). Defense Authorization Act for FY86, U.S. Congress, Washington, DC. This law required the Secretary of Defense to dispose of the unitary agent stockpile while providing "maximum protection for the environment, the general public, and the personnel who are involved in [such] destruction."

U. S. Department of the Army. Chemical Surety Program, Army Regulation 50-6. 1986. This regulation (under review) provides controls for chemical weapons materiel, including CAIRA operations, chemical event notification, safety guidance, and requirements pertaining to military contractors.

U.S. Department of the Army, 1991. Chemical Accident/Incident Response and Assistance (CAIRA) Operations, Pamphlet 50-6, May 17, 1991. This document provides technical guidance to Army elements responsible for responding to a chemical event. The basis for this document is Army Regulation 50-6.

\section{RELATED LEGISLATION AND REGULATIONS}

Public Law 95-95 (42 U. S. C. 7401 et seq.). Clean Air Act of 1977, as amended. U. S. Congress.

Public Law 96-510 (42 U. S. C. 9601-9675). Comprehensive Environmental Response, Compensation and Liability Act of 1980, as amended (CERCLA). U. S. Congress.

Public Law 94-580 (42 U. S. C. 6901-6991). Resource, Conservation and Recovery Act of 1976, as amended (RCRA). U.S. Congress.

Public Law 96-482 (42 U. S. C. 3251 et seq.). Solid Waste Disposal Act of 1980, as amended by RCRA U. S. Congress.

Public Law 99-499 (42 U. S. C. 9601-9675). Superfund Amendments and Reauthorization Act of 1986 (SARA). U. S. Congress.

Public Law 94-469 (15 U. S. C. 2601 et seq.). Toxic Substances Control Act of 1976, as amended (TSCA). U. S. Congress.

\section{POLICY PAPERS}

CSEPP Policy Paper \#1, Definition of Maximum Protection, May 7, 1991. This Policy Paper provides the operational definition of "maximum protection" for the CSEPP. 
CSEPP Policy Paper \#2, Environmental Sampling to Determine Agent Contamination, September 30 , 1993. This Policy Paper identifies roles and responsibilities for agent monitoring activities in a chemical event.

CSEPP Policy Paper \#5, County Public Information Officers in CSEPP, December 11, 1992. This Policy Paper allows Immediate Response Zone Couties to hire CSEPP-funded Public Information Officers.

CSEPP Policy Paper \#7, Interim Policy Regarding Offpost Meteorological Towers for CSEPP, March 26, 1993. This Policy Paper allows CSEPP jurisdictions to purchase a limited number of wind monitoring devices for use offpost.

CSEPP Policy Paper \#8, Review of Exercise Initiating Events, April 23, 1993. This Policy Paper describes the process to be used for approval of the initiating event for the CSEPP exercises.

CSEPP Policy Paper \#9, Public Information in Connection with CSEPP Exercises,

April 23, 1993. This Policy Paper describes the type of public information needed for CSEPP exercises.

CSEPP Policy Paper \#11, Compensation for Volunteer CSEPP Exercise Participants, September 10 , 1993. This Policy Paper outlines the concept for compensating CSEPP exercise participants.

CSEPP Policy Paper \#12, CSEPP Exercises, March 2, 1994. This Policy Paper promulgates the February, 1994, exercise policies, procedures, and objectives document.

Note: Policy Papers \#3, 6, and 10 have not been issued. Policy Paper \#4, Roles and Responsibilities of the Joint Steering Committee Subcommittees, March 3, 1992, is no longer in effect.

\section{GENERAL PROGRAM DOCUMENTS}

Argonne National Laboratory. The Chemical Stockpile Emergency Preparedness Program Management Plan, U.S. Department of the Army and Federal Emergency Management Agency, March 1990.

Oak Ridge National Laboratory and Schneider Engineers. Planning Guidance for the Chemical Stockpile Disposal Program Final Draft, U.S. Department of the Army and Federal Emergency Management Agency, November 25, 1992.

Appendix A Planning Guidelines for Command and Control Appendix B Planning Guidelines for EOC Location, Design, and Equipment

Appendix C Communications Support Network: System Design Criteria and Evaluation Guide

Appendix D Planning Guidelines for Protective Action Decision Making

Appendix E Planning Guidelines for Protective Actions and Responses

Appendix $F$ Public Alert and Notification Systems: System Design Criteria and Evaluation Guide

Appendix $G \quad$ Planning Guidelines for Traffic and Access Control

Appendix $H \quad$ Planning Guidelines for Emergency Support Operations (interim)

Appendix 1 Planning Guidelines for Emergency Medical Services (Draft)

Appendix J Planning Guidelines for Public Education and Information

Appendix K Planning Guidelines for Evacuee Support

Appendix $L \quad$ Planning Guidelines for Response-Phase Decontamination

Appendix $M$ Planning Guidelines for Recovery-Phase Activities (Draft)

Appendix N Functional Requirements For the CSEPP Automated Emergency Management Information System.

National CSEPP Benchmarks, May 3, 1993. This paper provides benchmarks against which to assess capabilities and funding requests.

Schneider Engineers and Jacobs Engineering. Emergency Response Program Guidance for the Chemical Stockpile Disposal Program, Office of the Program Manager for Chemical Demilitarization, Aberdeen, MD, 1987. 
U. S. General Accounting Otfice (GAO). Chemical Weapon Stockpile: Army's Emergency Preparedness Program Has Been Slow to Achieve Results, Report to the Chairman, Subcommittee on Environment, Energy, and Natural Resources, Committee on Government Operations, House of Representatives, (GAO/NSIAD-94-91), 1994.

\section{MEMORANDA/LETTERS}

Funding EOCs for CSEPP, Associate Director, SLPS, memo to Regional Directors, September 24, 1991. This memorandum explained the requirements for EOC location and funding eligibility.

Process for Approving IRZJPAZ Boundaries, July 17, 1992. Assistant Associate Director, Office of Technological Hazards, memorandum to Regional Directors explaining process for approving IRZ/PAZ boundaries.

Interim Decontamination Policy for CSEPP, Associate Director, SLPS, September 23, 1992. This policy allowed the provision of limited decontamination assets to off-post authorities and required compliance with OSHA standards governing hazmat response.

Army/FEMA MOU, January 22, 1993, Joint Memorandum for Record, Assistant Associate Director, Office of Technological Hazards, memo to Regional Directors.

Federal Emergency Management Agency and U.S. Department of the Army. Reaffirmation of Federal Emergency Management Agency and U.S. Department of Army Memorandum of Understanding (MOU), January 1993. This document re-confirmed the two agencies' commitment to the CSEPP and to the division of responsibilities under the original MOU.

Memorandum from the Assistant Director, National Institute for Occupational Safety and Health, to Acting Director National Center for Environmental Health, April 14, 1994, containing recommendations on the use of personal protective equipment.

Letter from Assistant Surgeon General and Acting Director, National Center for Environmental Health, U.S. Public Health Service to the Acting Assistant Secretary of the Army (I, L, \& E), April 26, 1994, concurring with Centers for Disease Control and Prevention's position on the personal protective equipment ensemble.

Letter from Deputy for Chemical Demilitarization to the Deputy Associate Director, Federal Emergency Management Agency, May 23, 1994, regarding personal protective equipment.

Restructuring CSEPP, February 24, 1994, Joint FEMA/Army Memorandum for the Record, providing the framework for restructuring the CSEPP and for cooperation between FEMA and the Army.

FEMA Resource Requirements to Support the Restructured CSEPP, February 25, 1994. Joint FEMAVArmy Memorandum for the Record outlining resource requirements for the CSEPP.

\section{PLANNING TECHNICAL REPORTS AND PUBLICATIONS}

Carnes, S. A. Site-Specific Emergency Response Concept Plans For the Chemical Stockpile Disposal Program: A Comparative Summary, Oak Ridge National Laboratory, ORNL/TM-11357, 1989.

Chester, C. V. Technical Options for Protecting Civilians from Toxic Vapors and Gases, Oak Ridge National Laboratory, ORNLTM-10423, 1989.

Chester, C. V. Accident Assessment for the Chemical Stockpile Emergency Preparedness Program, Oak Ridge National Laboratory, ORNL/TM-11354, 1990.

Department of Defense Explosives Study Board. Methodology for Chemical Hazard Prediction, Technical Paper No. 10, Change 3, Department of Defense, 1980. 
FEMA, U. S. DOT, U. S. EPA. Handbook of Chemical Hazard Analysis Procedures, Washington, DC, 1989.

Feldman, D. L. Intergovernmental Consultation and Coordination and Emergency Response: The Relationship Between ICCB and SARA Title III in the U.S. Army's Chemical Stockpile Disposal Program, Oak Ridge National Laboratory, ORNL/TM-10923, 1989.

Feldman, D. L. Implications of SARA Title III for Community-Based Emergency Planning in the U.S. Army's CSDP: The Acquisition of Emergency Equipment, Oak Ridge National Laboratory, ORNLTM11388,1990 .

IEM, Inc. "CSEPP Glossary" (Draft Paper), Baton Rouge, LA, 1994.

IEM, Inc. "Planning For Emergencies: Lessons from General Emergency Response Planning for the Chemical Stockpile Emergency Preparedness Program" (Draft Paper), Baton Rouge, LA, 1993.

Linnabary, R. D., J. C. New, B. M. Vogt, C. Griffith-Davies and L. Williams. "Emergency Evacuation of Horses-A Madison County, Kentucky Survey," J. Equine Vet. Sci. 13: 153-158, 1993.

Lombardi, D. P. D2PC Sensitivity Analysis, Oak Ridge National Laboratory, ORNL/TM -12134, 1992.

Miller, R. L. Atmospheric Dispersion Modeling and Meteorological Monitoring in Support of Emergency Planning and Response for the U.S. Army's Chemical Stockpile Disposal Program, Oak Ridge National Laboratory, ORNL/TM-11508, 1990.

Myerski, M. and T. Lemcke. Reference Manual: D2PC and Hazard Analysis, IEM, Inc., 1993.

Rathi, A. K., et al. OREMS User Guide Version 1.0, Oak Ridge National Laboratory, 1994.

Rathi, A. K., and R. S. Solanki. The Oak Ridge Evacuation Modeling System (OREMS), Proceedings of the 1993 Winter Simulation Conference, December, 1993.

Rogers, G. O., and R. D. Sharp. Protective Action Evaluator for Chemical Emergencies: A User's Manual (MS-DOS Version 1.0), Oak Ridge National Laboratory, ORNLTM-11594, 1990.

Rogers, G. O., A. P. Watson, J. H. Sorensen, R. O. Sharp, and S. A. Carnes. Evaluating Protective Actions for Chemical Agent Emergencies, Oak Ridge National Laboratory, ORNL-6615, 1990.

Rogers, G. O., J. H. Sorensen, and A. P. Watson. "Protecting Civilian Populations During Chemical Agent Emergencies," pp. 357-386 in S. Somani, ed., Chemical Warfare Agents, Academic Press, London, 1992.

Schneider Engineers. Final Report: Emergency Program Technical Support, Office of the Program Manager for Chemical Demilitarization, Aberdeen, MD, 1989.

Schneider Engineers. Assessment of Emergency Operations Centers for Immediate Response Zone Counties, Final Draft, Harrisburg, PA, 1990.

Sorensen, J. H. Evaluation of Warning and Protective Action Implementation Times for Chemical Weapons Accidents, Oak Ridge National Laboratory, ORNL/TM-10437, 1988.

Sorensen, J. H. Assessment of the Need for Dual Indoor/Outdoor Warning Systems and Enhanced Tone Alert Technologies In the CSEPP, Oak Ridge National Laboratory, ORNLTM-12095,1992.

Sorensen, J. H., G. O. Rogers, and M. Meador. "Modeling Protective Action Decisions for Chemical Weapons Accidents," pp. 30-34 in J. Sullivan and B. Clymer, eds., Managing Risk with Computer Simulation, Society for Computer Simulation, San Diego, CA, 1992. 
Sorensen, J. H., S. A. Carnes, and G. O. Rogers. "An Approach for Deriving Emergency Planning Zones for Chemical Stockpile Emergencies," Journal of Hazardous Materials 30: 223-242, 1992.

Southworth, F. Regional Evacuation Modeling: A State-of-the-Art Review, Oak Ridge National Laboratory, ORNL/TM-11740, 1990.

U.S. EPA, FEMA, and U.S. DOT. Technical Guidance for Hazards Analysis: Emergency Planning for Extremely Hazardous Substances, Washington, DC, 1987.

Vogt, B. M. Evacuation in Emergencies: An Annotated Bibliography, Knoxville, TN: Energy, Environment, and Resource Center, University of Tennessee, 1991.

Vogt, B. M., and J. H. Sorensen. Evacuation Research: A Reassessment, Oak Ridge National Laboratory, ORNL/TM-11908, November, 1992.

\section{TRAINING TECHNICAL REPORTS AND PUBLICATIONS}

Clevenger, W. F., C. J. Coomer, E. D. Copenhaver, and J. H Sorensen. Technical Planning and Evaluation Student Workbook (Draft), Oak Ridge National Laboratory, ORNL/M-3096, 1993.

Clevenger, W. F, C. J. Coomer, E. D. Copenhaver and J. H. Sorensen, 1993. Technical Planning and Evaluation Workbook (Draft), Oak Ridge National Laboratory, ORNL/M-3096, 1993.

Copenhaver, E. D. Management Plan for Chemical Stockpile Emergency Preparedness Program Medical Course (Re)Design, Oak Ridge National Laboratory, ORNLTM-11842, 1991.

Copenhaver, E. D., A. P. Watson, and E. Sample. ACT FAST: Agent Characteristics and Toxicology, First Aid and Special Treatment, Oak Ridge National Laboratory, ORNL/M-2097,1992.

Copenhaver, E. D. Decontamination for CSEPP: Training Guide, Oak Ridge National Laboratory, ORNL/M-3081, 1994.

Copenhaver, E. D. Use of Auto-Injectors by Civilian Emergency Medical Personnel to Treat Civilians Exposed to Nerve Agent, Study Guide [Draft], Oak Ridge National Laboratory, ORNL/M-3319, 1994.

Copenhaver, E. D., A. P. Watson (ORNL), G. D. Graves, R. C. Rempes, P. Carnithan, and J. R. McDaniel (USADACS). CSEPP Chemical Awareness, Oak Ridge National Laboratory, ORNL/M-2099, 1992.

Copenhaver, E. D. (ed.) Proceedings of the Utah CSEPP Health and Medical Symposium, Chemical Agents and Man, Salt Lake City, Utah, June 24-25, 1992.

Copenhaver, E. D., et al. Chemical Stockpile Agent Characteristics and Effects (Video), Oak Ridge National Laboratory, 1993.

Copenhaver, E. D., and C. J. Coomer. Risk Communication for CSEPP Study Guide (Draft), Oak Ridge National Laboratory, 1994.

Copenhaver, E. D., and C. J. Coomer. Using Interactive Techniques to Teach Risk Communication for CSEPP: An Instructor's Guide (Draft), Oak Ridge National Laboratory, ORNL/M-2819, 1994.

Copenhaver, E. D., C. J. Coomer, J. H. Sorensen, and W. F. Clevenger. Technical Planning and Evaluation Facilitator's Guide (Draft), Oak Ridge National Laboratory, ORNL/M-3184, 1994.

Federal Emergency Management Agency and U.S. Department of the Army. Training Plan for the Chemical Stockpile Emergency Preparedness Program, Washington, DC, 1993. 
Foust, C. B., C. J. Coomer, and E. D. Copenhaver. Personal Protective Equipment Study Guide (Draft), Oak Ridge National Laboratory, ORNL/M-3638, 1994.

Foust, C. B., C. J. Coomer, and E. D. Copenhaver. Personal Protective Equipment Instructor's Guide (Draft), Oak Ridge National Laboratory, ORNL/M-3638, 1994.

Johnson, M. L., and A. F. Twitty. CSEPP CHEMICAL AWARENESS Computer-Aided Instruction, KJDSRD-1331, Data Systems Research and Development Program, Technical Operations, Center for Intelligent Systems, Oak Ridge, TN, 1993.

Jones, E. C. Instructor's Guide and Lesson Plan for ACT FAST: Agent Characteristics and Toxicology, First Aid and Special Treatment, Oak Ridge National Laboratory, ORNL/M-2098, 1992.

Jones, E. C. Instructor's Guide and Lesson Plan for CSEPP Chemical Awareness, Oak Ridge National Laboratory, ORNL/M-2100, 1992.

Jones, E. C., and S. Adams. Techniques for CSEPP Instructors, Oak Ridge National Laboratory, ORNL/M-2101, 1992.

Jones, E. C. Instructor Guide for Techniques for CSEPP Instructors, Oak Ridge National Laboratory, ORNL/M-2102, 1992.

Thompson, P. G., Clevenger, W. F., Copenhaver, E. D., and C. J. Coomer. "An Integrated Approach to Technological Risk Analysis and Protective Action Decision-Making," pp. 232-237 in Proceedings from The International Emergency Management and Engineering Conference, Hollywood, FL, April 18-21, 1994.

Twitty, A. F., and M. L. Johnson. ACT FAST Characteristics and Toxicology First Aid and Special Treatment Computer-Aided Instruction, Data Systems Research and Development Program, Applied Technology Center for Intelligent Systems, Oak Ridge K-25 Site, 1992.

Vogt, B. M., and J. H. Sorensen. Risk Communication for the CSEPP (Draft), Oak Ridge National Laboratory, 1994.

Yow, T. CACTIS (Computer-Aided CSEPP Training Information Systems) User's Guide, Beta Software National Version, Oak Ridge National Laboratory, 1993.

Yow, T. CACTIS (Computer-Aided CSEPP Training Information Systems) User's Guide, Beta Software State Version, Oak Ridge National Laboratory, 1993.

\section{AUTOMATION TECHNICAL REPORTS AND PUBLICATIONS}

Applied Computing Systems, Inc. Integrated Baseline Systems (IBS) Communication Documentation for the U.S. Army Emergency Management Information System, Emergency Management Information System (EMIS) Version 2.04, Albuquerque, NM, 1994.

Applied Computing Systems, Inc. Quick Start Documentation for the U.S. Army Emergency Management Information System, EMIS Version 2.04, Albuquerque, NM, 1994.

Applied Computing Systems, Inc. System Administration Documentation for the U.S. Army Emergency Management Information System, EMIS Version 2.04, Albuquerque, NM, 1994.

Applied Computing Systems, Inc. User Documentation for the U.S. Army Emergency Management Information System, EMIS Version 2.04, Albuquerque, NM, 1994.

Black, Gary D., et al. Federal Emergency Management Information System (FEMIS): System Requirements Specification (SRS) FEMIS: Phase 1, Version 2.0, Pacific Northwest Laboratory, Richland, WA, 1994. 
CSEPP Automation Subcommittee. SRFX91/CSEPP Automation Exercise Evaluation After Action Report, 1991.

Feldman, D., and J. Dobson. Decision Making Technical Support Study for the U.S. Army's Chemical Stockpile Emergency Preparedness Program, Oak Ridge National Laboratory, ORNLTM-11412, 1990.

Hucks II, J. A., and F. E. Strycker, Jr. Federal Emergency Management Information System (FEMIS): Hardware Requirements Specification (HRS) FEMIS: Phase I, Version 2.0, Pacific Northwest Laboratory, Richland, WA, 1994.

IEM, Inc. Computer Based Training (CBT) for EMIS 2.04 Spin Up Training, Baton Rouge, LA, 1994. IEM, Inc. EMIS 2.04 Spin-Up Training Manual, Baton Rouge, LA, 1994.

IEM, Inc. EMIS 2.04-IBS 2.04 Interface Control Document, Baton Rouge, LA, 1994.

IEM, Inc. EMIS Workflow Manual, Baton Rouge, LA, 1994.

IEM, Inc. Computer Based Training (CBT) for IBS 2.04 Spin Up Training, Baton Rouge, LA, 1994.

IEM, Inc. IBS 2.04 Spin-Up Training Manual, Baton Rouge, LA, 1994.

IEM, Inc. IBS Workflow Manual, Baton Rouge, LA, 1994.

IEM, Inc. CSEPP Automation Staffing Study, Baton Rouge, LA, 1994.

IEM, Inc. CSEPP Automation Training Management Plan: CY 1994-1995, Baton Rouge, LA, 1994.

IEM, Inc. CSEPP Integrated Baseline System (IBS) Database Plan, Baton Rouge, LA, 1993.

IEM, Inc. CSEPP Integrated Baseline System (IBS) Database Utilities: Documentation, Baton Rouge, LA, 1993.

IEM, Inc. Executive Overview, (Instructional Materials), Baton Rouge, LA, 1993.

IEM, Inc. Federal Emergency Management Information System (FEMIS): Requirements Analysis and Functional Baseline, Baton Rouge, LA, 1993.

Oak Ridge National Laboratory. Draft Functional Specifications for the CSEPP Automated Emergency Management Information System, Oak Ridge National Laboratory, 1993.

Pacific Northwest Laboratory. Integrated Baseline System (IBS) Version 2.0: Data Management Guide, Richland, WA, 1994.

Pacific Northwest Laboratory. Integrated Baseline System (IBS) Version 2.0: Models Guide, Richland, WA, 1994.

Pacific Northwest Laboratory. Integrated Baseline System (IBS) Version 2.0: System Management Guide, Richland, WA, 1994.

Pacific Northwest Laboratory. Integrated Baseline System (IBS) Version 2.0: User Guide, Richland, WA, 1994.

Pacific Northwest Laboratory. Integrated Baseline System (IBS) Version 2.0: Utilities Guide, Richland, WA, 1994. 
Yardley, Christian K., et al. Federal Emergency Management Information System (FEMIS): Software Subsystem Component Recommendations (Parts 1 \& 2), Pacific Northwest Laboratory, 1994.

\section{REENTRY TECHNICAL REPORTS AND PUBLICATIONS}

Caton, J. E., K. H. Hazen, W. H. Griest, A. P. Watson and M. V. Buchanan. "Rapid Method for Isolating Targeted Organic Molecules in Tissue," Analytical Letters 27 (2): 351-362, 1994.

Daugherty, M. W., A. P. Watson, and T. Vo-Dinh. "Currently Available Permeability and Breakthrough Data Characterizing Organophosphates and Warfare Agent Simulants in Civilian Protective Clothing Materials," J. of Hazardous Materials 30: 243-267, 1992.

Halbrook, R. S., et al. "A Rapid Whole Blood Cholinesterase Assay With Potential Use for Biological Monitoring During Chemical Weapons Disposal," J. Assoc. Offic. Anal. Chem. 75: 549-553,1992.

Halbrook, R. S., et al. "Characterizing Biological Variability in Livestock Blood Cholinesterase Activity for Biomonitoring Organophosphate Nerve Agent Exposure," J. of the American Veterinary Medical Association 201: 714-725, 1992.

Herzenberg et al. Recovery from a Chemical Weapons Accident or Incident: A Concept Paper on Planning, ANLDIS/TM-14, Argonne, IL, 1994.

Jenkins, R. A., et al. Protocol for Determination of Chemical Warfare Agent Simulant Movement through Porous Media, Oak Ridge National Laboratory, ORNL/TM-12002, 1992.

Jenkins, R. A., et al. "Movement of Chemical Warfare Agent Simulants Through Porous Media," J. of Hazardous Materials 37: 303-325.

Kistner, S. L., et al. "Unitary Agents: A Roadmap to Control Limits and Analytical Methods," Procedures of the 16th Annual Army Environmental R\&D Symposium, Williamsburg, VA, June 23-25, 1992.

Leffingwell, S. S. "Results of a Workshop Meeting to Discuss Protection of Public Health and Safety During Reentry into Areas Potentially Contaminated with a Lethal Chemical Agent (GB, VX, or Mustard Agent)," Availability announced in 55 FR 28940 (July 16, 1990); comment period closed August 30 , 1990.

Lombardi, D. A., M. Morris and A. P. Watson. "Using Air Dispersion Modeling as a Key Tool for Reentry Decision-Making Following an Accidental Release of Chemical Warfare Agent," Proceedings of Air and Waste Management Association, Vol1, (June 14-18, 1993), Denver, CO, Paper \#93-TP-26B.04,1993.

Munro, N. B., L. R. Shugart, A. P Watson and R. S. Halbrook. "Reviewing Cholinesterase Activity Levels in Domestic Animals as a Potential Biomonitor for Organophosphate Exposure," J. of the American Veterinary Medical Association 199: 103-115, 1991.

Munro, N. B., K. R. Ambrose and A. P. Watson. "Toxicity of Organophosphate Chemical Warfare Agents GA, GB, and VX: Implications for Public Protection," Environmental Health Perspectives 102: 18-32, 1994.

Pal, T., et al. "Permeation Measurements of Chemical Agent Simulants Through Protective Clothing Materials," J. of Hazardous Materials 33: 123-141, 1993.

Vo-Dinh, T., and T. Pal. Development of a Spectrochemical Modification (SM) Technique to Detect Permeation of Chemical Warfare Agent Simulants Through Protective Clothing Materials, Oak Ridge National Laboratory, ORNL/TM-11915, 1991. 
Vo-Dinh, T., and T. Pal. "Development of a Fluorescence Quenching Technique to Detect Permeation of Chemical Agent Simulants Through Protective Clothing Materials," Applied Spectroscopy 46: 677$681,1992$.

Watson, A. P., and N. B. Munro, 1992. Reentry Planning: The Technical Basis for Offsite Recoveny Following Warfare Agent Contamination, Oak Ridge National Laboratory, ORNL-6628, 1992.

Watson, A. P., et al. Estimated General Population Control Limits for Unitary Agents in Drinking Water, Milk, Soil, and Unprocessed Food Items, Oak Ridge National Laboratory, ORNL/TM-12035, 1992.

Watson, A. P., et al. General Guidelines for Medically Screening Mixed Population Groups Potentially Exposed to Nerve or Vesicant Agents, Oak Ridge National Laboratory, ORNL/TM-12034, 1992.

Watson, A. P., T. D. Jones, and J. D. Adams. "A Relative Potency Approach for Estimating Allowable Residues and Reentry Intervals Following Organophosphate Nerve Agent Release," Ecotoxicology and Environmental Safety 23: 328-342, 1992.

Watson, A. P., and G. D. Griffin. "Toxicity of Vesicant Agents Scheduled for Destruction by the Chemical Stockpile Disposal Program," Environmental Health Perspectives 98: 259-280, 1992

Watson, A. P., and G. D. Griffin. "Sulfur Mustard," pp. 681-691 in Handbook of Hazardous Materials, Academic Press, Inc., 1992.

\section{PUBLIC AFFAIRS TECHNICAL REPORTS AND PUBLICATIONS}

Federal Emergency Management Agency. Guidelines for Conducting Public Affairs Activities in Support of Alert and Notification System Development, Installation and Operation, 1991.

Federal Emergency Management Agency. Chemical Stockpile Emergency Preparedness Program Brochure, 1991.

Federal Emergency Management Agency. CSEPP Public Affairs Plan, (no date).

Federal Emergency Management Agency. Local Officials Briefing Package: CSEPP Overview, 1991.

Vogt, B. M., and J. H. Sorensen. Preparing EBS Messages, Oak Ridge National Laboratory, ORNLTM12163, 1992.

\section{EXERCISE TECHNICAL REPORTS AND PUBLICATIONS}

Adler, M. V., and K. S. Gant. "From Nuclides to Nerve Gas: The Development of the Chemical Stockpile Emergency Preparedness Exercise Program," pp. 11-16 in Managing Changes and Priorities (Proceedings from the 15th Annual TRADE Conference, St. Petersburg, Florida, November 18-20, 1991), Oak Ridge Institute for Science and Education, Oak Ridge, TN, 1992.

IEM, Inc. CAIRA Exercise Report: 30 March 1994, Baton Rouge, LA, 1994.

IEM, Inc. CAIRA Exercise Report: 28 April 1994, Baton Rouge, LA, 1994.

Oak Ridge National Laboratory. Chemical Stockpile Emergency Preparedness Program Exercises, Oak Ridge National Laboratory, 1994.

Oak Ridge National Laboratory. Chemical Stockpile Emergency Preparedness Program Exercise Program II. Exercise Objectives and Points of Review, Oak Ridge National Laboratory, 1992 (to be replaced as Appendix C to basic document in 1994). 


\section{GENERAL REFERENCES ON CHEMICAL AGENTS AND DISPOSAL}

Cames, S. A., (ed.). "Special Report: Integrated Environmental Assessment for a Major Project (Chemical Stockpile Disposal)", Special edition of The Environmental Professional 11 (4), 1989.

Carnes, S. A., and A. P. Watson. "Disposing of the U.S. Chemical Weapons Stockpile: An Approaching Reality," J. of the American Medical Association 262 (5): 653-659, 1989.

Fraize, W. E., R. M. Cutler, and G. F. Flanagan. "The Probabilistic Treatment of Potential Accidents: What Are the Relative Risks of Lethal Chemical Agent Releases to the Atmosphere," Environmental Professional 11 (4): 297-314, 1989.

Miller , R. L., and F. C. Komegay. "Downwind Doses from Potential Releases Associated with the Chemical Stockpile Disposal Program," Environmental Professional 11 (4): 315-323, 1989.

MITRE Corporation. Risk Analysis Supporting the Chemical Stockpile Disposal Program, Prepared for the Program Manager for Chemical Demilitarization, Aberdeen Proving Grounds, MD, 1987.

National Research Council. Disposal of Chemical Munitions and Agents, National Academy Press, Washington, DC, 1984.

National Research Council. Proceedings of the Alternative Technologies Forum, National Academy Press, 1993.

National Research Council. Alternative Technologies for the Destruction of Chemical Agents and Munitions, National Academy Press, 1993.

National Research Council. Evaluation of the Johnston Atoll Chemical Agent Disposal System Operational Verification Testing: Part II, National Academy.

National Research Council. Review of Monitoring Activities within the Army Chemical Stockpile Disposal Program, National Academy Press, 1994.

National Research Council. Recommendations for the Disposal of Chemical Agents and Munitions, National Academy Press, 1994.

Office of Technology Assessment. Disposal of Chemical Weapons: Atternative TechnologiesBackground Paper, U. S. Congress, 1992.

Rogers, G., J. Sorensen, J. Long and D. Fisher. "Emergency Planning For Chemical Weapons Accidents," Environmental Professional 11: 396-408. 1989.

U.S. Army Chemical and Biological Defense Agency. Material Safety Data Sheets, Aberdeen Proving Ground, MD, 1993 (Reprinted by FEMA).

U.S. Department of the Army. Chemical Stockpile Disposal Program Final Programmatic Environmental Impact Statement, Vols. 1, 2, \& 3, U.S. Department of the Army, Washington, DC, 1987.

\section{SITE-SPECIFIC DOCUMENTS}

\section{ANAD}

Carnes, S. A., et al. Emergency Response Concept Plan For ANAD and Vicinity, Oak Ridge National Laboratory, ORNL/TM-11093, 1989. 
Hunsaker, D. B., et al. Final Phase I Environmental Report: Disposal of Chemical Agents and Munitions Stored at Anniston Army Depot, Anniston, Alabama, Oak Ridge National Laboratory, ORNL/TM-11206V1 \& 2, 1992.

IEM, Inc. CSEPP IBS Databases: Documentation for the Alabama Database, Baton Rouge, LA, 1993.

Metzger, D., et al. Evacuation Time Estimates for Anniston Army Depot and Vicinity (Draft), Oak Ridge National Laboratory, 1991.

Program Manager for Chemical Demilitarization. Disposal of Chemical Agents Stored at Anniston Army Depot, Anniston, Alabama, Final Environmental Impact Statement, Aberdeen Proving Ground, MD, 1991.

Schneider Engineers. Pre-engineering Report: Equipment and Cost Estimates for Emergency Notification/Communication System Concept and Public Alent and Notification Design Concept, Harrisburg, PA, 1989.

Schneider Engineers. Training Needs Analysis for Chemical Emergency Response at ANAD (Draft), Harrisburg, PA., 1989.

Schneider Engineers. Public Alert and Notification System Study for ANAD (Draft), Harrisburg, PA, 1989.

Schneider Engineers. Emergency Notification/Communication System Study for Chemical Accident/Incidents at ANAD (Draft), Harrisburg, PA, 1989.

\section{APG}

Carnes, S. A., et al. Emergency Response Concept Plan For APG and Vicinity, Oak Ridge National Laboratory, ORNL/TM-11096,1989.

IEM, Inc. Analysis of Current Response Plans: APG Site. Baton Rouge, LA. 1994.

Schneider Engineers. Pre-engineering Report: Equipment and Cost Estimates for Emergency Notification/Communication System Concept and Public Alert and Notification Design Concept, Harrisburg, PA, 1989.

Schneider Engineers. Training Needs Analysis for Chemical Emergency Response at APG, Harrisburg, PA, 1989.

Schneider Engineers. Public Alert and Notification System Study for APG (Draft), Harrisburg, PA, 1989.

Schneider Engineers. Emergency Notification/Communication System Study for Chemical

Accident/Incidents at APG (Draft), Harrisburg, PA, 1989.

Southworth, F., et al. Evacuation Time Estimates for Aberdeen Proving Ground and Vicinity (Draft), Oak Ridge National Laboratory, 1991.

\section{BGAD}

Carnes, S. A., et al. Emergency Response Concept Plan For LBAD and Vicinity, Oak Ridge National Laboratory, ORNL/TM-11099, 1989.

IEM, Inc. Analysis of Current Response Plans: BGAD Site (Draft). Baton Rouge, LA, 1994.

IEM, Inc. CSEPP IBS Databases: Documentation for the Kentucky Database, Baton Rouge, LA, 1993.

Rathi, A. K., et al. Evacuation Time Estimates for Lexington-Blue Grass Army Depot and Vicinity (Draft), Oak Ridge National Laboratory, 1992. 
Schneider Engineers. Pre-engineering Report: Equipment and Cost Estimates for Emergency . Notification/Communication System Concept and Public Alert and Notification Design Concept, Harrisburg, PA, 1989.

Schneider Engineers. Training Needs Analysis for Chemical Emergency Response at LBAD (Draft), Harrisburg, PA, 1989.

Schneider Engineers. Public Alert and Notification System Study for LBAD (Draft), Harrisburg, PA, 1989.

Schneider Engineers. Emergency Notification/Communication System Study for Chemical Accident/Incidents at LBAD (Draft), Harrisburg, PA, 1989.

\section{NAAP}

Carnes, S. A., et al. Emergency Response Concept Plan For NAAP and Vicinity, Oak Ridge National Laboratory, ORNL/TM-11095, 1989.

IEM, Inc. Analysis of Current Response Plans: NAAP Site (Draft), Baton Rouge, LA, 1994.

IEM, Inc. CSEPP IBS Databases: Documentation for the Illinois Database, Baton Rouge, LA, 1994.

IEM, Inc. CSEPP IBS Databases: Documentation for the Indiana Database, Baton Rouge, LA, 1993.

Rathi, A. K., et al. Evacuation Time Estimates for Newport Army Ammunition Plant and Vicinity (Draft), Oak Ridge National Laboratory, 1992.

Schneider Engineers. Pre-engineering Report: Equipment and Cost Estimates for Emergency Notification/Communication System Concept and Public Alert and Notification Design Concept, Harrisburg, PA, 1989.

Schneider Engineers. Training Needs Analysis for Chemical Emergency Response at NAAP (Draft), Harrisburg, PA, 1989.

Schneider Engineers. Public Alert and Notification System Study for NAAP (Draft), Harrisburg, PA, 1989.

Schneider Engineers. Emergency Notification/Communication System Study for Chemical Accident/Incidents at NAAP (Draft), Harrisburg, PA, 1989.

\section{PBA}

Carnes, S. A., et al. Emergency Response Concept Plan For PBA and Vicinity, Oak Ridge National Laboratory, ORNL/TM-11092, 1989.

Ensminger, J. T., et al. Disposal of Chemical Agents and Munitions Stored at Pine Bluff Arsenal, Pine Bluf, Arkansas, Oak Ridge National Laboratory, ORNL/TM-11209, 1991.

Schneider Engineers. Pre-engineering Report: Equipment and Cost Estimates for Emergency Notification/Communication System Concept and Public Alert and Notification Design Concept, Harrisburg, PA, 1989.

Schneider Engineers. Training Needs Analysis for Chemical Emergency Response at PBA (Draft), Harrisburg, PA, 1989.

Schneider Engineers. Public Alert and Notification System Study for PBA (Draft), Harrisburg, PA, 1989.

Schneider Engineers. Emergency Notification/Communication System Study for Chemical Accident/lncidents at PBA (Draft), Harrisburg, PA, 1989. 
Venigalla, M. M., et al. Evacuation Time Estimates for Pine Bluff Arsenal and Vicinity (Draft), Oak Ridge National Laboratory, 1992.

\section{PUDA}

Carnes, S. A., et al. Emergency Response Concept Plan For PUDA and Vicinity, Oak Ridge National Laboratory, ORNL/TM-11098, Oak Ridge National Laboratory, 1989.

IEM, Inc. Analysis of Current Response Plans: PUDA Site (Draft), Baton Rouge, LA, 1994.

IEM, Inc. CSEPP IBS Databases: Documentation for the Colorado Database, Baton Rouge, LA, 1993.

Schneider Engineers. Pre-engineering Report: Equipment and Cost Estimates for Emergency Notification/Communication System Concept and Public Alert and Notification Design Concept, Harrisburg, PA, 1989.

Schneider Engineers. Training Needs Analysis for Chemical Emergency Response at PUDA (Draft), Harrisburg, PA, 1989.

Schneider Engineers. Public Alert and Notification System Study for PUDA (Draft), Harrisburg, PA, 1989.

Schneider Engineers. Emergency Notification/Communication System Study for Chemical Accident/Incidents at PUDA (Draft), Harrisburg, PA, 1989.

Venigalla, M., Southworth, F., and Davies, C. Griffith. Evacuation Time Estimates for Pueblo Depot Activity and Vicinity (Draft), Oak Ridge National Laboratory, 1992.

\section{TEAD}

Cames, S. A., et al. Emergency Response Concept Plan For TEAD and Vicinity, Oak Ridge National Laboratory, ORNL/TM-11094, 1989.

IEM, Inc. Analysis of Current Response Plans: TEAD Site, Baton Rouge, LA, 1994.

IEM, Inc. CSEPP IBS Databases: Documentation for the Utah Database, Baton Rouge, LA, 1993.

Program Manager for Chemical Demilitarization. Final Environmental Impact Statement: Disposal of Chemical Agents and Munitions Stored at Tooele Army Depot, Tooele, UT, Aberdeen Proving Ground, MD, 1989.

Schneider Engineers. Pre-engineering Report: Equipment and Cost Estimates for Emergency Notification/Communication System Concept and Public Alert and Notification Design Concept, Harrisburg, PA, 1989.

Schneider Engineers. Training Needs Analysis for Chemical Emergency Response at TEAD (Draft), Harrisburg, PA, 1989.

Schneider Engineers. Public Alert and Notification System Study for TEAD (Draft), Harrisburg, PA, 1989.

Schneider Engineers. Emergency Notification/Communication System Study for Chemical Accident/Incidents at TEAD (Draft), Harrisburg, PA, 1989.

Rathi, A. K., et al. Evacuation Time Estimates for Tooele Army Depot and Vicinity (Draft), Oak Ridge National Laboratory, 1992.

Zimmerman, G. P., et al. Chemical Stockpile Disposal Program-Final Phase I Environmental Report for Tooele Army Depot, Oak Ridge National Laboratory, ORNLTM-11211, 1988. 


\section{UMDA}

Cames, S. A., et al. Emergency Response Concept Plan For UMDA and Vicinity, Oak Ridge National Laboratory, ORNL/TM-11097, 1989.

IEM, Inc. Analysis of Current Response Plans: UMDA Site, Baton Rouge, LA, 1994.

IEM, Inc. CSEPP IBS Databases: Documentation for the Oregon Database, Baton Rouge, LA, 1993.

IEM, Inc. CSEPP IBS Databases: Documentation for the Washington Database, Baton Rouge, LA, 1993.

Program Manager for Chemical Demilitarization. Final Phase I Environmental Report: Disposal of Chemical Agents and Munitions Stored at Umatilla Depot Activity, Hermiston, OR, 1991.

Rathi, A. K., et al. Evacuation Time Estimates for Umatilla Depot Activity and Vicinity (Draft), Oak Ridge National Laboratory, 1989.

Schneider Engineers. Pre-engineering Report: Equipment and Cost Estimates for Emergency Notification/Communication System Concept and Public Alert and Notification Design Concept, Harrisburg, PA, 1989.

Schneider Engineers. Training Needs Analysis for Chemical Emergency Response at UMDA (Draft), Harrisburg, PA, 1989.

Schneider Engineers. Public Alert and Notification System Study for UMDA (Draft), Harrisburg, PA, 1989.

Schneider Engineers. Emergency Notification/Communication System Study for Chemical Accident/Incidents at UMDA (Draft), Harrisburg, PA, 1989. 
Appendix D

\title{
General and Detailed Facts About...
}

\author{
Mustard Agents (H, HD, and HT); \\ Nerve Agents GA and GB; \\ Nerve Agent VX; . \\ and \\ Lewisite (L)
}

Developed by U.S. Army Environmental Hygiene Agency and the CSEPP Sub-Committee on Reentry Restoration. 


\section{D-2}




\section{General Facts About Mustard Blister Agents (H, HD, and HT)}

Agent H-Levinstein mustard. Mixture of $70 \%$ bis(2-chloroethyl) sulfide and $30 \%$ sulfur impurities produced by the unstable Levinstein process.

\begin{abstract}
Agent $H D$-Distilled mustard or bis(2-chloroethyl) sulfide, chemical abstract service registry No. 505-60-2. HD is $H$ that has been purified by washing and vacuum distillation to reduce sulfur impurities.
\end{abstract}

\begin{abstract}
Agent HT-Plant-ran mixture containing about $60 \% \mathrm{HD}$ and $40 \% \mathrm{~T}$, plus a variety of sulfur contaminants and impurities. $T$ is bis-[2- (2chloroethylthio)-ethyl]ether, chemical abstract service registry No. 63918-89-8.
\end{abstract}

\section{Where are mustard agents stored?}

Mustard agents are found in ton containers (heavy steel cylinders), artillery shells, and other munitions. They are currently stockpiled in seven military installations on the continental United States: Aberdeen Proving Ground, MD; Anniston Army Depot, AL; Blue Grass Army Depot, KY; Pine Bluff Arsenal, AR; Pueblo Depot Activity, CO; Tooele Army Depot, UT; and Umatilla Depot Activity, OR.

\section{How would you describe them?}

Mustard agent liquid is colorless when pure, but is normally a yellow to brown oily substance. Mustard agent vapor is colorless with a slight garlic- or mustard-like odor.

\section{What are the possible effects of exposure to mustard agents?}

Signs or symptoms of mustard agent liquid or vapor exposure:

- Include burning or stinging sensations, and redness, on skin and in eyes. Additionally, includes blisters on skin.

- Are likely to first appear on delicate tissues such as the soft membranes surrounding the eyes and eyeball, the lung tissue, and the tissues of the nose, mouth, and throat. These agents have their greatest effect on warm, moist body areas, such as the eyes, respiratory tract, armpits, groin, buttocks, and other skin folds. Direct liquid splash causes ulceration of eyeball.

- Are usually delayed between 2 and 24 hours, or as long as 48 hours.

Symptoms of mustard ingestion can include weakness, nausea, vomiting, and fever.

Exposure to high concentrations of mustard agents can cause respiratory tract or skin cancer. 
For additional information, contact:

Mr. Robert Valis

U.S. Army Environmental Hygiene Agency

Aberdeen Proving Ground, MD 21010-5422

COMMERCIAL: (410) 671-8295 DSN: 584-8295

FAX: (410) 671-2084

Email: rvalis@aehal.apgea.army.mil 


\section{General Facts About Nerve Agents GA and GB}

Agent $G A$-The chemical Ethyl $\mathrm{N}_{2} \mathrm{~N}$-dimethylphosphoramidocyanidate, chemical abstract service registry No. 77-81-6.

Agent GB--The chemical isopropyl methylphosphonofluoridate, chemical abstract service registry No.

107-44-8.

\section{Where are nerve agents GA and GB stored?}

Nerve agents are found in ton containers (heavy steel cylinders), artillery shells, mortar projectiles, rockets, and land mines. GA is stockpiled at Tooele Army Depot, UT. GB is stockpiled at Anniston Army Depot, AL; Blue Grass Army Depot, KY; Pine Bluff Arsenal, AR; Tooele Army Depot, UT; and Umatilla Depot Activity, OR.

\section{How would you describe them?}

G-type nerve agents are clear, colorless, and tasteless liquids, chemically similar to organophosphate pesticides such as Malathion or Parathion. GA has a slightly fruity odor and GB has no odor.

\section{What are the possible effects of exposure to nerve agents GA and GB?}

\section{Vapor Exposure}

Mild signs/symptoms:

- Pinpoint pupils, pain behind the eyes, blurred vision

- Runny nose or drooling

- Tight chest

Moderate sings/symptoms:

- Increasing shortness of breath, coughing, wheezing

- Weakness, muscle twitching

- Nausea, vomiting, diarrhea

Severe signs/symptoms:

- Loss of consciousness

- Seizures

- Complete muscle weakness and paralysis

- Cessation of respiration

\section{Skin Exposure}

Mild signs/symptoms:

- Localized sweating at the exposure site

- Muscle twitching at the exposure site

Moderate signs/symptoms:

- Nausea, vomiting, diarrhea

- Weakness followed by general muscle twitching (no respiratory signs or symptoms)

Severe signs/symptoms:

- Sudden loss of consciousness and collapse

- Seizures

- Complete muscle weakness and paralysis

- Cessation of respiration 
For additional information, contact:

Mr. Robert Valis

U.S. Army Environmental Hygiene Agency

Aberdeen Proving Ground, MD 21010-5422

COMMERCIAL: (410) 671-8295 DSN: $584-8295$

FAX: (410) 671-2084

Email: rvalis@aehal.apgea.army.mil 


\section{General Facts About Nerve Agent VX}

Agent VX--The chemical O-ethyl S-(2-diisopropylaminoethyl) methylphosphonothioate, chemical abstract service registry No. 50782-69-9.

\section{Where is nerve agent VX stored?}

Nerve agent $\mathrm{VX}$ is found in ton containers (heavy steel cylinders), artillery shells, mortar projectiles, rockets, and land mines. VX is stockpiled at Anniston Army Depot, AL; Blue Grass Army Depot, KY; Newport Army Ammunition Plant, IN; Pine Bluff Arsenal, AR; Tooele Army Depot, UT; and Umatilla Depot Activity, OR.

\section{How would you describe it?}

Nerve agent VX is an oily liquid that is clear, colorless, odorless, and tasteless.

\section{What are the possible effects of exposure to nerve agent VX?}

Nerve agent $V X$ is primarily a liquid exposure hazard to the skin or eyes, although small amounts of VX vapor may be generated under extremely high temperatures.

\section{Vapor Exposure}

Mild signs/symptoms:

- Pinpoint pupils, pain behind the eyes, blurred vision

- Runny nose or drooling

- Tight chest

Moderate sings/symptoms:

- Increasing shortness of breath, coughing, wheezing

- Weakness, muscle twitching

- Nausea, vomiting, diarrhea

Severe signs/symptoms:

- Loss of consciousness

- Seizures

- Complete muscle weakness and paralysis

- Cessation of respiration

\section{Skin Exposure}

Mild signs/symptoms:

- Localized sweating at the exposure site

- Muscle twitching at the exposure site

Moderate signs/symptoms:

- Nausea, vomiting, diarrhea

- Weakness followed by general muscle twitching (no respiratory signs or symptoms)

Severe signs/symptoms:

- Sudden loss of consciousness and collapse

- Seizures

- Complete muscle weakness and paralysis

- Cessation of respiration 
For additional information, contact:

Mr. Robert Valis

U.S. Army Environmental Hygiene Agency

Aberdeen Proving Ground, MD 21010-5422

COMMERCIAL: (410) 671-8295 DSN: $584-8295$

FAX: (410) 671-2084

Email: rvalis@aeha1.apgea.army'mil 


\section{General Facts About Blister Agent Lewisite (L)}

Lewisite-The chemical 2-Chlorovinyldichloroarsine, chemical abstract service registry No. 541-25-3.

\section{Where is Lewisite stored?}

Lewisite is stored in ton containers (heavy steel cylinders) at one military installation on the continental United States--Tooele Army Depot, Utah.

\section{How would you describe it?}

Lewisite is a colorless, oily liquid with a faint geranium-like odor.

\section{What are the possible effects of exposure to Lewisite?}

Lewisite presents both a vapor and liquid hazard, and may damage the eyes, skin, respiratory tract, and circulatory system. Exposure to Lewisite causes immediate (within 30 seconds) irritation or pain.

The vapor may be inhaled into the respiratory tract, causing the immediate onset of burning pain, irritation of the nose, and reflex coughing and chest tightness.

The vapor also affects the eyes, with the immediate onset of pain, redness, uncontrollable blinking, and swelling of the eyelids.

The vapor or a liquid splash of Lewisite on the skin may cause immediate stinging pain and destruction of tissue, followed by blistering within 12 hours. 
For additional information, contact:

Mr. Robert Valis

U.S. Army Environmental Hygiene Agency

Aberdeen Proving Ground, MD 21010-5422

COMMERCIAL: (410) 671-8295 DSN: $584-8295$

FAX: (410) 671-2084

Email: rvalis@aehal.apgea.army.mil 
Agent H--Levinstein mustard. Mixture of $70 \%$. bis(2-chloroethyl) sulfide. and $30 \%$ sulfur impurities: produced by the unstable: Levinstein process.
Agent $H D$--Distilled mustard or bis(2-chloroethyl) sulfide, chemical: abstract: service registry $\mathrm{No}$ 505-60-2 $\mathrm{HD}$ is $\mathrm{H}$ that has been purified by washing and vacuum distillation to reduce sulfur impurities.
Agent $H T$-Plant-run mixture containing about $60 \%$. HD and $40 \% \cdot T$, plus a variety of sulfur contaminants and. impurities. $T$ is bis 2 . (chloroethylthioethyl) ether, chemical abstract service registry No. 63918-89-8.

\section{Physical Properties of Mustard (HD)}

Chemical structure

Description

Molecular weight

Boiling point

Freezing point

Density

Solubility

Stability<smiles>ClCCCCCCl</smiles>

Mustard agent liquid is colorless when pure, but is normally a yellow to brown oily substance. Mustard agent vapor is colorless with a slight garlic- or mustard-like odor.

159.08

$215-217^{\circ} \mathrm{C}$; slowly vaporizes at ordinary temperatures

$14.5^{\circ} \mathrm{C}$

Liquid $=1.27$

Vapor $=5.4($ air $=1)$

Very sparingly soluble in $\mathrm{H}_{2} \mathrm{O}$; freely soluble in animal oils, fats, organic solvents

Stable for days-weeks, under normal ranges of atmospheric temperature; slowly hydrolyzed by water; destroyed by strong oxidizing agents (e.g., household chlorine bleach, ammonia)

\section{References}

Department of the Army. 1991. DA PAM 40-173, Occupational Health Guridelines for the Evaluarion and Control of Occuparional Exposure to Mustard Agenes $H, H D$, and HT. Washington, DC: U.S. GPO.

Institute of Medicine, National Academy of Sciences, C.M. Pechura and D.P. Rall, eds. 1993. Veterans as Risk: The Health Effecrs of Mustard Gas and Lexrisite. Washington, DC: National Academy Press.

Papirmeister, B., et al. 1991. Medical Defense Against Mustard Gas: Toxic Mechanisms and Pharmacological Implicarions. Boca Raton, FL: CRC Press.

Department of the Army. 1975. DA FM 3-9, Military Chemistry and Chemical Compounds. Washington, DC: U.S. GPO. 


\section{Toxic Properties of Mustard}

Mustard agents stored in the unitary stockpile are in ton containers, artillery shells, and other munitions. Stockpiled at Aberdeen Proving Ground, MD; Anniston Army Depot, AL; Blue Grass Army Depot, KY; Pine Bluff, AR; Pueblo Depot Activity, CO; Tooele Army Depot, UT; and Umatilla Depot Activity, OR.

The signs and symptoms of acute mustard-induced lesions characteristically are delayed in appearance. The length of the delay and the degree of injury are both dependent on the severity of the exposure as well as the organs affected. The delay of onset is typically between 2 and 24 hours, or as long as 48 hours.

The eye is the most sensitive organ and may become inflamed at mustard levels that do not affect the skin or respiratory tract significantly. Mustard agent conjunctivitis may be present with lacrimation, discomfort, and erythema of the lids and conjunctiva. More severe exposures may produce photophobia, blepharospasm, pain, corneal erosion, iritis, conjunctival vascularization, ulceration, and corneal opacification. Delayed keratitis has been documented in some cases as long as 45 years after the original exposure.

Exposure of the skin to mustard vapor is marked by the appearance of erythema and edema, later followed by the development of vesication. Itching and burning may occur during the erythematous phase. Multiple small vesicles arise in the erythematous skin and gradually enlarge and coalesce to form typical large, fragile, yellowish bullae (the fluid of which has no irritating properties). These are usually painless. Liquid mustard contamination of the skin may result in an area of gray-white necrotic skin surrounded by erythema and vesication.

If mustard inhalation occurs, the signs and symptoms may develop slowly over several days. Early signs could include hoarseness and a cough. The cough may later become productive and the hoarseness may progress to aphonia. Pseudomembranes, fever, dyspnea, and moist rales may develop.

Ingestion of mustard can produce nausea, vomiting, abdominal pain, diarrhea, and prostration.

Mạalaise, nausea, vomiting, and fever may accompany any significant exposure to mustard by any route.

Symptoms/signs referable to central nervous system depression may accompany severe exposure to mustard.

At high concentrations, and accompanying severe blistering or skin burns, signs of leukopenia and thrombocytopenia such as infection, abnormal bruising, or bleeding may develop. Bradycardia and cardiac arrhythmias may occur. Shock may develop in severely affected patients.

Chronic mustard-induced illness is most commonly referable to the respiratory tract.

Dyspnea, productive cough, loss of exercise tolerance, frequent pulmonary infections, and changes in pulmonary function tests may indicate possible mustard-induced chronic lung disease.

The delayed development (sometimes for years) of leukoplakia, masses, or ulcerations that fail to heal on the skin or in the upper respiratory tract might indicate carcinoma. Other respiratory tract symptoms such as chest pain, dyspnea, cough, hemoptysis, or hoarseness could suggest a respiratory tract malignancy.

For additional information, contact:

Mr. Robert Valis

U.S. Army Environmental Hygiene Agency

Aberdeen Proving Ground, MD 21010-5422

COMMERCIAL: (410) 671-2208 DSN: 584-2208

FAX: (410) 671-2084

Email: rvalis@aehal.apgea.army.mil 


\section{Detailed Facts About Nerve Agents GA and GB}

Agent:GA-The chemical Ethy! $\mathrm{N}, \mathrm{N}$-dimethylphosphoramidocyanidate, chemical abstract service-registry No::77-81-6:: :::: :

Agent: $G B$-The chemical isopropyl methylphosphonofluoridate, chemical abstract service registry No. 107-44-8:

\section{Physical Properties of G-type Nerve Agents}

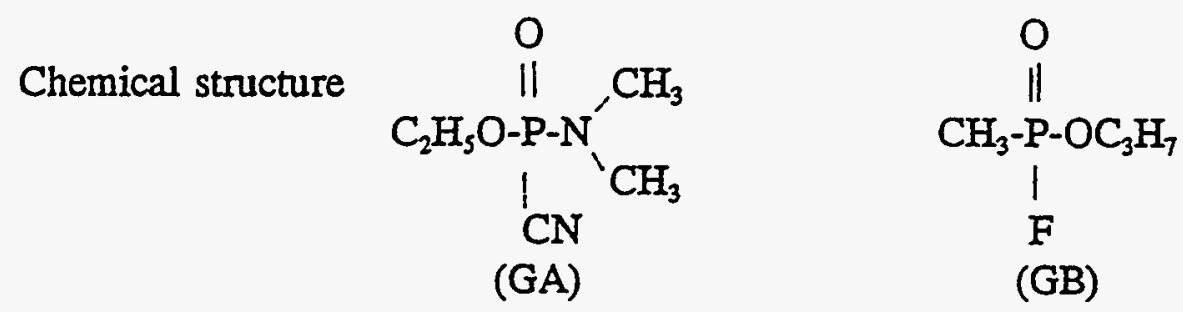

Description

G-type nerve agents are clear, colorless, and tasteless liquids, chemically similar to organophosphate pesticides such as Malathion or Parathion. GA has a slightly fruity odor and GB has no odor.

Molecular weight

140.1

Boiling point .

$240^{\circ} \mathrm{C}$

$158^{\circ} \mathrm{C}$

Freezing point

$-50^{\circ} \mathrm{C}$

$-56^{\circ} \mathrm{C}$

Density

Liquid $=1.07$

Vapor $=5.6(a \mathrm{ir}=1)$

1.09

4.9

Solubility

Miscible

Miscible

Stability

$\sim 24$ hours.

-20 hours.

\section{References}

Department of the Army. 1990. DA PAM 40-8, Occupational Health Guidelines for the Evaluarion and Control of Occupational Exposure to Nerve Agents GA, GB, GD, and VX. Washington, DC: U.S. GPO.

Department of the Army. 1975. DA FM 3-9, Military Chemistry and Chemical Compounds. Washington, DC: U.S. GPO. 


\section{Toxic Properties of G-type Nerve Agents}

G-type nerve agents stored in the unitary stockpile are in ton containers, artillery shells, mortar projectiles, rockets, and land mines. GA is stockpiled at Tooele Amm Depot, UT. GB is stockpiled at Anniston Army Depot, AL; Blue Grass Army Depot; KY; Pine Bluff Arsenal, AR; Tooele Army Depot, UT; and Umatilla Depot, $O R$.

G-type nerve agents are considered to be nonpersistent chemical agents that may present a significant vapor hazard to the respiratory tract, eyes, or skin. G-type nerve agents affect the body by blocking the action of the enzyme acetylcholinesterase. When this enzyme is blocked, large amounts of the chemical acetylcholine build up at critical places within the nervous system, causing hyperactivity of the body organs stimulated by these nerves. The signs and symptoms of exposure to G-type nerve agents depend upon the route of exposure and the amount of exposure.

\section{Vapor Exposure}

G-type nerve agents primarily pose a vapor hazard. Exposure to small amounts of vapor will usually affect the eyes, nose, and/or lungs. These effects may occur within seconds of exposure and reach their peak within several minutes after exposure ceases. Early, mild signs/symptoms might include: pinpoint pupils, pain behind the eyes, and/or blurred vision; runny nose or drooling; and a tight chest. Moderate signs/symptoms might include: increasing shortness of breath or worsening of respiratory signs such as coughing or wheezing; a feeling of weakness, followed by muscle twitching in the large muscles; and nausea, vomiting, and/or diarthea. Severe signs/symptoms following exposure to high concentrations might include: loss of consciousness, seizures, complete muscle weakness and paralysis, and cessation of respiration.

\section{Skin Exposure}

Effects from skin exposure to liquid G-type nerve agents are slower to develop and slower to reach their peak, compared to vapor exposures of the eyes or respiratory tract. This is because agent uptake across the skin is slower than via inhalation, and there is continued absorption of agent through the various skin layers, even hours after the skin surface has been decontaminated. In general, signs and symptoms of percutaneous exposure may occur within minutes or be delayed up to 18 hours. Mild initial signs of skin exposure might include: localized sweating and/or muscle twitching at the exposure site. Moderate signs/symptoms might include: nausea, vomiting, and/or diarrhea and a feeling of weakness followed by generalized muscle twitching (no respiratory signs or symptoms). Severe signs/symptoms might include: sudden loss of consciousness and collapse, seizures, complete muscle weakness and paralysis, and cessation of respiration.

The larger the skin exposure to liquid nerve agent, the shorter the time of onset to signs and symptoms. The first sign following a large skin exposure to liquid nerve agent may be loss of consciousness. Pinpoint pupils do not occur early on following skin exposüres to-nerve agent; pinpoint pupils are generally the direct result of a vapor exposure to the eye. Death following vapor or liquid exposures to nerve agent is usually due to compromise or failure of the respiratory system.

For additional information, contact:

Mr. Robert Valis

U.S. Army Environmental Hygiene Agency

Aberdeen Proving Ground, MD 21010-5422

COMMERCIAL: (410) 671-2208 DSN: 584-2208

FAX: (410) 671-2084

Email: rvalis@aehal.apgea.army.mil 


\section{Detailed Facts About Nerve Agent VX}

Agent VX-The chemical O-ethyl S-(2-disopropylaminoethyl) methylphosphonothioate chemical abstract service registry: No. 50782-69-9:

\section{Physical Properties of Nerve Agent VX}

Chemical structure<smiles>CCO[P@](C)(=O)SCCN(C(C)C)C(C)C</smiles>

Description

Molecular weight

Boiling point

Freezing point

Density

Solubility

Stability
Nerve agent VX is an oily liquid that is clear, colorless, odorless, and tasteless.

\section{4}

$298^{\circ} \mathrm{C}$

$-51^{\circ} \mathrm{C}$

Liquid $=1.01$

Vapor $=9.2(\operatorname{air}=1)$

Moderate in $\mathrm{H}_{2} \mathrm{O}$

Persistent

References

Department of the Army. 1990. DA PAM 40-8, Occupational Health Guidelines for the Evaluarion and Control of Occupational Exposure to Nerve Agents GA, GB, GD, and VX- Washington, DC: U.S. GPO.

Department of the Army. 1975. DA FM 3-9, Mititary Chemistry and Chemical Compounds. W2shington, DC: U.S. GPO. 


\section{Toxic Properties of Nerve Agent VX}

Nerve agent VX is stored in the unitary stockpile in ton containers, artillery shells, mortar projectiles, rockets, and land mines. Stockpiled at Anniston Army Depot, AL; Blue Grass Army Depot, KY; Newport Army Ammunition Plant, IN; Pine Bluff Arsenal, AR; Tooele Army Depot, UT; and Umatilla Depot Activity, OR.

Nerve agent $\mathrm{VX}$ is a persistent, nonvolatile agent that is primarily a liquid exposure hazard to the skin or eyes, although small amounts of $\mathrm{VX}$ vapor may be generated under extremely high temperatures. Nerve agent VX affects the body by blocking the action of the enzyme acetylcholinesterase. When this enzyme is blocked, large amounts of the chemical acetylcholine build up at critical places within the nervous system, causing hyperactivity of the body organs stimulated by these nerves. The signs and symptoms of exposure to nerve agent VX depends upon the route of exposure and the amount of exposure.

\section{Vapor Exposure}

Nerve agent VX does not pose a vapor hazard, except at high temperatures. Exposure to small amounts of vapor will usually affect the eyes, nose, and/or lungs. These effects may occur within seconds of exposure and reach their peak within several minutes after exposure ceases. Early, mild signs/symptoms might include: pinpoint pupils, pain behind the eyes, and/or blurred vision; runny nose or drooling; and a tight chest. Moderate signs/symptoms might include: increasing shortness of breath or worsening of respiratory signs such as coughing or wheezing; a feeling of weakness, followed by muscle twitching in the large muscles; and nausea, vomiting, and/or diarrhea. Severe signs/symptoms following exposure to high concentrations might include: loss of consciousness, seizures, complete muscle weakness and paralysis, and cessation of respiration.

\section{Skin Exposure}

Nerve agent VX penetrates the skin extremely well and may be up to 100-200 times more toxic than a G-type nerve agent. Effects from skin exposure to liquid nerve agent VX are slower to develop and slower to reach their peak, compared to vapor exposures of the eyes or respiratory tract. This is because agent uptake across the skin is slower than via inhalation, and there is continued absorption of agent through the various skin layers, even hours after the skin surface has been decontaminated. In general, signs and symptoms of percutaneous exposure may occur within minutes or be delayed up to 18 hours. Mild initial signs of skin exposure might include: localized sweating and/or muscle twitching at the exposure site. Moderate signs/symptoms might include: nausea, vomiting, and/or diarrhea and a feeling of weakness followed by generalized muscle twitching (no respiratory signs or symptoms). Severe signs/symptoms might include: sudden loss of consciousness and collapse, seizures, complete muscle weakness and paralysis, and cessation of respiration.

The larger the skin exposure to liquid nerve agent, the shorter the time of onset to signs and symptoms. The first sign following a large skin exposure to liquid nerve agent may be loss of consciousness. Pinpoint pupils do not occur early on following skin exposures to nerve agent; pinpoint pupils are generally the direct result of a vapor exposure to the eye. Death following vapor or liquid exposures to nerve agent is usually due to compromise or failure of the respiratory system.

For additional information, contact:

Mr. Robert Valis

U.S. Army Environmental Hygiene Agency

Aberdeen Proving Ground, MD 21010-5422

COMMERCIAL: (410) 671-2208 DSN: 584-2208

FAX: (410) 671-2084

Email: rvalis@aeha l.apgea.army.mil 


\section{Detailed Facts About Blister Agent Lewisite (L)}

Lewisite-The chemical 2-Chlorovinyldichloroarsine, chemical abstract. service registry No. 541-25-3.

\section{Physical Properties of Lewisite}

Chemical structure<smiles>ClC=CCCCCCCl</smiles>

(Trans Form)<smiles>ClC=C[AsH2]</smiles>

(Cis Form)

Description

Pure Lewisite is a colorless, oily liquid with very little odor. "War gas" has a geranium-like odor and is an amber to dark brown liquid.

Molecular weight

Boiling point

Freezing point

Density

Solubility

Stability
207.32

$190^{\circ} \mathrm{C}$ (Trans)

$170^{\circ} \mathrm{C}$ (Cis)

$-1^{\circ} \mathrm{C}$ (Trans)

$-45^{\circ} \mathrm{C}$ (Cis)

Liquid $=1.89$

Vapor $=7.2(a \mathrm{ar}=1)$

Insoluble in $\mathrm{H}_{2} \mathrm{O}$; soluble in ordinary organic solvents

Rapidly hydrolyzed by water to 2-chlorovinyl arsine oxide which also has blistering properties.

References

Institute of Medicine, National Academy of Sciences, C.M. Pechura and D.P. Rall, eds. 1993. Veterans as Risk: The Health Effects of Mustard Gas and Lewisite. Washington, DC: National Academy..Press.

U.S. Army Edgewood Research, Development and Engineering Center. 11 January 1993. "Material Safety Data Sheet: Lewisite." Aberdeen Proving Ground, MD.

Department of the Army. 1975. DA FM 3-9, Military Chemistry and Chemical Compounds. Washington, DC: U.S. GPO. 


\section{Toxic Properties of Blister Agent Lewisite (L)}

Lewisite stored in the unitary stockpile is in ton containers. Stockpile is at Tooele Army Depot, UT.

\section{Acute Exposure}

Eyes. Instant pain, conjunctivitis, and blepharospasm leading to closure of eyelids, followed by comeal scarring and iritis. Mild exposure produces reversible eye damage if decontaminated instantly; otherwise, more permanent injury or blindness is possible within one minute of exposure.

Skin. Immediate stinging pain increasing in severity with time. Erythema (skin reddening) appears within 30 minutes after exposure accompanied by pain with itching and irritation for 24 hours. Blisters appear within 12 hours after exposure with more pain, which diminishes after two to three days.

Respiratory Tract. Irritating to nasal passages and produces a burning sensation followed by a profuse nasal secretion and violent sneezing. Prolonged exposure causes coughing and production of large quantities of frothy mucus.

Systemic Effects. Lewisite on the skin and inhaled vapor are absorbed and may cause systemic poisoning. A manifestation of this is a change in capillary permeability, which permits loss of sufficient fluid from the bloodstream to cause hemoconcentration, shock, and death.In nonfatal cases, hemolysis of erythrocytes has occurred with a resultant hemolytic anemia. The excretion of oxidized products into the bile by the liver produces focal necrosis of the liver, necrosis of the mucosa of the biliary passages with periobiliary hemorrhages, and some. injury to the intestinal mucosa. Acute systematic poisoning from large skin burns causes pulmonary edema, diarhea, restlessness, weakness, subnormal temperature, and low blood pressure in animals.

\section{Chronic Exposure}

Lewisite can cause sensitization and chronic lung impairment. Some evidence suggests that Lewisite might also be a carcinogen.

For additional information, contact:

Mr. Robert Valis

U.S. Army Environmental Hygiene Agency

Aberdeen Proving Ground, MD 21010-5422

COMMERCIAL: (410) 671-2208 DSN: 584-2208

FAX: (410) 671-2084

Email: rvalis@achal.apgea.2rmy.mil 
ORNL-6824

\section{INTERNAL DISTRIBUTION}

1. M. V. Adler

2. J. B. Cannon

3. S. A. Carnes

4. Central Research Library

5. W. F. Clevenger

6. C. J. Coomer

7. E. D. Copenhaver

8. T. R. Curlee

9. Document Reference Section

10. K. S. Gant

11. S. G. Hildebrand

12. C. T. Hunsaker

13. M. W. Knazovich

14. M. A. Kuliasha

15. Laboratory Records
16.

17.

18.

19.

20.

21.

22.

23.

24-73.

74.

75-124.

125.

126-150.

151.
Laboratory Records-RC

D. A. Lombardi

ORNL Patent Office

R. M. Reed

D. E. Reichle

R. B. Shelton

B. L. Shumpert

M. L. Socolof

J. H. Sorensen

E. G. Thompson

B. M. Vogt

B. A. Walker

L. A. Warneke

A. P. Watson

\section{EXTERNAL DISTRIBUTION}

152. Dr. Douglas R. Bohi, Director, Energy and Natural Resources Division, Resources for the Future, 1616 P Street, N.W., Washington, DC 20036

153-177. Marvin Davis, Federal Emergency Management Agency, 500 C Street, S.W., Washington, DC 20472

178. Dr. Thomas E. Drabek, Professor, Department of Sociology, University of

179-188. Denver, Fisher, U.S. Department of the Army, Office of the Assistant Secretary, Installations, Logistics, and Environment, The Pentagon, Washington, DC 20310

189-198. Laurel C. Lacy, Federal Emergency Management Agency, 500 C St., S.W., Room 621, Washington, DC 20472

199. Calvin D. MacCracken, President, Calmac Manufacturing Corporation, 101 West Sheffield Avenue, P.O. Box 710, Englewood, New Jersey, 07631

200. Office of Assistant Manager for Energy Research and Development, DOEORO, P.O. Box 2001, Oak Ridge, TN 37831-8600

201. OSTI, U.S. Department of Energy, P.O. Box 62, Oak Ridge, TN 37831

202. Jacqueline B. Shrago, Vice-Chancellor, Information Technologies, Tennessee Board of Regents, 1415 Murfreesboro Road, Suite 350, Nashville, TN 37217

203. George F. Sowers, P.E., Senior Vice President, Law Companies Group, Inc., 114 Townpark Drive, Suite 250, Kennesaw, GA 30144-5599

204-228. Phyllis P. Thompson, Federal Emergency Management Agency, 500 C St., S.W., Room 625, Washington, DC 20472

229. Dr. C. Michael Walton, Ernest H. Cockrell Centennial Chair in Engineering and Chairman, Department of Civil Engineering, University of Texas at Austin, Austin, TX 78712-1076 